\title{
Investigação da Camada Limite Planetária Convectiva com Modelo LES Aplicado à Dispersão de Poluentes
}

por

Edson Pereira Marques Filho

Orientador: Prof. Dr. Amauri Pereira de Oliveira

Tese de Doutorado

Submetida ao Instituto de Astronomia, Geofísica e Ciências Atmosféricas

da Universidade de São Paulo

No estabelecimento parcial dos requerimentos necessários para a obtenção do

Título de Doutor em Ciências - Área de concentração: Meteorologia

22 de junho de 2004

São Paulo - SP Brasil 


\section{COMISSÃO DE PÓS-GRADUAÇÃO \\ RELATÓRIO DE TESE DE DOUTORADO}

\section{NOME DO ALUNO: EDSON PEREIRA MARQUES FILHO}

NIVEL: DOUTORADO

ÁREA: METEOROLOGIA

TíTULO: "Investigação da Camada Limite Planetária Convectiva com Modelo LES Aplicado à Dispersão de Poluentes"

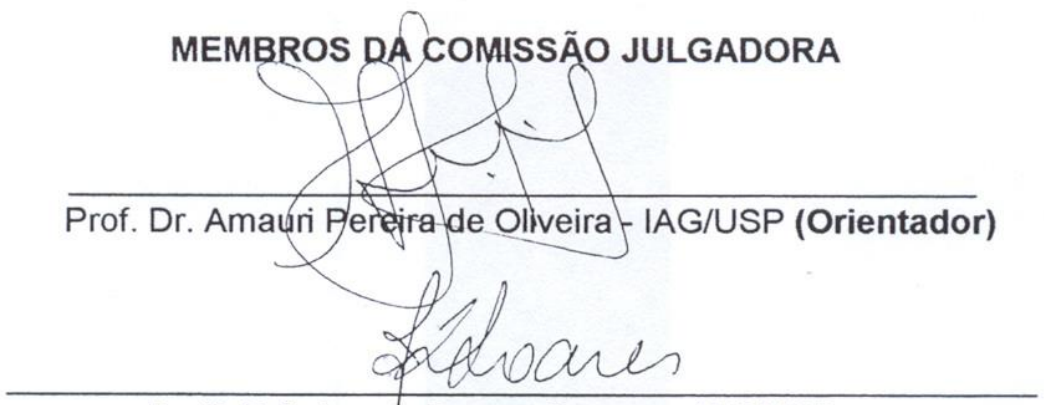

Prof $^{\mathrm{a}}$. Dra. Jacyra Ramos Soares - IAG/USP

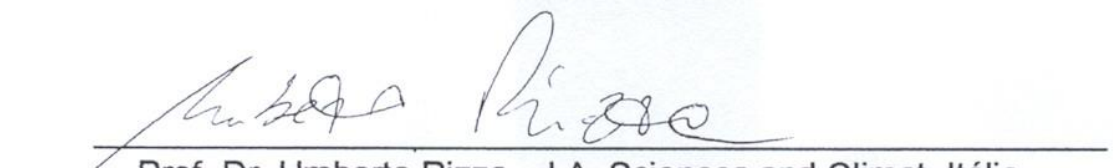

Prof. Dr. Umberto Rizza - I.A. Sciences and Climat, Itália
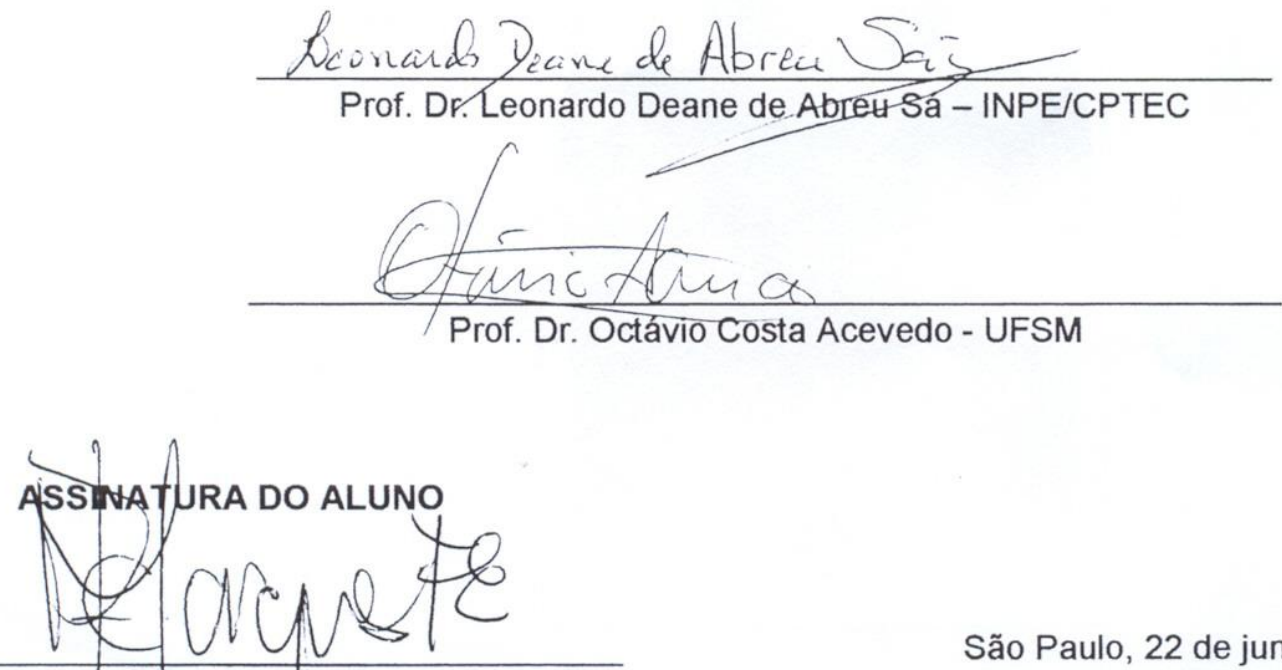

São Paulo, 22 de junho de 2004. 


\section{RESUMO}

Esse trabalho descreve a evolução espacial e temporal da dispersão de um poluente inerte e passivo em uma CLP altamente convectiva $\left(60 \leq-\mathrm{z}_{\mathrm{i}} / \mathrm{L} \leq 800\right)$ simulada com um modelo LES. A versão do modelo LES utilizado foi desenvolvida por Moeng (1984) e modificada por Sullivan et al. (1994). A condição de quase-equilíbrio é verificada através da energia cinética turbulenta (ECT) total integrada na CLP. Os perfis verticais dos momentos estatísticos de primeira, segunda e terceira ordem, concordam com os prognósticos da teoria da similaridade da camada de mistura apresentados na literatura. Os termos da equação de ECT estão em balanço e o transporte de ECT devido às flutuações de pressão é um termo fonte na região próxima à superfície. Os espectros espaciais apresentam uma região de subintervalo inercial com inclinação proporcional a $\mathrm{k}^{-2 / 3}$, onde as relações de isotropia são reproduzidas para a componente vertical de velocidade. O valor estimado da constante de Kolmogorov é $\alpha_{\mathrm{k}} \approx 0,52$. Resultados equivalentes foram obtidos para os espectros temporais de velocidade. Os espectros das componentes de velocidade apresentam uma região de produção bem definida, permitindo estimar as escalas de comprimento dos turbilhões mais energéticos. Nos espectros espaciais, os comprimentos de onda associados aos turbilhões mais energéticos $\left(\lambda_{\mathrm{m}}\right)_{\mathrm{u}, \mathrm{v}}$ são aproximadamente constantes e iguais a $1,3 \mathrm{z}_{\mathrm{i}}$. Os valores de $\left(\lambda_{\mathrm{m}}\right)_{\mathrm{u}, \mathrm{v}}$ estimado pelos espectros temporais são 1,5 maiores. O mesmo fator é encontrado nas estimativas espaciais e temporais de $\left(\lambda_{\mathrm{m}}\right)_{\mathrm{w}}$. Esses resultados confirmam as restrições da aplicação da hipótese de Taylor em uma CLP em condições altamente convectivas. No caso de um poluente emitido por uma fonte área contínua localizada próxima à superfície, representativo das emissões de CO na região metropolitana de São Paulo, o grau de limpeza da CLP está relacionado à intensidade dos processos de entranhamento no topo. As abordagens euleriana e lagrangiana para a descrição da dispersão de um poluente emitido por fonte pontual contínua são similares para alturas elevadas e reproduzem o comportamento esperado das plumas em condições convectivas, quando estão associadas ao modelo LES. Essa concordância confirma a hipótese levantada neste trabalho de que o modelo LES pode ser utilizado como uma ferramenta de validação de modelos operacionais de dispersão. 


\begin{abstract}
This work describes the spatial and temporal evolution of the dispersion of an inert and passive pollutant in a highly convective Planetary Boundary Layer (PBL) $\left(60 \leq-\mathrm{z}_{\mathrm{i}} / \mathrm{L} \leq 800\right)$ simulated by LES model. The LES model used here was developed by Moeng (1984) and modified by Sullivan et al. (1994). The quasi-stationary state is verified by total turbulent kinetic energy (TKE) integrated in the PBL. The vertical profiles of the first, second and third order statistical moments, agreed with the predictions of the mixed layer similarity theory available in the literature. The TKE equation terms are balance and TKE pressure-transport is a source in the near to the surface. The spatial spectra show a inertial subrange proportional $\mathrm{k}^{-2 / 3}$, were isotropy relations are reproduced for vertical velocity. The Kolmogorov constant estimated is $\alpha_{\mathrm{k}} \approx 0,52$. The equivalent results are obtained for temporal wind velocity spectra. The wind velocity spectra show very well defined production region, allowing to estimate the spectral peak wavelength and characteristic length. In the spatial spectra cases, the horizontal velocity peak wavelengths $\left(\lambda_{\mathrm{m}}\right)_{\mathrm{u}, \mathrm{v}}$ are approximately constants and equal to $1,3 z_{i}$. The values of $\left(\lambda_{m}\right)_{u, v}$ obtained from temporal spectra are 1.5 larger. The same factor is found for temporal and spatial estimates of $\left(\lambda_{\mathrm{m}}\right)_{\mathrm{w}}$. These results confirm the restrictions to the Taylor's hypothesis applications in highly convective PBL. The concentration of pollutant released from a continuous area source located near to the surface, representing CO emissions in São Paulo city, is strongly dependent on the intensity of the entrainment at the top of PBL.

The eulerian and lagrangian approaches are equally capable to describe the dispersion of continuous elevated point source located in PBL, reproducing the plume behaviour for convective conditions, when associated to LES model. This agreement indicates that LES model can be used as a tool to validated operational dispersion models.
\end{abstract}


"Deixar que os fatos sejam fatos naturalmente

Sem que sejam forjados para acontecer Deixar que os olhos vejam pequenos detalhes lentamente Deixar que as coisas que lhe circundam estejam sempre inertes

Como móveis inofensivos Para lhe servir quando for preciso

E nunca lhe causar danos Morais, físicos ou psicológicos”

Francisco de Assis França 


\section{AGRADECIMENTOS}

O autor agradece ao Conselho Nacional de Desenvolvimento Científico e Tecnológico, CNPq (Procs. $\mathrm{n}^{\text {os }}$. 140702/2000-8 e 202585/02-06) pelo suporte financeiro recebido.

Ao meu orientador Prof. Dr. Amauri Pereira de Oliveira pela transmissão dos conhecimentos e por sempre acreditar na realização deste trabalho.

Ao co-orientador estrangeiro Dr. Umberto Rizza por ceder gentilmente os códigos do modelo LES, por auxiliar-nos em questões técnicas e pela oportunidade de estágio no ISAC-CNR.

Ao Dr. Hugo Abi Karam que me inseriu no mundo da modelagem matemática e cujas idéias foram vitais na realização e conclusão deste trabalho.

Ao Dr. Maxsuel M. da Rocha Pereira, ao Ms. João E. Lamesa, à Prof. Dra. Jacyra Soares e ao Ms. Antônio J. Machado, que contribuem ou contribuíram com o grupo de micrometeorologia do IAG-USP.

À doutoranda Giulia Gioia, aos Drs. Gian Paolo Marra, Guiglelmo Lacorata, Mario Marcello Miglietta e Andrea Mazzino, ao administrativo Luca Ciricugno e ao técnico Cosimo Elefante, todos do ISAC-CNR, pelo auxílio e convívio nos tempos que passei distante de minha casa.

Ao Laboratório de Computação Científica Avançada da Universidade de São Paulo (LCCAUSP), que disponibilizou todos os recursos computacionais necessários para a realização desse trabalho. Ao analista Francisco Ribacionka e ao Dr. Nick Chepurniy pela otimização do código serial.

Ao Prof. Dr. Leonardo Deane de Abreu Sá que sempre esteve à disposição para nos ajudar.

À Fundação de Amparo à Pesquisa do Estado de São Paulo, FAPESP (Proc. nº 98/15402-5), pelo microcomputador.

E a todos aqueles que por sentimentos inerentes a raça humana desejaram que este trabalho não fosse realizado. 


\section{ÍNDICE}

LISTA DE SÍMBOLOS vii

LISTA DE NOTAÇÕES $\quad$ ix

LISTA DE ABREVIAÇÕES $\quad$ X

1 - INTRODUÇÃO

2 - MODELOS NUMÉRICOS

2.1 - O modelo LES ......................................................................................... $\quad 7$

2.2 - Esquemas numéricos e condições de fronteiras ........................................ 13

2.3 - Abordagem euleriana da dispersão de poluentes ....................................... 14

2.4 - Abordagem lagrangiana da dispersão de poluentes .................................. 15

3 - RECURSOS COMPUTACIONAIS 18

3.1 - Experimentos numéricos .................................................................. 19

3.1.1 - Momentos estatísticos ............................................................... 21

3.1.2 - Espectros turbulentos ....................................................... 22

4 - PROPRIEDADES DA CLP ALTAMENTE CONVECTIVA 26

4.1 - Condição de quase-equilíbrio ................................................................... 27

4.2 - Estrutura da turbulência ........................................................................ 29

4.3 - Balanço de energia cinética turbulenta ...................................................... 43

4.4 - Análise espectral ................................................................................. 53

4.4.1 - Espectros espaciais .................................................................... 58

4.4.2 - Escala de comprimento associada aos espectros espaciais ........... 62

4.4.3 - Espectros temporais ................................................................... 71

4.4.4 - Escala de comprimento associada aos espectros temporais .......... 76

4.4.5 - Espectros de escalares ............................................................... 83

4.4.6 - Sumário dos resultados da análise espectral ................................ 84

5 - DISPERSÃO DE POLUENTES

5.1 - Dispersão euleriana para fonte área contínua (próxima à superfície) ....... 87

5.2 - Dispersão euleriana para fontes pontuais contínuas (alturas elevadas) .... $\quad 97$

5.3 - Dispersão lagrangiana para fontes pontuais contínuas ............................ 105

5.4 - Sumário dos resultados da dispersão de poluentes ................................... 112

$\begin{array}{ll}6-\text { CONCLUSÕES } & 114\end{array}$

7 - REFERÊNCIAS BIBLIOGRÁFICAS 120 


\section{LISTA DE SÍMBOLOS}

\begin{tabular}{|c|c|}
\hline $\mathrm{c}$ & Concentração de poluente \\
\hline $\mathrm{C}_{\mathrm{K}}$ & Constante do coeficiente de momento $(0,10)$ \\
\hline$c_{p}$ & Calor específico à pressão constante $\left(1004 \mathrm{~J} \mathrm{Kg}^{-1} \mathrm{~K}^{-1}\right)$ \\
\hline $\mathrm{C}_{\max }$ & Concentração máxima \\
\hline $\mathrm{C}_{\mathrm{y}}$ & Concentração integrada lateralmente \\
\hline $\mathrm{C}_{\varepsilon}$ & Constante da dissipação de ECT $(0,93)$ \\
\hline $\mathrm{C}_{*}$ & Escala de concentração de poluente na CLP convectiva \\
\hline e & Energia cinética turbulenta de subgrade \\
\hline $\mathrm{E}$ & Energia cinética turbulenta total (resolvida + subgrade) \\
\hline $\mathrm{f}$ & Freqüência \\
\hline $\mathrm{f}_{\mathrm{c}}$ & Força de Coriolis \\
\hline$f_{r_{i}}$ & Freqüências máximas resolvidas pelo modelo LES \\
\hline $\mathrm{F}_{0}$ & Termo fonte de poluente \\
\hline g & Aceleração da gravidade $\left(9,81 \mathrm{~m} \mathrm{~s}^{-2}\right)$ \\
\hline $\mathrm{H}_{\mathrm{i}}$ & Forçante dinâmica na direção i \\
\hline $\mathrm{k}$ & Número de onda \\
\hline $\mathrm{k}_{\mathrm{x}, \mathrm{y}}$ & Número de onda nas direções longitudinal e lateral \\
\hline $\mathrm{K}_{\mathrm{M}}$ & Coeficiente de difusão turbulenta de momento \\
\hline $\mathrm{K}_{\mathrm{H}}$ & Coeficiente de difusão turbulenta de calor \\
\hline $\mathrm{K}_{\mathrm{C}}$ & Coeficiente de difusão turbulenta do poluente \\
\hline $\mathrm{L}$ & Escala de comprimento de Monin-Obukhov \\
\hline $\mathrm{L}_{\mathrm{i}}$ & Dimensão da grade na direção i \\
\hline M & Massa total de poluente inserida no domínio \\
\hline $\mathrm{p}$ & Pressão atmosférica \\
\hline $\mathrm{p}_{0}$ & Pressão atmosférica de referência \\
\hline $\mathrm{p}_{00}$ & Valor da pressão no estado básico na superfície (1000mb) \\
\hline $\mathrm{P}^{*}$ & Pressão atmosférica modificada \\
\hline Q & Taxa de emissão de poluente \\
\hline $\mathrm{R}_{\mathrm{d}}$ & Constante do ar seco $\left(287 \mathrm{~J} \mathrm{Kg}^{-1} \mathrm{~K}^{-1}\right)$ \\
\hline $\mathrm{R}_{\mathrm{ij}}$ & Tensor tensão de Reynolds de subgrade \\
\hline$S_{i j}$ & Tensor taxa de deformação na escala resolvida \\
\hline
\end{tabular}


$\mathrm{S}_{\mathrm{C}}$

$$
\mathrm{S}_{\mathrm{u}_{\mathrm{i}}}
$$$$
\mathrm{S}_{\theta}
$$$$
\mathrm{t}_{\mathrm{T}}
$$$$
\mathrm{t}_{*}
$$

$\mathrm{T}_{*}$

$\mathrm{u}_{\mathrm{i}}^{\prime \prime}$

$\mathrm{u}_{\mathrm{G}}$

$\mathrm{u}_{*}$

v

$\mathrm{v}_{\mathrm{G}}$

$\mathrm{X}_{\mathrm{i}}$

$\mathrm{X}_{*}$

W

$\mathrm{w}_{\mathrm{e}}$

$\mathrm{W}_{*}$

Z

z/L

$\mathrm{z}_{0}$

$\mathrm{Z}_{\mathrm{i}}$

$\mathrm{z}_{\mathrm{i}} / \mathrm{L}$

$\mathrm{z}_{\mathrm{s}}$

$\overline{\mathrm{Z}}$

$\overline{\mathrm{z}^{2}}$

$\alpha_{\mathrm{K}}$

$\varepsilon$

$\Gamma_{\theta}$

$\gamma$

$\delta$

$\Delta \overline{\mathrm{C}}$

$\Delta \mathrm{s}$
Densidade espectral de concentração de poluente

Densidades espectrais das componentes de velocidade

Densidade espectral de temperatura potencial

Escala de tempo de Taylor

Escala de tempo na CLP convectiva

Escala de temperatura na CLP convectiva

Componente de velocidade da escala de subgrade

Componente do vento geostrófico

Componente longitudinal de velocidade

Velocidade horizontal do vento

Escala de velocidade da TSMO

Componente lateral de velocidade

Componente do vento geostrófico

Vetor posição

Distância longitudinal adimensional da fonte

Componente vertical de velocidade

Taxa de entranhamento

Escala de velocidade na CLP convectiva

Altura acima da superfície

Parâmetro de estabilidade de Monin-Obukhov

Comprimento de rugosidade

Altura da CLP

Parâmetro de estabilidade na CLP convectiva

Altura da fonte

Altura média da fonte

Dispersão vertical da pluma

Constante de Kolmogorov

Taxa de dissipação de energia cinética turbulenta

Gradiente vertical de temperatura na atmosfera livre

Fator de isotropia

Escala de comprimento resolvida pelo modelo LES

Variação da concentração de poluente

Dimensão geométrica média da grade 


$\begin{array}{ll}\Delta \mathrm{t} & \text { Passo no tempo } \\ \Delta \mathrm{x}, \Delta \mathrm{y}, \Delta \mathrm{z} & \text { Resolução da grade nas direções } \mathrm{x}, \mathrm{y} \text { e } \mathrm{z} \\ \Delta \bar{\theta} & \text { Variação de temperatura potencial } \\ \lambda_{\mathrm{m}} & \text { Comprimento de onda associado aos turbilhões mais energéticos } \\ \theta & \text { Temperatura potencial } \\ \theta_{0} & \text { Temperatura potencial de referência } \\ \theta_{*} & \text { Escala de temperatura da TSMO } \\ \rho_{0} & \text { Densidade do ar de referência } \\ \sigma_{\mathrm{h}}^{2} & \text { Variância horizontal } \\ \tau_{\mathrm{cj}} & \text { Fluxo turbulento de concentração de poluente de subgrade } \\ \tau_{\mathrm{ij}} & \text { Tensor tensão de Reynolds modificado de subgrade } \\ \tau_{\mathrm{u}_{\mathrm{i}} \mathrm{u}_{\mathrm{i}}} & \text { Variâncias das componentes de velocidade de subgrade } \\ \tau_{\theta \mathrm{j}} & \text { Fluxo turbulento de calor sensível de subgrade } \\ \tau_{\theta \theta} & \text { Variância da temperatura potencial de subgrade } \\ \bar{\zeta}_{\mathrm{i}} & \text { Componentes da vorticidade nas direções x, y e z }\end{array}$

\section{LISTA DE NOTAÇÕES}

\begin{tabular}{ll}
\hline $\bar{f}$ & Variáveis meteorológicas na escala resolvida \\
$\langle\bar{f}\rangle$ & Médias do plano horizontal na escala resolvida \\
$f^{\prime}=\bar{f}-\langle\bar{f}\rangle$ & Flutuações com relação à média no plano horizontal \\
$\mathrm{w}^{\prime} f^{\prime}$ & Fluxos turbulentos na escala resolvida \\
$f^{\prime 2}$ & Variâncias na escala resolvida \\
$f^{\prime 3}$ & Momentos estatísticos de terceira ordem na escala resolvida \\
()$_{\mathrm{CM}}$ & Indica os valores na camada de mistura \\
()$_{\mathrm{eq}}$ & Indica os valores no instante de tempo que os campos turbulentos atingiram a \\
()$_{\mathrm{i}}$ & condição de quase-equilíbrio \\
()$_{\mathrm{ini}}$ & Indica os valores no topo da CLP ou na camada de entranhamento
\end{tabular}



()$_{\max }$
Indica os valores máximos
()$_{\min }$
Indica os valores mínimos
()$_{0}$
Indica os valores na superfície
\{\}
Média de conjunto de todas simulações
$\langle\langle\rangle\rangle$
Média no volume total da CLP
[]
Média de Reynolds

\section{LISTA DE ABREVIAÇÕES}

\begin{tabular}{ll}
\hline CLP & Camada limite planetária \\
CLS & Camada limite superficial \\
CM & Camada de mistura \\
CO & Monóxido de carbono \\
D & Termo de dissipação de ECT \\
ECT & Energia cinética turbulenta \\
FFT & Transformada rápida de Fourier \\
P & Transporte de ECT devido à flutuação de pressão \\
PM & Produção mecânica de ECT \\
PT & Produção térmica de ECT \\
R & Resíduo da equação do balanço de ECT \\
RMSP & Região Metropolitana de São Paulo \\
T & Transporte turbulento de ECT \\
TSMO & Teoria da Similaridade de Monin-Obukhov \\
VL & Variação local de ECT \\
\hline
\end{tabular}




\section{1 - INTRODUÇÃO}

A determinação do transporte de poluentes na atmosfera é um fator importante no gerenciamento ambiental e envolve o conhecimento detalhado da evolução temporal e espacial da atmosfera, como um todo, e da Camada Limite Planetária (CLP), em particular.

A CLP pode ser definida como a camada inferior da troposfera que está sobre influências diretas da superfície e é caracterizada por turbilhões em um amplo intervalo de escalas temporais e espaciais. A complexidade dos processos envolvidos na evolução da atmosfera, principalmente os associados à descrição da turbulência na CLP, requer o uso de modelos matemáticos para determinar o transporte de poluentes na atmosfera.

Os modelos matemáticos que determinam as propriedades da atmosfera e o seu efeito sobre o(s) poluente(s) são denominados modelos de dispersão. Eles representam uma importante ferramenta de investigação dos transportes de poluentes desde que sejam validados através de observações detalhadas da dispersão atmosférica.

O transporte turbulento de poluentes na CLP pode ser dividido em três diferentes escalas (Zannetti, 1990):

a) Transporte de longo alcance (escalas maiores que $100 \mathrm{~km}$ );

b) Transporte de médio alcance (escalas entre 10 km e 50 km);

c) Transporte de curto alcance (escalas menores que $10 \mathrm{~km}$ ).

Inexistem dados de concentração de poluentes e das variáveis meteorológicas relevantes (vento, altura da CLP, rugosidade aerodinâmica, parâmetro de estabilidade, etc.) que possam ser utilizadas para validar os modelos de dispersão. No Brasil, em particular, a aplicação indiscriminada desses modelos em estudos de licenciamento ambiental não reflete as condições climáticas esperadas para as regiões tropicais e subtropicais, e deve ser revista.

Uma forma alternativa de determinar o transporte turbulento de curto alcance e que será explorada nessa Tese é o emprego do modelo de simulação direta dos grandes turbilhões, denominado Large-Eddy Simulation (LES). Nesse modelo, as propriedades da CLP convectiva são simuladas com precisão suficiente para gerar um conjunto de dados das variáveis meteorológicas e da dispersão de poluentes, que pode ser utilizado na validação dos modelos operacionais existentes. 
Duas abordagens serão utilizadas nos estudos de dispersão de poluentes inertes e passivos, a euleriana e a lagrangiana.

Em virtude da complexidade dos processos físicos que envolvem a descrição da CLP, ainda não é possível realizar simulações numéricas diretas (DNS) desses escoamentos, pois os recursos computacionais existentes não permitem simulações com $10^{18}$ pontos de grade (Lesieur e Métais, 1996; Moeng e Sullivan, 2002). A maior vantagem dos modelos do tipo LES é que eles resolvem explicitamente os turbilhões responsáveis pelo transporte de poluentes na escala de curto alcance, e com isso, descrevem com boa precisão os principais processos físicos desses escoamentos turbulentos.

A primeira aplicação deste tipo de modelo no estudo da dispersão de poluentes na CLP foi realizada por Deardorff (1972). Em seu trabalho pioneiro, Deardorff estabeleceu as escalas características de velocidade $\left(\mathrm{w}_{*}\right)$ e de comprimento $\left(\mathrm{z}_{\mathrm{i}}\right)$ que, posteriormente, revelaram ser as mais apropriadas para descrever a estrutura vertical das propriedades estatísticas da CLP em condições convectivas. Essas simulações produziram um conjunto de dados que, posteriormente, foram extensivamente utilizados em estudos de dispersão de poluentes (Lamb, 1984).

As primeiras tentativas de descrever a complexidade da difusão turbulenta de um escalar na CLP convectiva foram realizadas por Wyngaard e Brost (1984) e Moeng e Wyngaard (1984). Seus resultados indicaram que os gradientes verticais de concentração juntos ao topo da CLP $\left(\mathrm{z}_{\mathrm{i}}\right)$ e próximos à superfície são dirigidos por processos físicos distintos. Desta forma, sugeriram que a distribuição vertical do fluxo turbulento de escalares é uma superposição de processos difusivos distintos, um deles controlado pelo fluxo de escalares na superfície, que atua em direção ao topo (bottom-up), e outro controlado pelo fluxo de entranhamento de escalares, que age do topo da CLP em direção à superfície (top-down). Posteriormente, Piper et al. (1995), por meio de experimentos realizados em tanque de convecção, validaram as parametrizações propostas por Moeng e Wyangaard (1984) para esses processos de difusão. Cuijpers e Holtslag (1998) propuseram novas expressões para os fluxos verticais de calor sensível e de outros escalares, combinando os efeitos locais e não locais, através da utilização de uma escala convectiva generalizada. Recentemente, Sorbjan (1999) propôs novas expressões para descrever o processo top-down que reduziram consideravelmente o 
espalhamento das estimativas dos gradientes adimensionais de escalares no topo CLP convectiva.

Nieuwstadt e Valk (1987) e van Haren e Nieuwstadt (1989) utilizaram o modelo LES para simular os padrões de dispersão de poluentes na CLP convectiva produzidos por uma fonte pontual contínua com base na liberação de uma fonte linha instantânea na direção longitudinal da grade. Nessas simulações, a pluma gerada por um poluente liberado continuamente de uma fonte localizada próxima à superfície eleva-se, gerando um máximo de concentração no topo da CLP. Em contraste, o poluente liberado de uma fonte localizada acima da camada limite superficial (CLS) é transportado em direção ao solo, causando um máximo de concentração na superfície. Esses resultados concordaram com os clássicos experimentos de tanque de convecção realizados por Willis e Deardorff (1976a, 1978). A reprodução desse comportamento tornou-se um procedimento padrão para validar a capacidade do modelo LES em simular a dispersão de um poluente liberado continuamente por uma fonte pontual, localizada na CLP convectiva sob condições horizontalmente homogêneas (Henn e Sykes, 1992; Nieuwstadt e Meeder, 1997). Importantes propriedades sobre a dispersão relativa de pares de partículas (Sawford, 2001) também podem ser investigadas com o modelo LES (Gioia et al., 2004).

Os efeitos da heterogeneidade da superfície, nas propriedades da CLP convectiva, foram investigados por Hechtel et al. (1990), Gopalakrishnan et al. (2000), Gopalakrishnan e Avissar (2000) e Cai (1999 e 2000). Segundo Hechtel et al. (1990), para escalas horizontais da ordem de $5 \mathrm{~km}$, a adoção de condições de contorno mais realísticas, como fluxos turbulentos diferencias na superfície, não apresentam diferenças significativas nos momentos estatísticos de primeira e segunda ordem das componentes de velocidade, quando comparados com condições de homogeneidade superficial. Por outro lado, Gopalakrishnan et al. (2000) avaliaram que características topográficas com escalas de comprimento maiores que $5 \mathrm{~km}$ organizam a distribuição dos turbilhões, diminuindo (aumentando) a variância da componente vertical (horizontal) de velocidade. Porém, não afetam as propriedades médias, mesmo considerando montanhas com 30\% da altura da CLP. O efeito conjunto da topografia e do fluxo diferencial de calor na dispersão de poluentes na CLP convectiva foi abordado por Gopalakrishnan e Avissar (2000). Em seus resultados, as heterogeneidades no fluxo de calor da superfície com escalas de comprimento maiores do que $5 \mathrm{~km}$ afetam a dispersão de partículas, que são advectadas horizontalmente por um período de tempo maior. Em geral, 
quanto mais fraco o fluxo de calor na superfície, mais significativo é o impacto da heterogeneidade superficial, e vice-versa.

Diversos estudos já demonstraram a habilidade do modelo LES em simular as principais características dos escoamentos turbulentos da CLP sob condições altamente convectivas. Os trabalhos realizados por Deardorff (1974a e 1974b) reproduziram os perfis verticais dos momentos estatísticos de primeira e segunda ordem, observados no experimento de Wangara, e avaliaram as influências do entranhamento sobre a distribuição vertical dos escalares atmosféricos. Os experimentos numéricos conduzidos por Schmidt e Schumann (1989) mostraram que as estruturas coerentes para a turbulência de origem puramente térmica apresentam formas poligonais na região próxima à superfície. Com a evolução na vertical, essas estruturas se organizam em extensas e isoladas regiões de movimentos verticais ascendentes. Esses resultados foram confirmados por Moeng e Sullivan (1994) que exploraram as diferenças entre a CLP gerada por uma forçante predominantemente mecânica e outra de regime misto, através das estimativas dos campos instantâneos e do balanço energia cinética turbulenta (ECT). Lin (2000) também mostrou por meio do balanço de ECT que o termo de transporte devido à flutuação de pressão na CLP convectiva de regime misto, tem uma contribuição positiva próximo à superfície.

Outras importantes propriedades da turbulência na CLP sobre regimes de transição também foram investigadas com auxílio de modelos do tipo LES (Nieuwstadt e Brost, 1986; Acevedo e Fitzjerrald, 2001; Goulart et al., 2003).

Em regiões tropicais e subtropicais do Brasil, em particular na região metropolitana de São Paulo (RMSP), condições de estabilidade altamente convectivas associadas à baixa velocidade do vento são freqüentemente observadas (Oliveira et al., 2003).

Desse modo, o objetivo principal deste trabalho é descrever as propriedades estatísticas da turbulência em uma CLP altamente convectiva associada à baixa velocidade do vento, sobre uma superfície horizontalmente homogênea, simulada numericamente com a versão do modelo LES desenvolvida por Moeng (1984) e modificada por Sullivan et al. (1994). Com essas simulações serão obtidas estimativas dos momentos estatísticos de primeira, segunda e terceira ordem, dos termos do balanço de ECT, além das propriedades espectrais espaciais e temporais. Posteriormente, com a estrutura da turbulência determinada, será realizado um estudo sobre a dispersão de um poluente inerte e passivo, tanto do ponto de vista euleriano, 
quanto do lagrangiano. A emissão desse poluente na CLP será feita de duas formas distintas, fonte área e fonte pontual contínua.

As abordagens euleriana e a lagrangiana para esses dois tipos de fontes de emissão permitirão o desenvolvimento de uma rotina de validação das simulações numéricas de dispersão de poluentes na CLP.

Uma das motivações para a aplicação do modelo LES em estudos de dispersão de poluentes emitidos por uma fonte área localizada na superfície é que, apesar de hipotético, os resultados obtidos podem ser utilizados para ilustrar o comportamento de poluentes atmosféricos, tal como o monóxido de carbono (CO) em uma região urbana densamente povoada e com elevado tráfego de veículos automotores, como é o caso de várias áreas da região metropolitana de São Paulo (RMSP), ou mesmo de outras metrópoles brasileiras. Podendo até, nesse caso, ser utilizado para suprir as lacunas observacionais de poluentes atmosféricos.

Com a estrutura tridimensional da turbulência fornecida pelo modelo LES também é possível compreender os padrões de dispersão de poluentes inertes e passivos, emitidos por fontes pontuais contínuas localizadas em diferentes alturas da CLP, que geralmente não são reproduzidos por modelos convencionais de CLP (Modelos de fechamento de $1^{\mathrm{a}}$ ou $2^{\mathrm{a}}$ ordem).

Este é o primeiro trabalho desenvolvido no Brasil que utiliza o modelo LES como ferramenta de pesquisa para investigar as propriedades estatísticas dos escoamentos turbulentos na CLP. Além de proporcionar uma melhor compreensão dos processos físicos envolvidos nesse tipo de escoamento, esse trabalho disponibilizará à comunidade científica brasileira uma avançada ferramenta computacional imprescindível ao desenvolvimento de futuras pesquisas em micrometeorologia e áreas afins.

No capítulo 2 será feita uma descrição detalhada das formulações utilizadas pelo modelo LES e pelos modelos euleriano e lagrangiano de dispersão de poluentes, além dos esquemas numéricos e das condições de fronteiras utilizadas. Os recursos computacionais, as estratégias de modelagem e a metodologia de análise dos resultados serão apresentadas no capítulo 3.

Os critérios utilizados para verificar se os escoamentos turbulentos simulados apresentam a condição de quase-equilíbrio serão discutidos no capítulo 4. Também serão efetuadas análises detalhadas da estrutura da turbulência na CLP convectiva através dos perfis verticais dos momentos estatísticos de primeira, segunda e terceira ordem das variáveis meteorológicas, 
bem como dos planos horizontais e verticais instantâneos. Além disso, as propriedades espectrais de uma CLP altamente convectiva serão exploradas. Alguns desses resultados serão validados com os prognósticos da teoria da similaridade da camada de mistura e da lei do equilíbrio universal concebida por Kolmogorov.

A dispersão de poluentes, tanto do ponto de vista euleriano, quanto do lagrangiano serão investigadas no capítulo 5, juntamente com as estratégias de validação. As conclusões e as referências bibliográficas são apresentadas nos capítulos 6 e 7, respectivamente. 


\section{2 - MODELOS NUMÉRICOS}

Os principais modelos numéricos utilizados para simular a estrutura da turbulência na CLP são os modelos do tipo média de Reynolds e os modelos do tipo média de volume. Os modelos numéricos de média de Reynolds estão baseados no tratamento estatístico dos escoamentos turbulentos e requerem a solução do problema de fechamento. As soluções existentes, independente da ordem do problema de fechamento, estão fundamentadas em medidas experimentais e apresentam deficiências na representação de muitos processos físicos (Garrat et al., 1996).

Os modelos de média de volume, também denominados de modelos LES, estão baseados na simulação direta dos grandes turbilhões (escala resolvida) e na parametrização dos processos que ocorrem em pequena escala (escala não resolvida ou de subgrade) (Deardorff, 1972; Moeng, 1984; Manson, 1994). A grande vantagem dos modelos de média de volume é que a hipótese de construção usada no caso dos modelos média de Reynolds está restrita a turbulência da escala de subgrade. Com isso, evita-se a utilização de parametrizações da turbulência da escala resolvida, que em geral é mais dependente das características geométricas do escoamento e, portanto, mais afetada pelas hipóteses de construção. Apesar disso, os modelos do tipo LES apresentam algumas limitações como, o fechamento da escala de subgrade e o domínio limitado da dimensão da grade, além do elevado custo computacional (Manson, 1994; Lesieur e Metais, 1996; Sorjan, 1996).

A seguir serão descritas as formulações dos modelos numéricos utilizados, bem como uma discussão sobre os esquemas numéricos e as condições de fronteiras adotadas.

\section{1 - O modelo LES}

Nos modelos LES a separação entre a escala resolvida e a escala de subgrade é obtida através da aplicação de um filtro passa-baixa sobre as variáveis das equações de Navier-Stokes para um fluido incompressível (Leonard, 1974). Dessa forma, as variáveis filtradas equivalem a uma média de volume e descrevem os movimentos turbulentos na escala resolvida (Deardorff, 1972). As escalas não resolvidas explicitamente pelo modelo LES são parametrizadas. 
De acordo com Moeng (1984), as equações que descrevem a evolução temporal e espacial das componentes de velocidade do vento na escala resolvida $(\overline{\mathrm{u}}, \overline{\mathrm{v}}$ e $\overline{\mathrm{w}})$ são as seguintes:

$$
\begin{aligned}
& \frac{\partial \overline{\mathrm{u}}}{\partial \mathrm{t}}=\overline{\overline{\mathrm{v}} \overline{\zeta_{\mathrm{z}}}}-\overline{\overline{\mathrm{w}} \overline{\zeta_{\mathrm{y}}}}+\mathrm{f}_{\mathrm{c}} \overline{\mathrm{v}}-\frac{\partial \mathrm{P}^{*}}{\partial \mathrm{x}}-\frac{\partial\langle\overline{\mathrm{p}}\rangle}{\partial \mathrm{x}}-\frac{\partial \tau_{\mathrm{uu}}}{\partial \mathrm{x}}-\frac{\partial \tau_{\mathrm{uv}}}{\partial \mathrm{y}}-\frac{\partial \tau_{\mathrm{uw}}}{\partial \mathrm{z}} \\
& \frac{\partial \overline{\mathrm{v}}}{\partial \mathrm{t}} \overline{\overline{\mathrm{w}} \overline{\zeta_{\mathrm{x}}}}-\overline{\overline{\mathrm{u}} \overline{\zeta_{\mathrm{z}}}}-\mathrm{f}_{\mathrm{c}} \overline{\mathrm{u}}-\frac{\partial \mathrm{P}^{*}}{\partial \mathrm{y}}-\frac{\partial\langle\overline{\mathrm{p}}\rangle}{\partial \mathrm{y}}-\frac{\partial \tau_{\mathrm{vu}}}{\partial \mathrm{x}}-\frac{\partial \tau_{\mathrm{vv}}}{\partial \mathrm{y}}-\frac{\partial \tau_{\mathrm{vw}}}{\partial \mathrm{z}} \\
& \frac{\partial \overline{\mathrm{w}}}{\partial \mathrm{t}}=\overline{\overline{\mathrm{u}} \overline{\zeta_{\mathrm{y}}}}-\overline{\overline{\mathrm{v}} \overline{\zeta_{\mathrm{x}}}}+\frac{\bar{\theta}}{\theta_{0}} \mathrm{~g}-\frac{\partial \mathrm{P}^{*}}{\partial \mathrm{z}}-\frac{\partial \tau_{\mathrm{wu}}}{\partial \mathrm{x}}-\frac{\partial \tau_{\mathrm{wv}}}{\partial \mathrm{y}}-\frac{\partial \tau_{\mathrm{ww}}}{\partial \mathrm{z}}-\left\langle\frac{\partial \overline{\mathrm{w}}}{\partial \mathrm{t}}\right\rangle
\end{aligned}
$$

onde - representa a escala resolvida; \langle\rangle a média no plano horizontal; u, v e w são as componentes de velocidade; $\theta$ é a temperatura potencial; $\mathrm{f}_{\mathrm{c}}$ é a força de Coriolis; $\zeta_{\mathrm{x}}, \zeta_{\mathrm{y}}$ e $\zeta_{\mathrm{z}}$ são as componentes de vorticidade nas direções x, y e z, respectivamente; $\tau_{\mathrm{ij}}$ são os tensores tensão de Reynolds modificados na escala de subgrade ${ }^{(1)}$; p é a pressão hidrostática do ar; $\theta_{0}$ é a temperatura potencial de referência do ar; e $\mathrm{P}^{*}$ é a pressão modificada.

Na Eq. (2.3) a média horizontal da aceleração vertical é subtraída para assegurar que tanto $\langle\overline{\mathrm{w}}\rangle$ quanto $\langle\partial \overline{\mathrm{w}} / \partial \mathrm{t}\rangle$ permaneçam nulos durante a evolução da CLP (Deardorff, 1972). Isto garante que o escoamento turbulento na escala resolvida satisfaça o equilíbrio hidrostático, $1 / \rho_{0} \partial \mathrm{p}_{0} / \partial \mathrm{z}=-\mathrm{g}$, onde $\mathrm{p}_{0}$ e $\rho_{0}$ são a pressão e a densidade atmosférica de referência, respectivamente.

O tensor tensão de Reynolds de subgrade modificado é descrito por:

$$
\tau_{\mathrm{ij}}=\mathrm{R}_{\mathrm{ij}}-\mathrm{R}_{\mathrm{kk}} \delta_{\mathrm{ij}} / 3
$$

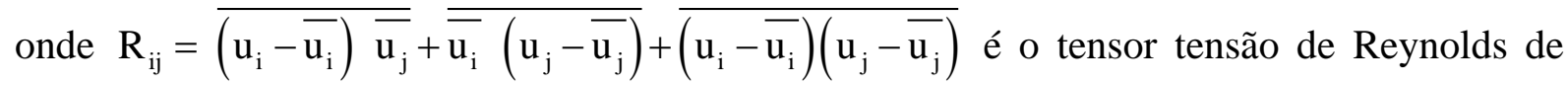
subgrade $^{(1)}$ e $\delta_{\mathrm{ij}}$ é o delta de Kronecker. Os termos desse tensor contêm as influências dos produtos cruzados entre as componentes da escala resolvida e de subgrade, produtos nãolineares das componentes de subgrade e a contribuição da escala resolvida conhecida como

(1) Essa notação difere da notação comumente utilizada para tensores (Moeng, 1984). 
termo de Leonard $\left(\overline{\overline{\mathrm{u}_{\mathrm{i}}}} \overline{\overline{\mathrm{u}_{\mathrm{j}}}}-\overline{\mathrm{u}_{\mathrm{i}}} \overline{\mathrm{u}_{\mathrm{j}}}\right)$. A importância do termo de Leonard depende do filtro passa-baixa utilizado na definição das equações governantes. Na versão do modelo LES utilizada nesse trabalho o filtro aplicado é uma expansão de Fourier truncada (Leonard, 1974; Wyngaard, 1984), que é eficaz na remoção de flutuações aleatórias dos menores turbilhões da escala de subgrade. Portanto, a utilização deste filtro implica em valor nulo para o termo de Leonard (Moeng e Sullivan, 2002), o que simplifica a equações das escalas resolvidas.

Os gradientes de pressão médios horizontais $-\partial\langle\overline{\mathrm{p}}\rangle / \partial \mathrm{x}$ e $-\partial\langle\overline{\mathrm{p}}\rangle / \partial \mathrm{y}$ nas Eqs. (2.1) e (2.2), respectivamente, são tratados como forçantes externas e prescritos como parâmetros de entrada do modelo através do vento geostrófico. Isto implica que o escoamento horizontal na escala resolvida está sendo continuamente acelerado para um estado de equilíbrio geostrófico. De acordo com Moeng (1984), os termos de advecção não-linear das Eqs. (2.1)-(2.3) são escritos na forma rotacional de modo a conservar a média de volume da energia cinética (Moeng, 1984).

O termo de pressão modificado $\mathrm{P}^{*}$ nas Eqs. (2.1)-(2.3) assume a seguinte forma:

$\mathrm{P}^{*}=\overline{\mathrm{p}} / \rho_{0}+\mathrm{R}_{\mathrm{kk}} / 3+\overline{\overline{\mathrm{u}_{\mathrm{k}}}} \overline{\overline{\mathrm{u}_{\mathrm{k}}}} / 2$

sendo que, o campo $\mathrm{P}^{*}$ é determinado pela equação de Poisson:

$$
\nabla^{2} \mathrm{P}^{*}=\frac{\partial \mathrm{H}_{\mathrm{x}}}{\partial \mathrm{x}}+\frac{\partial \mathrm{H}_{\mathrm{y}}}{\partial \mathrm{y}}+\frac{\partial \mathrm{H}_{\mathrm{z}}}{\partial \mathrm{z}}
$$

onde $\mathrm{H}_{\mathrm{x}}, \mathrm{H}_{\mathrm{y}}$ e $\mathrm{H}_{\mathrm{z}}$ são as somas dos termos do lado direito das Eqs. (2.1)-(2.3), respectivamente, com exceção dos gradientes de pressão modificados, e representam os efeitos dinâmicos da turbulência sobre o campo de pressão na escala resolvida. Na ausência de movimento, a pressão normalizada é igual à pressão hidrostática do escoamento na escala resolvida.

É importante ressaltar que as equações do movimento satisfazem todas as condições das aproximações de Boussinesq para convecção rasa (Dutton e Fitchl, 1969). Essas condições implicam que as flutuações de temperatura potencial e de densidade estão relacionadas por $-\bar{\rho} / \rho_{0}=\bar{\theta} / \theta_{0}$, e que a equação da continuidade é $\partial \overline{u_{i}} / \partial x_{i}=0$. Isto também implica que o estado básico obedece a lei do gás ideal, $\mathrm{p}_{0}=\rho_{0} \mathrm{R}_{\mathrm{d}} \mathrm{T}_{0}$. 
A equação de conservação de temperatura potencial na escala resolvida é descrita por:

$\frac{\partial \bar{\theta}}{\partial \mathrm{t}}=-\overline{-\mathrm{u} \frac{\partial \bar{\theta}}{\partial \mathrm{x}}}-\overline{\overline{-v} \frac{\partial \bar{\theta}}{\partial \mathrm{y}}}-\overline{\overline{\mathrm{w}} \frac{\partial \bar{\theta}}{\partial \mathrm{z}}}-\overline{\mathrm{w}} \frac{\partial \theta_{0}}{\partial \mathrm{z}}-\frac{\partial \tau_{\theta \mathrm{u}}}{\partial \mathrm{x}}-\frac{\partial \tau_{\theta \mathrm{v}}}{\partial \mathrm{y}}-\frac{\partial \tau_{\theta \mathrm{w}}}{\partial \mathrm{z}}$

onde $\tau_{\theta \mathrm{j}}$ representa o fluxo turbulento de calor sensível de subgrade e expresso como:

$$
\tau_{\theta j}=\overline{(\theta-\bar{\theta}) \overline{u_{j}}}+\overline{\bar{\theta}\left(\mathrm{u}_{\mathrm{j}}-\overline{\mathrm{u}_{\mathrm{j}}}\right)}+\overline{(\theta-\bar{\theta})\left(\mathrm{u}_{\mathrm{j}}-\overline{\mathrm{u}_{\mathrm{j}}}\right)}
$$

A Eq. (2.7) satisfaz as aproximações de Boussinesq para convecção rasa, o que implica que as variações de temperatura potencial do estado básico satisfaz a relação: $\theta_{0}=T_{0}\left(p_{0} / p_{00}\right)^{-R_{d} / c_{p}}$.

A parametrização dos tensores $\tau_{\mathrm{ij}}$ e $\tau_{\theta \mathrm{j}}$ resultam em incertezas nas soluções geradas pelo modelo LES, particularmente nas regiões próximas da superfície e da camada de entranhamento, onde os pequenos turbilhões dominam (Moeng e Sullivan, 2002). Contudo, nas regiões onde os grandes turbilhões são bem resolvidos, os escoamentos turbulentos gerados pelo modelo LES têm se mostrado pouco sensível ao modelo de subgrade adotado.

Em geral, os tensores $\tau_{\mathrm{ij}}$ e $\tau_{\theta \mathrm{j}}$ estão relacionados ao campo da escala resolvida através dos coeficientes de difusividade turbulenta, que por sua vez são parametrizados de acordo com o modelo de viscosidade não-linear proposto por Smagorinsky (1963). Esse modelo assume a existência de um equilíbrio local entre a produção mecânica e a dissipação molecular da energia cinética turbulenta (ETC) e também, garante a cascata de energia da maior para a menor escala (Smagorinsky, 1984).

Na CLP em condições convectivas a principal fonte de ECT é de origem térmica, implicando que a parametrização proposta por Smagorinsky deve ser modificada. Além disso, o aumento do cisalhamento do vento próximo à superfície induz anisotropia nas flutuações das componentes de velocidade e as escalas dominantes decrescem em dimensão (Sullivan et al., 1994). Esses fatores, especialmente o último, afetam a habilidade do modelo LES em reproduzir os movimentos turbulentos próximo à superfície, prejudicando sua capacidade de descrever processos turbulentos de subgrade.

Sullivan et al. (1994) propôs a divisão dos tensores de subgrade em contribuição isotrópica e contribuição não-homogênea, onde o termo isotrópico depende da magnitude da flutuação do tensor taxa de deformação e o termo não-homogêneo varia de acordo com a tensão média. $\mathrm{O}$ 
modelo de subgrade de Sullivan assegura o perfil logaritmo do vento próximo à superfície e satisfaz os prognósticos da teoria da similaridade de Monin-Obukhov, que são utilizados nas estimativas dos fluxos turbulentos na superfície (Khanna e Brasseur, 1998).

Os fluxos turbulentos de momento $\left(\tau_{\mathrm{ij}}\right)$ e calor sensível $\left(\tau_{\theta \mathrm{j}}\right)$ de subgrade são descritos por:

$$
\begin{aligned}
& \tau_{\mathrm{ij}}=-2 \mathrm{~K}_{\mathrm{M}} \gamma \overline{\mathrm{S}_{\mathrm{ij}}}-2 \mathrm{~K}_{\langle\mathrm{M}\rangle}\left\langle\overline{\mathrm{S}_{\mathrm{ij}}}\right\rangle \\
& \tau_{\theta \mathrm{j}}=-\mathrm{K}_{\mathrm{H}}\left(\frac{\partial \bar{\theta}}{\partial \mathrm{x}_{\mathrm{j}}}\right)
\end{aligned}
$$

onde $K_{M}$ e $K_{\langle M\rangle}$ são os coeficientes de difusividade turbulenta de momento relacionado a parte isotrópica e a parte não-homogênea, respectivamente; $K_{H}$ é o coeficiente de difusividade turbulenta de calor; $\overline{\mathrm{S}_{\mathrm{ij}}}=1 / 2\left(\partial \overline{\mathrm{u}_{\mathrm{i}}} / \partial \mathrm{x}_{\mathrm{j}}+\partial \overline{\mathrm{u}_{\mathrm{j}}} / \partial \mathrm{x}_{\mathrm{i}}\right)$ é o tensor taxa de deformação na escala resolvida; $\left\langle\overline{S_{i j}}\right\rangle$ é a média horizontal do tensor taxa de deformação na escala resolvida e $\left.\gamma^{2}=\left\langle\left(\overline{S_{i j}}-\left\langle\overline{S_{i j}}\right\rangle\right)^{2}\right\rangle /\left(\left\langle\overline{S_{i j}}-\left\langle\overline{S_{i j}}\right\rangle\right)^{2}\right\rangle+\left\langle\overline{S_{i j}}\right\rangle^{2}\right)$ é o quadrado do fator de isotropia.

Os coeficientes de difusividade turbulenta são dados por:

$$
\begin{aligned}
& \mathrm{K}_{\mathrm{M}}=\mathrm{c}_{\mathrm{K}} \delta \sqrt{\mathrm{e}} \\
& \mathrm{K}_{\mathrm{H}}=[1+(2 \delta / \Delta \mathrm{s})] \mathrm{K}_{\mathrm{M}}
\end{aligned}
$$

onde e é a energia cinética turbulenta de subgrade $\left(\mathrm{e}=0,5 \mathrm{R}_{\mathrm{kk}}\right), \mathrm{c}_{\mathrm{K}}$ é constante e igual a 0,10 (Moeng, 1984), $\Delta$ s é o espaçamento médio da grade $\Delta s=(\Delta x \Delta y \Delta z)^{1 / 3}$ e $\delta$ é a escala de comprimento de mistura de subgrade. Como forma de assumir os efeitos diretos da estabilidade local, $\delta$ é definido como o mínimo entre duas escalas de comprimento (Deardorff, 1980):

$$
\delta=\min \left[0,76 \mathrm{e}^{1 / 2}\left(\frac{\mathrm{g}}{\theta_{0}} \frac{\partial \bar{\theta}}{\partial \mathrm{z}}\right)^{-1 / 2} ; \Delta \mathrm{s}\right]
$$


Assim, em condições muito estáveis $\mathrm{K}_{\mathrm{H}}=\mathrm{K}_{\mathrm{M}}$ e em condições convectivas $\mathrm{K}_{\mathrm{H}}=3 \mathrm{~K}_{\mathrm{M}}$, ou seja, $\delta=\Delta$ s .

Considerando uma CLP horizontalmente homogênea, a parte não-homogênea do coeficiente de difusividade turbulenta de momento é dada por:

$$
\mathrm{K}_{\langle\mathrm{M}\rangle}=\left(\mathrm{c}_{\mathrm{K}} \delta\right)^{2} \sqrt{(\partial\langle\overline{\mathrm{u}}\rangle / \partial \mathrm{z})^{2}+(\partial\langle\overline{\mathrm{v}}\rangle / \partial \mathrm{z})^{2}}
$$

No modelo LES utilizado nesse trabalho os fluxos turbulentos de subgrade são estimados de acordo com o modelo de Sullivan et al. (1994), descrito acima.

A energia cinética turbulenta na escala de subgrade (e) é obtida através de uma equação prognóstica similar a adotada por Deardorff (1980):

$\frac{\partial e}{\partial t}=-\overline{u_{j}} \frac{\partial e}{\partial x_{j}}-\overline{\left(u_{i}-\overline{u_{i}}\right)\left(u_{j}-\overline{u_{j}}\right)} \frac{\partial \overline{u_{i}}}{\partial x_{j}}+\frac{g}{\theta_{0}} \overline{(w-\bar{w})(\theta-\bar{\theta})}-\frac{\partial}{\partial x_{i}}\left\{\overline{\left(u_{i}-\overline{u_{i}}\right)}\left[e+\overline{(p-\bar{p}) / \rho_{0}}\right]\right\}-\varepsilon$

onde $\varepsilon$ é a taxa de dissipação molecular.

Na Eq. (2.13), a taxa de dissipação molecular e o termo de transporte de ECT de subgrade, são parametrizados da seguinte forma (Moeng, 1984):

$$
\varepsilon=\mathrm{c}_{\varepsilon} \frac{(\mathrm{e})^{3 / 2}}{\delta}
$$

$$
\overline{\left(\mathrm{u}_{\mathrm{i}}-\overline{\mathrm{u}_{\mathrm{i}}}\right)}\left[\mathrm{e}+\overline{(\mathrm{p}-\overline{\mathrm{p}}) / \rho_{0}}\right]=-2 \mathrm{~K}_{\mathrm{M}} \frac{\partial \mathrm{e}}{\partial \mathrm{x}_{\mathrm{i}}}
$$

onde $\mathrm{c}_{\varepsilon}=0,19+0,74(\delta / \Delta \mathrm{s})$. Em condições convectivas $\delta=\Delta \mathrm{s}$ e conseqüentemente $\mathrm{C}_{\varepsilon}=0,93$.

O modelo de subgrade discutido acima é baseado na descrição estatística da turbulência e utilizado nos campos instantâneos gerados pelo modelo LES para representar os efeitos da escala de subgrade. De acordo com Moeng e Sullivan (2002), estudos realizados em laboratório e com modelos DNS mostram que os movimentos turbulentos nas escalas menores podem ser intermitentes, implicando que, localmente, pode ocorrer transferência de energia das escalas maiores para menores (forwardscatter) e vice-versa (backscatter). Este fato pode estar associado a um possível desvio da lei do equilíbrio universal de Kolmogorov, e, 
portanto, os modelos de subgrade que representam os processos próximos à superfície ainda necessitam de melhorias (Porté-Agel et al., 2000).

\section{2 - Esquemas numéricos e condições de fronteiras}

O conjunto de equações do modelo LES é resolvido numericamente utilizando um método pseudo-espectral nas direções horizontais e um esquema de diferenças finitas de segunda ordem centrado no espaço, na direção vertical. O avanço dos campos tridimensionais no tempo é realizado através a aplicação do esquema numérico de $2^{\mathrm{a}}$ ordem Adams-Bashforth, estável para pequenos passos de tempo (Mesinger e Arakawa, 1982).

No passo de tempo $n$, as forçantes dinâmicas $H_{i}$ são utilizadas para calcular o campo de pressão modificado $\mathrm{P}^{*}$. Como forma de assegurar a incompressibilidade, é adicionada uma pequena correção ao campo de divergência representada pela adição do termo $2 / 3 \partial^{2} \overline{u_{i}} / \partial t \partial x_{i}$ no lado direito da Eq. (2.6). Esta modificação evita a ocorrência de campos de divergência não-nula, além de corrigir possíveis erros de truncamento (Deardorff, 1973; Moeng, 1984). Após a aplicação da transformada de Fourier nas direções x e y , e do esquema numérico centrado no espaço na direção z, a matriz tridiagonal resultante é então resolvida e se obtêm a solução de $\mathrm{P}^{*}$.

A estabilidade numérica é verificada a cada passo no tempo $(\Delta \mathrm{t})$, através do cálculo do número de Courant.

As condições de fronteiras laterais são assumidas periódicas (cíclicas). Esse tipo de fronteira é apropriado para representar escoamentos turbulentos da CLP sobre superfícies homogêneas e são convenientes computacionalmente, uma vez que não necessitam que as condições laterais sejam impostas. Entretanto, o uso de fronteiras periódicas dificulta a realização de simulações de escoamentos turbulentos sobre superfícies heterogêneas com domínio limitado (Moeng e Sullivan, 2002).

A fronteira inferior é rígida e a velocidade vertical é nula. As formulações da teoria similaridade de Monin-Obukhov são empregadas para estimar os fluxos turbulentos de momento na superfície. Embora esta teoria tenha sido desenvolvida para quantidades definida como médias Reynolds é pratica comum utilizá-la para descrever os campos instantâneos no 
modelo LES. Essas parametrizações não consideram os efeitos dos gradientes de pressão presentes nos campos instantâneos do modelo LES e também podem ocasionar problemas na representação dos fluxos turbulentos quando a resolução horizontal da grade é comparável ou menor que a altura definida pelo primeiro nível da grade (Porté-Agel et al., 2000; Moeng e Sullivan, 2002). Apesar disso, ainda não foi desenvolvido nenhum outro modelo de subgrade que represente os processos que ocorrem na superfície de maneira mais consistente.

Para evitar as influências das condições de fronteira superior, o topo da CLP é assumido na metade do domínio vertical da grade. A condição de fronteira é radiativa, com gradientes verticais nulos para as componentes horizontais de velocidade do vento e fluxos turbulentos de subgrade. Por consistência, no modelo LES a velocidade vertical também é nula no topo da grade.

O valor das componentes do vento geostrófico $\left(\mathrm{u}_{\mathrm{G}}, \mathrm{v}_{\mathrm{G}}\right)$ são prescritas no modelo. Os fluxos turbulentos de calor sensível $\left(w^{\prime} \theta^{\prime}\right)_{0}$ e de concentração de poluente $\left(w^{\prime} c^{\prime}\right)_{0}$ (para o caso de fonte do tipo área) na superfície são mantidos constantes. O mesmo acontece com o comprimento de rugosidade $\mathrm{z}_{0}$. A temperatura potencial do estado básico é considerada igual à temperatura potencial média na CLS.

\section{3 - Abordagem euleriana da dispersão de poluentes}

A evolução temporal e espacial de um poluente inerte e passivo na CLP é obtida através da adição de uma equação prognóstica de conservação de um escalar atmosférico na escala resolvida no sistema de equações resolvido pelo modelo LES, e pode ser descrita da seguinte forma (Moeng e Wyngaard, 1984):

$\frac{\partial \bar{c}}{\partial \mathrm{t}}=\overline{-\overline{\mathrm{u}} \frac{\partial \overline{\mathrm{c}}}{\partial \mathrm{x}}}-\overline{-\overline{\mathrm{v}} \frac{\partial \overline{\mathrm{c}}}{\partial \mathrm{y}}}-\overline{\overline{\mathrm{w}}} \frac{\partial \overline{\mathrm{c}}}{\partial \mathrm{z}}-\frac{\partial \tau_{\mathrm{cu}}}{\partial \mathrm{x}}-\frac{\partial \tau_{\mathrm{cv}}}{\partial \mathrm{y}}-\frac{\partial \tau_{\mathrm{cw}}}{\partial \mathrm{z}}+\mathrm{F}_{0}$

onde c é a concentração do poluente, $F_{0}$ é o termo fonte e $\tau_{c j}$ os fluxos turbulentos do poluente na escala de subgrade $\left(\tau_{\mathrm{cj}}=\overline{(\mathrm{c}-\overline{\mathrm{c}}) \overline{\overline{\mathrm{u}_{j}}}}+\overline{\overline{\mathrm{c}}\left(\mathrm{u}_{\mathrm{j}}-\overline{\mathrm{u}_{\mathrm{j}}}\right)}+\overline{(\mathrm{c}-\overline{\mathrm{c}})\left(\mathrm{u}_{\mathrm{j}}-\overline{\mathrm{u}_{\mathrm{j}}}\right)}\right)$. 
O modelo utilizado para representar o fluxo do poluente de subgrade é similar ao adotado na descrição do fluxo turbulento de calor sensível, Eq. (2.9), e supõem que $\tau_{\text {cj }}$ está relacionado ao campo da escala resolvida por meio de um coeficiente de difusividade turbulenta (Sullivan et al., 1994):

$$
\tau_{\mathrm{cj}}=-\mathrm{K}_{\mathrm{C}}\left(\frac{\partial \overline{\mathrm{c}}}{\partial \mathrm{x}_{\mathrm{j}}}\right)
$$

onde $\mathrm{K}_{\mathrm{C}}$ é o coeficiente de difusividade turbulento do poluente atmosférico, usualmente assumido igual a $\mathrm{K}_{\mathrm{H}}$.

O campo de concentração de poluente em pontos de grade é calculado simultaneamente aos demais campos tridimensionais das componentes de velocidade e de temperatura potencial. Esse procedimento pode ocasionar alguns problemas numéricos devido ao esquema de discretização adotado pelo modelo LES. Segundo Nieuwstadt e Meeder (1997) o esquema numérico de discretização do campo de concentração deve satisfazer: (a) conservação de massa; (b) concentração sempre positiva e (c) apresentar baixa difusão e baixa dispersão numérica.

Os poluentes são emitidos por dois tipos de fontes: (a) fonte área contínua localizada na superfície e (b) fonte pontual contínua (aproximada por fonte linha instantânea) localizada em diferentes alturas da CLP.

No caso de fonte área contínua, o poluente inerte e passivo foi inserido no domínio da grade no instante inicial da simulação. Contudo, as análises foram feitas após os escoamentos turbulentos simulados atingirem a condição de quase-equilíbrio.

Para o caso de fonte pontual contínua o poluente foi liberado de forma instantânea ao longo de uma linha (fonte linha instantânea) orientada na direção longitudinal x. Neste caso, a emissão foi iniciada somente após os campos turbulentos atingirem a condição de quaseequilíbrio. O procedimento de cálculo para este tipo de fonte segue Nieuwstadt e Valk (1987). 


\section{4 - Abordagem lagrangiana da dispersão de poluentes}

Nos modelos lagrangianos a concentração do poluente inerte e passivo na atmosfera é determinada através do acompanhamento da trajetória de um conjunto de partículas liberadas continuamente, ou instantaneamente, em um escoamento turbulento. Essas partículas comportam-se como os elementos do fluido e viajam com a velocidade dos elementos que compõem o escoamento turbulento. As trajetórias descritas pelas partículas são simuladas numericamente a partir do campo de velocidade.

A concentração do poluente é determinada através da distribuição espacial das partículas em um dado volume a cada instante de tempo. Assim, a posição de uma partícula num tempo $(t+\Delta t)$ é dada pelo vetor posição $x_{i}$ no instante $t$ e pela velocidade da partícula no instante $t$, ou seja:

$\mathrm{x}_{\mathrm{i}}(\mathrm{t}+\Delta \mathrm{t})=\mathrm{x}_{\mathrm{i}}(\mathrm{t})+\left[\overline{\mathrm{u}}_{\mathrm{i}}(\mathrm{t})+\mathrm{u}_{\mathrm{i}}^{\prime \prime}(\mathrm{t})\right] \Delta \mathrm{t}$

onde $\overline{\mathrm{u}}_{\mathrm{i}}$ são as componentes de velocidade da partícula, assumidas iguais às componentes de velocidade na escala resolvida geradas pelo modelo LES, e $\mathrm{u}_{\mathrm{i}}$ " são as componentes de velocidade na escala de subgrade. Em geral, a determinação de $u_{i}$ " pode ser feita por meio de um processo de Markov (Lamb, 1984; Nieuwstadt e Meeder, 1997; Pereira, 2004) ou através da utilização de um modelo cinemático (Boffetta et al., 2002).

A importância de $\mathrm{u}_{\mathrm{i}}$ depende da capacidade do modelo LES resolver os turbilhões responsáveis pelo transporte das partículas na CLP. Nas simulações realizadas por Gopalakrishnan e Avissar (2000) e Gioia et al. (2004), a contribuição de subgrade não foi incluída na Eq. (2.18), uma vez que utilizaram uma resolução fina de grade.

Nas simulações de dispersão lagrangiana desenvolvidas neste trabalho a contribuição das componentes de velocidade na escala de subgrade também foi desconsiderada, pois em condições convectivas os turbilhões dominantes na CLP apresentam escalas de comprimento comparáveis a $\mathrm{z}_{\mathrm{i}}$ (Kaimal et al., 1976) e a resolução da grade é da ordem de $100 \mathrm{~m}$.

As trajetórias das partículas são calculadas após a determinação dos campos tridimensionais das componentes de velocidade na escala resolvida, simulados numericamente pelo modelo LES. As partículas são liberadas por fontes pontuais contínuas localizadas em diferentes 
alturas da CLP convectiva, sendo que aquelas que ultrapassam o domínio horizontal da grade são abandonadas. No topo da CLP e na superfície é assumida a condição de reflexão. O campo de velocidade necessário para integrar a Eq. (2.18) é obtido por meio de uma interpolação bilinear entre os oito pontos de grade mais próximos da posição partícula naquele dado instante (Press et al., 1986).

No capítulo seguinte será feita uma breve descrição dos recursos computacionais existentes, bem como dos principais experimentos numéricos utilizados neste trabalho. 


\section{3 - RECURSOS COMPUTACIONAIS}

A realização de simulações numéricas da CLP com modelos do tipo LES envolve a disponibilidade de recursos computacionais de alta performance, que possibilitam o processamento de um grande volume de operações (determinação de, no mínimo, seis variáveis por ponto de grade) no menor espaço de tempo possível. Além disso, essas simulações geram uma enorme quantidade de dados, sendo necessários sistemas de leitura/gravação suficientemente rápidos para não afetar o tempo de processamento e uma grande capacidade de armazenamento em disco.

Essa é uma das principais dificuldades em desenvolver no Brasil projetos de pesquisa desse porte, pois os recursos computacionais existentes não são dedicados e impossibilitam a realização de simulações por longos períodos de tempo e com elevado número de pontos de grade.

Durante a execução desta pesquisa de doutorado o Laboratório de Computação Científica Avançada da Universidade de São Paulo (LCCA-USP) disponibilizou todos os recursos computacionais existentes para a implementação do modelo LES. Nos três primeiros anos, as simulações foram realizadas no supercomputador CRAY-J90 com uma das versões seriais do código LES desenvolvido por Moeng (1984) e, posteriormente, modificado por Sullivan et al. (1994), e que foi gentilmente cedida pelo pesquisador Dr. Umberto Rizza do Istituto di Scienze dell'Atmosfera e del Clima (CNR-ISAC) de Lecce, Itália.

Nessa versão do código foram implementadas diversas modificações, como arquivos de saídas contendo os campos tridimensionais dos fluxos turbulentos de subgrade, módulo de restart para inicialização dos campos turbulentos com base em dados gerados pelas simulações anteriores, cálculo do balanço de energia cinética turbulenta, inserção de fonte linha instantânea para estimar a dispersão de poluentes pela abordagem euleriana, entre outras.

Para se ter uma idéia do custo computacional nessa primeira fase da pesquisa as simulações de $3.000 \Delta \mathrm{t}$ com $80^{3}$ pontos de grade demoravam cerca de 5 dias para serem executadas, ou aproximadamente 80 horas de CPU no CRAY-J90. Devido a esse fato, tornou-se muito difícil idealizar experimentos numéricos com maior resolução da grade computacional e por tempos de simulação mais longos. 
Depois de uma série de problemas técnicos, no primeiro semestre de 2003, o LCCA-USP fez uma atualização de hardware no supercomputador CRAY-J90, que passou a se chamar supercomputador vetorial CRAY-SV1 (com 8 processadores e 16Gb de memória), para aumentar sua capacidade de processamento. Em conjunto com o corpo científico da CRAY, a versão do código serial do modelo LES também foi otimizada, o que possibilitou a realização de simulações de $10.000 \Delta$ t e $96^{3}$ pontos de grade em 5 dias, ou seja, até 100 vezes mais rápidas que as versões anteriores, permitindo a execução de até 4 simulações simultaneamente. Infelizmente, essa atualização de hardware não foi acompanhada da atualização do sistema de leitura/gravação, acarretando em diversos problemas de operação.

No período compreendido entre os meses de maio e outubro de 2003, foi realizado um estágio de pesquisa no ISAC-CNR de Lecce, Itália, com o intuito de desenvolver uma rotina de cálculo de trajetórias de partículas com base nos campos tridimensionais de velocidade gerados pelo modelo LES. Durante esse estágio, o Dr. Umberto Rizza disponibilizou a versão paralela do modelo LES desenvolvido por Moeng, que foi posteriormente instalada na cluster HP-Compaq S45 (com 4 processadores e 6Gb de memória) do LCCA-USP. Essa versão paralela do código proporcionou uma redução ainda maior no tempo de processamento das simulações numéricas, que permitirá a idealização de experimentos numéricos de longo tempo e com maior resolução de grade (até $128^{3}$ pontos).

\section{1 - Experimentos numéricos}

Durante a execução deste trabalho, foram realizados diversos experimentos numéricos que possibilitaram a caracterização dos principais processos físicos dos escoamentos turbulentos da CLP convectiva.

Em virtude do grande volume de dados gerados, selecionou-se um conjunto representativo de simulações numéricas com diferentes graus de instabilidade, dimensões e resoluções de grade. Cinco dessas simulações foram utilizadas como base de dados para os estudos de caracterização das propriedades estatísticas da turbulência na CLP altamente convectiva, e são apresentadas na Tabela 3.1 em conjunto com suas respectivas condições iniciais. As demais simulações, com condições iniciais similares às simulações bases, foram utilizadas nos estudos de dispersão de poluentes inertes e passivos, emitidos por uma fonte pontual contínua 
localizada em diferentes alturas da CLP convectiva e serão descritas em detalhes no capítulo 5.

Os fluxos turbulentos de calor sensível $\left(w^{\prime} \theta^{\prime}\right)_{0}$ e de concentração de poluente (w'c') na superfície são mantidos constantes no espaço e no tempo durante cada simulação. O mesmo acontece com o comprimento de rugosidade $\mathrm{z}_{0}$, definido igual a $0,15 \mathrm{~m}$.

Os perfis verticais iniciais das componentes horizontais de velocidade são assumidos iguais aos valores das componentes do vento geostrófico em todo o domínio do modelo. Os perfis verticais iniciais de temperatura potencial são representativos de uma CLP com intensa mistura vertical e são assumidos constantes e iguais a $\bar{\theta}_{\text {ini }}$ por toda camada de mistura até a altura inicial da CLP $\mathrm{z}_{\mathrm{ini}}$. Acima disto, a temperatura potencial tem um aumento de $\left(\Delta \bar{\theta}_{\text {ini }}\right)_{\mathrm{i}}$ em 6 níveis verticais da grade e, posteriormente, um gradiente vertical na atmosfera livre $\Gamma_{\theta}$ igual a $3 \mathrm{~K}(\mathrm{~km})^{-1}$.

No estudo de dispersão de um poluente emitido por uma fonte área localizada na superfície, a concentração inicial de 10 ppm é distribuída espacialmente por todo domínio horizontal e considerada constante nos primeiros 40 níveis verticais da grade computacional e nula no restante do domínio do modelo.

Tabela 3.1 - Parâmetros iniciais de um conjunto de simulações numéricas realizadas, onde: $\Delta$ t é o passo no tempo; $\left(\mathrm{u}_{\mathrm{G}}, \mathrm{v}_{\mathrm{G}}\right)$ são as componentes do vento gestrófico; $\bar{\theta}_{\mathrm{ini}}$ é a temperatura potencial; $\left(\text { w'}^{\prime}\right)_{0}$ é o fluxo turbulento de calor sensível na superfície; (w'c') é o fluxo turbulento de concentração de poluente na superfície; $\left(\Delta \bar{\theta}_{\text {ini }}\right)_{\mathrm{i}}$ e a variação vertical de temperatura potencial no topo da CLP; $\mathrm{z}_{\mathrm{ini}}$ é a altura da CLP.

\begin{tabular}{cccccccccc}
\hline \hline Casos & $\begin{array}{c}\text { Pontos de } \\
\text { Grade } \\
(\mathrm{x}, \mathrm{y}, \mathrm{z})\end{array}$ & $\begin{array}{c}\text { Domínio } \\
(\mathrm{Lx}, \mathrm{Ly}, \mathrm{Lz}) \\
(\mathrm{km})\end{array}$ & $\begin{array}{c}\text { Tempo } \\
(\Delta \mathrm{t})\end{array}$ & $\begin{array}{c}\left(\mathrm{u}_{\mathrm{G}}, \mathrm{v}_{\mathrm{G}}\right) \\
\left(\mathrm{ms}^{-1}\right)\end{array}$ & $\begin{array}{c}\bar{\theta}_{\text {ini }} \\
(\mathrm{K})\end{array}$ & $\begin{array}{c}\left(\mathrm{w}^{\prime} \theta^{\prime}\right)_{0} \\
\left(\mathrm{mKs}^{-1}\right)\end{array}$ & $\begin{array}{c}\left(\mathrm{w}^{\prime} \mathrm{c}^{\prime}\right)_{0} \\
\left(\mathrm{ppm} \mathrm{ms}^{-1}\right)\end{array}$ & $\begin{array}{c}\left(\Delta \bar{\theta}_{\text {ini }}\right)_{\mathrm{i}} \\
(\mathrm{K})\end{array}$ & $\begin{array}{c}\mathrm{z}_{\text {ini }} \\
(\mathrm{m})\end{array}$ \\
\hline HC1 & $(80,80,80)$ & $(5 ; 5 ; 2)$ & 10000 & $(5 ; 0)$ & 295 & 0,20 & - & 3 & 1000 \\
HC2 & $(80,80,80)$ & $(5 ; 5 ; 2)$ & 10000 & $(2 ; 0)$ & 298 & 0,23 & - & 3 & 1200 \\
HC3 & $(96,96,96)$ & $(5 ; 5 ; 2)$ & 10000 & $(2 ; 0)$ & 298 & 0,23 & - & 10 & 1000 \\
DA1 & $(96,96,96)$ & $(5 ; 5 ; 2)$ & 10000 & $(5 ; 0)$ & 300 & 0,24 & 0,18 & 8 & 1000 \\
DA2 & $(96,96,96)$ & $(5 ; 5 ; 2)$ & 10000 & $(1 ; 0)$ & 300 & 0,24 & 0,18 & 8 & 1100 \\
\hline \hline
\end{tabular}


A altura da $\operatorname{CLP}\left(\mathrm{z}_{\mathrm{i}}\right)$ é definida como o nível vertical onde o fluxo turbulento de calor sensível médio no plano horizontal atinge o valor mínimo.

Nas simulações descritas na Tabela 3.1, o domínio horizontal da grade é um quadrado de 5 km de lado. De acordo com Manson e Brown (1999), esse domínio é estatisticamente adequado para representar as estruturas da turbulência na CLP convectiva, uma vez que sua extensão horizontal é da ordem de $5 \mathrm{z}_{\mathrm{i}}$.

As inicializações dos campos turbulentos de velocidade, temperatura potencial e de concentração de poluente, são feitas através da sobreposição de flutuações aleatórias aos valores prescritos dos perfis verticais iniciais. No caso das componentes de velocidade, essa flutuação tem uma amplitude $0,5 \mathrm{~ms}^{-1}$. Para a temperatura potencial e concentração de poluente essas flutuações foram iguais a 1,0 K e 1,0 ppm, respectivamente.

As simulações numéricas realizadas com o modelo LES geram um grande volume de dados. Os arquivos de saída com os campos tridimensionais das variáveis meteorológicas têm as mesmas dimensões da grade e são gravados em intervalos de tempo pré-definidos. Esses arquivos contêm: (a) as três componentes de velocidade $(\overline{\mathrm{u}}, \overline{\mathrm{v}}, \overline{\mathrm{w}})$, temperatura potencial $(\bar{\theta})$, concentração de um poluente inerte e passivo $(\bar{c})$ e energia cinética turbulenta na escala de subgrade (e); (b) os valores da pressão modificada $\mathrm{P}^{*}$ definida pela Eq. (2.5) e (c) os fluxos turbulentos de momento $\left(\tau_{\mathrm{wu}}, \tau_{\mathrm{wv}}\right)$, calor sensível $\left(\tau_{\theta_{\mathrm{w}}}\right)$ e de poluente $\left(\tau_{\mathrm{cw}}\right)$, todos na escala de subgrade. Um outro arquivo contêm a evolução temporal dos principais parâmetros turbulentos da CLP $\left(\mathrm{u}_{*}, \mathrm{~L}, \mathrm{z}_{\mathrm{i}}, \mathrm{w}_{*}\right.$, etc) e a evolução temporal dos termos do balanço de ECT.

\subsection{1 - Momentos estatísticos}

As análises estatísticas espaciais e temporais apresentadas nesse trabalho foram obtidas com base nos campos tridimensionais gerados pelo modelo LES após os 3.000 $\Delta$ t iniciais, ou seja, quando os campos turbulentos já apresentavam a condição de quase-equilíbrio, discutida em detalhes na Seção 4.1. Todas análises foram desenvolvidas em software gráfico Matlab ou implementadas diretamente no código do modelo LES. 
Nas simulações HC1 e HC2, os campos tridimensionais são salvos a cada 500 $\Delta$ t e nos demais casos a cada $1.000 \Delta \mathrm{t}$. O passo no tempo é assumido constante $(\Delta \mathrm{t}=1 \mathrm{~s})$, de forma a obter séries temporais de $1 \mathrm{~Hz}$ das componentes de velocidade do vento $(\overline{\mathrm{u}}, \overline{\mathrm{v}}, \overline{\mathrm{w}})$. As estatísticas espaciais e temporais referem-se ao mesmo período de tempo.

\subsection{2 - Espectros turbulentos}

As estimativas espectrais foram realizadas de duas formas distintas, espacial e temporal. Os espectros espaciais foram estimados de acordo com o procedimento adotado por Moeng e Wyngaard (1988), através da aplicação da transformada rápida de Fourier (FFT) bidimensional em cada um dos planos horizontais dos campos tridimensionais das flutuações das componentes de velocidade, temperatura potencial e concentração de poluente. Em função da FFT, os planos horizontais foram assumidos iguais a $64^{2}$ pontos de grade (potência de 2), centrados nos diferentes planos horizontais originais de $80^{2}$ pontos (casos HC1 e HC2) e $96^{2}$ pontos (casos HC3, DA1 e DA2).

Para obter os espectros espaciais na direção $\mathrm{x}\left(\mathrm{k}_{\mathrm{x}}\right)$ somam-se as estimativas dos espectros bidimensionais ao longo do eixo $\mathrm{y}$, e na direção y $\left(\mathrm{k}_{\mathrm{y}}\right)$ somam-se as estimativas espectrais ao longo do eixo $\mathrm{x}$.

Os espectros temporais foram estimados apenas para as componentes de velocidade do vento e obtidos a partir da aplicação da FFT unidimensional em séries temporais de aproximadamente 115 minutos $(3.000 \leq \Delta \mathrm{t} \leq 10.000)$, geradas à razão de amostragem de 1Hz. O número total de pontos da série temporal $(\mathrm{N})$ deve ser potência de 2, neste caso um múltiplo de $2^{10}(1024$ pontos $)$.

Nos espectros temporais as baixas e altas freqüências foram tratadas separadamente, de acordo com procedimento apresentado por Kaimal e Finnigan (1994) (esquematizado na Fig. 3.1) e descrito de forma bastante detalhada por Lamesa (2001).

No tratamento das baixas freqüências faz-se a média de bloco de $N_{s}$ pontos $\left(N_{s}=N / 1024\right)$ sobre a série temporal de $\mathrm{N}$ pontos, o que fornece uma nova série de 1024 valores médios. 
Esse procedimento equivale a reduzir a freqüência de amostragem $f_{a}$ de $1 \mathrm{~Hz}$ para $\mathrm{f}_{\mathrm{r}}=\left(\mathrm{f}_{\mathrm{a}} / \mathrm{N}_{\mathrm{s}}\right) \mathrm{Hz}$, resultando em espectros temporais com freqüência mínima resolvida igual $\left(\mathrm{f}_{\mathrm{r}}\right)_{\min }=\left(\mathrm{f}_{\mathrm{r}} / 1024\right) \mathrm{Hz}\left(\approx 2 \times 10^{-4} \mathrm{~Hz}\right)$. Nas altas freqüências, o espectro turbulento é obtido a partir da média das FFT’s aplicadas sobre $\mathrm{N}_{\mathrm{s}}$ séries de 1024 pontos.

Como as variáveis meteorológicas são amostradas de forma discreta, são necessários no mínimo dois pontos por período para que se possa resolver uma onda. Desse modo, a freqüência máxima resolvida pela FFT é igual a $\left(\mathrm{f}_{\mathrm{r}}\right)_{\max }=\mathrm{f}_{\mathrm{a}} / 2 \quad(\approx 0,5 \mathrm{~Hz})$, onde $\left(\mathrm{f}_{\mathrm{r}}\right)_{\max }$ é também conhecida como freqüência de Nyquist.

\begin{tabular}{|c|c|c|c|c|c|c|}
\hline Co & prime & o tota & s sér & & 7000 & \\
\hline número de pontos & 1024 & 1024 & 1024 & 1024 & 1024 & 1024 \\
\hline segmentos & 1 & 2 & 3 & 4 & 5 & 6 \\
\hline Baixa frequiênc & & & & & & \\
\hline $1^{\circ}$ ) aplicaçẫo & média & e bloo & cada & ntos & rie ori & \\
\hline $2^{\circ}$ ) série result & & & & & & \\
\hline $3^{\circ}$ ) aplicaçẫo & FFT r & série & Itante & & & \\
\hline Alta frequiência & & & & & & \\
\hline 10) aplicaçẫo & FFT & cada & dos & me & a séri & iginal \\
\hline $\left.2^{\circ}\right)$ média das & $\mathrm{FT}^{\prime} \mathrm{s}$ & & & & & \\
\hline
\end{tabular}

Fig. 3.1 - Esquematização da metodologia utilizada nas estimativas dos espectros temporais.

Nas simulações realizadas com $80^{3}$ pontos de grade (casos HC1 e HC2), as séries temporais foram coletadas em 5 diferentes pontos localizados no centro da grade de cada plano horizontal e para 5 níveis verticais distintos, num total de 25 séries temporais.

Nos demais casos com $96^{3}$ pontos de grade (HC3, DA1 e DA2), as séries temporais foram coletadas de forma similar, só que para 9 diferentes pontos localizados no centro da grade de cada plano horizontal e em 9 diferentes níveis verticais, num total de 81 séries temporais distribuídas pelo volume. 
Um esboço dos experimentos idealizados acima pode ser visto na Fig. (3.2) para simulações com $80^{3}$ pontos de grade (HC1 e HC2). O plano horizontal (linha tracejada) representa a área onde foram calculados os espectros espaciais, em diversos níveis verticais. Os pontos de amostragem (círculos em preto) representam uma torre micrometeorológica hipotética, com 5 sensores de medida em cada um dos 5 diferentes níveis verticais de coleta.

A tendência linear foi removida dos sinais turbulentos das componentes de velocidade, da temperatura potencial e da concentração do poluente. Tanto no caso temporal como no espacial, as componentes horizontais de velocidade são corrigidas na direção do vento horizontal $\overline{\mathrm{U}}$.

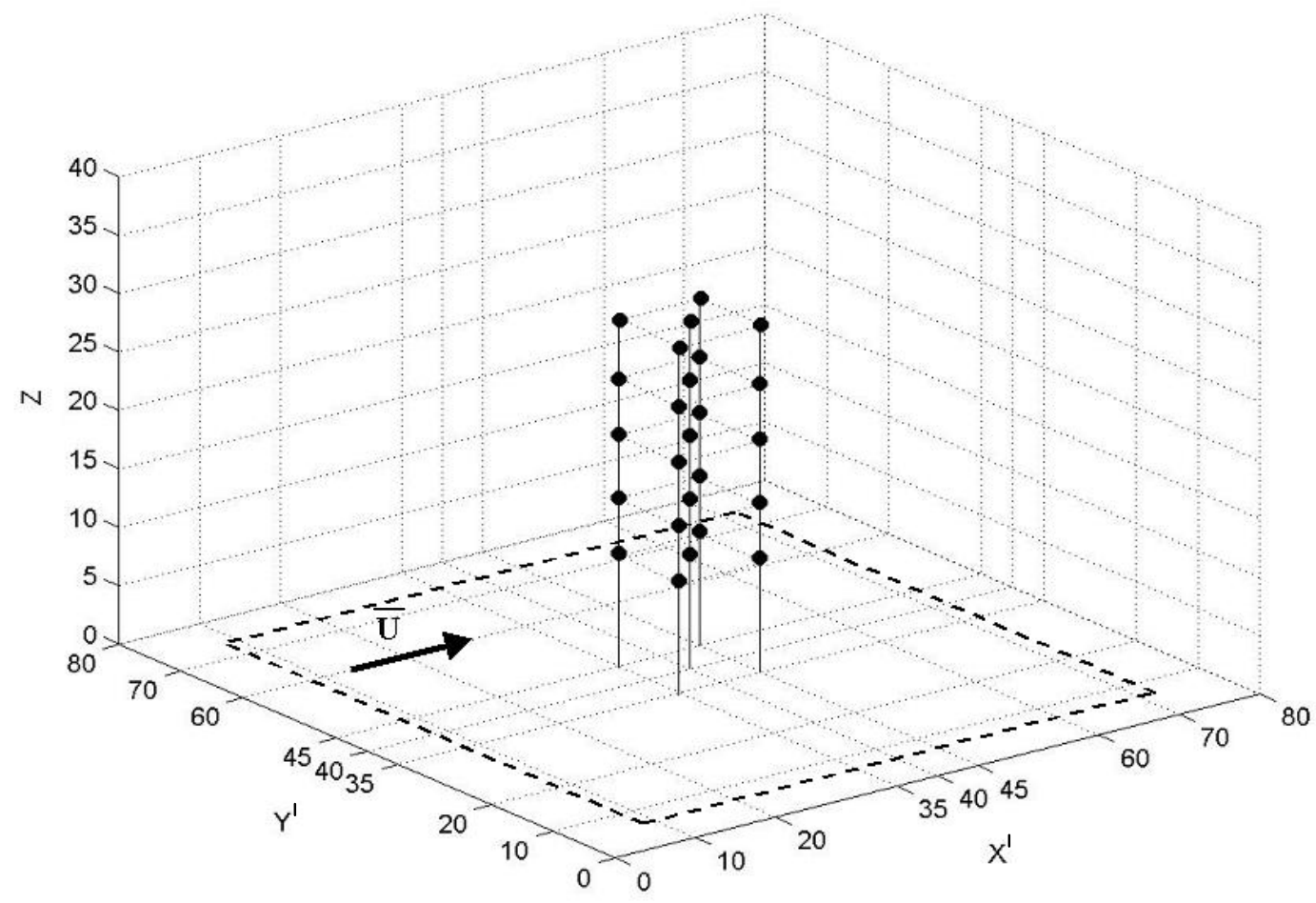

Fig. 3.2 - Grade tridimensional idealizada para obtenção dos espectros turbulentos nos casos HC1 e HC2 com $80^{3}$ pontos de grade. Os círculos (em preto) representam pontos de coleta das séries temporais e a linha tracejada representa a área do plano horizontal para obtenção das estimativas espectrais espaciais. Nos casos com $96^{3}$ pontos de grade (HC3, DA1 e DA2), foram incluídos mais 4 pontos de coleta igualmente espaçados no plano horizontal e em 9 diferentes níveis verticais. A seta indica a direção do vento horizontal $\overline{\mathrm{U}}$. 
Uma vez definido e descrito o conjunto de experimentos numéricos utilizados nesse trabalho, será realizado um estudo detalhado da estrutura da turbulência na CLP em condições altamente convectivas. Os resultados simulados serão confrontados com os prognósticos da teoria da similaridade da camada de mistura e com parametrizações apresentadas na literatura. 


\section{4 - PROPRIEDADES DA CLP ALTAMENTE CONVECTIVA}

Grande parte dos trabalhos apresentados na literatura sobre CLP convectiva simulada com o modelo LES não retrata a estrutura da turbulência sob condições altamente convectivas associadas à baixa velocidade do vento (Schmidt e Schumann, 1989; Moeng e Sullivan, 1994; Lin, 2000). Esse tipo de regime de estabilidade é encontrado com freqüência em regiões continentais e marítimas tropicais em razão das elevadas temperaturas da superfície e, em particular, nas áreas urbanas das grandes metrópoles tropicais e subtropicais, como a região metropolitana de São Paulo (RMSP).

Esse trabalho investiga a estrutura vertical da turbulência sob condições altamente convectivas $\left(60 \leq-\mathrm{z}_{\mathrm{i}} / \mathrm{L} \leq 800\right)$, com o auxílio do modelo LES, que é um dos modelos numéricos mais apropriados ao estudo da CLP convectiva.

TABELA 4.1 - Escalas características da CLP

\begin{tabular}{ccc}
\hline \hline Escalas & Símbolos & Formulação \\
\hline Altura da CLP & $\mathrm{z}_{\mathrm{i}}$ & - \\
Velocidade & $\mathrm{w}_{*}$ & {$\left[\frac{\mathrm{g}}{\theta_{0}} \mathrm{z}_{\mathrm{i}}\left(\left\langle\overline{\mathrm{w}^{\prime} \theta^{\prime}}\right\rangle+\left\langle\tau_{\theta \mathrm{w}}\right\rangle\right)_{0}\right]^{1 / 3}$} \\
Temperatura & $\mathrm{T}_{*}$ & $\left(\left\langle\overline{\mathrm{w}^{\prime} \theta^{\prime}}\right\rangle+\left\langle\tau_{\theta \mathrm{w}}\right\rangle\right)_{0} / \mathrm{w}_{*}$ \\
Concentração do poluente & $\mathrm{C}_{*}$ & $\left(\left\langle\overline{\mathrm{w}^{\prime} \mathrm{c}^{\prime}}\right\rangle+\left\langle\tau_{\mathrm{cw}}\right\rangle\right)_{0} / \mathrm{w}_{*}$ \\
Tempo & $\mathrm{t}_{*}$ & $\left(\left(\left\langle\mathrm{w}^{\prime} \mathrm{u}^{\prime}\right\rangle+\left\langle\tau_{\mathrm{wu}}\right\rangle\right)^{2}+\left(\left\langle\mathrm{w}^{\prime} \mathrm{v}^{\prime}\right\rangle+\left\langle\tau_{\mathrm{wv}}\right\rangle\right)^{2}\right)_{0}^{1 / 4}$ \\
Velocidade & $\mathrm{u}_{*}$ & $-\left(\left\langle\overline{\mathrm{w}^{\prime} \theta^{\prime}}\right\rangle+\left\langle\tau_{\theta \mathrm{w}}\right\rangle\right)_{0} / \mathrm{u}_{*}$ \\
Temperatura & $\theta_{*}$ & $\mathrm{u}_{*}^{2} /\left(\mathrm{g} / \theta_{0}\right) \theta_{*}$ \\
\hline
\end{tabular}

Em primeiro lugar, discutem-se os critérios de verificação da condição de quase-equilíbrio dos campos turbulentos tridimensionais gerados pelo modelo LES. Em virtude da escassez de dados experimentais de turbulência na CLP medidos diretamente nas regiões tropicais, as variáveis meteorológicas simuladas são comparadas com os prognósticos fornecidos pela teoria de similaridade da camada de mistura e com alguns resultados experimentais 
apresentados na literatura. As escalas características utilizadas na adimensionalização dessas variáveis são definidas na Tabela 4.1.

\section{1 - Condição de quase-equilíbrio}

O escoamento turbulento na CLP atinge uma condição de quase-equilíbrio quando suas propriedades variam com uma escala de tempo menor que as escalas de tempo de variação das suas condições de fronteira e das forçantes externas (Sorbjan, 1986). Sob tais circunstâncias, as propriedades estatísticas da CLP podem ser determinadas em função das escalas características definidas de acordo com a natureza da CLP.

De acordo com Nieuwstadt et al. (1992), uma das maneiras de identificar se os campos turbulentos da CLP convectiva alcançaram a condição de quase-equilíbrio é por meio da evolução temporal da ECT total (resolvida + subgrade) adimensional integrada na CLP $\langle\langle\mathrm{E}\rangle\rangle / \mathrm{w}_{*}^{2}$.

Na Fig. (4.1) é apresentada a evolução temporal de $\langle\langle E\rangle\rangle / \mathrm{w}_{*}^{2}$ para os diferentes casos simulados. No período inicial de integração $\left(t<5 t_{*}\right)$ ocorrem grandes oscilações de $\langle\langle E\rangle\rangle / \mathrm{w}_{*}^{2}$ provavelmente ocasionadas em razão do desenvolvimento de turbilhões convectivos em forma de rolos organizados (Lemone, 1976). Quando alcançam a condição de quase-equilíbrio, esses rolos distribuem-se e tornam-se movimentos aleatórios (Nieuwstadt et al., 1992).

Após o período inicial de integração a ECT total mantém-se aproximadamente constante em $\langle\langle\mathrm{E}\rangle\rangle \approx 0,21 \mathrm{w}_{*}^{2}$, com exceção dos casos HC1 e HC2 que apresentam um crescimento linear com o tempo para $\mathrm{t} \geq 5 \mathrm{t}_{*}$. Como a taxa de aquecimento da CLP é constante, é possível que o aumento de $\langle\langle E\rangle\rangle / \mathrm{w}_{*}^{2}$ nesses casos esteja associado à maior taxa de crescimento da altura da $\operatorname{CLP}\left\{\partial \mathrm{z}_{\mathrm{i}} / \partial \mathrm{t}\right\} \approx 0,06 \mathrm{~ms}^{-1}$, devido à fraca variação vertical da temperatura potencial na camada de entranhamento $(\Delta \bar{\theta})_{\mathrm{i}}$, considerada igual ao gradiente vertical de temperatura potencial na atmosfera livre $\left(\Gamma_{\theta}=3.0 \times 10^{-3} \mathrm{~K} \mathrm{~m}^{-1}\right)$. Nos demais casos (HC3, DA1 e DA2), a 
variação de $(\Delta \bar{\theta})_{\mathrm{i}}$ é maior e funciona como uma barreira à elevação de $\mathrm{z}_{\mathrm{i}}$, $\left\{\partial \mathrm{z}_{\mathrm{i}} / \partial \mathrm{t}\right\} \approx 0,01 \mathrm{~ms}^{-1}$.

Segundo Fedorovich et al. (2004), na ausência de ondas de gravidade, a condição de quaseequilíbrio da CLP convectiva é definida pelo balanço entre os termos de empuxo, dissipação e entranhamento no topo da camada. Como a intensidade da inversão térmica $(\Delta \bar{\theta})_{\text {i }}$ é menor nos casos HC1 e HC2, a interação da CLP com a atmosfera livre induz a formação de ondas de gravidade. No modelo LES, o uso de condições de fronteira laterais periódicas faz com que a energia transportada pelas ondas de gravidade se acumule no domínio da CLP, ocasionando o aumento de $\langle\langle E\rangle\rangle / \mathrm{w}_{*}^{2}$. Apesar desse aumento linear de energia a partir de $t \geq 5 t_{*}$, os casos HC1 e HC2 também são representativas de um escoamento turbulento em condição de quaseequilíbrio, como será visto posteriormente nas análises dos perfis verticais do fluxo de calor sensível (Fig. 4.3a) e do balanço de ECT (Fig. 4.10).

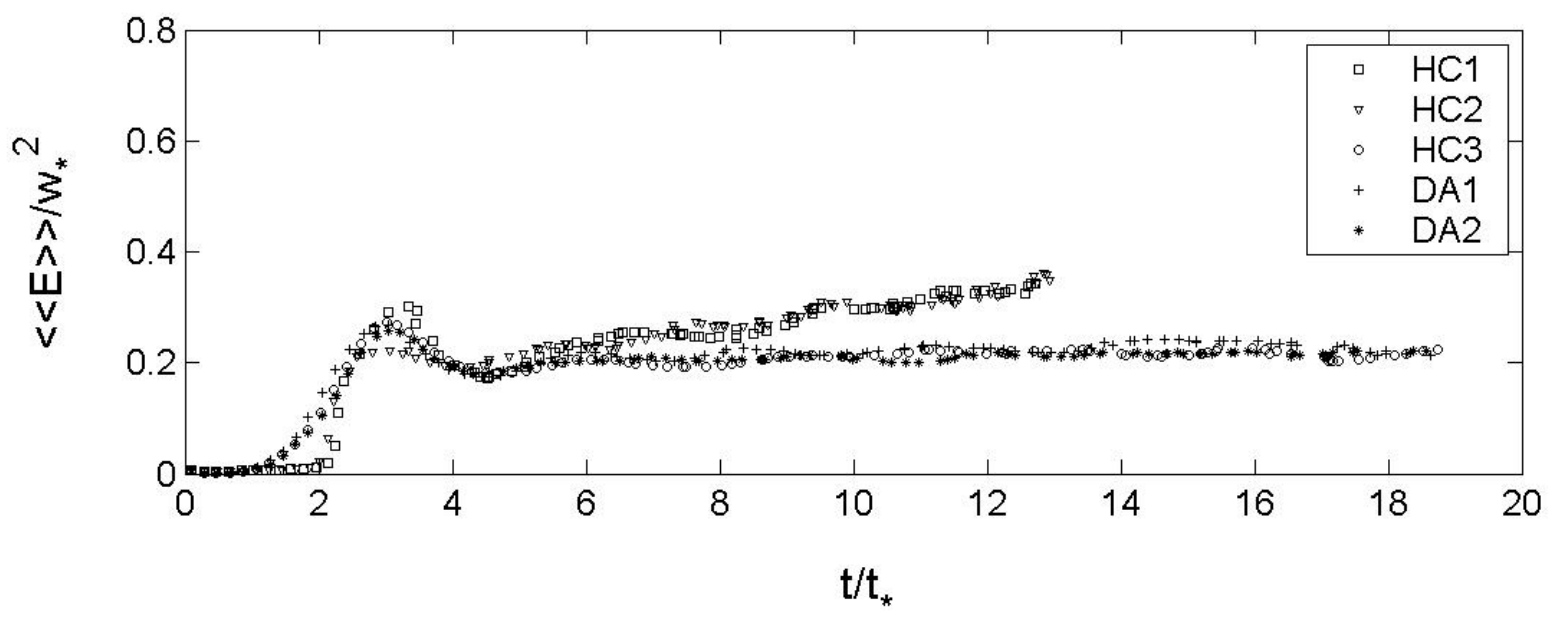

Fig. 4.1 - Evolução temporal da ECT total adimensional integrada na CLP.

Portanto, o período de tempo $\mathrm{t} / \mathrm{t}_{*}<5$ (aproximadamente 3000s) pode ser interpretado como o tempo no qual os campos turbulentos simulados alcançam a condição de quase-equilíbrio e, portanto, espera-se que todos os parâmetros turbulentos obtidos a partir desse período sejam representativos de CLP's em regime de convecção livre. 


\section{2 - Estrutura da turbulência}

As condições iniciais utilizadas nas simulações numéricas dos diferentes casos permitiram a geração de CLPs convectivas com distintos graus de instabilidade $\left(62 \leq-\mathrm{Z}_{\mathrm{i}} / \mathrm{L} \leq 800\right)$. Os valores médios das principais escalas características, bem como o de alguns parâmetros turbulentos da CLP convectiva, são apresentados na Tabela 4.2. Essas escalas serão utilizadas na adimensionalização dos perfis verticais das variáveis meteorológicas médias no plano horizontal e servem como base para caracterização da estrutura vertical das CLPs simuladas. No capítulo 5, são apresentadas as simulações utilizadas nas estimativas de dispersão de poluentes, cujas condições de instabilidade estendem-se até $-\mathrm{z}_{\mathrm{i}} / \mathrm{L} \leq 800$.

Tabela 4.2 - Valores médios das escalas características e dos parâmetros turbulentos do conjunto de cinco simulações descritos na seção 3.1.

\begin{tabular}{|c|c|c|c|c|c|c|c|c|c|c|c|}
\hline Casos & $\begin{array}{c}\mathrm{u}_{*} \\
\left(\mathrm{~ms}^{-1}\right)\end{array}$ & $\begin{array}{c}\mathrm{L} \\
(\mathrm{m})\end{array}$ & $\begin{array}{l}\mathrm{Z}_{\mathrm{i}} \\
(\mathrm{m})\end{array}$ & $-\mathrm{z}_{\mathrm{i}} / \mathrm{L}$ & $\begin{array}{c}\mathrm{W}_{*} \\
\left(\mathrm{~ms}^{-1}\right)\end{array}$ & $\begin{array}{l}\mathrm{t}_{*} \\
(\mathrm{~s})\end{array}$ & $\begin{array}{l}\mathrm{T}_{*} \\
(\mathrm{~K})\end{array}$ & $\begin{array}{c}\mathrm{C}_{*} \\
(\mathrm{ppm})\end{array}$ & $\begin{array}{c}\langle\overline{\mathrm{U}}\rangle_{\mathrm{CM}} \\
\left(\mathrm{ms}^{-1}\right)\end{array}$ & $\begin{array}{c}\left(\langle\bar{\theta}\rangle-\langle\bar{\theta}\rangle_{\mathrm{eq}}\right)_{\mathrm{CM}} \\
(\mathrm{K})\end{array}$ & $\frac{\left(\left\langle w^{\prime} \theta^{\prime}\right\rangle+\left\langle\tau_{a_{v}}\right\rangle\right)_{\mid}}{w_{\text {. }}}$ \\
\hline HC1 & 0,36 & -17 & 1360 & 80 & 2,1 & 648 & 0,10 & - & 4,5 & 1,1 & 0,10 \\
\hline HC2 & 0,23 & -4 & 1400 & 345 & 2,2 & 636 & 0,11 & - & 1,9 & 1,2 & 0,09 \\
\hline HC3 & 0,23 & -4 & 1040 & 270 & 2,0 & 520 & 0,12 & - & 1,7 & 1,9 & 0,20 \\
\hline DA1 & 0,38 & -17 & 1060 & 62 & 2,0 & 530 & 0,12 & 0,09 & 4,2 & 2,0 & 0,16 \\
\hline DA2 & 0,20 & -2 & 1065 & 434 & 2,0 & 533 & 0,12 & 0,09 & 0,8 & 2,0 & 0,20 \\
\hline
\end{tabular}

A escala temporal $t_{*}$ (turnover time) representa o tempo no qual um constituinte atmosférico é transportado da superfície em direção ao topo da CLP e serve como indicativo da intensidade da mistura vertical na CLP convectiva. Nos diferentes casos simulados os valores de $\mathrm{t}_{*}$ variaram de $520 \mathrm{~s} \leq \mathrm{t}_{*} \leq 648 \mathrm{~s}(\approx 10 \mathrm{~min})$, o que está de acordo com o valor sugerido Sorbjan (1986).

Nas análises dos perfis verticais de temperatura potencial (Fig. 4.2a) é possível observar a formação de uma extensa camada bem misturada $(\partial\langle\bar{\theta}\rangle / \partial \mathrm{z} \approx 0)$, características de condições convectivas e consistente com os valores obtidos de $t_{*}$. As variações de $\langle\bar{\theta}\rangle$, junto ao topo da CLP, estão diretamente relacionadas à variação vertical da temperatura potencial na camada 
de entranhamento $\langle\Delta \bar{\theta}\rangle_{\mathrm{i}}$ e ao gradiente vertical positivo $\Gamma_{\theta}$ da atmosfera livre acima. O aumento médio da temperatura potencial na camada de mistura após os campos turbulentos alcançarem a condição de quase-equilíbrio $\left\{\left(\langle\bar{\theta}\rangle-\langle\bar{\theta}\rangle_{\text {eq }}\right)_{\text {См }}\right\}$ foi da ordem de $(1,6 \pm 0,2) \mathrm{K}$ e está consistente com a taxa de aquecimento de $\left\{\partial\langle\bar{\theta}\rangle / \partial \mathrm{t}=-\left[\left\langle\mathrm{w}^{\prime} \theta^{\prime}\right\rangle_{\mathrm{i}}+\left\langle\tau_{\theta \mathrm{w}}\right\rangle_{\mathrm{i}}-\left\langle\mathrm{w}^{\prime} \theta^{\prime}\right\rangle_{0}-\left\langle\tau_{\theta \mathrm{w}}\right\rangle_{0}\right] / \mathrm{z}_{\mathrm{i}}\right\} \approx 2 \times 10^{-4} \mathrm{Ks}^{-1}$.

(a)

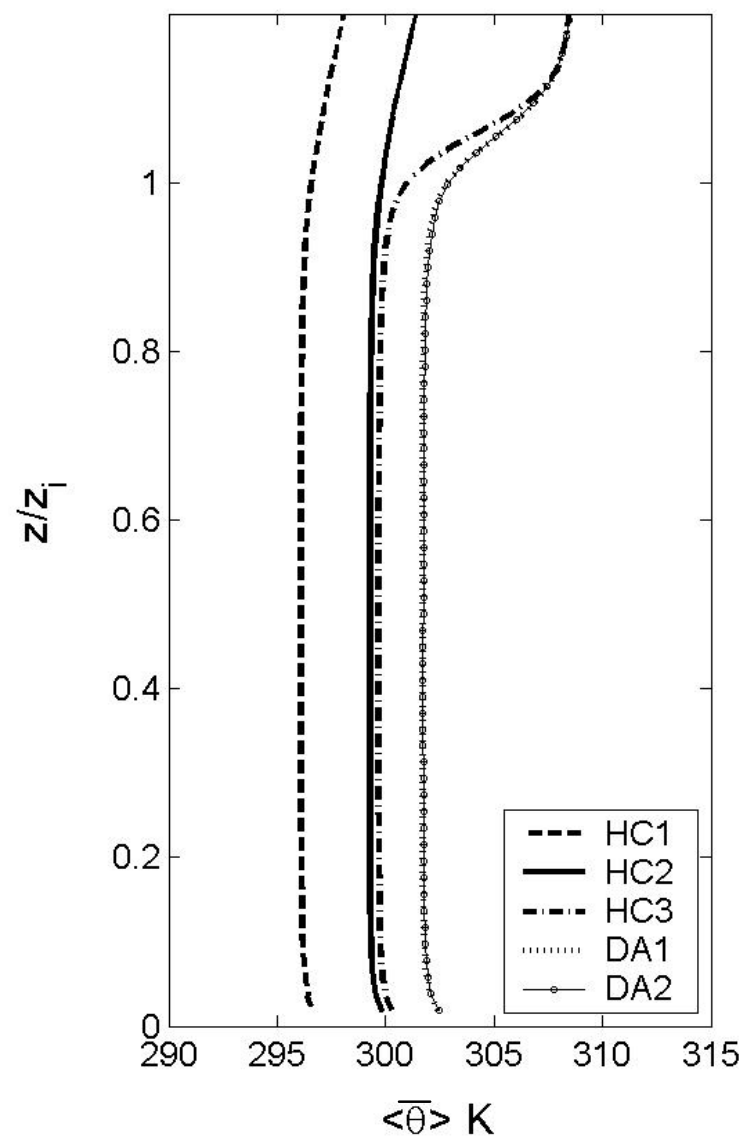

(b)

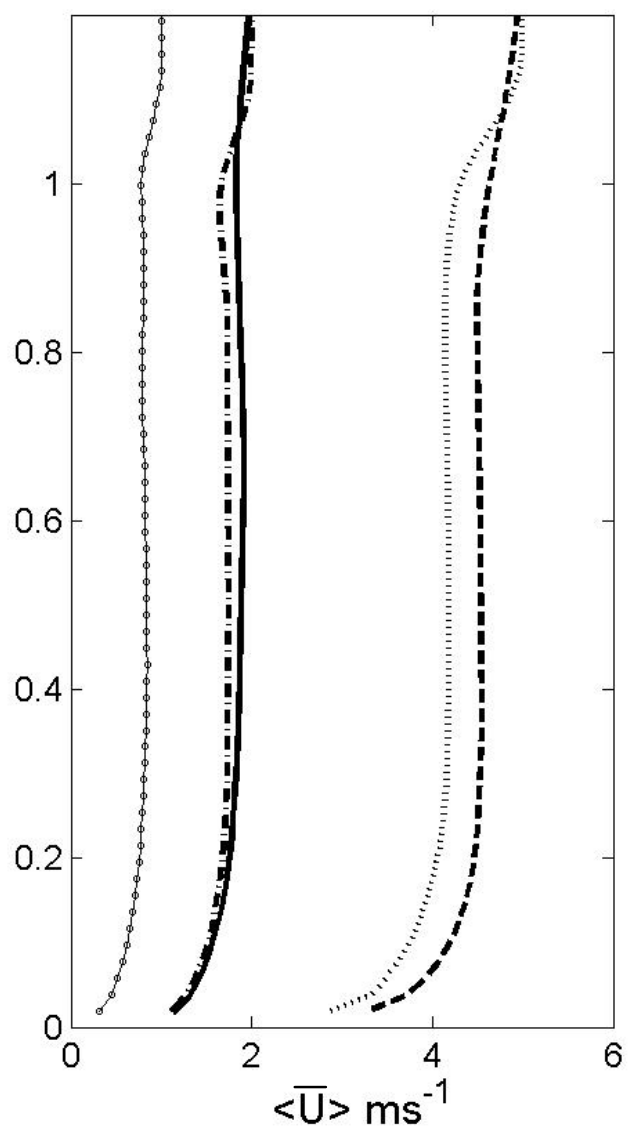

Fig. 4.2 - Perfis verticais das variáveis médias em função da altura adimensional: (a) temperatura potencial; (b) velocidade horizontal do vento.

Na Fig. (4.2a) observa-se que na região próxima à superfície $\left(\mathrm{z} \leq 0,1 \mathrm{z}_{\mathrm{i}}\right)$ a velocidade horizontal do vento $\langle\bar{U}\rangle$ apresenta um perfil logarítmico (Sulivan et al., 1994). Acima desta 
camada $\left(\mathrm{z}>0,1 \mathrm{z}_{\mathrm{i}}\right)$, o gradiente vertical de $\langle\overline{\mathrm{U}}\rangle$ é aproximadamente nulo, indicando que a forte atividade turbulenta tende a homogeneizar as componentes horizontais de momento em uma CLP convectiva e barotrópica. No topo da CLP, $\langle\bar{U}\rangle$ tende ao valor do vento geostrófico.

Os fluxos turbulentos verticais de calor sensível $\left\langle\mathrm{w}^{\prime} \theta^{\prime}\right\rangle+\left\langle\tau_{\theta \mathrm{w}}\right\rangle$ (resolvida + subgrade), adimensionalizados por $\mathrm{w}_{*} \mathrm{~T}_{*}$ (Fig. 4.3a), mostram um decréscimo linear com a altura por quase toda extensão vertical da CLP. Este perfil linear induz a uma razão de aquecimento constante na camada de mistura, característico de um regime turbulento em condição de quase-equilíbrio (Nieuwstadt et al., 1992).

Próximo ao topo, o fluxo de calor devido ao entranhamento $\left\{\left\langle w^{\prime} \theta^{\prime}\right\rangle_{i}+\left\langle\tau_{\theta_{\mathrm{w}}}\right\rangle_{\mathrm{i}}\right\}$ é da ordem de $-(0,15 \pm 0,02) \mathrm{w}_{*} \mathrm{~T}_{*}$, similar ao valores de $-0,17 \mathrm{w}_{*} \mathrm{~T}_{*}$ encontrado por Moeng (1984) e $-(0,17 \pm 0,02) \mathrm{w}_{*} \mathrm{~T}_{*}$ por Schmidt e Schumann (1989).

A extensão vertical da região de fluxo de calor negativo é consideravelmente maior nos casos HC1 e HC2, se comparado aos demais casos. Esse comportamento já era esperado, pois, nos demais casos, a inversão térmica mais intensa $\langle\Delta \bar{\theta}\rangle_{\mathrm{i}}$ inibe a penetração do fluido da camada de mistura na atmosfera livre acima (estável), confinando a camada de entranhamento em uma região de menor profundidade (Willis e Deardorff, 1974). Acima da camada de entranhamento $\left(\left\langle\mathrm{w}^{\prime} \theta^{\prime}\right\rangle+\left\langle\tau_{\theta \mathrm{w}}\right\rangle\right) / \mathrm{w}_{*} \mathrm{~T}_{*}$ tende a zero.

O fluxo de calor sensível na escala de subgrade $\left\langle\tau_{\theta_{\mathrm{w}}}\right\rangle$ (não mostrado) tem uma contribuição significativa apenas próximo à superfície. Contudo, decresce rapidamente com a altura, tornando-se aproximadamente nulo em $\mathrm{z}>0,2 \mathrm{z}_{\mathrm{i}}$.

O fluxo vertical de momento horizontal (Fig. 4.3b) apresenta um padrão bastante distinto do fluxo vertical de calor sensível (Fig. 4.3a) em todos os casos analisados. A grande dispersão desses perfis é um indicativo de que o fluxo vertical de momento não obedece à similaridade da camada de mistura. Tentativas de normalizar os fluxos verticais turbulentos de momento com a velocidade de atrito $\mathrm{u}_{*}$ não reduziram a dispersão dos perfis. 
(a)

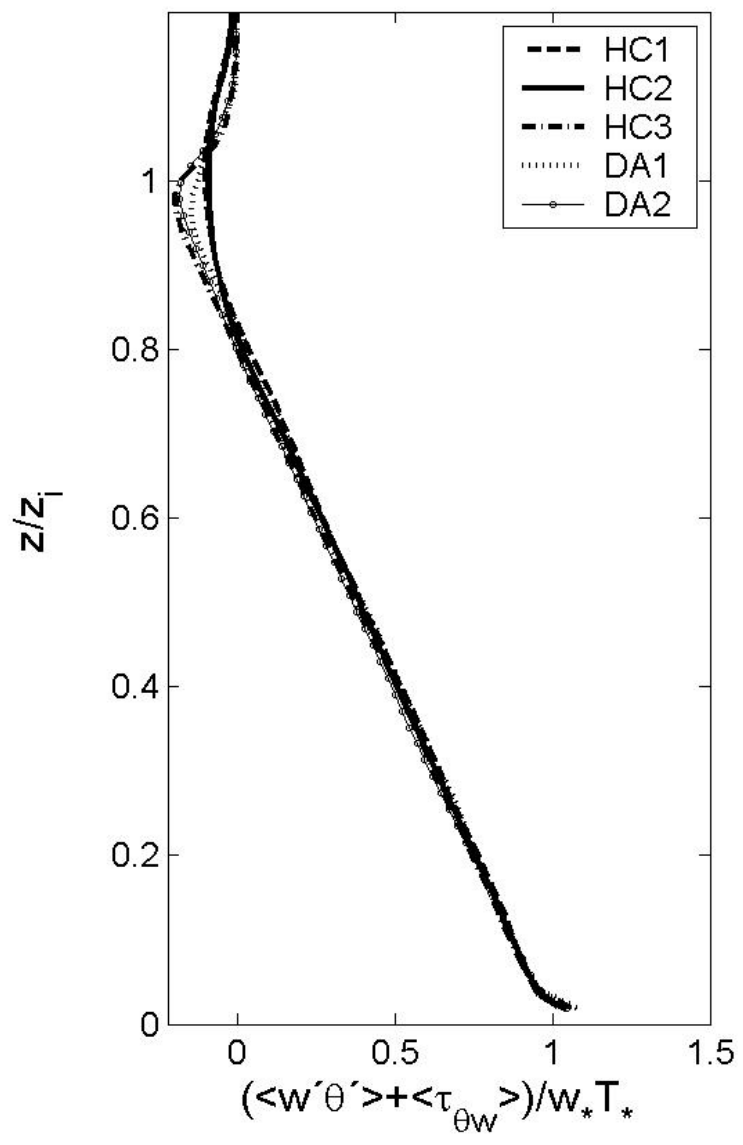

(b)

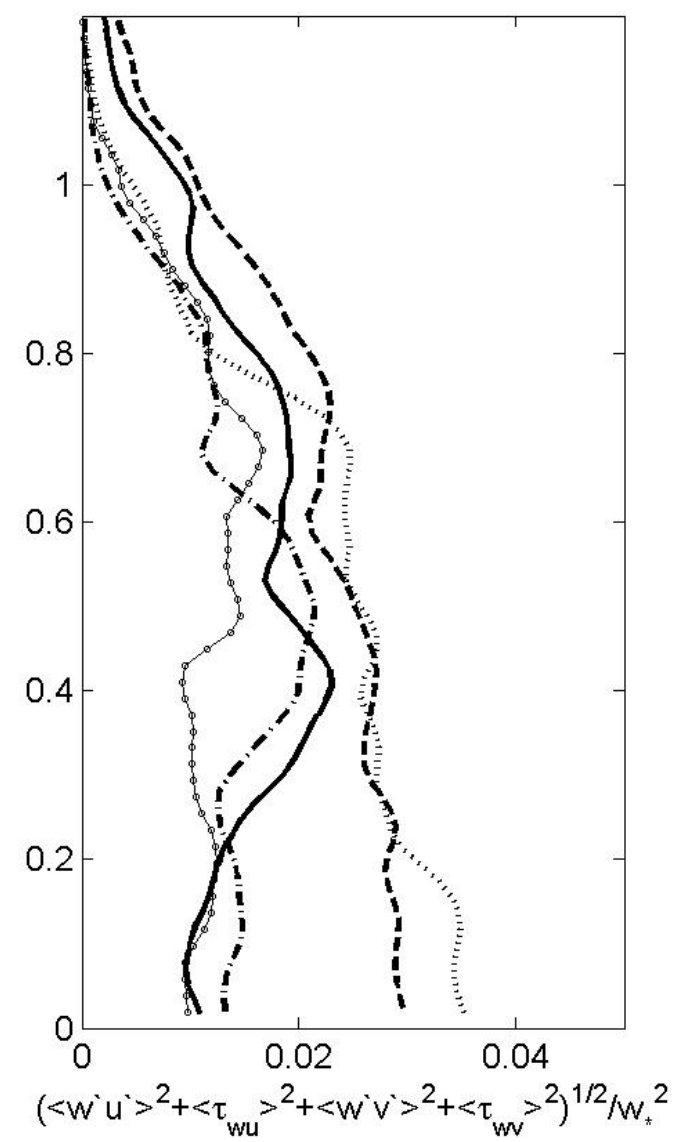

Fig. 4.3 - Perfis verticais dos fluxos turbulentos totais (escala resolvida + subgrade) adimensionais: (a) calor sensível; (b) momento horizontal.

As variâncias adimensionais das componentes de velocidade (resolvida + subgrade) são apresentadas na Figs. (4.4). As contribuições da escala de subgrade não foram obtidas diretamente, mas estimadas assumindo a isotropia das contribuições de subgrade para as flutuações das componentes de velocidade, ou seja, $\left\langle\tau_{\mathrm{uu}}\right\rangle=\left\langle\tau_{\mathrm{vv}}\right\rangle=\left\langle\tau_{\mathrm{ww}}\right\rangle=\frac{2}{3}\langle\mathrm{e}\rangle$ (Nieuwstadt et al., 1992).

As variâncias adimensionais das componentes horizontais de velocidade (Fig. 4.4a) são aproximadamente constantes e inferiores a variância da componente vertical $\left(\left\langle\mathrm{w}^{\prime 2}\right\rangle+\left\langle\tau_{\mathrm{ww}}\right\rangle\right)$ (Fig. 4.4b) em grande parte da camada de mistura. Isto ocorre porque, na maior parte desta camada, a produção térmica de ECT contribui significativamente para $\left(\left\langle\mathrm{w}^{\prime 2}\right\rangle+\left\langle\tau_{\mathrm{ww}}\right\rangle\right)$. Próximo à superfície $\left(\mathrm{z} \leq 0,1 \mathrm{z}_{\mathrm{i}}\right)$ e junto ao topo da CLP $\left(\mathrm{z}>0,8 \mathrm{z}_{\mathrm{i}}\right)$ os efeitos das flutuações 
de pressão são relevantes e a variância das componentes horizontais é maior que $\left(\left\langle\mathrm{w}^{\prime 2}\right\rangle+\left\langle\tau_{\mathrm{ww}}\right\rangle\right)$ (Schmidt e Schumann, 1989).

a)

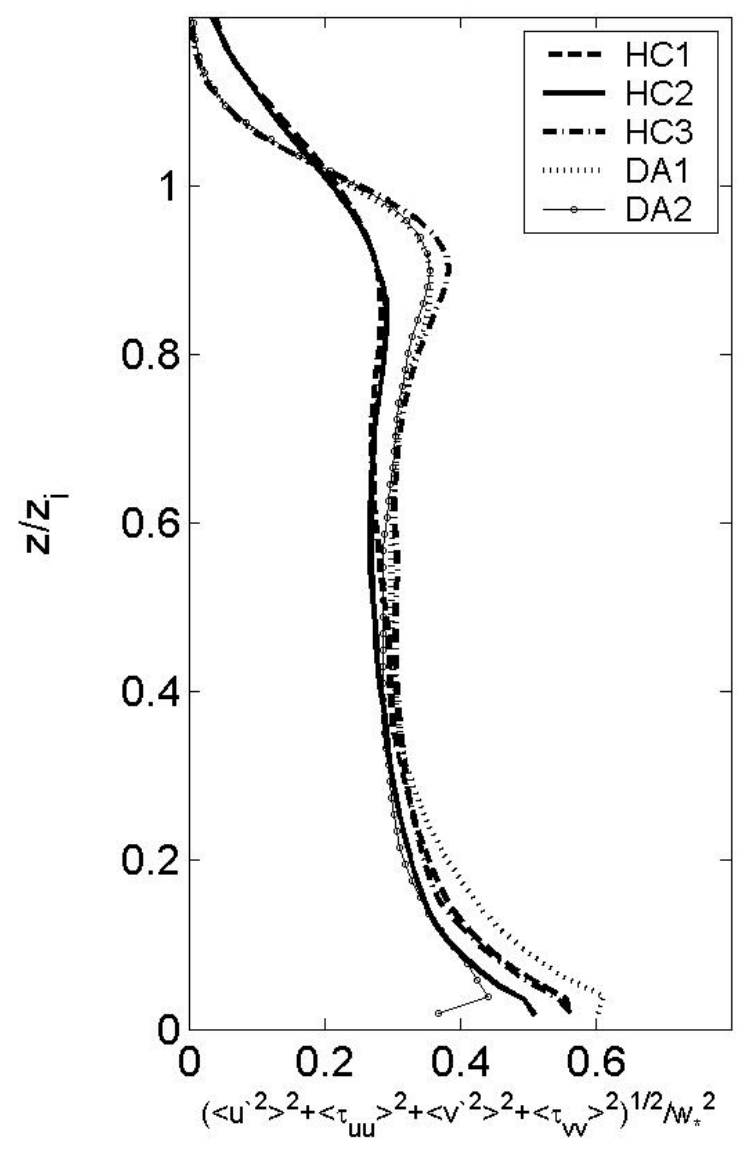

b)

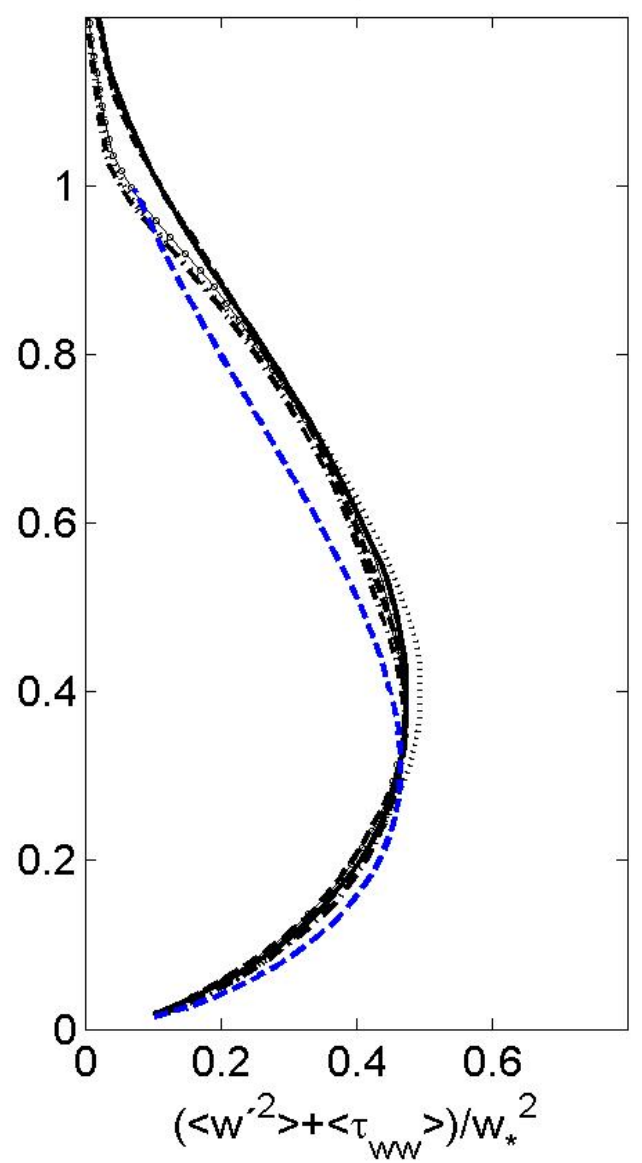

Fig. 4.4 - Perfis verticais das variâncias adimensionais das componentes de velocidade: (a) componentes horizontais; (b) componente vertical. Em (b) a linha tracejada em azul representa a curva experimental proposta por Lenschow et al. (1980).

A distribuição vertical da variância da velocidade vertical indica que $\left\{\left\langle\mathrm{w}^{\prime 2}\right\rangle+\left\langle\tau_{\mathrm{ww}}\right\rangle\right\}$ alcança um máximo de $(0,48 \pm 0,01) \mathrm{w}_{*}^{2}$ em torno de $\mathrm{z} \approx 0,38 \mathrm{z}_{\mathrm{i}}$, o que está aproximadamente de acordo com $0,44 \mathrm{w}_{*}^{2}$ em $\mathrm{z} \approx 0,33 \mathrm{z}_{\mathrm{i}}$ sugerido por Deardorff (1974b), que não estimou a contribuição de subgrade $\left\langle\tau_{\mathrm{ww}}\right\rangle$. Na metade superior da CLP, $\left\{\left\langle\mathrm{w}^{\prime 2}\right\rangle+\left\langle\tau_{\mathrm{ww}}\right\rangle\right\}$ decresce com a altura, alcançando um mínimo de $(0,08 \pm 0,01) \mathrm{w}_{*}^{2}$ junto ao topo. Acima deste nível, os valores das variâncias das componentes de velocidade, apesar de pequenos, não decaem para 
zero, em virtude da produção local pelo cisalhamento do vento e da possível geração de ondas de gravidade (Wyngaard e Moeng, 1984).

De acordo com Bernard-Trottolo et al. (2004), parte da variabilidade encontrada nos perfis verticais dos momentos estatísticos de segunda ordem pode ser reduzida se os processos bottom-up (convecção) e top-down (entranhamento) forem considerados, uma vez que a escala dos movimentos bottom-up é $\mathrm{z} / \mathrm{z}_{\mathrm{i}}$, enquanto que para os movimentos top-down é $\left(1-\mathrm{z} / \mathrm{z}_{\mathrm{i}}\right)$

Comparando-se os perfis verticais de $\left\{\left\langle\mathrm{w}^{\prime 2}\right\rangle+\left\langle\tau_{\mathrm{ww}}\right\rangle\right\} / \mathrm{w}_{*}^{2}$ (Fig. 4.4b) com a curva experimental proposta por Lenschow et al. (1980) $\left(\overline{\left[\mathrm{w}^{\prime 2}\right]} / \mathrm{w}_{*}^{2}=1,8\left(\mathrm{z} / \mathrm{z}_{\mathrm{i}}\right)^{2 / 3}\left(1-0,8 \mathrm{z} / \mathrm{z}_{\mathrm{i}}\right)^{2}\right)$ observa-se que eles apresentam formas similares. Porém, o máximo simulado encontra-se acima do proposto por Lenschow. Apesar dessas pequenas diferenças, os resultados gerados pelo LES são similares aos modelados por Schmidt e Schumann (1989), que se ajustaram melhor aos dados experimentais tanto de Lenschow et al. (1980), quanto de Deardorff e Willis (1985).

Na Fig. (4.5) são apresentados os perfis verticais da variância adimensional da temperatura potencial $\left(\left\langle\theta^{\prime 2}\right\rangle+\left\langle\tau_{\theta \theta}\right\rangle\right) / \mathrm{T}_{*}^{2}$ (resolvida + subgrade). As contribuições da escala de subgrade $\left\langle\tau_{\theta \theta}\right\rangle$ são estimadas através da formulação proposta por Nieuwstadt et al. (1992) $\left(\left\langle\tau_{\theta \theta}\right\rangle=(0,67)^{-4}\left\langle\tau_{\theta \mathrm{w}}\right\rangle^{2} /\langle\mathrm{e}\rangle\right)$ e são significativas apenas próximo a superfície, mantendo-se aproximadamente nula no restante da camada.

Os perfis de $\left(\left\langle\theta^{\prime 2}\right\rangle+\left\langle\tau_{\theta \theta}\right\rangle\right) / \mathrm{T}_{*}^{2}$ apresentam dois máximos distintos. O primeiro localiza-se próximo à superfície e está associado ao intenso gradiente de temperatura potencial (mostrado na Fig. 4.2a). Acima da CLS os perfis decrescem rapidamente com a altura, alcançando o mínimo em $\mathrm{z} \approx 0,7 \mathrm{z}_{\mathrm{i}}$ e, posteriormente, voltam a crescer definindo um máximo secundário na camada de entranhamento. Esse segundo máximo é menos pronunciado nos casos HC1 e HC2 em virtude de baixa intensidade da inversão térmica $\langle\Delta \bar{\theta}\rangle_{\mathrm{i}}$. Esse é o termo de produção na equação da variância de temperatura $\left(-\overline{\mathrm{w}^{\prime} \theta^{\prime}} \frac{\partial \bar{\theta}}{\partial \mathrm{z}}\right)$ que determina a magnitude de $\left\langle\theta^{\prime 2}\right\rangle / \mathrm{T}_{*}^{2}$ 
(Nieuwstadt et al., 1992). Além disso, próximo ao topo, as escalas características para condições convectivas não são apropriadas para representar as flutuações de temperatura (Deardorff, 1974b).

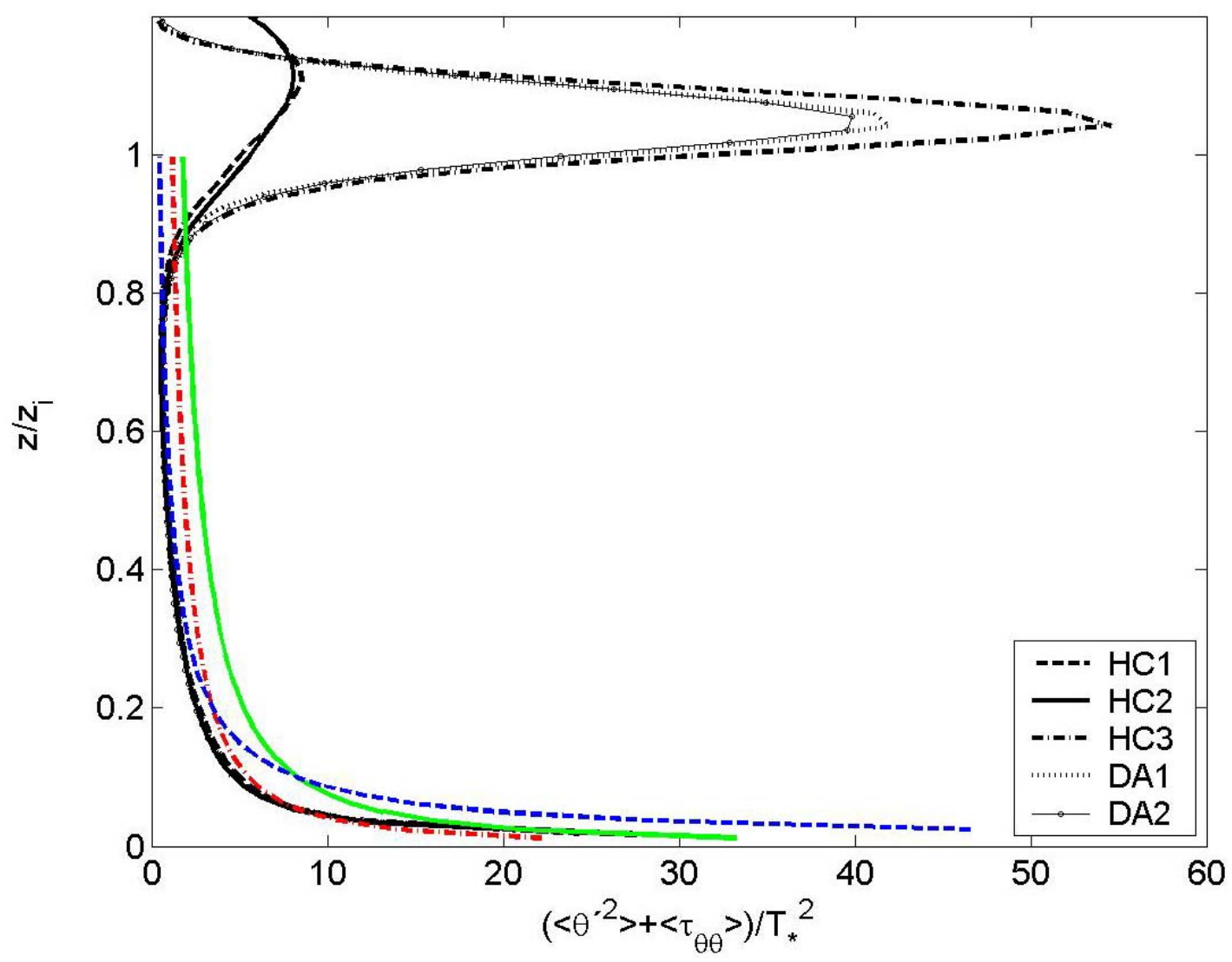

Fig. 4.5 - Perfis verticais das variâncias adimensionais de temperatura potencial. As linhas coloridas representam as curvas experimentais propostas por: (contínua em verde) Kaimal et al. (1976); (tracejada em azul) Moeng e Wyngaard (1984) e (tracejada em vermelho) Bernard-Trottolo et al. (2004).

Deve ser salientado que os valores de $T_{*}$ na atmosfera são pequenos (em torno de $0,1 \mathrm{~K}$ ) (de acordo com Tabela 4.2) e, portanto, erros instrumentais tornam-se significativos apresentando uma grande variabilidade (Schmidt e Schumann, 1989), o que dificulta a formulação de parametrizações.

Os perfis de $\left(\left\langle\theta^{\prime 2}\right\rangle+\left\langle\tau_{\theta \theta}\right\rangle\right) / \mathrm{T}_{*}^{2}$ simulados também são comparados às curvas experimentais propostas por Kaimal et al. (1976), $\overline{\left[\theta^{\prime 2}\right]} / \mathrm{T}_{*}^{2}=1,8\left(\mathrm{z} / \mathrm{z}_{\mathrm{i}}\right)^{-2 / 3}$, e por Bernard-Trottolo et al. 
(2004), $\overline{\left[\theta^{\prime 2}\right]} / \mathrm{T}_{*}^{2}=1,2\left(\mathrm{z} / \mathrm{z}_{\mathrm{i}}\right)^{-2 / 3}$. Essas duas curvas experimentais definem a forma prevista pela similaridade de convecção livre na CLP e diferem da curva proposta por Moeng e Wyngaard (1984), $\overline{\left[\theta^{\prime 2}\right]} / \mathrm{T}_{*}^{2}=0,47\left(\mathrm{z} / \mathrm{z}_{\mathrm{i}}\right)^{-5 / 4}$, que representa os processos bottom-up.

As estimativas de $\left(\left\langle\theta^{\prime 2}\right\rangle+\left\langle\tau_{\theta \theta}\right\rangle\right) / \mathrm{T}_{*}^{2}$ concordam com as curvas experimentais propostas, sendo que a curva de Bernard-Trottolo et al. (2004) mostrou-se a mais adequada. A curva sugerida por Moeng e Wyngaard (1984) superestima os valores de $\left(\left\langle\theta^{\prime 2}\right\rangle+\left\langle\tau_{\theta \theta}\right\rangle\right) / \mathrm{T}_{*}^{2}$ na região $\mathrm{z}<0,4 \mathrm{z}_{\mathrm{i}}$, mas apresenta um excelente acordo na região entre $0,4 \mathrm{z}_{\mathrm{i}} \leq \mathrm{z} \leq 0,8 \mathrm{z}_{\mathrm{i}}$. Segundo Moeng e Wyngaard (1984), o valor do expoente -2/3 é mais apropriado para descrever os processos que ocorrem abaixo de $\mathrm{z}<0,1 \mathrm{z}_{\mathrm{i}}$, o que é discutido por BernardTrottolo et al. (2004).

Os escoamentos turbulentos na CLP convectiva são caracterizados por movimentos verticais descendentes (downdrafts) e por estruturas assimétricas compostas de pequenas regiões com intenso movimento vertical ascendente (updrafts). Os updrafts são os principais responsáveis pelo transporte de constituintes atmosféricos da região adjacente à superfície para as camadas superiores da CLP. De acordo com Kaimal et al. (1976) e Lenschow e Stephens (1980), essas estruturas espaciais podem ser identificadas por meio da correlação entre as flutuações da componente vertical de velocidade $\left(\mathrm{w}^{\prime}\right)$ e da temperatura potencial $\left(\theta^{\prime}\right)$.

Nas Figs. (4.6) são apresentados os campos instantâneos verticais no plano xz das flutuações w' e $\theta^{\prime}$ e dos fluxos locais $w^{\prime} \theta^{\prime}$ e w'u' $^{\prime}$. Todas as análises de campos instantâneos são feitas com base nas estimativas obtidas para o caso DA2 $\left(-\mathrm{z}_{\mathrm{i}} / \mathrm{L}=434\right)$ no instante final da simulação $\left(\mathrm{t} \approx 18 \mathrm{t}_{*}\right)$. Os campos instantâneos de $\mathrm{w}^{\prime}$ e $\theta^{\prime}$ (Figs. 4.6a e 4.6b) permitem identificar um updraft bem definido (área escura com $\mathrm{w}^{\prime}>0$ entre $2500 \mathrm{~m}<\mathrm{x}<3000 \mathrm{~m}$ ), que se desenvolve a partir da união de pequenas plumas geradas próximas à superfície e atinge uma extensão vertical da ordem de $\mathrm{z}_{\mathrm{i}}$. Ao alcançar a parte superior da CLP, os updrafts perdem seu empuxo inicial, mas têm momento suficiente para penetrarem na capa de inversão trazendo ar potencialmente quente da camada estável acima para dentro da CLP convectiva. 

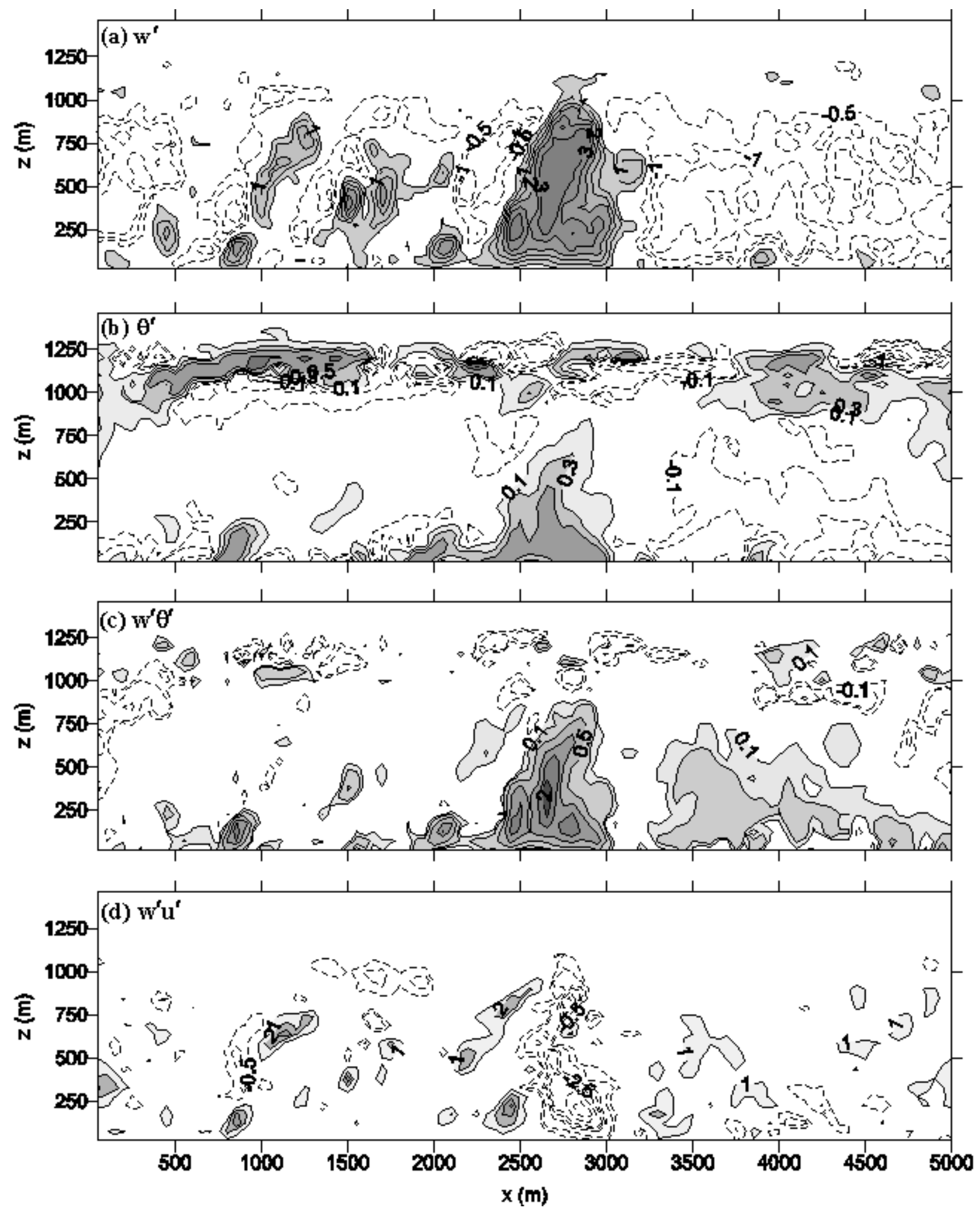

Fig. 4.6 - Campos verticais instantâneos das flutuações de: (a) velocidade vertical; (b) temperatura potencial; (c) fluxo local de calor sensível; (d) fluxo local de momento. As áreas escuras e as linhas sólidas indicam valores positivos, enquanto as áreas em branco e as linhas tracejadas representam valores negativos. Estimativas obtidas para o caso DA2 $\left(\mathrm{z}_{\mathrm{i}} / \mathrm{L}=-434\right)$ no instante $\mathrm{t} \approx 18 \mathrm{t}_{*}$. 
Esse processo de entranhamento gera flutuações positivas de temperatura potencial próximo ao topo da CLP, na camada definida por $750 \mathrm{~m}<\mathrm{z}<1250 \mathrm{~m}$ (Fig. 4.6b), onde é possível observar uma zona de penetração de ar potencialmente quente e limpo na CLP $\left(\mathrm{w}^{\prime}<0\right)$. Após atingir a camada de entranhamento, os updrafts espalham-se lateralmente e retornam em direção à superfície através de movimentos verticais descendentes, existentes em boa parte da CLP.

Os updrafts contribuem significativamente para os fluxos verticais de calor e de momento, se comparados aos downdrafts (Khanna e Brasseur, 1998). Isso fica evidente nos contornos dos campos instantâneos dos fluxos locais w'$^{\prime} \theta^{\prime}$ e w'u' apresentados nas Figs. (4.6c e 4.6d).

As análises da evolução vertical dos campos horizontais instantâneos do fluxo local de calor sensível $\mathrm{w}^{\prime} \theta^{\prime}$ (Figs. 4.7) fornecem informações sobre as distribuições espaciais dos updrafts e downdrafts na CLP. Próximo à superfície (Fig. 4.7a), a convecção é organizada em linhas de fluxo positivo $\left(\mathrm{w}^{\prime} \theta^{\prime}>0\right)$ que se assemelham à forma poligonal (plumas), característicos de escoamentos puramente convectivos (Schmidt e Schumann, 1989). Essas plumas estão inseridas em uma região de ambiente predominantemente de downdrafts ( $\mathrm{w}^{\prime} \theta^{\prime}<0$ ) e são marcadas por um forte gradiente horizontal de $\mathrm{w}^{\prime} \theta^{\prime}$. Com o aumento da altura, algumas dessas plumas são suprimidas pelo movimento descendente, sendo que, as demais se organizam em pequenas áreas de forte movimento ascendente formando os updrafts (regiões escuras nas Figs 4.7b e 4.7c). Ao alcançar a região próxima ao topo da CLP, os updrafts perdem força e os movimentos descendentes intensificam-se. Essas estimativas estão de acordo com os resultados apresentados por Schmidt e Schumann (1989), Moeng e Sullivan (1994) e Khanna e Brasseur (1998).

Na Fig. (4.8) é mostrado o campo tridimensional instantâneo de velocidade vertical em conjunto com cortes verticais e horizontais, onde as flutuações positivas mais intensas de $\overline{\mathrm{w}}\left(2,5 \mathrm{~m} \mathrm{~s}^{-1} \leq \overline{\mathrm{w}} \leq 6,0 \mathrm{~m} \mathrm{~s}^{-1}\right)$ são representadas pelas superfícies em vermelho. Nessa figura é possível ter uma clara idéia do padrão assimétrico das estruturas verticais da CLP convectiva. Algumas dessas estruturas apresentam escalas de comprimento da ordem de $z_{i}$ e são as principais responsáveis pelos transportes de constituintes atmosféricos na CLP. 

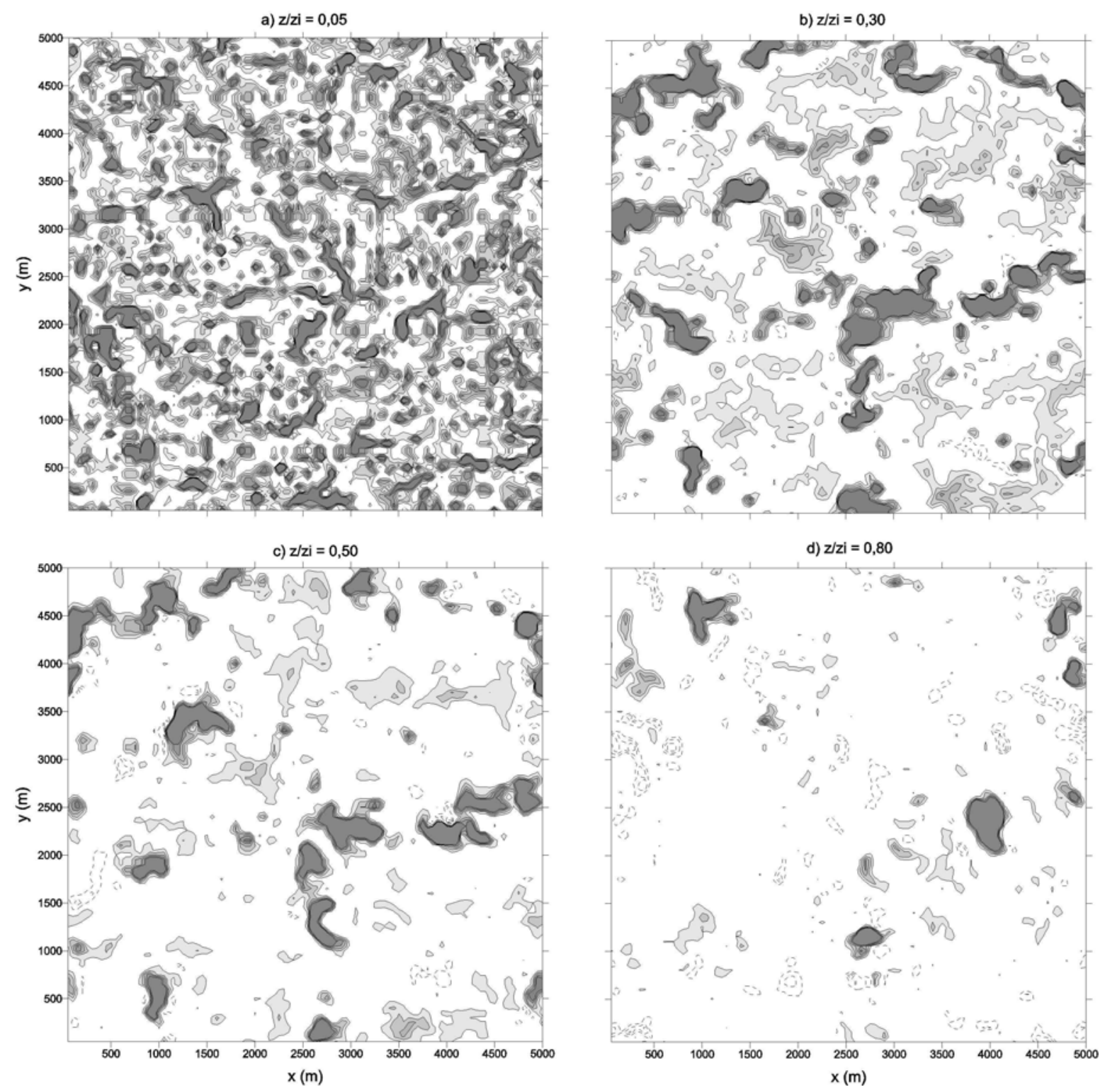

Fig. 4.7 - Campos horizontais instantâneos de fluxo local de calor sensível w' $\theta^{\prime}$ em diferentes níveis verticais. Linhas de contorno variaram de -0,3:0,1:0,5, onde as áreas escuras e linhas sólidas indicam $\mathrm{w}^{\prime} \theta^{\prime}>0$, enquanto as áreas em branco e as linhas tracejadas representam $\mathrm{w}^{\prime} \theta^{\prime}<0$. Estimativas obtidas para o caso DA2 $\left(\mathrm{z}_{\mathrm{i}} / \mathrm{L}=-434\right)$ no instante $\mathrm{t} / \mathrm{t}_{*} \approx 18$.

Um indicativo desse padrão assimétrico de w em condições convectivas é o valor positivo do perfil vertical adimensional do momento estatístico de terceira ordem das flutuações da componente vertical de velocidade na escala resolvida $\left\langle\mathrm{w}^{\prime 3}\right\rangle / \mathrm{w}_{*}^{3}$ (Fig. 4.9a). Os perfis verticais simulados são similares à curva experimental proposta por Sorbjan (1986), $\overline{\left[\mathrm{w}^{\prime 3}\right]} / \mathrm{w}_{*}^{3}=0,8 \mathrm{z} / \mathrm{z}_{\mathrm{i}}\left(1-0,87 \mathrm{z} / \mathrm{z}_{\mathrm{i}}\right)^{-5 / 4}$, apesar de subestimados acima de $\mathrm{z} \approx 0,7 \mathrm{z}_{\mathrm{i}}$. A 
ocorrência de pequenos valores negativos próximos à superfície é considerada irreal, pois isto implicaria em downdrafts com movimentos mais intensos que os updrafts (Nieuwstadt et al., 1992). Este problema torna-se mais evidente ao se observarem os perfis do parâmetro de assimetria do escoamento turbulento $\left\langle\mathrm{w}^{\prime 3}\right\rangle /\left\langle\mathrm{w}^{\prime 2}\right\rangle^{1 / 2}$, ou skewness (Fig. 4.9b). Possivelmente, a ocorrência de tal fato está relacionada ao modelo de subgrade adotado que parece ser inadequado para descrever condições de convecção livre próxima à superfície (Moeng, 1984; Schmidt e Schumann, 1989; Moeng e Rotunno, 1990).
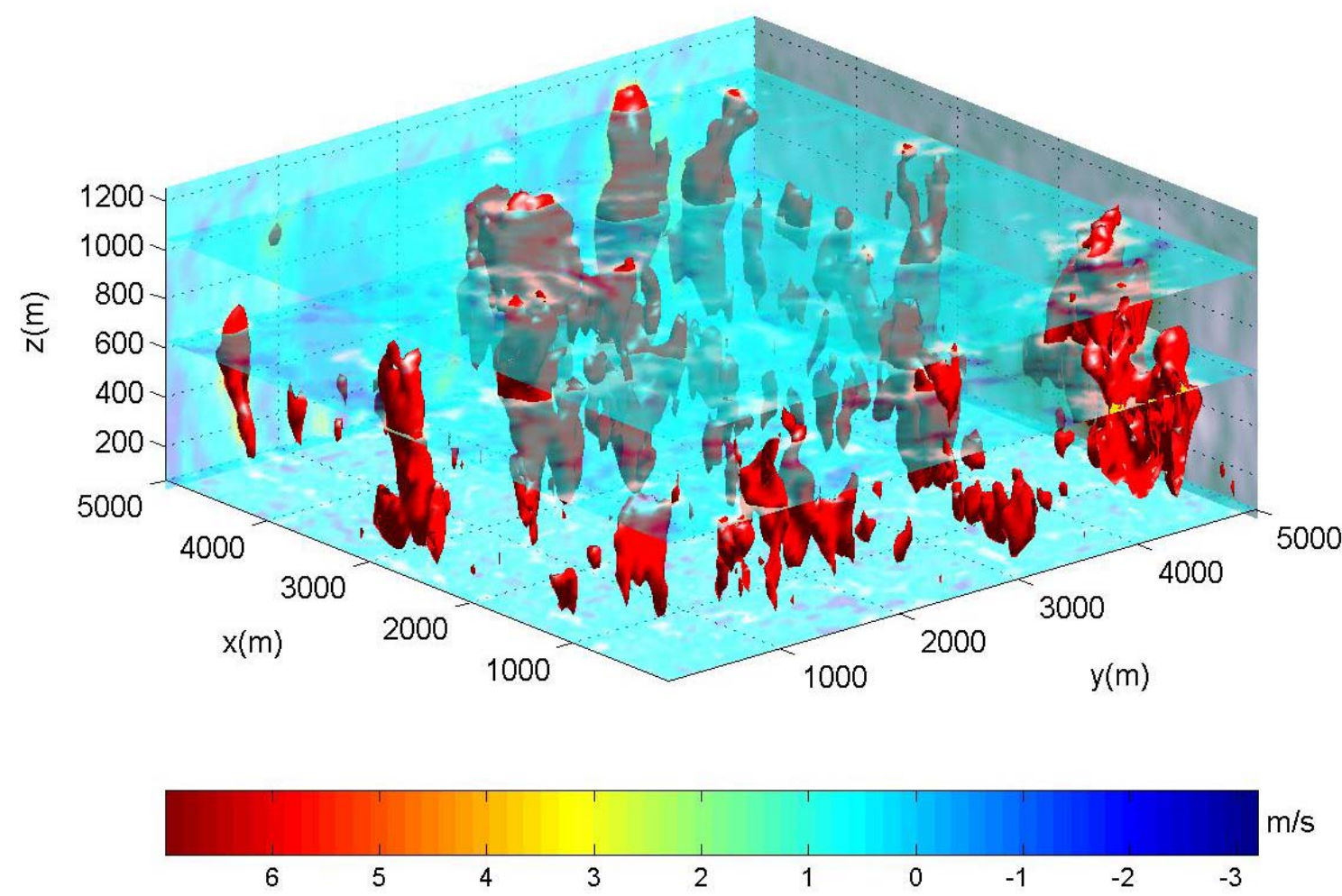

Fig. 4.8 - Campo tridimensional instantâneo da componente vertical de velocidade $\overline{\mathrm{w}}$ para o caso DA2 $\left(\mathrm{z}_{\mathrm{i}} / \mathrm{L}=-434\right)$ no instante $\mathrm{t} / \mathrm{t}_{*} \approx 18$. A barra de cores refere-se aos cortes verticais e horizontais instantâneos de $\overline{\mathrm{w}}$. As superfícies em vermelho representam $2,5 \mathrm{~ms}^{-1} \leq \overline{\mathrm{w}} \leq 6,0 \mathrm{~m} \mathrm{~s}^{-1}$.

Nas simulações realizadas, $\left\{\left\langle\mathrm{w}^{\prime 3}\right\rangle /\left\langle\mathrm{w}^{\prime 2}\right\rangle^{1 / 2}\right\} \approx 0,4$ em $\mathrm{z} \approx 0,1 \mathrm{z}_{\mathrm{i}}$, o que está de acordo com o valor obtido experimentalmente por Hunt et al. (1980) a partir de observações para a CLS. 
Acima da CLS $\left\langle\mathrm{w}^{\prime 3}\right\rangle /\left\langle\mathrm{w}^{\prime 2}\right\rangle^{1 / 2}$ aumenta linearmente com a altura, alcançando um máximo de $1,39 \pm 0,03$ em $\mathrm{z} \approx 0,9 \mathrm{z}_{\mathrm{i}}$.

a)

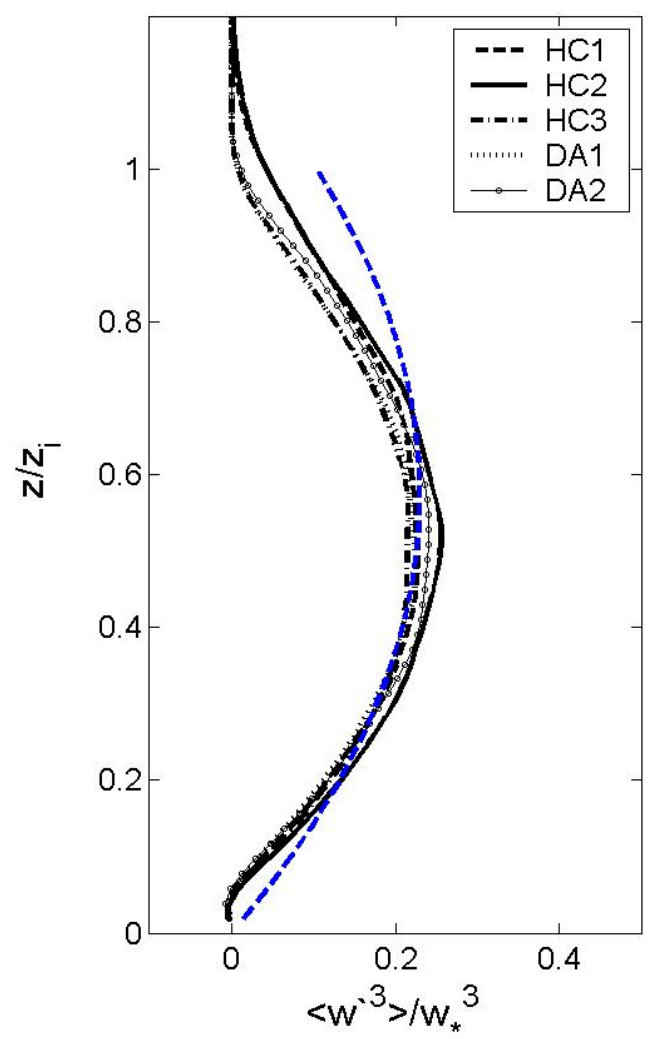

b)

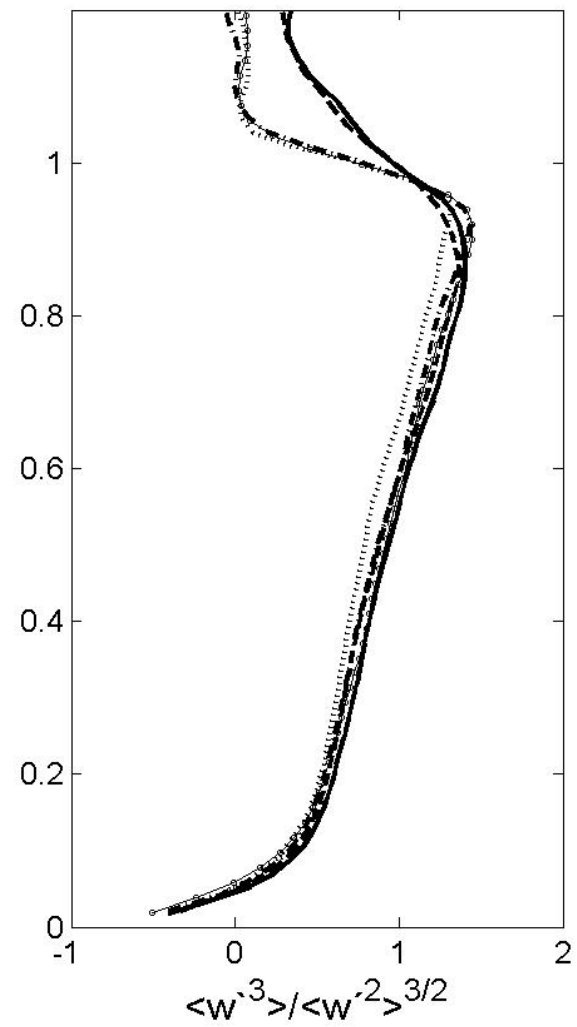

Fig. 4.9 - Perfis verticais adimensionais: (a) momento estatístico de $3^{\mathrm{a}}$ ordem; (b) skewness. A linha tracejada em azul representa a curva experimental proposta por Sorbjan (1986).

O modelo LES foi capaz de reproduzir as principais características da estrutura da turbulência na CLP altamente convectiva $\left(62 \leq-\mathrm{z}_{\mathrm{i}} / \mathrm{L} \leq 434\right)$. Os principais resultados obtidos nesta seção concordam com os prognósticos da teoria da similaridade da camada de mistura e com as curvas experimentais propostas na literatura, e são sumarizados a seguir.

Os perfis verticais de velocidade horizontal do vento apresentaram uma forma logarítmica na região próxima à superfície e um gradiente praticamente nulo no restante da CLP. Nessas condições de estabilidade, os fluxos de momento não seguiram a teoria da similaridade da camada de mistura. 
A variância das componentes horizontais de velocidade é aproximadamente constante com a altura em quase toda a camada de mistura. Por outro lado, a variância da componente vertical de velocidade $\left\{\left\langle\mathrm{w}^{\prime 2}\right\rangle+\left\langle\tau_{\mathrm{ww}}\right\rangle\right\}$ apresentou um máximo de $(0,48 \pm 0,01) \mathrm{w}_{*}^{2}$ em torno de $\mathrm{z} \approx 0,38 \mathrm{z}_{\mathrm{i}}$, o que está aproximadamente de acordo com os valores sugeridos por Deardorff (1974b).

Comparando-se os perfis verticais de $\left\{\left\langle\mathrm{w}^{\prime 2}\right\rangle+\left\langle\tau_{\mathrm{ww}}\right\rangle\right\} / \mathrm{w}_{*}^{2}$ com a curva experimental proposta por Lenschow et al. (1980) $\left(\overline{\left[\mathrm{w}^{\prime 2}\right]} / \mathrm{w}_{*}^{2}=1,8\left(\mathrm{z} / \mathrm{z}_{\mathrm{i}}\right)^{2 / 3}\left(1-0,8 \mathrm{z} / \mathrm{z}_{\mathrm{i}}\right)^{2}\right)$ observa-se que eles apresentam formas similares, porém, o máximo simulado encontra-se acima do proposto por Lenschow.

Os perfis verticais da variância de temperatura potencial $\left(\left\langle\theta^{\prime 2}\right\rangle+\left\langle\tau_{\theta \theta}\right\rangle\right) / \mathrm{T}_{*}^{2}$ mostram dois máximos distintos, um próximo à superfície e outro junto ao topo da CLP, e concordam qualitativamente com as curvas experimentais propostas por Moeng e Wyngaard (1984) e Bernard-Trottolo et al. (2004).

Os campos instantâneos das flutuações de velocidade vertical, temperatura potencial e dos fluxos turbulentos locais permitiram identificar o padrão assimétrico das estruturas coerentes na CLP altamente convectiva. As análises dos campos instantâneos do fluxo local de calor sensível mostram que as distribuições espaciais dos updrafts e downdrafts estão de acordo com os resultados apresentados na literatura (Schmidt e Schumann, 1989; Moeng e Sullivan, 1994; Khanna e Brasseur, 1998). Isto ficou evidenciado no campo tridimensional instantâneo da componente vertical de velocidade $\overline{\mathrm{w}}$.

O parâmetro de assimetria do escoamento turbulento ou skewness, é positivo por quase toda a CLP com exceção da região próxima à superfície, em virtude de limitações do modelo de subgrade.

A grande vantagem do modelo LES é possibilitar a obtenção de estimativas diretas dos termos de geração/destruição da turbulência, bem como dos transportes turbulentos na CLP, e que são difíceis de serem obtidas experimentalmente. Dessa forma, na próxima seção serão discutidos os principais processos físicos responsáveis pelo balanço de ECT na CLP altamente convectiva. 


\section{3 - Balanço de energia cinética turbulenta}

A ECT é uma medida da intensidade da turbulência, e sua variação está diretamente relacionada aos processos físicos que descrevem as propriedades da CLP. A análise da distribuição vertical dos termos da equação do balanço de ECT oferece detalhes sobre a natureza da produção/destruição da turbulência, bem como sobre o comportamento dos transportes de ECT na CLP. Em condições horizontalmente homogêneas e na ausência de movimentos subsidentes, a equação do balanço de ECT (escala resolvida + subgrade) $\left(\mathrm{E}=\frac{\mathrm{u}_{\mathrm{i}}^{\prime 2}}{2}+\mathrm{e}\right)$ pode ser expressa da seguinte forma:

$$
\begin{array}{ccc}
\frac{\partial \mathrm{E}}{\partial \mathrm{t}}=-\mathrm{u}_{\mathrm{i}}^{\prime} \mathrm{u}_{\mathrm{j}}^{\prime} \frac{\partial \overline{\mathrm{u}_{\mathrm{i}}}}{\partial \mathrm{x}_{\mathrm{j}}}+\frac{\mathrm{g}}{\theta_{0}} \mathrm{w}^{\prime} \theta^{\prime}-\left(\frac{\partial \mathrm{u}_{\mathrm{i}}^{\prime} \mathrm{E}}{\partial \mathrm{x}_{\mathrm{i}}}+\frac{1}{\rho_{0}} \frac{\partial \mathrm{u}_{\mathrm{i}}^{\prime} \mathrm{p}^{\prime}}{\partial \mathrm{x}_{\mathrm{i}}}\right)-\varepsilon \\
\mathrm{VL}
\end{array}
$$

onde os termos representam: (VL) variação local de ECT; (PM) produção mecânica ECT; (PT) produção/destruição térmica de ECT; (T) transporte turbulento de ECT; (P) transporte de ECT devido às flutuações de pressão; (D) taxa de dissipação de ECT devido à viscosidade molecular. Os termos de dissipação e de transporte na escala de subgrade são parametrizados de acordo com as Eqs. (2.14) e (2.15), respectivamente. Na CLP convectiva, os termos de produção (PM e PT) são considerados fontes, enquanto D é responsável pela destruição de ECT. Os termos de transporte $\mathrm{T}$ e $\mathrm{P}$ apenas distribuem a energia espacialmente na camada. Em condições estacionárias a variação local de ECT é identicamente nula.

O balanço de ECT na CLP tem sido objeto de diversos estudos experimentais e numéricos (Wyngaard, 1992). O experimento de Kansas, realizado em 1968, foi um dos primeiros a obter medidas diretas da maioria dos termos da equação do balanço de ECT na CLS.

Wyngaard e Coté (1971) argumentaram com base nos dados do experimento de Kansas que a taxa de dissipação em condições instáveis está aproximadamente em balanço com a produção total de ECT, e que o termo de divergência do fluxo vertical de pressão (estimado como resíduo) tem um papel importante na determinação do transporte de ECT. Baseado em dados experimentais obtidos por avião e na extrapolação das formulações propostas por Wyngaard e Coté, Lenchow (1974) realizou um estudo detalhado sobre o comportamento dos perfis verticais dos termos da equação do balanço de ECT, a partir do qual propôs um conjunto de 
parametrizações dos processos turbulentos na CLP convectiva. Seus resultados indicam que a taxa de dissipação é aproximadamente constante por toda camada de mistura, enquanto o transporte de ECT $(\mathrm{T}+\mathrm{P})$ aumenta linearmente com a altura de forma a balancear o decréscimo linear da produção térmica de ECT.

Através de medidas experimentais diretas da flutuação de pressão, McBean e Elliott (1975) verificaram que o transporte devido à flutuação de pressão funciona como fonte de ECT na CLS. Esse resultado foi confirmado por Caughey e Wyngaard (1979), apesar das incertezas quanto ao comportamento do termo de produção mecânica e da taxa de dissipação na camada de mistura. Lenschow et al. (1980), com dados obtidos de avião, observaram que na camada de mistura os termos da equação de ECT estão aproximadamente em balanço, mas na região próxima à superfície é necessário um termo fonte adicional associado à flutuação de pressão. A importância do transporte devido à flutuação de pressão em condições convectivas foi confirmada por Deardorff e Willis (1985) em experimentos de laboratório realizados com o auxílio de um tanque de convecção.

Os modelos numéricos do tipo LES representam uma importante alternativa às dificuldades experimentais de se obterem estimativas diretas de todos os termos da equação do balanço de ECT na CLP. Além de fornecer informações detalhadas sobre os campos tridimensionais das variáveis meteorológicas (velocidade, temperatura potencial e outros escalares), é possível obter os campos de flutuação de pressão de forma explícita. A flutuação de pressão é de fundamental importância para estimar o termo de retorno à isotropia das variâncias das componentes de velocidade e para a determinação do transporte turbulento de ECT (Moeng e Sullivan, 2002).

Por meio de estudos numéricos realizados com o modelo LES, Moeng e Sullivan (1994) mostraram como os diferentes regimes turbulentos da CLP afetam a distribuição vertical do balanço de ECT e propuseram um conjunto de formulações para representá-lo. Lin (2000) verificou que na CLP convectiva o transporte local devido à flutuação de pressão está espacialmente associado a regiões de baixa pressão e de intensas flutuações da componente vertical da vorticidade. Pino et al. (2003) mostraram que as distribuições verticais de vários termos do balanço de ECT na CLP convectiva sofrem influências do cisalhamento do vento na camada de inversão junto ao topo da CLP. 
As estimativas dos perfis verticais adimensionais dos termos da equação do balanço de ECT na CLP em condições convectivas com baixa velocidade do vento são apresentadas nas Figs. (4.10). A variação local de ECT (VL) é praticamente nula em todas as simulações, enfatizando que o regime turbulento atingiu a condição de quase-equilíbrio (conforme discutido na seção 4.1). A pequena variação positiva junto ao topo (Figs. 4.10a e 4.10b) pode ser considerada como conseqüência da presença de ondas de gravidade (conforme discutido na seção 4.1), sendo que a ordem de grandeza dessas variações é inferior aos demais termos do balanço de ECT (Caughey e Wyngaard, 1979; Fedorovich et al., 2004).

A produção térmica de ECT (PT) mostra um comportamento similar em todas as simulações, com máximo próximo à superfície e decréscimo linear com a altura até atingir o mínimo em $\mathrm{Z}_{\mathrm{i}}$. Esse comportamento é característico de uma CLP em condições convectivas (conforme discutido na Fig. 4.3).

Os perfis verticais adimensionais do termo de produção mecânica de ECT (PM) apresentam dois regimes distintos próximos à superfície. Nos casos onde a velocidade do vento é da ordem de $4 \mathrm{~ms}^{-1}$ (Figs. 4.10a e 4.10d) existe uma contribuição positiva significativa na região próxima à superfície $\left(\mathrm{z}<0,2 \mathrm{z}_{\mathrm{i}}\right)$, sendo que nos demais casos essa contribuição é praticamente nula por toda a CLP.

A taxa de dissipação (D) tem um máximo pronunciado próximo à superfície, principalmente nos casos onde a velocidade vento é maior (HC1 e DA1), o que contribui para a manutenção do balanço de ECT. Acima dessa região, decresce rapidamente com a altura até $\mathrm{z} \approx 0,2 \mathrm{z}_{\mathrm{i}} \mathrm{e}$ decai para zero acima da CLP. Os valores integrados da taxa de dissipação e dos termos de produção de ECT por toda a camada (não mostrados) estão bem próximos, enfatizando a existência de um equilíbrio entre esses termos. Dessa forma, os termos de transporte (T e P) têm como função apenas distribuir a ECT espacialmente na CLP, uma vez que seus valores integrados na camada são praticamente nulos.

O transporte turbulento de ECT (T) tem um comportamento similar em todos os casos considerados. Na metade inferior da CLP, ele age como um sorvedouro de ECT e no restante da camada atua como fonte. Portanto, a ECT é transportada das camadas inferiores para as superiores da CLP e o nível vertical que define as regiões fontes/sorvedouros de ECT 
localiza-se em torno de $\mathrm{z} \approx 0,5 \mathrm{z}_{\mathrm{i}}$. Este padrão está de acordo com os dados experimentais coletados por avião e reportados por Lenschow (1974) e Lenschow et al. (1980).
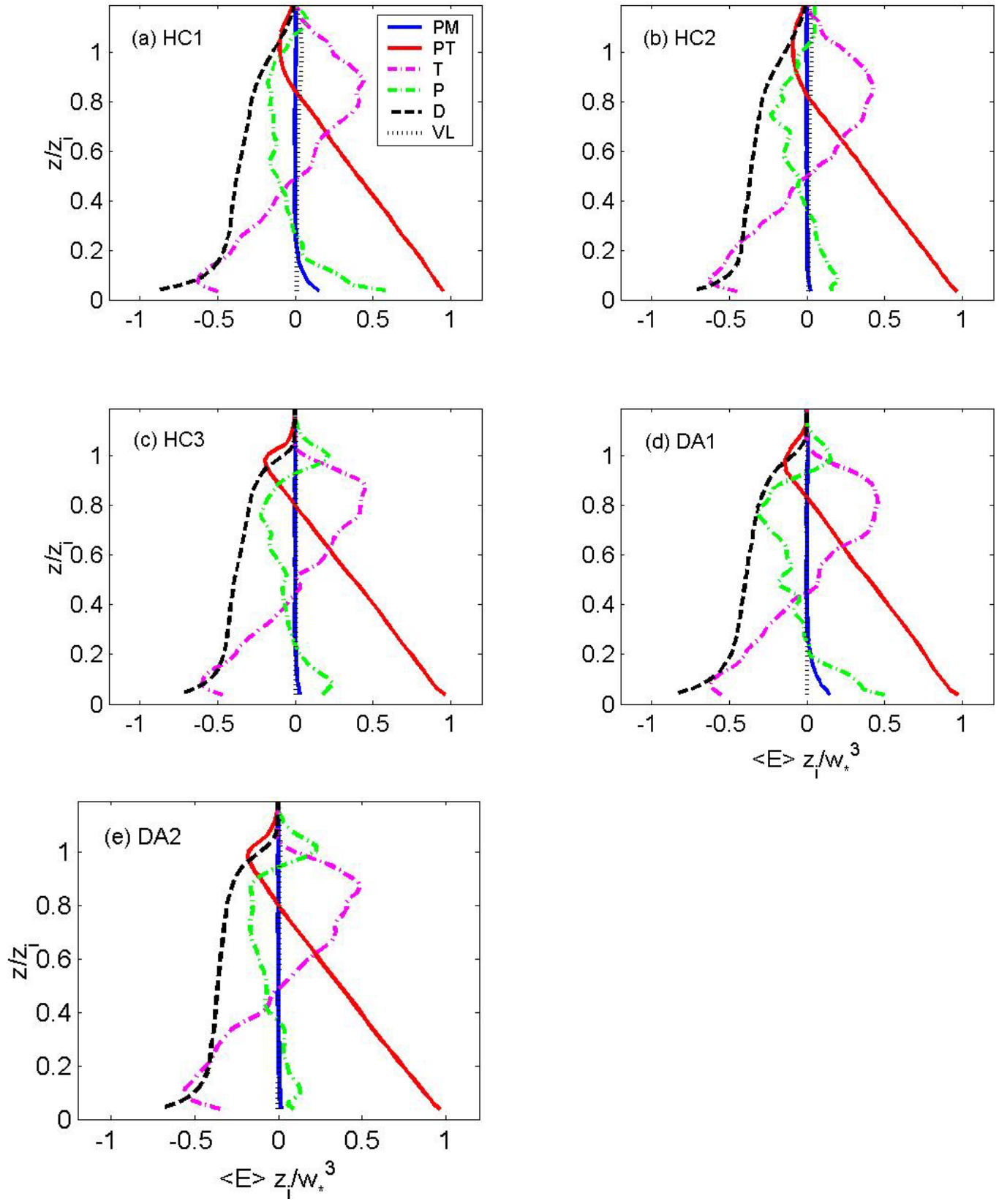

Fig. 4.10 - Balanço adimensional de ECT (resolvida + subgrade) na CLP altamente convectiva, para cada um dos casos simulados. Os termos representam: (PM) a produção mecânica de ECT; (PT) produção térmica de ECT; $(\mathrm{T})$ transporte turbulento de ECT; (P) transporte devido à flutuação de pressão e (VL) a variação local de ECT. 
O termo de transporte de ECT devido à flutuação de pressão (P) tem um comportamento oposto ao observado para transporte turbulento de ECT.

Os perfis adimensionais do fluxo vertical de ECT $\left\langle\mathrm{w}^{\prime} \mathrm{E}\right\rangle / \mathrm{w}_{*}^{3}$ (Fig. 4.11a) são positivos por toda CLP convectiva e têm formas similares à curva experimental proposta por Lenschow (1974, Eq. 21). A posição do máximo ficou em torno de $\mathrm{z} \approx 0,5 \mathrm{z}_{\mathrm{i}}$, similar ao nível encontrado por Willis e Deardorff (1974b) e superior aos reportados por Lenschow et al. (1980) e Deardorff e Willis (1985). Como pode ser observado na Fig. (4.11b), aproximadamente 80\% do transporte turbulento de ECT está associado à contribuição vertical $\left\langle 0,5 \mathrm{w}^{\prime 3}\right\rangle$ na CLP convectiva. O espalhamento das estimativas próximo à superfície está relacionado a problemas do modelo de subgrade. Já os valores negativos de $\left\langle\mathrm{w}^{\prime}\left(\mathrm{u}^{\prime 2}+\mathrm{v}^{\prime 2}\right)\right\rangle / \mathrm{w}^{\prime 3}$ são ocasionados pelo processo de entranhamento. Dados experimentais reportados por Wyngaard e Coté (1971) indicam que na CLS a razão $\left\langle\mathrm{w}^{\prime}\left(\mathrm{u}^{\prime 2}+\mathrm{v}^{\prime 2}\right)\right\rangle / \mathrm{w}^{\prime 3}$ é aproximadamente igual a 2. Acima da CLS, as estimativas geradas pelo modelo LES variam de 0,3 em $\mathrm{z} \approx 0,1 \mathrm{z}_{\mathrm{i}}$ a $0,1 \mathrm{em}$ $\mathrm{z} \approx 0,8 \mathrm{z}_{\mathrm{i}}$ e estão aproximadamente de acordo com a curva experimental sugerida por Lenschow (1974), $\overline{\left[\mathrm{w}^{\prime}\left(\mathrm{u}^{\prime 2}+\mathrm{v}^{\prime 2}\right)\right] / \mathrm{w}^{\prime 3}}=0,55 \mathrm{z} / \mathrm{z}_{\mathrm{i}}+0,4$.

Como visto anteriormente, sempre houve controvérsias com relação ao papel da flutuação de pressão no transporte de ECT na CLP convectiva, principalmente a associada às dificuldades experimentais de se medir a flutuação de pressão diretamente (Mahrt, 1998). Conseqüentemente, grande parte dos trabalhos apresentados na literatura (Wyngaard e Coté, 1971; Caughey e Wyngaard, 1979; Lenschow et al., 1980; Deardorff e Willis, 1985) estimaram o transporte turbulento de ECT devido à flutuação de pressão como um termo de resíduo, o que gerou incertezas quanto aos erros dos demais termos do balanço de ECT (problemas experimentais, numéricos, além de não-estacionaridade e não-homogeneidade do escoamento turbulento).

Na CLP convectiva, os termos de produção de ECT (PM+PT) devem estar em balanço com a soma dos termos de dissipação (D) e de transporte (T+P). Nas Figs. (4.12a e 4.12b) são apresentados os perfis verticais adimensionais do termo residual $\mathrm{R}$ da equação do balanço de ECT, obtido através dos termos do lado direito da Eq. (4.1) exceto o termo $\mathrm{P}$ 
$(\mathrm{R}=-\mathrm{PM}-\mathrm{PT}-\mathrm{T}-\mathrm{D}$, com $\mathrm{VL} \approx 0)$, e o próprio termo $\mathrm{P}$ determinado diretamente pelo modelo LES.

(a)

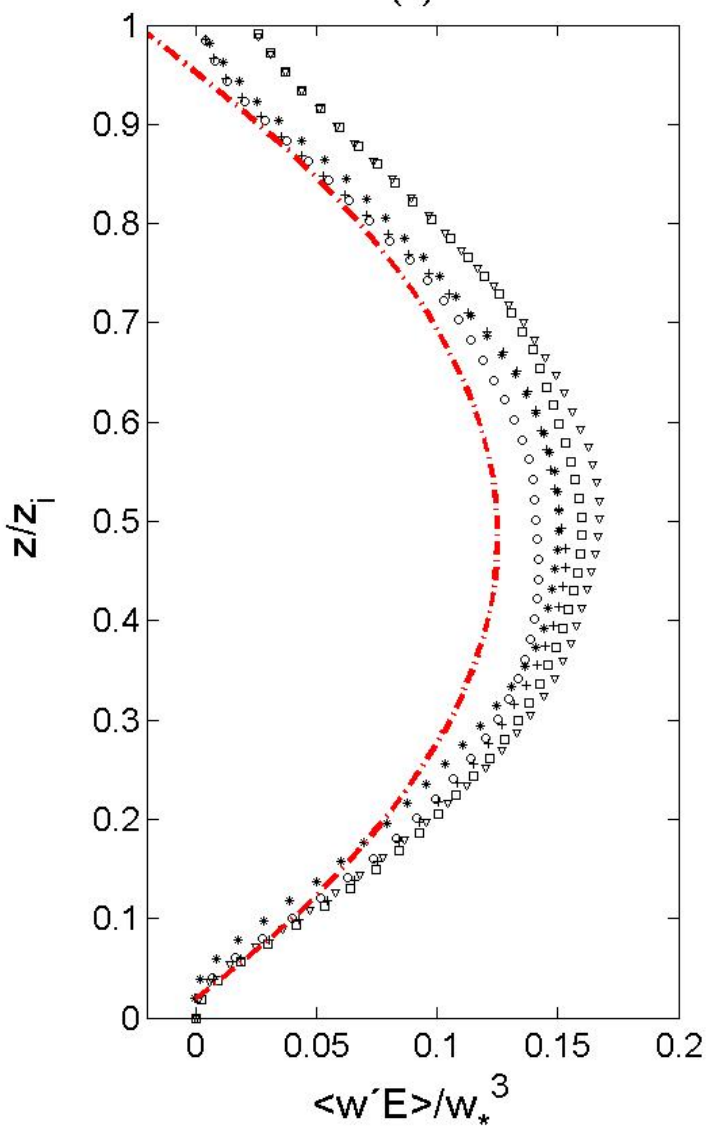

(b)

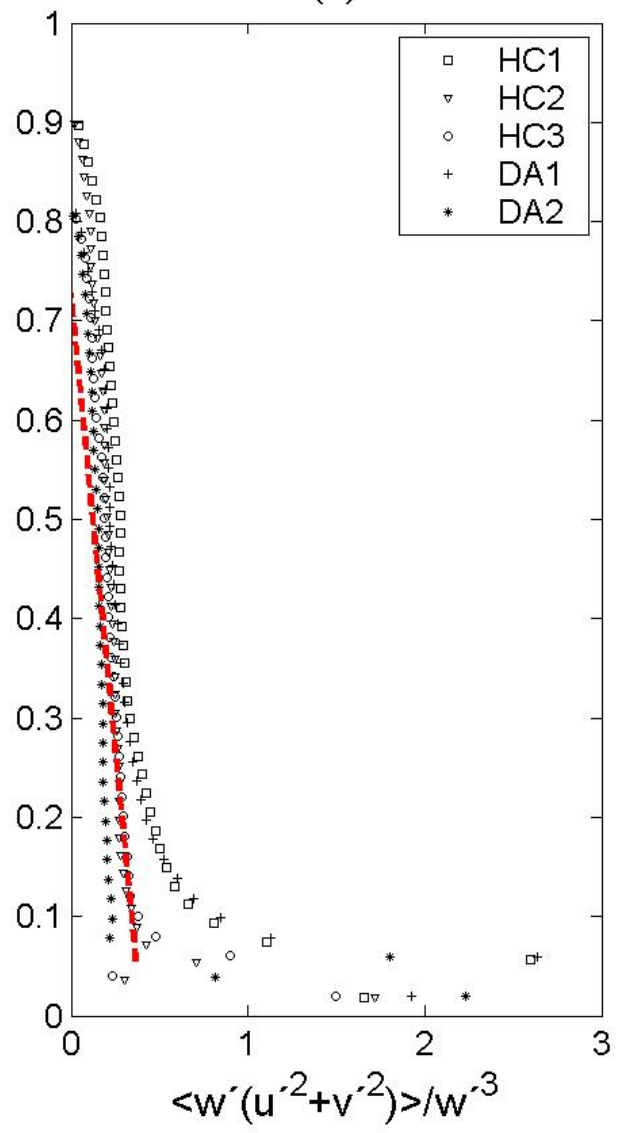

Fig. 4.11 - Perfis verticais adimensionais: (a) fluxo vertical de ECT; (b) razão entre os fluxos verticais de variâncias horizontais e vertical. As linhas tracejadas em vermelho representam as curvas experimentais propostas por Lenschow (1974).

As estimativas diretas do termo $\mathrm{P}$ mostram um excelente acordo com as estimativas do termo R, enfatizando a existência do balanço de ECT através dos termos estimados diretamente pelo modelo LES. Os perfis de R (Fig. 4.12a) indicam na região da CLP com altura inferior $0,4 \mathrm{z}_{\mathrm{i}}$ o transporte de ECT devido a flutuação de pressão deve contribuir positivamente para geração de ECT como forma para manter o balanço de energia nessa região, o que está de acordo com a Fig. (4.12b). As diferenças próximas à superfície estão relacionadas às deficiências do modelo de subgrade e as diferentes intensidades de cisalhamento do vento consideradas nas 
simulações (ver Fig. 4.2b). Acima dessa camada, R é negativo e, portanto, o transporte devido à flutuação de pressão age como um termo de sorvedouro de ECT. De acordo com Moeng e Wyngaard (1986), os valores positivos de P na camada de entranhamento são ocasionados pela formação de ondas de gravidade, devido à interação dos escoamentos da atmosfera livre acima com a CLP, e pelo cisalhamento do vento.
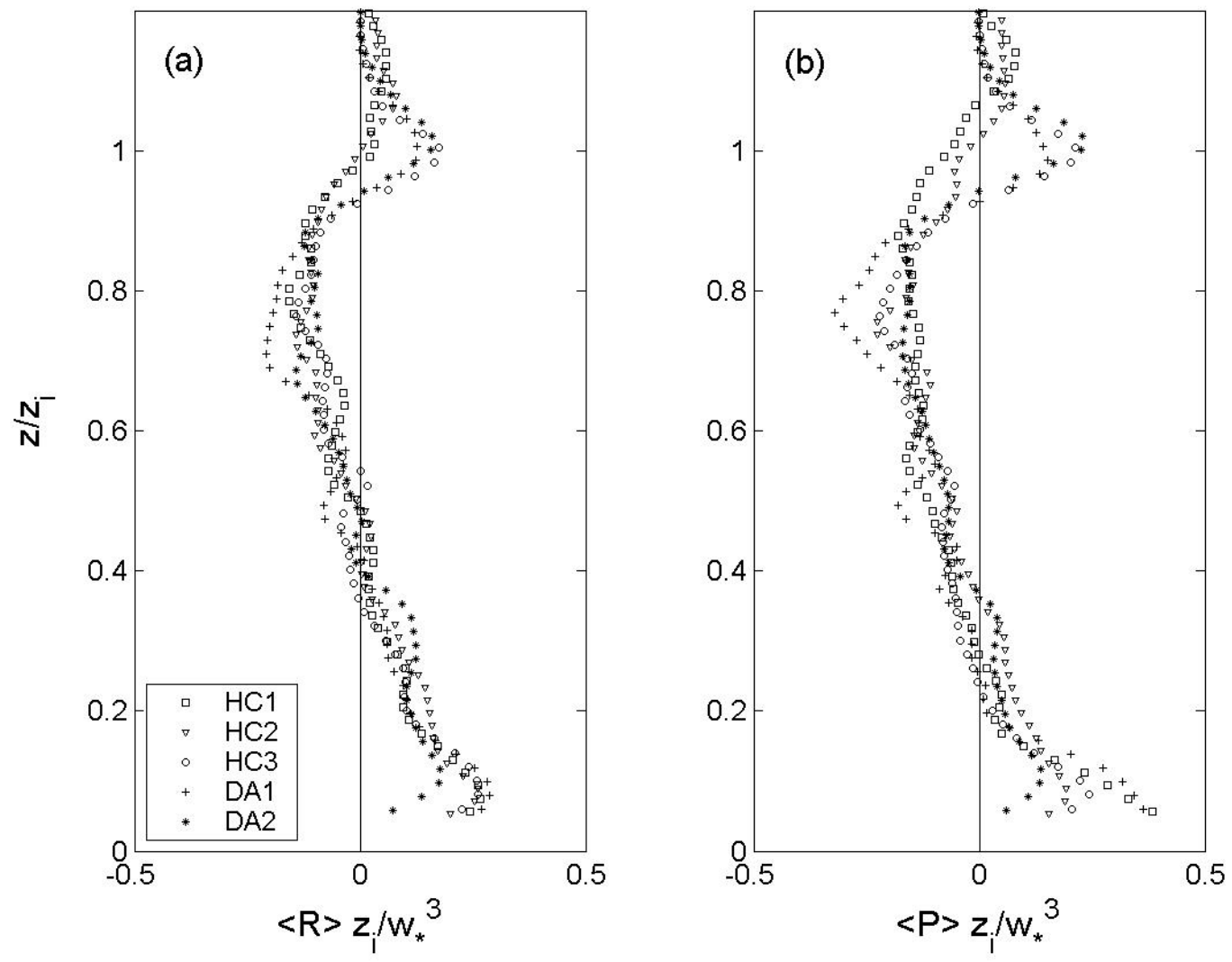

Fig. 4.12 - Perfis verticais adimensionais dos termos de: (a) resíduo da equação do balanço de ECT; (b) transporte devido à flutuação de pressão. O resíduo foi obtido através dos termos do lado direito de (4.1), exceto o termo P.

Em razão da escassez de dados experimentais, a validação dos termos do balanço de ECT estimados pelo modelo LES será feita com base nas parametrizações para CLP convectiva propostas por Lenschow (1974), Lenschow et al. (1980) e Moeng e Sullivan (1994) (Tabela 4.3). Essas parametrizações são, em grande parte, baseadas na extrapolação das formulações propostas por Wyngaard e Coté (1971) para o balanço de ECT na CLS instável, em dados experimentais coletados por avião e por experimentos idealizados em laboratório. 
Nas Figs. (4.13) são apresentados separadamente os perfis verticais adimensionais dos termos da equação do balanço de ECT para todos os casos, e suas respectivas parametrizações. As estimativas dos perfis de produção térmica de ECT (Fig. 4.13a) estão de acordo com os modelos propostos, exceto próximo ao topo da CLP onde os processos de entranhamento, difíceis de serem representados, influenciam tais estimativas.

Tabela 4.3 - Parametrizações propostas na literatura para o balanço de ECT na CLP convectiva

Termo Lenschow (1974) / Lenschow et al. (1980) Moeng e Sullivan (1994)

\begin{tabular}{|c|c|c|}
\hline PT & $\begin{array}{l}\frac{\mathrm{w}_{*}^{3}}{\mathrm{z}_{\mathrm{i}}}\left(1-1,15 \frac{\mathrm{z}}{\mathrm{z}_{\mathrm{i}}}\right), 0<\mathrm{z} / \mathrm{z}_{\mathrm{i}}<0,9 \\
\frac{\mathrm{w}_{*}^{3}}{\mathrm{z}_{\mathrm{i}}} \mathrm{f}\left(\mathrm{z} / \mathrm{z}_{\mathrm{i}}\right) \quad, \mathrm{z} / \mathrm{z}_{\mathrm{i}} \geq 0,9\end{array}$ & $\frac{\mathrm{w}_{*}^{3}}{\mathrm{z}_{\mathrm{i}}}\left(1-1,2 \frac{\mathrm{z}}{\mathrm{z}_{\mathrm{i}}}\right)-\frac{\mathrm{u}_{*}^{3}}{\mathrm{z}_{\mathrm{i}}} \frac{\mathrm{z}}{\mathrm{z}_{\mathrm{i}}}$ \\
\hline PM & $\frac{\mathrm{w}_{*}^{3}}{\mathrm{z}_{\mathrm{i}}}\left\{-\mathrm{L} / \mathrm{z}_{\mathrm{i}} \frac{\left[1-15\left(\mathrm{z}_{\mathrm{i}} / \mathrm{L}\right) \mathrm{z} / \mathrm{z}_{\mathrm{i}}\right]^{-1 / 4}}{\mathrm{z} / \mathrm{z}_{\mathrm{i}}}\right\}$ & $\mathrm{u}_{*}^{3}\left(1-\frac{\mathrm{z}}{\mathrm{z}_{\mathrm{i}}}\right) \frac{(1-15 \mathrm{z} / \mathrm{L})^{-1 / 4}}{\kappa \mathrm{z}}$ \\
\hline$(T+P)$ & $\mathrm{PM}+\mathrm{PT}+\mathrm{a}\left(\langle\mathrm{PM}\rangle_{\mathrm{CM}}-\mathrm{PM}\right)+0,7\left(\langle\mathrm{PT}\rangle_{\mathrm{CM}}-\mathrm{PT}\right)$ & $\begin{array}{c}-\frac{\mathrm{w}_{*}^{3}}{\mathrm{z}_{\mathrm{i}}}\left(0,6-1,2 \frac{\mathrm{z}}{\mathrm{z}_{\mathrm{i}}}\right)+\frac{\mathrm{u}_{*}^{3}}{\mathrm{z}_{\mathrm{i}}} \frac{\mathrm{z}}{\mathrm{z}_{\mathrm{i}}} \\
-0,4 \frac{\mathrm{w}_{*}^{3}}{\mathrm{z}_{\mathrm{i}}}-\mathrm{u}_{*}^{3}\left(1-\frac{\mathrm{z}}{\mathrm{z}_{\mathrm{i}}}\right) \frac{(1-15 \mathrm{z} / \mathrm{L})^{-1 / 4}}{\kappa \mathrm{z}}\end{array}$ \\
\hline
\end{tabular}

Nas simulações onde o regime turbulento é misto, ou seja, tanto a força de empuxo quanto o cisalhamento do vento atuam na geração de turbulência na região próxima a superfície, o modelo proposto por Moeng e Sullivan ajusta-se melhor as estimativas dos termos de produção mecânica de ECT (Fig. 4.13b).

O transporte total de ECT é subestimados por ambas as parametrizações na região próxima a superfície $\left(\mathrm{z}<0,2 \mathrm{z}_{\mathrm{i}}\right)$. Isto se deve, em grande parte, a dificuldade do modelo LES em representar adequadamente os processos dessa região (Moeng e Sullivan, 1994). Na metade superior da CLP ocorre o contrário e as parametrizações de $(T+P) \mathrm{z}_{\mathrm{i}} / \mathrm{w}_{*}^{3}$ são superestimadas, principalmente próximo ao topo da CLP. Essa diferença está possivelmente relacionada à contribuição do termo P nessa região. 

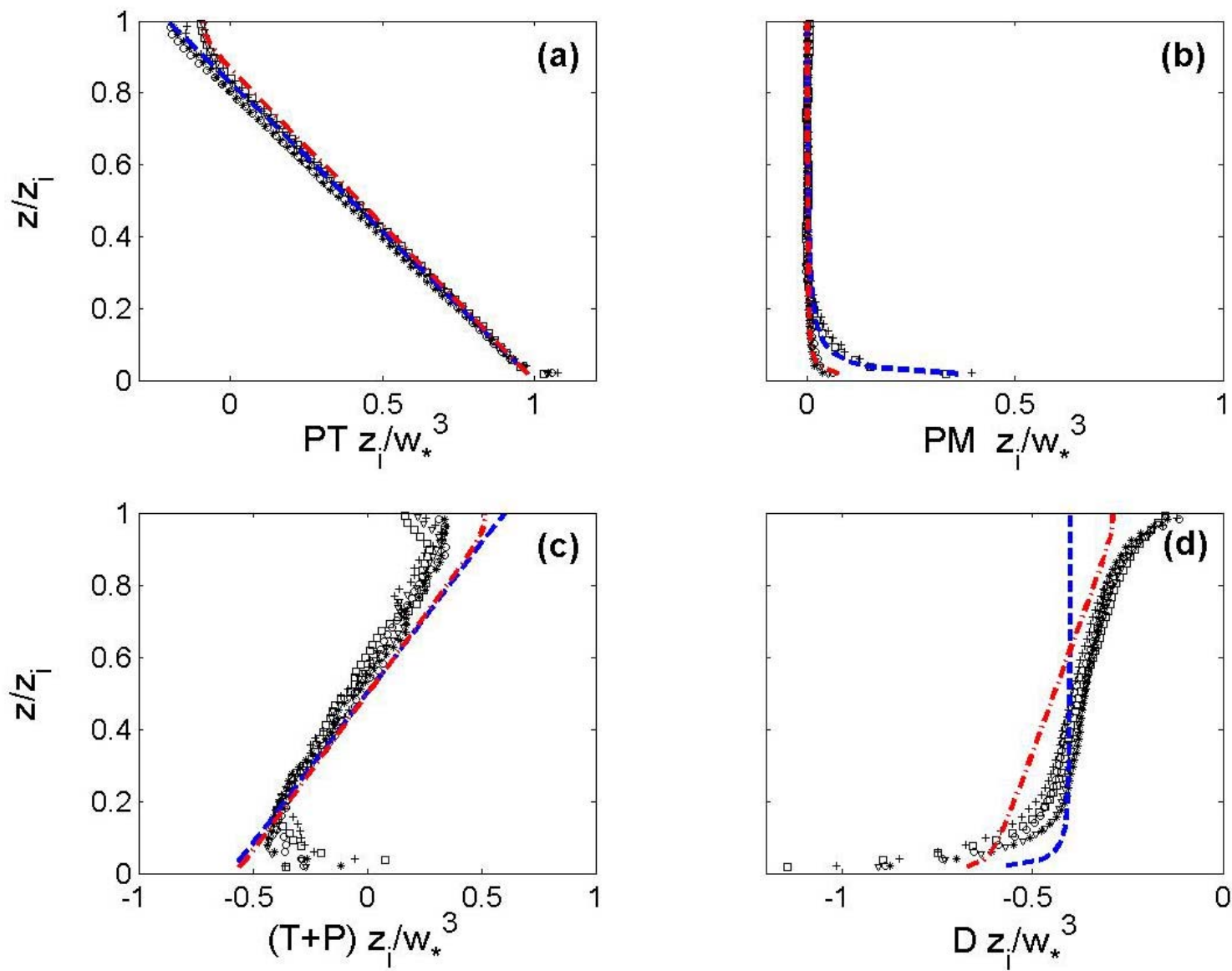

Fig. 4.13 - Perfis verticais adimensionais dos termos da equação do balanço de ECT para todas simulações: (a) produção térmica; (b) produção mecânica; (c) transporte; (d) taxa de dissipação. As linhas tracejadas em vermelho representam as parametrizações propostas por Lenschow (1974 )/Lenschow et al. (1980), e em azul por Moeng e Sullivan (1994). Os demais símbolos são iguais aos utilizados na Fig. (4.12)

As estimativas da taxa de dissipação adimensional de ECT aumentam linearmente de $\left\{D z_{i}\right\}=-0,45 w_{*}^{3}$ em $\mathrm{z} \approx 0,2 z_{\mathrm{i}}$ até $\left\{D z_{i}\right\}=-0,11 w_{*}^{3}$ próximo ao topo da CLP, e os perfis verticais têm formas similares à parametrização proposta por Lenschow, apesar de superestimadas por quase toda CLP. Na parametrização proposta por Lenchow, onde o termo de dissipação é determinado como resíduo, as diferenças podem estar relacionadas a problemas na determinação dos demais termos da equação do balanço de ECT. A parametrização proposta por Moeng e Sullivan é baseada nos resultados apresentados por Willis e Deardorff (1974b) e mostrou deficiências na representação da variação vertical de $\mathrm{D} \mathrm{z}_{\mathrm{i}} / \mathrm{w}_{*}^{3}$, uma vez que a mesma foi considerada constante e igual $-0,4$. 
Uma outra forma de validar as estimativas da taxa de dissipação de ECT geradas pelo modelo LES será explorada na seção 4.4 através da determinação do valor da constante de Kolmogorov $\left(\alpha_{K}\right)$ na região do subintervalo inercial do espectro turbulento das componentes de velocidade.

Os resultados apresentados nesta seção mostram que o modelo LES é uma boa alternativa as dificuldades experimentais de se obter estimativas diretas dos termos da equação do balanço de ECT.

Com relação ao balanço de ECT, a variação local de ECT foi aproximadamente nula, confirmando a condição de quase-equilíbrio dos escoamentos turbulentos simulados.

A produção térmica de ECT é o termo predominante na geração da turbulência por quase toda a CLP, como esperado em condições de estabilidade altamente convectivas. Nos casos onde a velocidade horizontal do vento é maior (HC1 e DA1), o termo de produção mecânica de ECT tem uma contribuição significativa apenas na região próxima à superfície, sendo aproximadamente nulo no restante da camada.

Os termos de transporte distribuem a ECT espacialmente e apresentam perfis verticais com sinais opostos, sendo que o transporte devido à flutuação de pressão é um termo fonte de ECT próximo à superfície.

As parametrizações dos termos da equação do balanço de ECT na CLP convectiva propostas por Lenschow (1974), Lenschow et al. (1980) e Moeng e Sullivan (1994), reproduziram com grande fidelidade as estimativas dos termos de produção de ECT na CLP convectiva. Já os termos de transporte de ECT foram superestimados junto ao topo. Os perfis verticais do termo de dissipação simulados com o modelo LES não concordam com os perfis propostos pelos pesquisadores acima.

Uma vez caracterizado o papel das forçantes que atuam na geração/destruição da turbulência, bem como do transporte de ECT na CLP altamente convectiva, será realizado um estudo dos espectros turbulentos para determinar as escalas temporais/espaciais representativas desse escoamento turbulento. 


\section{4 - Análise espectral}

Os movimentos turbulentos na CLP são caracterizados por turbilhões com um amplo intervalo de escalas, temporais e espaciais, e a análise espectral possibilita uma melhor compreensão das trocas de energia entre as diferentes escalas.

A teoria do equilíbrio universal concebida por Kolmogorov em 1941 (Monin e Yaglom, 1971; Phillips, 1991; Frisch, 1995) constitui um dos primeiros esforços teóricos importantes para compreensão das características universais dos espectros turbulentos na CLP. Segundo sua concepção, quando o número de Reynolds de um escoamento turbulento é suficientemente grande o espectro de ECT apresenta três regiões distintas (Fig.4.14): região de produção (A); subintervalo inercial (B) e a região de dissipação de energia (C).

Na região de produção a ECT é gerada principalmente pela força de empuxo e pelo cisalhamento do vento. Os turbilhões têm escalas de comprimento que variam de alguns quilômetros a dezenas de metros e escalas temporais de dezenas de segundos á vários minutos.

O subintervalo inercial engloba os turbilhões menores e não sofre influência direta dos turbilhões maiores da região de produção de ECT. Nesse subintervalo deve existir um equilíbrio universal de modo que a ECT não seja produzida e nem destruída, mas transferida das escalas maiores para as menores, num processo denominado cascata de energia. Os turbilhões menores tendem a ter propriedades universais para todos os tipos de escoamentos turbulentos e por conseqüência, a turbulência deve ser localmente isotrópica. Quanto maior o número de Reynolds (Re) do escoamento turbulento, maior a extensão do subintervalo inercial.

Na região de dissipação a ECT é consumida pela viscosidade molecular mediante a destruição dos turbilhões de pequena escala. A escala de comprimento na qual a ECT é dissipada denomina-se microescala de Kolmogorov $(\eta)$, e depende unicamente da taxa de dissipação $(\varepsilon)$ e da viscosidade molecular cinemática $(v)$.

Pela hipótese de construção, os modelos o tipo LES são capazes de resolver numericamente turbilhões com escalas de comprimento pertencente ao subintervalo inercial do espectro turbulento de ECT (Moeng, 1984). Portanto, informações sobre as escalas de comprimento 
dos turbilhões mais energéticos, bem como sobre a validade das relações do subintervalo inercial, podem ser exploradas em detalhes.

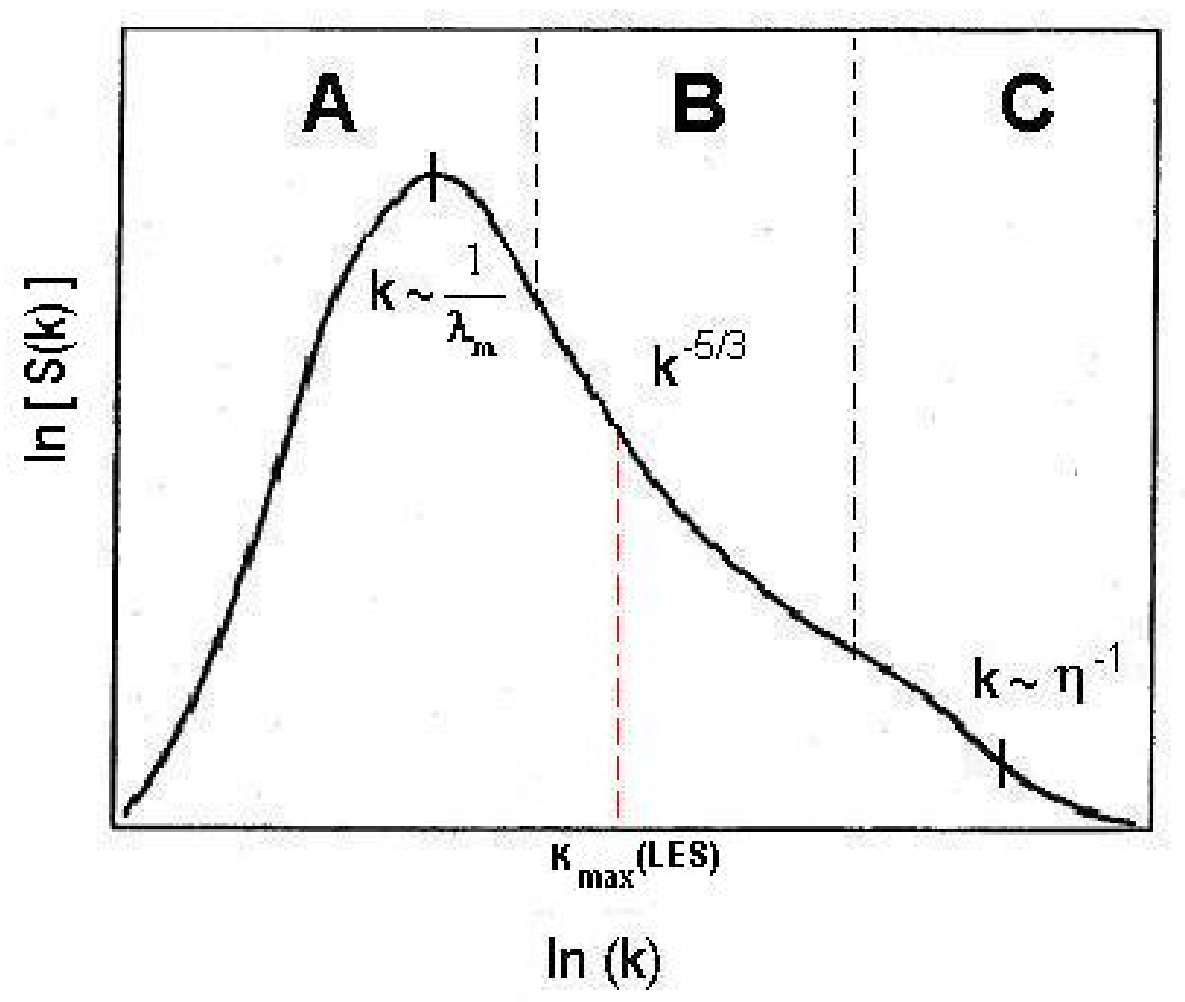

Fig. 4.14 - Esquema do espectro de energia na CLP mostrando as três regiões distintas: (A) região de produção; (B) subintervalo inercial; (C) região de dissipação. k representa o número de onda, $\lambda_{\mathrm{m}}$ é o comprimento de onda associado ao turbilhão mais energético e $\eta$ é a microescala de Kolmogorov. O número de onda máximo resolvido pelo modelo LES é representado por $\mathrm{k}_{\max }$ (LES). Fonte: Adaptada de Kaimal e Finnigan (1994).

De acordo com a teoria proposta por Kolmogorov, na região do subintervalo inercial a turbulência é considerada localmente isotrópica e a função densidade espectral do campo tridimensional de velocidade $\mathrm{S}_{\mathrm{u}_{\mathrm{i}}}(\mathrm{k})$ é proporcional a $\propto \varepsilon^{2 / 3} \mathrm{k}^{-5 / 3}$. Dessa forma, o espectro unidimensional da componente longitudinal de velocidade $\left(S_{u}\right)$ pode ser descrito como:

$\mathrm{S}_{\mathrm{u}}\left(\mathrm{k}_{1}\right)=\alpha_{\mathrm{K}} \varepsilon^{2 / 3} \mathrm{k}_{1}^{-5 / 3}$ 
onde $\mathrm{k}_{1}$ é o número de onda na direção do vento médio e $\alpha_{\mathrm{K}}$ a constante universal de Kolmogorov. De acordo com Kaimal e Finnigan (1994) o valor estimado de $\alpha_{\mathrm{K}}$ varia entre 0,5 e 0,6 .

A condição de isotropia local estabelece que as densidades espectrais das componentes de velocidade estão relacionadas entre si através da seguinte expressão (Panofsky e Dutton, 1984; Phillips, 1991):

$\mathrm{S}_{\mathrm{v}}\left(\mathrm{k}_{1}\right)=\mathrm{S}_{\mathrm{w}}\left(\mathrm{k}_{1}\right)=\frac{4}{3} \mathrm{~S}_{\mathrm{u}}\left(\mathrm{k}_{1}\right)$

onde $\mathrm{S}_{\mathrm{v}}$ e $\mathrm{S}_{\mathrm{w}}$ representam, respectivamente, as densidades espectrais das componentes lateral e vertical de velocidade.

O espectro de temperatura potencial e de outros escalares, tem a seguinte forma no subintervalo inercial:

$\mathrm{S}_{\theta}\left(\mathrm{k}_{1}\right)=\beta_{1} \varepsilon^{-1 / 3} \mathrm{~N}_{\theta} \mathrm{k}_{1}^{-5 / 3}$

onde $\mathrm{N}_{\theta}$ é a taxa de dissipação de metade da variância de temperatura potencial e $\beta_{1}$ é uma constante universal igual a 0,8 (Kaimal et al., 1976; Hogström, 1996).

Devido ao fato dos turbilhões observados na CLP serem estruturas espacialmente extensas, suas análises requer informações de muitos pontos no espaço. Em princípio, tais medidas seriam disponíveis se coletadas por aviões, mas grande parte dos dados micrometeorológicos existentes são derivados de medidas realizadas num ponto fixo no espaço em função do tempo (torres micrometeorológicas).

Para estabelecer uma relação entre as estatísticas temporais e espaciais, Taylor (1938) formulou a conhecida hipótese de Taylor ou frozen turbulence. Segundo tal hipótese, se a velocidade horizontal do vento $(\overline{\mathrm{U}})$ for suficientemente alta, as propriedades dos turbilhões quando advectados horizontalmente, sofrem alterações desprezíveis e as estatísticas temporais do escoamento turbulento podem ser consideradas equivalentes às estatísticas espaciais. Dessa forma, medidas temporais coletadas em um ponto fixo do espaço são equivalentes às medidas espacialmente distribuídas através das seguintes relações (Lumley e Panofsky, 1964; Kaimal e Finnigan, 1994): 
$\mathrm{x}=\overline{\mathrm{U}} \mathrm{t} \quad \mathrm{e} \quad \mathrm{k}_{1}=\mathrm{f} / \overline{\mathrm{U}}$

onde x e t são as coordenadas espacial e temporal, com x na direção da velocidade horizontal do vento, e f é a freqüência.

Contudo, se as flutuações das componentes de velocidade do vento forem maiores do que a velocidade horizontal do vento $\left(\mathrm{u}^{\prime}, \mathrm{v}^{\prime}, \mathrm{w}^{\prime}>>\overline{\mathrm{U}}\right)$ os turbilhões podem sofrer alterações significativas em suas propriedades, invalidando a aplicação da hipótese Taylor (Wyngaard e Clifford, 1977). Portanto, existem muitas incertezas quanto à utilização desta hipótese em condições altamente convectivas.

Nas últimas décadas, a realização de diversos experimentos de campo possibilitou uma melhor compreensão do comportamento espectral da turbulência na CLP sob diversas condições de estabilidade. Em um de seus trabalhos pioneiros, Panofsky (1969) realizou um estudo sobre o comportamento espectral das componentes de velocidade e mostrou que a região de baixa freqüência é influenciada pelas condições de estabilidade atmosférica, e os máximos espectrais das componentes horizontais de velocidade são invariantes com a altura. Esse resultado foi confirmado por Kaimal et al. (1976) que propôs que em condições convectivas, o comprimento de onda associado ao máximo espectral das componentes horizontais de velocidade $\left(\lambda_{\mathrm{m}}\right)_{\mathrm{u}, \mathrm{v}}$ é igual a $1,3 \mathrm{z}_{\mathrm{i}}$. As relações do subintervalo inercial também foram exploradas por Kaimal et al. (1972). Em um trabalho de revisão, Sorbjan (1986) discute a validade da teoria de similaridade local nas estimativas espectrais da CLP noturna.

Alguns trabalhos já demonstraram a capacidade do modelo LES em simular as propriedades espectrais da turbulência. Deardorff (1974) simulou o comportamento espectral das componentes de velocidade, temperatura potencial, umidade relativa e da flutuação de pressão em diferentes alturas da CLP. Apesar da baixa resolução da grade, na região do subintervalo inercial os espectros reproduziram a inclinação esperada $\left(\propto \mathrm{k}^{-5 / 3}\right)$, mas o fator de isotropia entre as componentes de velocidade excedeu o valor teórico de 4/3. Por outro lado, o comprimento de onda associado ao máximo espectral da componente vertical de velocidade esteve de acordo com as medidas realizadas por Lenschow (1970). Utilizando uma grade com resolução mais fina, Moeng e Wyngaard (1988) mostraram que as propriedades estatísticas da turbulência na região do subintervalo inercial são sensíveis ao tipo de filtro passa-baixa e ao 
modelo de subgrade adotado. As propriedades espectrais de uma CLP puramente convectiva foram exploradas por Schmidt e Schumann (1989) e seus resultados mostraram que as relações do subintervalo inercial não são totalmente reproduzidas pelo modelo LES em função das deficiências do modelo de subgrade. Eles também argumentaram sobre a possibilidade das flutuações de pressão não serem suficientes para garantir a isotropia local das componentes de velocidade nessas escalas. Manson e Brown (1999) realizaram um estudo detalhado sobre o comportamento dos espectros de ECT variando as resoluções da grade e as escalas de comprimento do modelo de subgrade. Eles concluíram que o modelo de subgrade determina a extensão do subintervalo inercial. Os trabalhos de Peltier et al. (1996) e de Lin (2000) também discutem estimativas espectrais obtidas através do modelo LES, mas apenas como forma de caracterizar os escoamentos turbulentos por eles simulados.

Contudo, em nenhum dos trabalhos citados acima foram obtidas estimativas espectrais temporais e espaciais conjuntamente. Dessa forma, um dos objetivos desse trabalho é utilizar o modelo LES para investigar as propriedades espectrais das componentes de velocidade do vento em condições altamente convectivas e sobre uma superfície horizontalmente homogênea, tanto no espaço de fase (espectro espacial) quanto no espaço de freqüência (espectro temporal). Para a temperatura potencial e concentração de poluente serão estimados apenas os espectros espaciais.

As análises dos espectros espaciais das componentes de velocidade, além de possibilitarem a identificação das diferentes escalas dos turbilhões que atuam nos escoamentos turbulentos da CLP convectiva, servem para avaliar a sensibilidade do modelo LES ao filtro passa-baixa e as parametrizações da escala de subgrade (Deardorff, 1974; Moeng e Wyngaard, 1988; Manson e Brown, 1999).

Essa parte do trabalho constitui também, uma importante etapa de validação do desempenho do modelo LES, pois os resultados simulados serão comparados com os prognósticos da teoria do equilíbrio universal e com alguns resultados apresentados na literatura para CLP em condições convectivas. Vale ressaltar, que poucos trabalhos na literatura exploram as características dos espectros temporais e espaciais simultaneamente (Kaimal et al., 1982), principalmente em condições de estabilidade altamente convectivas, o que fornece um caráter inovador a esse estudo. 
Não se espera que os espectros turbulentos obtidos por meio de simulações numéricas consigam resolver as menores escalas dos escoamentos turbulentos, pois os valores obtidos em cada ponto da grade representam os valores médios sobre o intervalo $\Delta x$. Para que o modelo LES seja capaz de reproduzir os prognósticos teóricos derivados por Kolmogorov, a resolução numérica da grade deve ser suficientemente grande para resolver uma parte significativa do subintervalo inercial do espectro turbulento (Schmidt e Schumann, 1989).

\subsection{1 - Espectros espaciais}

As estimativas espectrais espaciais das componentes de velocidade são obtidas a partir do conjunto de simulações descrito na Tabela 3.1. A metodologia utilizada foi proposta por Moeng e Wyngaard (1988) e descrita em detalhes na seção 3.1. Como a FFT requer que o número total de pontos da série seja uma potência de 2, as densidades espectrais são estimadas com base em campos bidimensionais com $64\left(2^{6}\right)$ pontos de grade nas direções x e y, centrados na grade original de $80^{3}$ ou $96^{3}$. Como os dados são amostrados de forma discreta, o menor comprimento de onda resolvido pelo modelo é igual $2 \Delta \mathrm{x}$, definido como o número de onda de Nyquist (Stull, 1988; Kaimal e Finnigan, 1994).

Os espectros espaciais são obtidos para cada um dos planos horizontais inseridos na CLP e as suas variações verticais serão apresentadas nos mesmos níveis onde foram coletados os sinais temporais (ver Fig. 3.2). Nos casos HC1 e HC2 foram feitas amostragem de sinais turbulentos em cinco níveis verticais $\left[\mathrm{z} \approx(0,2: 0,1: 0,6) \mathrm{z}_{\mathrm{i}}\right]$, contra nove níveis $\left[\mathrm{z} \approx(0,1: 0,1: 0,9) \mathrm{z}_{\mathrm{i}}\right]$ nos demais casos (HC3, DA1 e DA2). Os espectros espaciais apresentados são obtidos a partir de uma média dos espectros de cinco planos horizontais, centrados no nível de amostragem.

O número de onda máximo $\left(\mathrm{k}_{\mathrm{x}, \mathrm{y}}\right)_{\max }$ e o mínimo $\left(\mathrm{k}_{\mathrm{x}, \mathrm{y}}\right)_{\min }$ resolvidos pelo modelo LES são funções da resolução da grade e da extensão do domínio, e, portanto, estão compreendidos nos seguintes intervalos:

$$
5,03 \times 10^{-2} \mathrm{~m}^{-1} \leq\left(\mathrm{k}_{\mathrm{x}, \mathrm{y}}\right)_{\max } \leq 6,03 \times 10^{-2} \mathrm{~m}^{-1} \text { e } 1,60 \times 10^{-3} \mathrm{~m}^{-1} \leq\left(\mathrm{k}_{\mathrm{x}, \mathrm{y}}\right)_{\min } \leq 1,90 \times 10^{-3} \mathrm{~m}^{-1}
$$

onde os subscritos x e y representam as direções longitudinal e lateral, respectivamente.

De forma similar, os comprimentos de onda resolvidos são: 


$$
104 \mathrm{~m} \leq\left(\lambda_{\mathrm{x}, \mathrm{y}}\right)_{\min } \leq 125 \mathrm{~m} \quad \text { e } 3307 \mathrm{~m} \leq\left(\lambda_{\mathrm{x}, \mathrm{y}}\right)_{\max } \leq 3927 \mathrm{~m}
$$

Primeiramente, serão verificados os prognósticos da lei do equilíbrio universal para a região do subintervalo inercial dos espectros simulados por meio de estimativas do valor da constante de Kolmogorov. As propriedades da região de produção dos espectros turbulentos serão discutidas posteriormente.

$\mathrm{Na}$ Fig. (4.15) os espectros espaciais adimensionais das componentes de velocidade na direção longitudinal $\left(\mathrm{k}_{\mathrm{x}}\right)$ são apresentados para cinco alturas adimensionais $\left[\mathrm{z} \approx(0,2: 0,1: 0,6) \mathrm{z}_{\mathrm{i}}\right]$, em conjunto com os prognósticos para o subintervalo inercial (Eqs. 4.2 e 4.3) considerando $\alpha_{K}=0,50$. Para uma melhor visualização, as densidades espectrais das componentes de velocidade foram multiplicadas por potências de 10 .

Em todas as alturas ocorre uma boa convergência dos espectros das componentes de velocidade, principalmente nas freqüências mais altas uma vez que os valores da taxa de dissipação estimados pela Eq. (2.14) são equivalentes.

A componente longitudinal de velocidade $\mathrm{k}_{\mathrm{x}} \mathrm{S}_{\mathrm{u}}\left(\mathrm{k}_{\mathrm{x}}\right) / \mathrm{w}_{*}^{2}$ (Fig. 4.15a) apresenta uma região bem definida com inclinação proporcional a $\mathrm{k}^{-2 / 3}$ e número de onda máximo resolvido da ordem de $\left(\mathrm{k}_{\mathrm{x}} \mathrm{z}_{\mathrm{i}} / 2 \pi\right)_{\max } \approx 7,3(\approx 3 \Delta \mathrm{x})$, ou $\left(\lambda_{\mathrm{x}}\right)_{\min } \approx 157 \mathrm{~m}$, inferior ao número de onda máximo resolvido pelo modelo LES $(\propto 2 \Delta x)$. Segundo Manson e Brown (1999) este problema de resolução é ocasionado pelo modelo de subgrade e para eliminá-lo seria necessário reduzir a escala do filtro passa-baixa para aumentar extensão do subintervalo inercial resolvido. Porém, tal redução na escala do filtro geraria um aumento significativo do custo computacional do modelo LES.

Vale salientar, que a realização de simulações com $128^{3}$ pontos de grade nas direções x e y permitiriam resolver um número maior de ondas pela FFT e conseqüentemente, a obtenção de um subintervalo inercial mais extenso. Porém, esse aumento na resolução da grade ocasionaria em um aumento do tempo das simulações, inviabilizando a realização de parte dos experimentos numéricos.

Os espectros da componente lateral de velocidade $\mathrm{k}_{\mathrm{x}} \mathrm{S}_{\mathrm{v}}\left(\mathrm{k}_{\mathrm{x}}\right) / \mathrm{w}_{*}^{2}$ (Fig 4.15b) apresentam uma região com inclinação proporcional a $\mathrm{k}^{-2 / 3}$, sendo que nas escalas menores esta inclinação é 
mais acentuada. Contudo a relação de isotropia não é satisfeita e seu valor ficou abaixo do esperado, como será visto posteriormente.
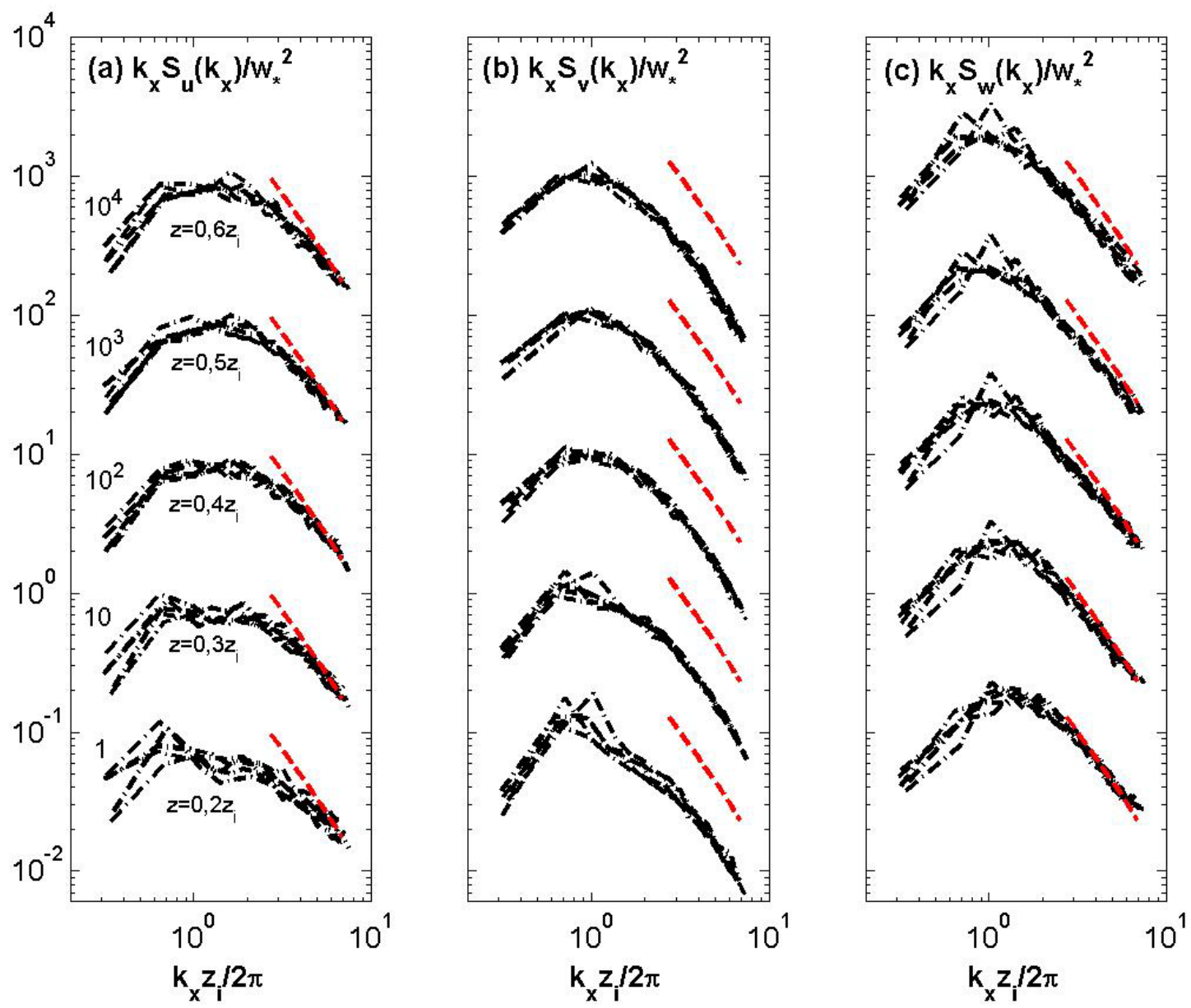

Fig. 4.15 - Variação vertical dos espectros espaciais das componentes de velocidade na direção x: (a) longitudinal; (b) lateral; (c) vertical. Para melhor visualização, os espectros foram multiplicados por potências de 10, mostradas no lado esquerdo de (a). A linha tracejada em vermelho representa as Eqs. (4.2) e (4.3), considerando $\alpha_{\mathrm{k}}=0,50$ para componente longitudinal e $\alpha_{\mathrm{k}}=(4 / 3) 0,50$ para as demais componentes de velocidade.

Os espectros da componente vertical $\mathrm{k}_{\mathrm{x}} \mathrm{S}_{\mathrm{w}}\left(\mathrm{k}_{\mathrm{x}}\right) / \mathrm{w}_{*}^{2}$ (Fig 4.15c) reproduzem os prognósticos esperados na região do subintervalo inercial e respeitam a relação de isotropia nas escalas menores. 
Na Fig. (4.16) são apresentadas ás variações das estimativas da constante de Kolmogorov $\alpha_{k}$ em função de $k_{x} z_{i} / 2 \pi$ para cada uma das componentes de velocidade, de acordo com as Eqs. (4.2) e (4.3). O valor médio de $\alpha_{\mathrm{k}}$ obtido de $\mathrm{S}_{\mathrm{u}}\left(\mathrm{k}_{\mathrm{x}}\right)$ (Fig 4.16a) é igual a 0,52 em um extenso intervalo de números de onda, principalmente na região das escalas menores, e concorda com os valores $\alpha_{k}=0,50$ sugeridos por Moeng e Wyngaard (1988), $\alpha_{k}=0,52$ por Schmidt e Schumann (1989) e $\alpha_{\mathrm{k}}=0,52 \pm 0,02$ por Hogström (1996).
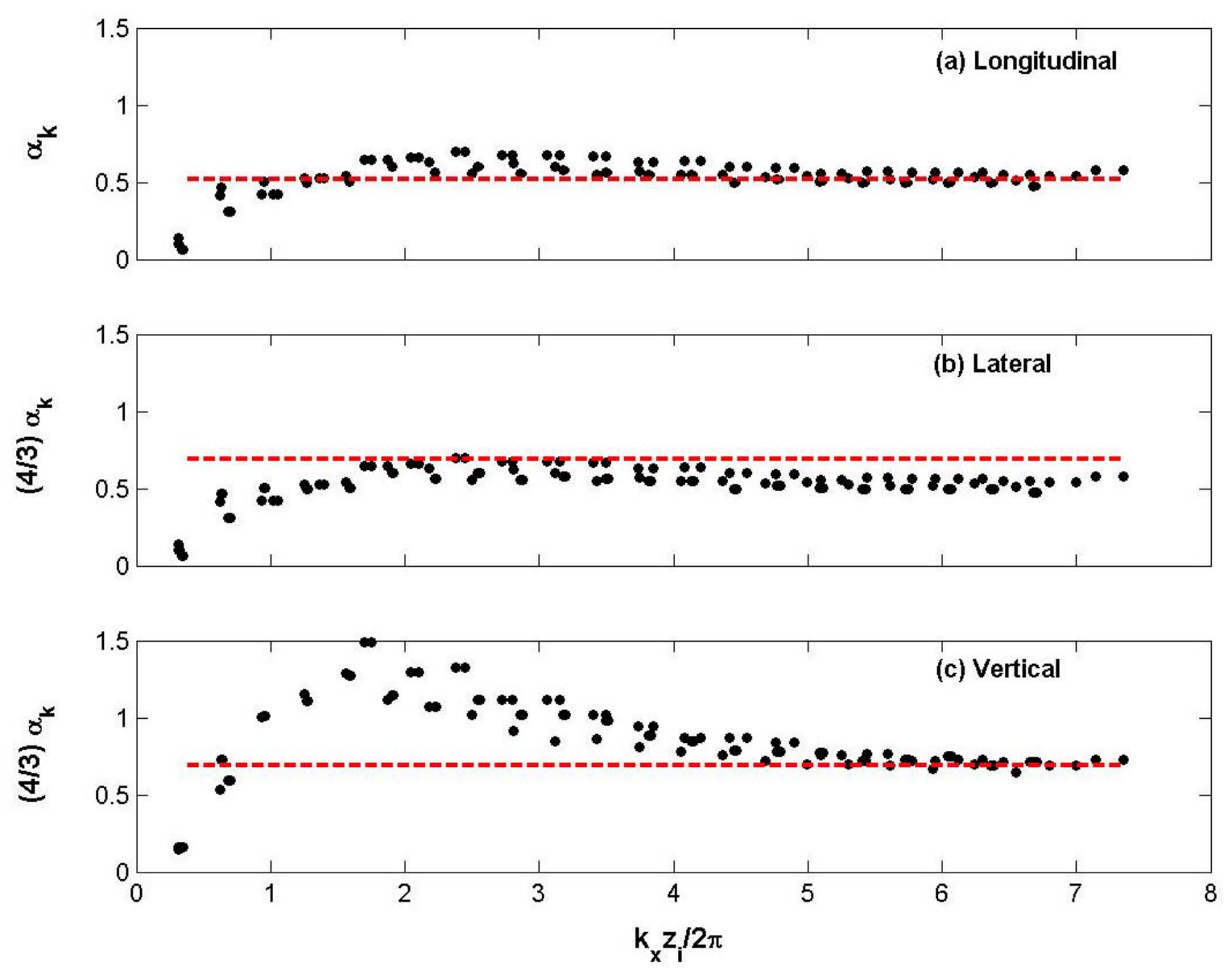

Fig. 4.16 - Valores médios da constante de Kolmogorov $\alpha_{\mathrm{k}}$ estimados através dos espectros das componentes de velocidade na direção x: (a) espectro longitudinal; (b) espectro lateral; (c) espectro vertical. A linha tracejada em vermelho representa a Eq. (4.2) considerando $\alpha_{k}=0,52$. 
Por outro lado, a razão entre $\mathrm{S}_{\mathrm{v}}\left(\mathrm{k}_{\mathrm{x}}\right) / \mathrm{S}_{\mathrm{u}}\left(\mathrm{k}_{\mathrm{x}}\right)$ está abaixo do valor previsto pela relação de isotropia $\left[(4 / 3) \alpha_{k}\right]$ (Fig. 4.16b). De acordo com Mestayer (1982) existem evidências experimentais de que isotropia local ocorre somente nas pequenas escalas do subintervalo inercial. Portanto, seria necessária uma resolução espacial maior para reproduzir tais características (Moeng e Wyngaard, 1988). Além desses fatores, Schmidt e Schumann (1989) ao simular as características espectrais da CLP convectiva argumentaram que as flutuações de pressão geradas pelo modelo LES são insuficientes para assegurar a condição de isotropia na região do subintervalo inercial.

Com relação a componente vertical é possível observar que nas escalas menores a razão $\mathrm{S}_{\mathrm{w}}\left(\mathrm{k}_{\mathrm{x}}\right) / \mathrm{S}_{\mathrm{u}}\left(\mathrm{k}_{\mathrm{x}}\right)$ (Fig. 4.16c) tende ao valor previsto pela relação de isotropia na região do subintervalo inercial $\left[(4 / 3) \alpha_{\mathrm{K}} \approx 0,69\right]$.

As estimativas espectrais na direção lateral $\left(\mathrm{k}_{\mathrm{y}}\right)$ (não mostradas) não apresentam nenhuma diferença significativa se comparada aos espectros obtidos para direção longitudinal $\left(\mathrm{k}_{\mathrm{x}}\right)$, a não ser o fato de que $\mathrm{k}_{\mathrm{y}} \mathrm{S}_{\mathrm{v}}\left(\mathrm{k}_{\mathrm{y}}\right) / \mathrm{w}_{*}^{2}$ tem mais energia se comparado a $\mathrm{k}_{\mathrm{y}} \mathrm{S}_{\mathrm{u}}\left(\mathrm{k}_{\mathrm{y}}\right) / \mathrm{w}_{*}^{2}$ por estar alinhado a direção lateral do vento horizontal. Porém, a razão de isotropia $\mathrm{S}_{\mathrm{v}}\left(\mathrm{k}_{\mathrm{y}}\right) / \mathrm{S}_{\mathrm{u}}\left(\mathrm{k}_{\mathrm{y}}\right)$ continua subestimada.

Esses resultados comprovam a capacidade do modelo LES em resolver turbilhões com escalas de comprimento pertencentes à região do subintervalo inercial do espectro turbulento, e reproduzem satisfatoriamente os prognósticos estabelecidos pela lei do equilíbrio universal para as componentes longitudinal e vertical de velocidade.

\subsection{2 - Escala de comprimento associada aos espectros espaciais}

A escala de comprimento dos turbilhões mais energéticos é uma escala característica do escoamento turbulento e fornece informações importantes sobre o comportamento da turbulência na CLP. O seu conhecimento é de vital importância na caracterização dos transportes turbulentos na CLP convectiva. Uma das formas utilizadas para estimá-la é por 
meio da determinação do comprimento de onda associado ao máximo das densidades espectrais adimensionais das componentes de velocidade $\left(\lambda_{m}\right)$ (Kaimal, 1973).

Desse modo, as estimativas espectrais adimensionais das componentes de velocidade obtidas com o modelo LES e discutidas na acima, serão utilizadas para determinar a variação vertical de $\lambda_{\mathrm{m}}$ na CLP convectiva. Para que $\lambda_{\mathrm{m}}$ seja estimado com precisão é necessário determinar a posição exata do máximo espectral, e por conseqüência, do número de onda adimensional associado. Existem duas maneiras distintas de obter $\lambda_{\mathrm{m}}$. A primeira, através do ajuste de uma curva espectral as estimativas da região de produção dos espectros turbulentos velocidade geradas pelo modelo LES. A segunda, por meio da verificação visual do máximo.

Kaimal (1978) sugere que na região de produção os espectros turbulentos das componentes horizontais de velocidade são adequadamente representados pela seguinte função:

$\frac{\mathrm{k}_{\mathrm{x}, \mathrm{y}} \mathrm{S}_{\mathrm{u}, \mathrm{v}}\left(\mathrm{k}_{\mathrm{x}, \mathrm{y}}\right)}{\sigma_{\mathrm{h}}^{2}}=\frac{\mathrm{k}_{\mathrm{i}}}{\left(1+\mathrm{Ak}_{\mathrm{i}}^{5 / 3}\right)}$

onde $\mathrm{k}_{\mathrm{i}}=\mathrm{k}_{\mathrm{x}, \mathrm{y}} \mathrm{z}_{\mathrm{i}} / 2 \pi$ é o número de onda adimensional, $\sigma_{\mathrm{h}}^{2}=\left(\mathrm{u}^{\prime 4}+\mathrm{v}^{\prime 4}\right)^{1 / 2}$ é variância horizontal média e A é o parâmetro de ajuste a ser determinado. No trabalho de Kaimal (1978) o valor estimado do parâmetro A foi igual a 3,1.

Nesse trabalho, a determinação do parâmetro A é feita através da utilização do algoritmo Simplex n-D (Press et al., 1986) para ajustar a curva descrita pela Eq. (4.6) as estimativas espectrais geradas pelo modelo LES. A principal vantagem desse algoritmo consiste em não requerer o cálculo de derivadas em relação às incógnitas para definir as direções de otimização, o que reduz significativamente possíveis erros de truncamento (Karam e Marques Filho, 2004).

Para efeito ilustrativo do ajuste são apresentados nas Figs. (4.17a e 4.17b, 4.18a e 4.18b) os espectros turbulentos adimensionais das componentes horizontais de velocidade, $\mathrm{k}_{\mathrm{x}} \mathrm{S}_{\mathrm{u}}\left(\mathrm{k}_{\mathrm{x}}\right) / \sigma_{\mathrm{h}}^{2}$ e $\mathrm{k}_{\mathrm{y}} \mathrm{S}_{\mathrm{v}}\left(\mathrm{k}_{\mathrm{y}}\right) / \sigma_{\mathrm{h}}^{2}$, em diferentes níveis verticais, para os dois casos mais convectivos HC2 e DA2, respectivamente. É possível observar que o algoritmo Simplex é capaz de ajustar com boa precisão a curva definida pela Eq. (4.6) a região de produção dos espectros turbulentos. O decaimento mais pronunciado dos espectros estimados pelo LES na 
região do subintervalo inercial está relacionado à falta de resolução da grade, que não é capaz de resolver estruturas espaciais com escalas de comprimento inferiores a 100 metros (Kaiser e Fedorovich, 1998). Portanto, para as componentes horizontais de velocidade, a posição dos máximos espectrais será estimada com base nessas curvas ajustadas pelo método Simplex.

(a) Componente Longitudinal
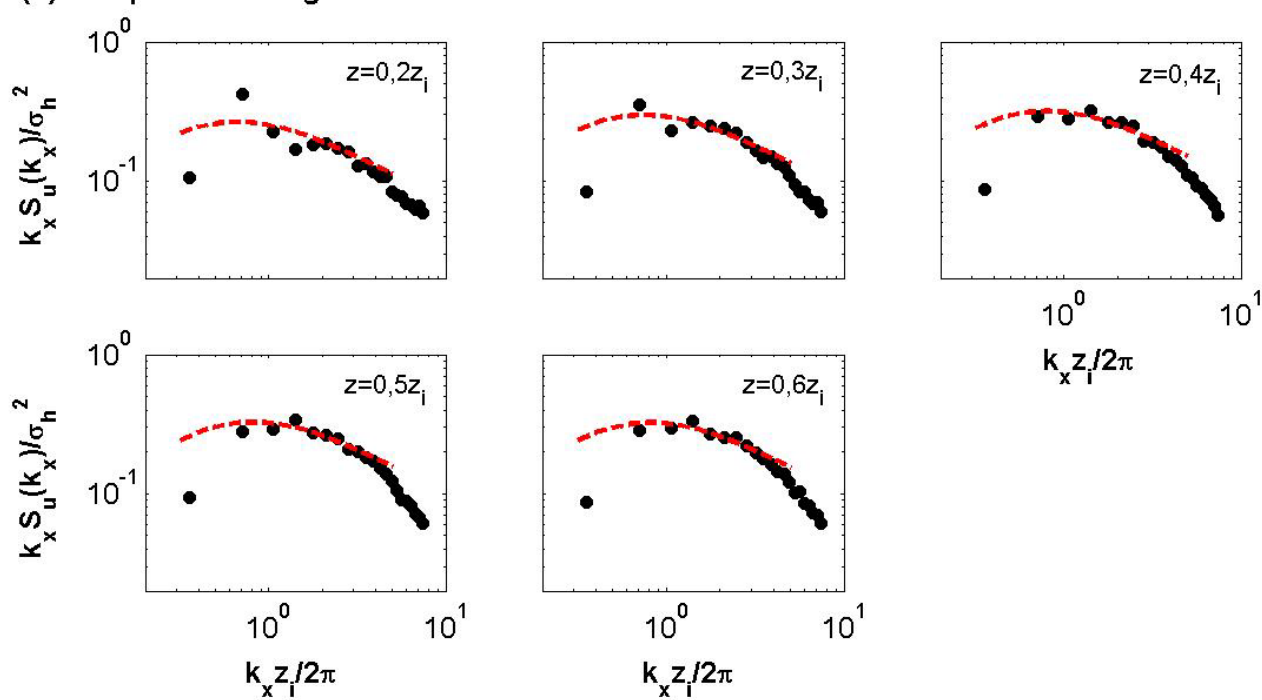

$k_{x} z_{i} / 2 \pi$

(b) Componente Lateral
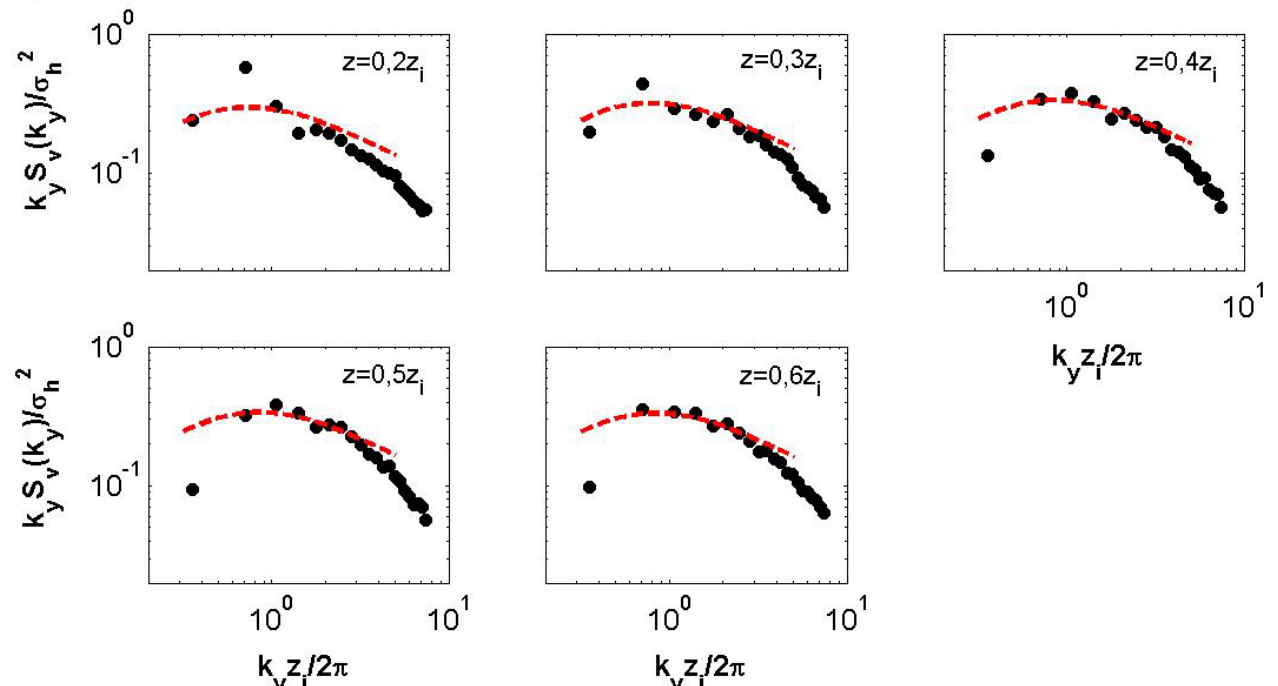

$k_{y} z_{i} / 2 \pi$

Fig. 4.17 - Espectros espaciais adimensionais das componentes de velocidade em diferentes níveis verticais para o caso HC2: (a) longitudinal; (b) lateral; (c) vertical. A linha tracejada em vermelho representa a curva de ajuste proposta por Kaimal (1978) e dada pela Eq.(4.6). 
(c) Componente vertical
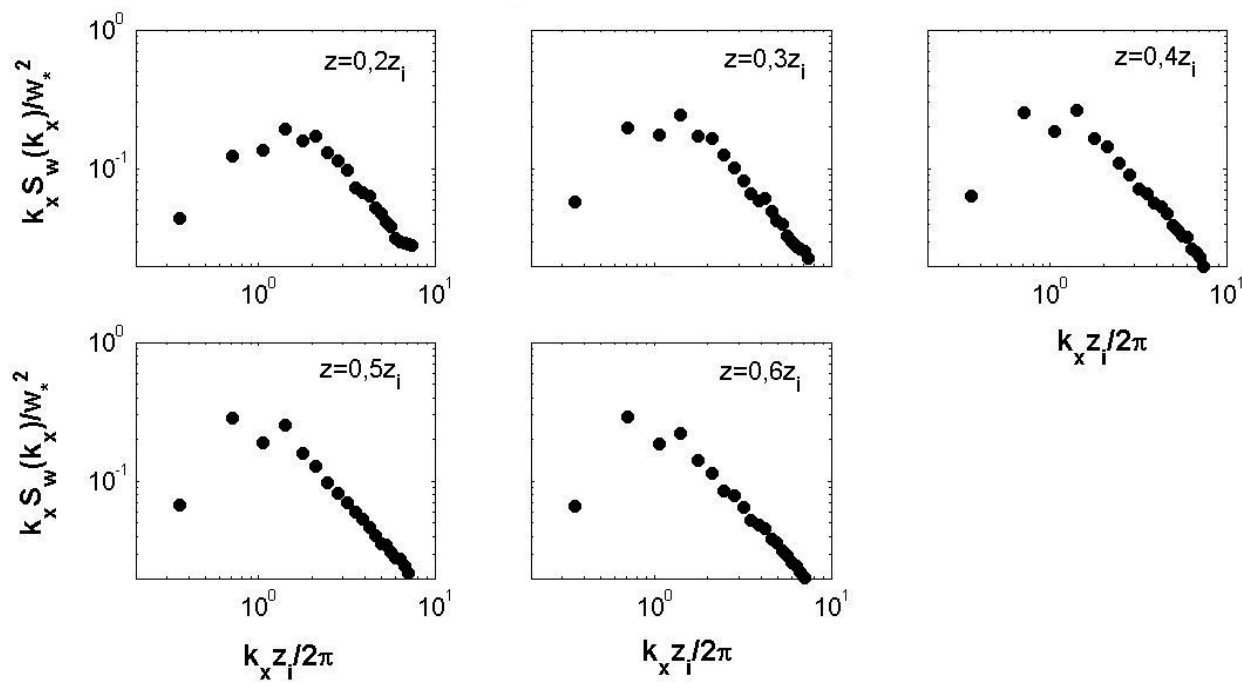

Fig. 4.17 - Continuação

(a) Componente Longitudinal
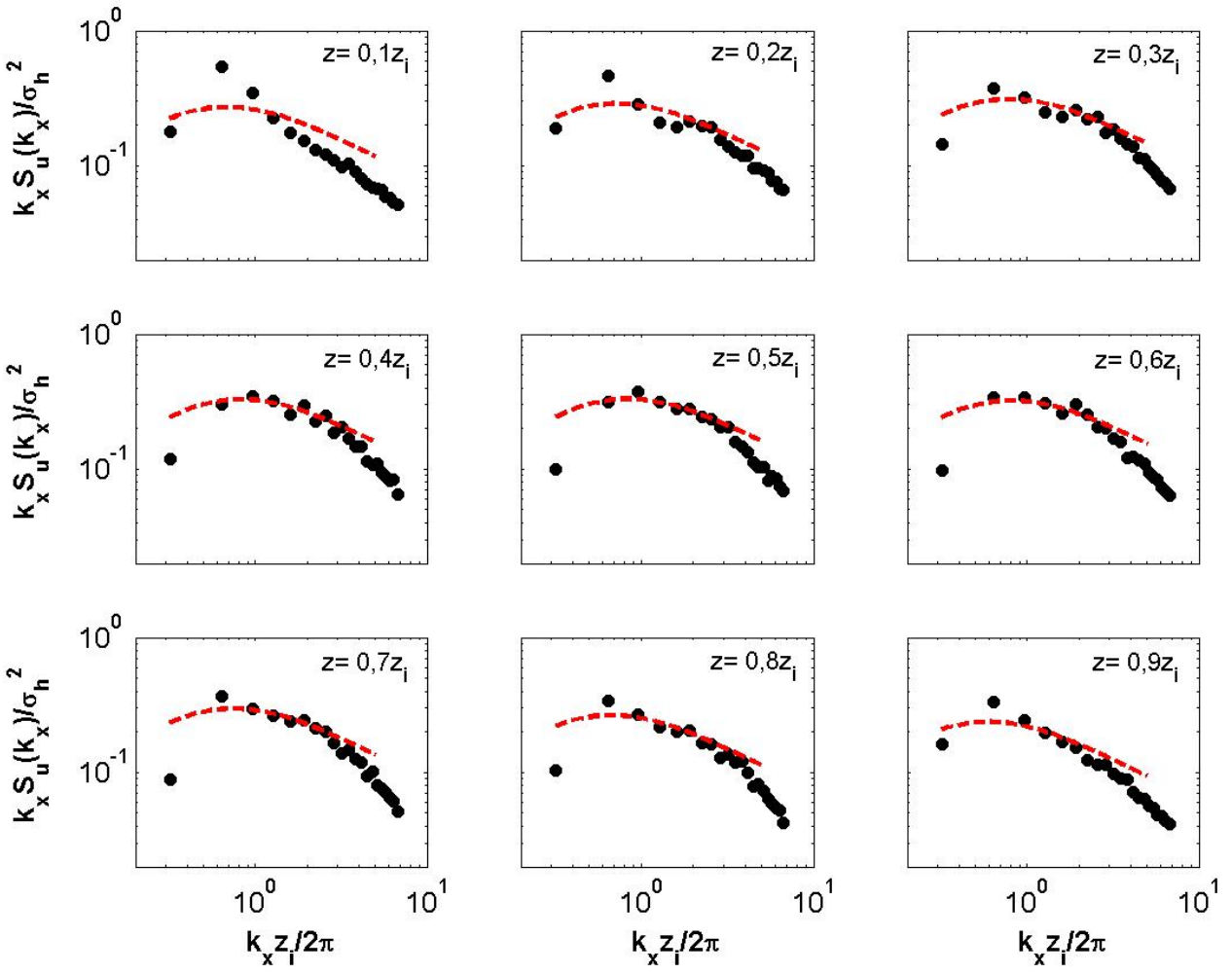

Fig. 4.18 - Similar a Fig. (4.17), mas para o caso DA2. 
(b) Componente Lateral
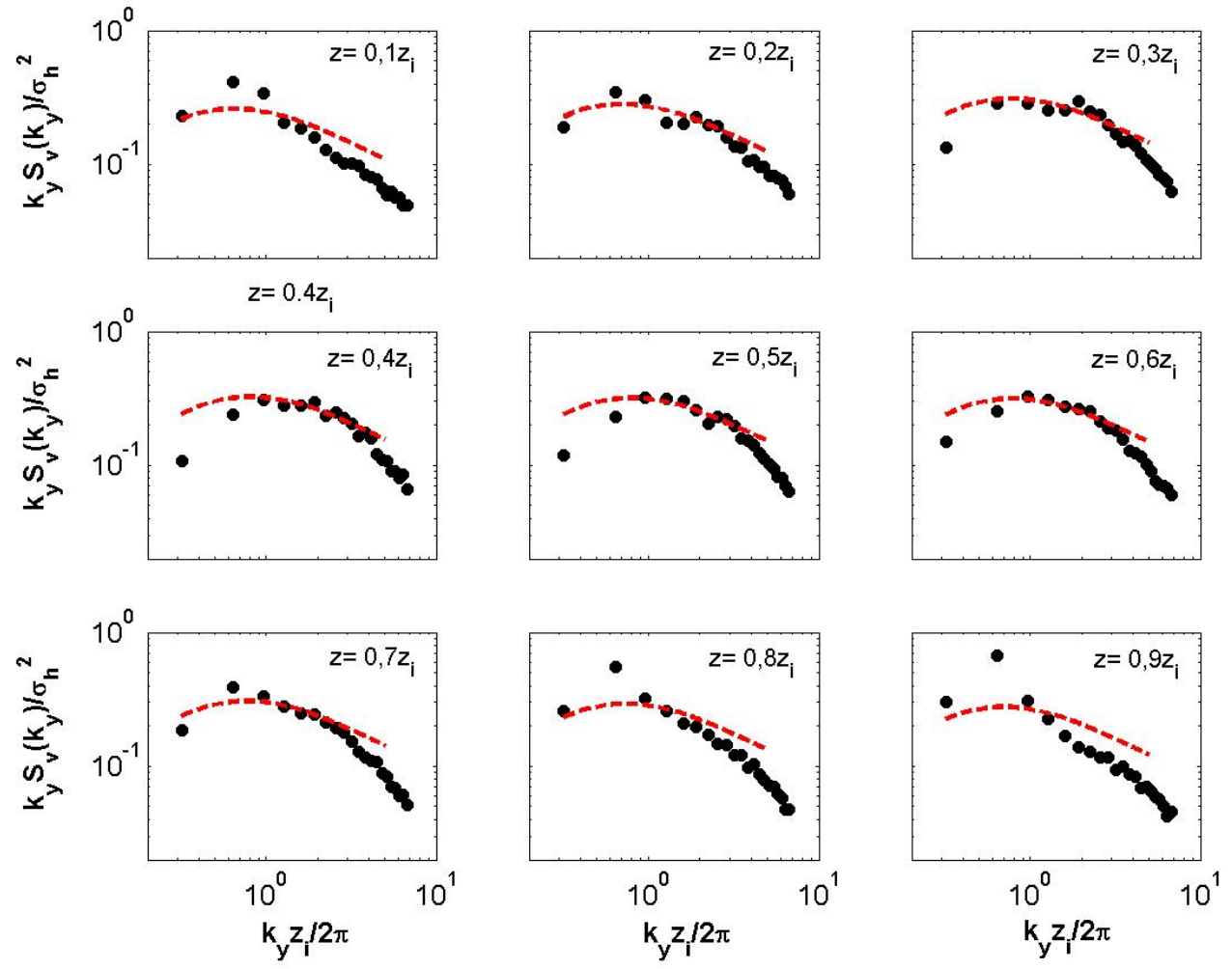

(c) Componente Vertical
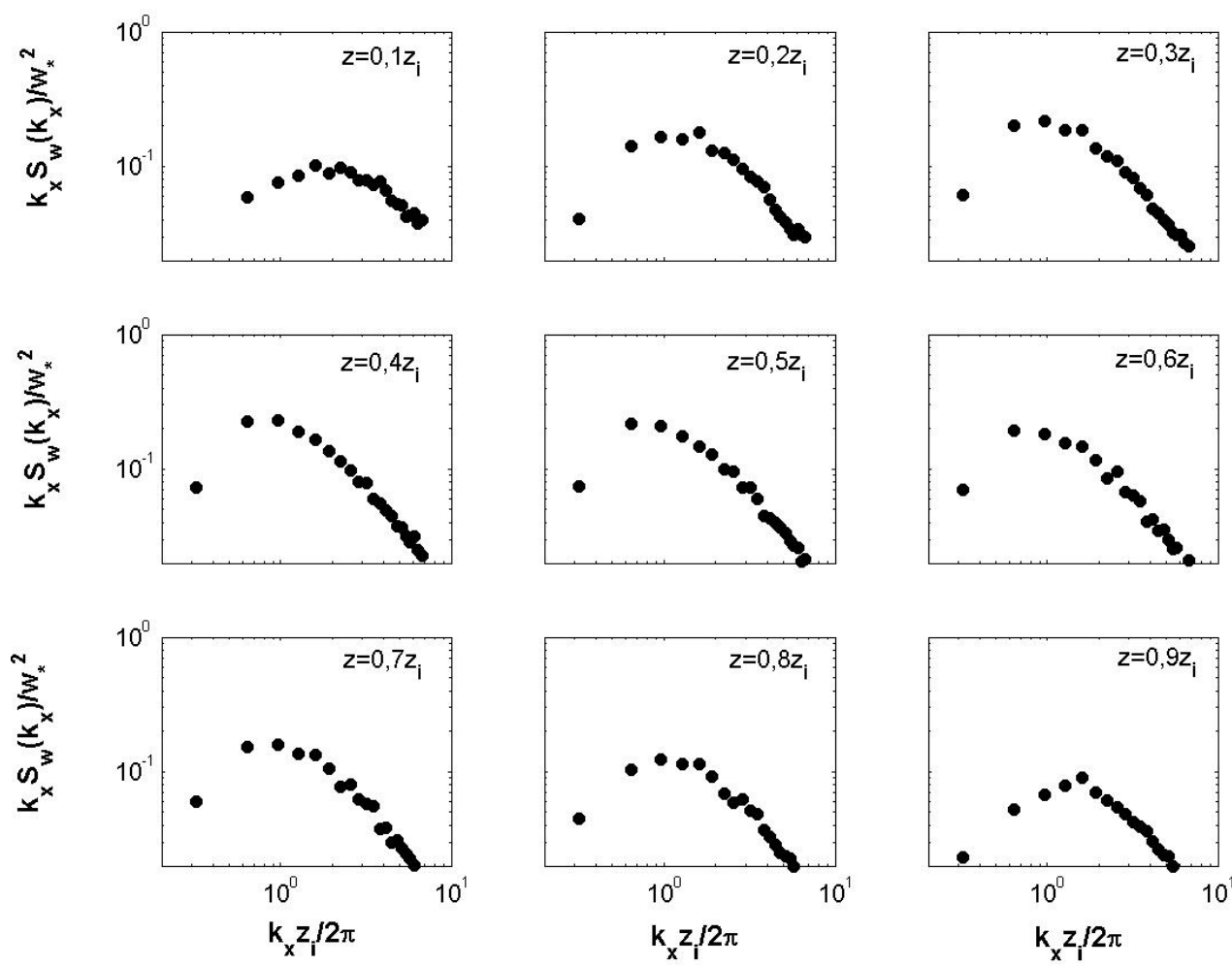

Fig. 4.18 - Continuação. 
Uma curva espectral similar a Eq. (4.6) foi utilizada na tentativa de representar a região de produção de $\mathrm{k}_{\mathrm{x}} \mathrm{S}_{\mathrm{w}}\left(\mathrm{k}_{\mathrm{x}}\right) / \mathrm{w}_{*}^{2}$. Porém, tal procedimento não se mostrou satisfatório em virtude da sensibilidade dos espectros verticais as diferentes leis de escala da CLP convectiva e a ocorrência de dois máximos em alguns espectros adimensionais $\mathrm{k}_{\mathrm{x}} \mathrm{S}_{\mathrm{w}}\left(\mathrm{k}_{\mathrm{x}}\right) / \mathrm{w}_{*}^{2}$ entre os níveis verticais $0,3 \mathrm{z}_{\mathrm{i}} \leq \mathrm{z} \leq 0,6 \mathrm{z}_{\mathrm{i}}$ (ver por exemplo, Fig. 4.17c). Esses máximos são persistentes e parecem refletir estruturas de grande escala do escoamento turbulento, correspondentes aos comprimentos de onda da ordem de $0,7 z_{\mathrm{i}}$ e $1,4 \mathrm{z}_{\mathrm{i}}$. Resultados similares foram encontrados por Schimdt e Schumann (1989) e por Kaiser e Fedorovich (1998), que associaram a ocorrência de tais máximos às escalas de comprimento típicas produzidas pelos downdrafts e updrafts. Portanto, os máximos espectrais de $\mathrm{k}_{\mathrm{x}} \mathrm{S}_{\mathrm{w}}\left(\mathrm{k}_{\mathrm{x}}\right) / \mathrm{w}_{*}^{2}$ serão estimados através da verificação visual de (Fig. 4.17c e 4.18c).

Os resultados obtidos por Kaimal et al. (1976) mostraram que as escalas características relacionadas as componentes horizontais de velocidade $\left(\lambda_{\mathrm{m}}\right)_{\mathrm{u}, \mathrm{v}}$ são invariantes com a altura na camada de mistura e seu valor médio é igual a $1,3 \mathrm{z}_{\mathrm{i}}$.

A variação vertical do comprimento de onda adimensional associado ao máximo espectral espacial das componentes longitudinal $\left(\lambda_{\mathrm{m}}\right)_{\mathrm{u}} / \mathrm{z}_{\mathrm{i}}$ e lateral $\left(\lambda_{\mathrm{m}}\right)_{\mathrm{v}} / \mathrm{z}_{\mathrm{i}}$ de velocidade, em ambas as direções ( $k_{x}$ e ky $)$, são apresentadas nas Figs. (4.19a) e (4.19b), respectivamente.

Os valores estimados de $\left(\lambda_{\mathrm{m}}\right)_{\mathrm{u}, \mathrm{v}} / \mathrm{z}_{\mathrm{i}}$ na camada de mistura $\left(0,2 \mathrm{z}_{\mathrm{i}} \leq \mathrm{z} \leq 0,8 \mathrm{z}_{\mathrm{i}}\right)$, $\left\{\left(\lambda_{\mathrm{m}}\right)_{\mathrm{u}, \mathrm{v}}\right\}_{\mathrm{CM}}=(1,29 \pm 0,01) \mathrm{z}_{\mathrm{i}}$, estão em acordo com o valor médio sugerido por Kaimal et al. (1976), igual a $1,3 \mathrm{z}_{\mathrm{i}}$. Próximo à superfície $\left(\mathrm{z}<0,2 \mathrm{z}_{\mathrm{i}}\right)$ e também junto ao topo $\left(\mathrm{z}>0,8 \mathrm{z}_{\mathrm{i}}\right)$ nota-se um pequeno espalhamento das estimativas de $\left(\lambda_{\mathrm{m}}\right)_{\mathrm{u}, \mathrm{v}} / \mathrm{z}_{\mathrm{i}}$.

Próximo à superfície o espalhamento está associado ao maior cisalhamento do vento (Fig. 4.2a), que contribui para o aumento da energia das flutuações de velocidade (Kaiser e Fedorovich, 1998). Junto ao topo, o entranhamento influencia consideravelmente as propriedades espectrais das componentes de velocidade e as escalas características da camada de mistura podem não ser adequadas para adimensionalizar os espectros nessa região. 
A determinação do comprimento de onda associado ao máximo do espectro espacial da componente vertical de velocidade $\left(\lambda_{\mathrm{m}}\right)_{\mathrm{w}}$ é de grande importância, uma vez que em condições convectivas as propriedades da CLP são transportadas de forma mais eficiente na direção vertical (Kaimal et al., 1976; Hanna, 1984; Bernard-Trottolo et al., 2004).
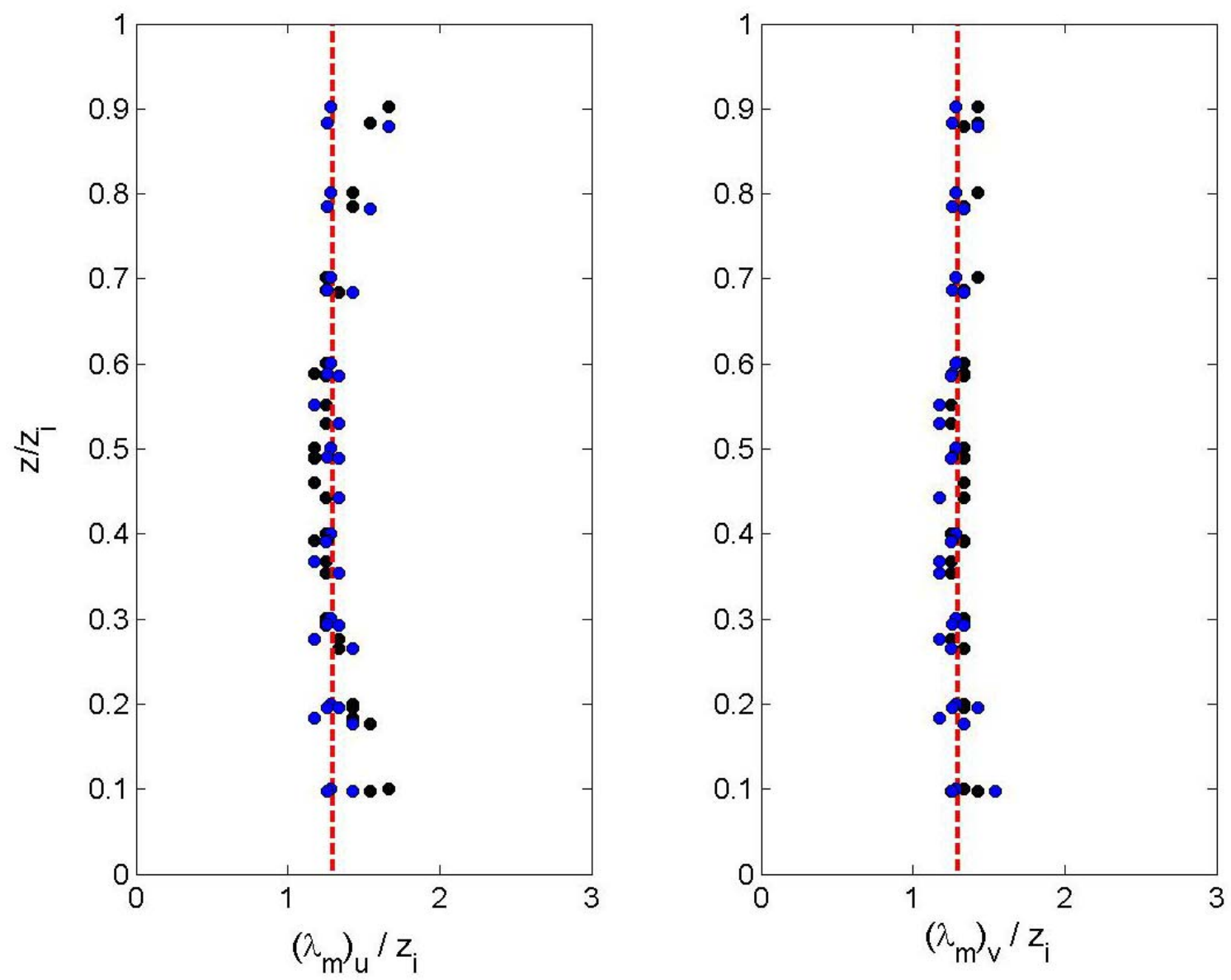

Fig. 4.19 - Comprimento de onda associado ao máximo espectral das componentes horizontais de velocidade: (a) longitudinal; (b) lateral. Os círculos representam: (preto) estimativas na direção $\mathrm{k}_{\mathrm{x}} \mathrm{e}$ (azul) na direção $\mathrm{k}_{\mathrm{y}}$. A linha tracejada em vermelho é o valor $\left(\lambda_{\mathrm{m}}\right)_{\mathrm{u}, \mathrm{v}}=1,3 \mathrm{z}_{\mathrm{i}}$ sugerido por Kaimal et al. (1976).

A variação vertical de $\left(\lambda_{m}\right)_{w} / z_{i}$ para ambas as direções são apresentadas na Fig. (4.20). Observa-se que na metade inferior da CLP convectiva, $\left(\lambda_{\mathrm{m}}\right)_{\mathrm{w}} / \mathrm{z}_{\mathrm{i}}$ aumenta rapidamente com a altura até alcançar um máximo de $\left\{\left(\lambda_{\mathrm{m}}\right)_{\mathrm{w}}\right\}=1,1 \mathrm{z}_{\mathrm{i}}$ em $\mathrm{z} \approx 0,5 \mathrm{z}_{\mathrm{i}}$, muito próximo do nível de 
máxima variância vertical $\left(\mathrm{z} \approx 0,4 \mathrm{z}_{\mathrm{i}}\right)$. A diminuição de $\left(\lambda_{\mathrm{m}}\right)_{\mathrm{w}} / \mathrm{z}_{\mathrm{i}}$ na parte superior da CLP está relacionada a redução do número e da dimensão dos updrafts, ocasionado pelas influências da camada de entranhamento e conseqüentemente pelo aumento da região ocupada pelos downdrafts. Esses resultados estão consistentes com os perfis verticais de $\left(\left\langle\mathrm{w}^{\prime 2}\right\rangle+\left\langle\tau_{\mathrm{ww}}\right\rangle\right) / \mathrm{w}_{*}^{2}$ (como pode ser observado na Fig. 4.4b).

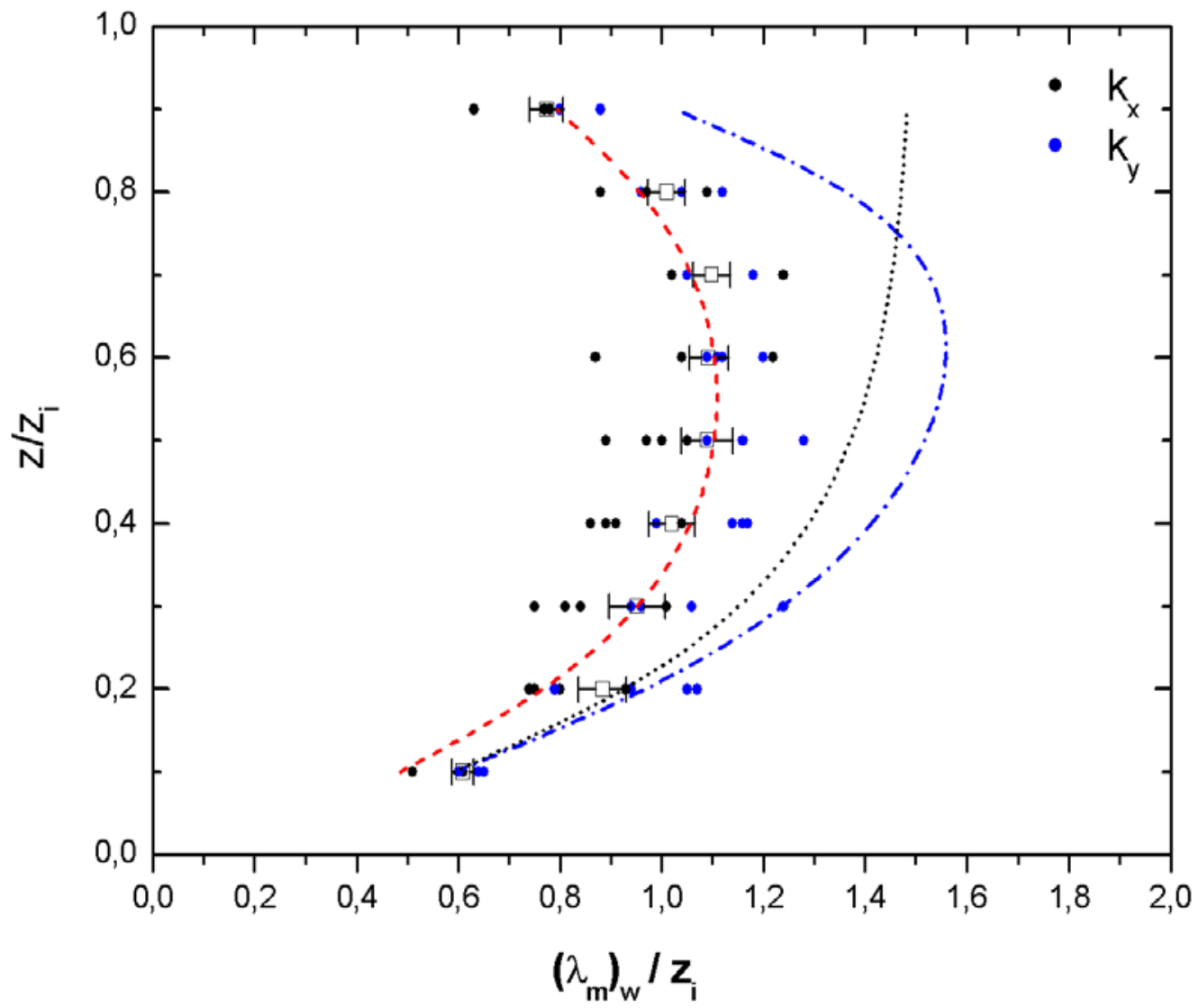

Fig. 4.20 - Comprimento de onda associado ao máximo espectral da componente vertical de velocidade. Os círculos representam: (preto) estimativas na direção $\mathrm{k}_{\mathrm{x}} \mathrm{e}$ (azul) na direção $\mathrm{k}_{\mathrm{y}}$. Os quadrados representam os valores médios em cada nível com suas respectivas barras de erro. As linhas representam as curvas propostas por: (pontilhada em preto) Kaimal et al. (1976); (tracejada em azul) Caughey e Palmer (1979); (tracejada em vermelho) proposta nesse trabalho, Eq. (4.7).

As estimativas de $\left(\lambda_{\mathrm{m}}\right)_{\mathrm{w}} / \mathrm{z}_{\mathrm{i}}$ são sistematicamente inferiores as curvas experimentais $\begin{array}{llll}\text { propostas } & \text { por } & \text { Caughey } & \text { Palmer }\end{array}$ (1979), 
$\left(\lambda_{\mathrm{m}}\right)_{\mathrm{w}}=1,8 \mathrm{z}_{\mathrm{i}}\left[1-\exp \left(-4 \mathrm{z} / \mathrm{z}_{\mathrm{i}}\right)-0,0003 \exp \left(-8 \mathrm{z} / \mathrm{z}_{\mathrm{i}}\right)\right]$, e por Kaimal et al. (1976), $\left(\lambda_{\mathrm{m}}\right)_{\mathrm{w}}=1,5 \mathrm{z}_{\mathrm{i}}\left[1-\exp \left(-5 \mathrm{z} / \mathrm{z}_{\mathrm{i}}\right)\right]$, por toda camada mistura com exceção dos valores mais próximos da CLS $\left(\mathrm{z} \approx 0,1 \mathrm{z}_{\mathrm{i}}\right)$.

Baseado em Caughey e Palmer (1979), uma nova formulação é proposta para representar a variação vertical de $\left(\lambda_{\mathrm{m}}\right)_{\mathrm{w}}$ na CLP altamente convectiva:

$$
\left(\lambda_{\mathrm{m}}\right)_{\mathrm{w}}=1,3 \mathrm{z}_{\mathrm{i}}\left[1-\exp \left(-4,8 \mathrm{z} / \mathrm{z}_{\mathrm{i}}\right)-0,005 \exp \left(-4,8 \mathrm{z} / \mathrm{z}_{\mathrm{i}}\right)\right]
$$

Os resultados apresentados na literatura apresentam algumas incertezas com relação a representação do comportamento de $\left(\lambda_{\mathrm{m}}\right)_{\mathrm{w}} / \mathrm{z}_{\mathrm{i}}$ na CLP convectiva. Por meio de experimentos numéricos realizados com o modelo LES, Deardorff (1974b) estimou $\left(\lambda_{\mathrm{m}}\right)_{\mathrm{w}} \approx 2 \mathrm{z}_{\mathrm{i}}$ entre $0,4 \mathrm{z}_{\mathrm{i}} \leq \mathrm{z} \leq 0,7 \mathrm{z}_{\mathrm{i}}$, o que está aproximadamente de acordo com as medidas de avião descritas por Lenschow (1970). Por outro lado, Kaimal et al. (1976) e Caughey e Palmer (1979) a partir de dados experimentais coletados em torre micrometeorológica mostraram que $\left(\lambda_{\mathrm{m}}\right)_{\mathrm{w}}$ varia com a altura, alcançando um valor máximo de aproximadamente $1,5 \mathrm{z}_{\mathrm{i}}$. O espalhamento dos perfis verticais de $\left(\lambda_{\mathrm{m}}\right)_{\mathrm{w}} / \mathrm{z}_{\mathrm{i}}$ pode ser verificado com clareza no trabalho de Kaiser e Fedorovich (1998), que compararam as estimativas experimentais com as simulações numéricas e encontraram na camada de mistura uma grande variação de $\left(\lambda_{\mathrm{m}}\right)_{\mathrm{w}}$, $0,7 \mathrm{z}_{\mathrm{i}}<\left(\lambda_{\mathrm{m}}\right)_{\mathrm{w}}<3,0 \mathrm{z}_{\mathrm{i}}$

Neste trabalho, um dos possíveis motivos da discordância entre os valores de $\left(\lambda_{\mathrm{m}}\right)_{\mathrm{w}} / \mathrm{z}_{\mathrm{i}}$ simulados e as curvas experimentais propostas por Kaimal et al. (1976) e Caughey e Palmer (1979), pode estar relacionado à incertezas na definição da posição do máximo espectral, pois os espectros variam exponencialmente com k e qualquer imprecisão na definição desse máximo pode gerar grandes erros nessas estimativas. Outro fator importante é a validade da hipótese de Taylor. Na maioria dos trabalhos sobre espectros, a hipótese de Taylor é utilizada para converter medidas temporais coletadas em um ponto fixo no espaço em medidas simultâneas distribuídas espacialmente.

Nas medidas temporais efetuadas em um ponto fixo do espaço (por exemplo, torre micrometeorológica) as escalas temporais maiores podem não corresponder necessariamente 
às escalas de comprimento maiores, pois a velocidade com que o escoamento passa pelo sensor de medida desempenha um papel importante na definição das escalas temporais mais energéticas que aparecem nos sinais turbulentos medidos (Marques Filho, 1999). Desse modo, a variabilidade temporal dos turbilhões no decorrer do tempo não deve ser, necessariamente, associada a uma variação similar na escala espacial dos mesmos (Mahrt, 1998).

Em 1938 Taylor postulou que, se a velocidade horizontal do vento $(\overline{\mathrm{U}})$ é suficientemente alta os grandes turbilhões podem não ter tempo de mudar suas características quando estão sendo advectados através de um ponto fixo do espaço (Lumley e Panosfky, 1964). Então, um turbilhão com escala de comprimento $l$ e escala de velocidade $u$ tem um tempo de vida da ordem de $l / u$ e é advectado através de um ponto fixo do espaço em um tempo $l / \bar{U}$. Portanto, espera-se que a hipótese de Taylor seja válida se o tempo de vida do turbilhão for muito maior que o tempo de advecção $(l / u>>l / \overline{\mathrm{U}})$, ou seja, $u / \overline{\mathrm{U}}<<1$. Esta condição é usualmente satisfeita em medidas realizadas por avião, mas pode falhar em diferentes regiões de números de onda para medidas coletadas em um ponto fixo do espaço (Wyngaard, 1985).

Uma maneira de verificar a validade da aplicação da hipótese de Taylor em uma CLP altamente convectivas é confrontar as escalas de comprimento dos turbilhões mais energéticos estimadas por meio dos espectros espaciais com as estimadas através dos espectros temporais.

\subsection{3 - Espectros temporais}

Como forma de verificar a validade da aplicação da hipótese de Taylor em escoamentos turbulentos em condições de estabilidade altamente convectivas serão efetuadas estimativas espectrais a partir de séries temporais das componentes de velocidade, coletadas em pontos fixos do espaço (ou seja, da grade numérica). Essas séries temporais representam as medidas obtidas experimentalmente por uma torre micrometeorológica hipotética, conforme os experimentos numéricos idealizados e já discutidos em detalhes no capítulo 3 (representados na Fig. 3.2).

Como mencionado anteriormente, na seção 4.4.1, nos experimentos numéricos os comprimentos de ondas resolvidos pelo modelo são funções da resolução espacial da grade (o modelo só resolve comprimentos de ondas múltiplos de $\Delta \mathrm{x}$ ) e limitados superiormente pela 
extensão do domínio horizontal. Por outro lado, as medidas coletadas em experimentos de campo representam um grande intervalo de número de ondas (da pequena a grande escala), já que são dependentes apenas da freqüência e do intervalo de tempo em que os dados são amostrados.

Os espectros das componentes de velocidade no espaço de freqüência são estimados a partir das séries temporais de 115 min obtidas a razão de amostragem $\mathrm{f}_{\mathrm{a}}=1 \mathrm{~Hz}$, coletadas no mesmo período de tempo das estimativas espaciais. Para resolver um intervalo máximo de freqüências adotou-se o procedimento sugerido por Kaimal e Finnigan (1994) e descrito em detalhes no capítulo 3.

Nas estimativas dos espectros espaciais (Fig. 4.15) observou-se que o menor comprimento de onda resolvido pelo modelo LES foi $(\lambda)_{\min } \approx 157 \mathrm{~m}$, equivalente ao número de onda máximo $(\mathrm{k})_{\max } \approx 0,04 \mathrm{~m}^{-1}$. Aplicando-se a hipótese de Taylor nas medidas temporais, o número de onda $(\mathrm{k})_{\max }$ equivalente freqüência $\left(\mathrm{f}_{\mathrm{r}}\right)_{\max }$ é superior a $0,04 \mathrm{~m}^{-1}$. Isso faz com que parte da região de alta freqüência dos espectros temporais não tenha significado físico, pois resolvem comprimentos de onda pertencentes à escala de subgrade do modelo LES, e, portanto, serão desconsideradas.

Para efeito ilustrativo é apresentado na Fig. (4.21) um espectro temporal da componente longitudinal de velocidade $\mathrm{S}_{\mathrm{u}}(\mathrm{f})$. As regiões de baixa e alta freqüência são tratadas separadamente. A identificação das freqüências máximas resolvidas pelo modelo LES $\left[\mathrm{f}_{\mathrm{r} 1}, \mathrm{f}_{\mathrm{r} 2}\right.$ e $\mathrm{f}_{\mathrm{r} 5}$, com $\left.\mathrm{f}_{\mathrm{r}_{\mathrm{i}}}<\left(\mathrm{f}_{\mathrm{r}}\right)_{\max }\right]$ variam de acordo com a velocidade horizontal do vento de cada um dos casos simulados (as condições iniciais dos casos simulados estão descritas na Tabela 3.1) e serão adotadas de modo a evitar a introdução de erros na representação dos espectros temporais. Para excluir os efeitos da aplicação da hipótese de Taylor nos espectros temporais, num primeiro momento, as freqüências não serão adimensionalizadas. 


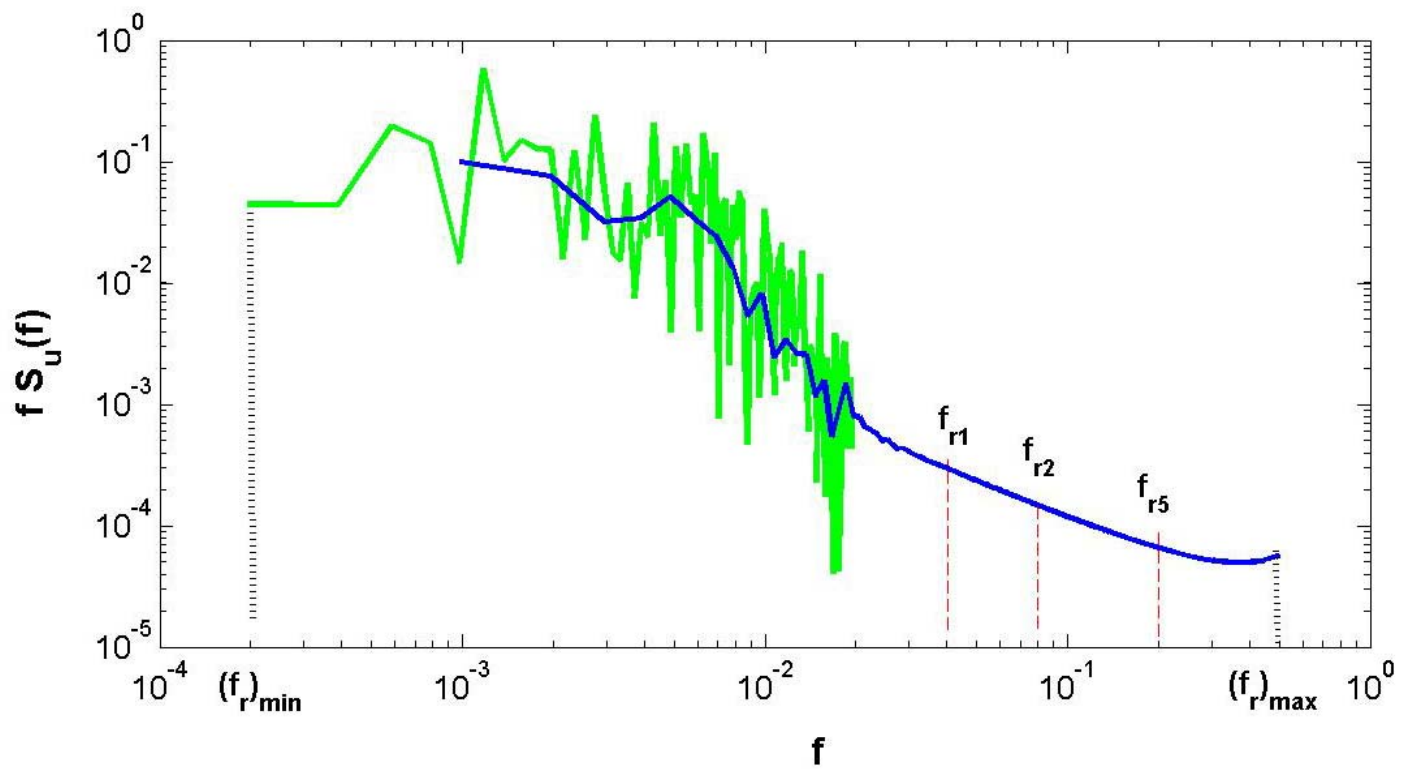

Fig. 4.21 - Composição do espectro temporal das componentes de velocidade com as bandas de baixa (verde) e alta (azul) freqüência. $\left(f_{r}\right)_{\min }$ é a menor e $\left(f_{r}\right)_{\max }$ é a maior freqüência resolvida pela FFT. $f_{r 1}, f_{r 2}$ e $f_{r 5}$ representam as maiores freqüências resolvidas pelo modelo LES (equivalentes a $\lambda_{\min }=157 \mathrm{~m}$ ) e que variam de acordo com a velocidade horizontal do vento adotada nas diferentes simulações: $1 \mathrm{~ms}^{-1}, 2 \mathrm{~m} \mathrm{~s}^{-1}$ e $5 \mathrm{~ms}^{-1}$, respectivamente.

Na Fig. (4.22) são apresentados os espectros temporais das componentes de velocidade nas mesmas alturas adimensionais dos espectros espaciais $\left[\mathrm{z} \approx(0,2: 0,1: 0,6) \mathrm{z}_{\mathrm{i}}\right]$, em conjunto com a inclinação esperada na região subintervalo inercial $\left(\mathrm{k}^{-5 / 3}\right)$. Para melhor visualização da variação vertical, as densidades espectrais das componentes de velocidade foram multiplicadas por potências de 20 .

Observa-se que os espectros temporais das componentes de velocidade simulados pelo modelo LES apresentam um maior espalhamento quando comparado aos espectros espaciais (Fig. 4.23). Uma das causas deste espalhamento está relacionada as diferentes velocidades do vento adotadas nas simulações numéricas e que influenciam a advecção dos turbilhões através da grade (sensores de medida da torre micrometeorológica hipotética). Nos espectros espaciais todas estruturas turbulentas são amostradas num dado tempo t, diferentemente dos espectros temporais que são amostrados em pontos fixos da grade. Também é possível notar (Fig. 4.22) que os espectros temporais apresentam uma região com inclinação proporcional a 
$\mathrm{k}^{-5 / 3}$, enfatizando que as menores escalas resolvidas pelo modelo LES pertencem a região do subintervalo inercial.
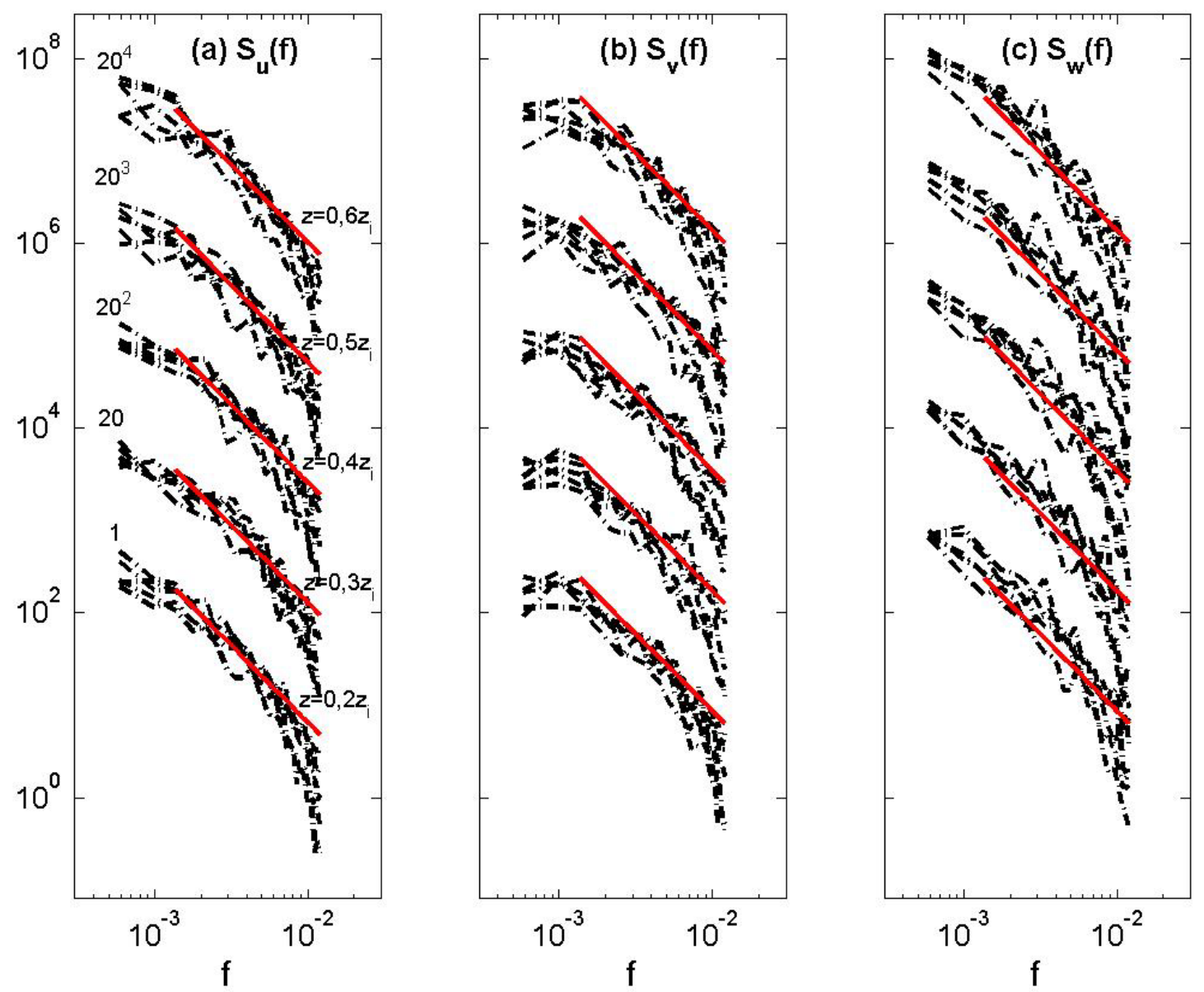

Fig. 4.22 - Variação vertical dos espectros temporais das componentes de velocidade: (a) longitudinal; (b) lateral; (c) vertical. A linha em vermelho representa a inclinação esperada na região do subintervalo inercial $\mathrm{f}^{-5 / 3}$

A relação de isotropia entre as componentes lateral e longitudinal de velocidade $S_{v}(f) / S_{u}(f)$ (Fig. 4.24a) concorda com os prognósticos teóricos nas freqüências superiores a $4 \times 10^{-3} \mathrm{~s}^{-1}$, onde o valor médio é igual a $(1,47 \pm 0,14)$. A razão entre as componentes vertical e longitudinal de velocidade $S_{w}(f) / S_{u}(f)$ (Fig. 4.24b) é ligeiramente superior $(1,73 \pm 0,26)$ para o mesmo alcance de freqüências. 

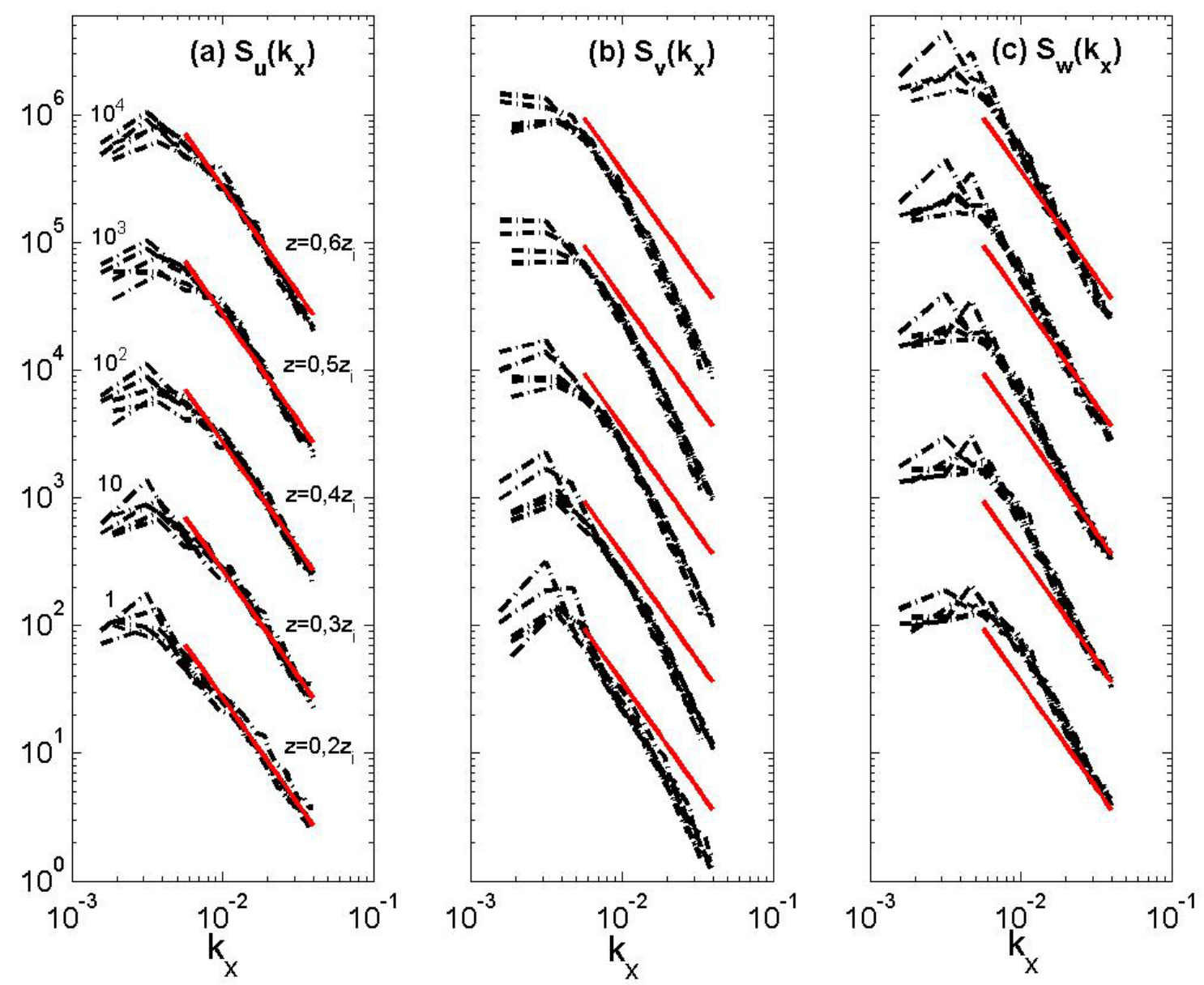

Fig. 4.23 - Variação vertical dos espectros espaciais das componentes de velocidade na direção x: (a) longitudinal; (b) lateral; (c) vertical. A linha em vermelho representa Eq.(4.2), sendo que $\alpha_{\mathrm{k}}=0,52$ para componente longitudinal e $\alpha_{\mathrm{k}}=(4 / 3) 0,52$ para as demais componentes.

Portanto, os espectros temporais das componentes de velocidade reproduzem o comportamento esperado para a região do subintervalo inercial de forma similar aos espectros espaciais. Para determinar a escala de comprimento a partir do espectro temporal é necessário adimensionalizar a freqüência pelas escalas de comprimento $\left(z_{i}\right)$ e de velocidade. Para avaliar a aplicação da hipótese de Taylor a escala de velocidade escolhida é a velocidade horizontal do vento $(\overline{\mathrm{U}})$.

Caso a escala de comprimento associada ao máximo dos espectros temporais das componentes de velocidade seja similar à obtida através dos espectros espaciais, a validade da hipótese de Taylor em condições convectivas estará confirmada. 

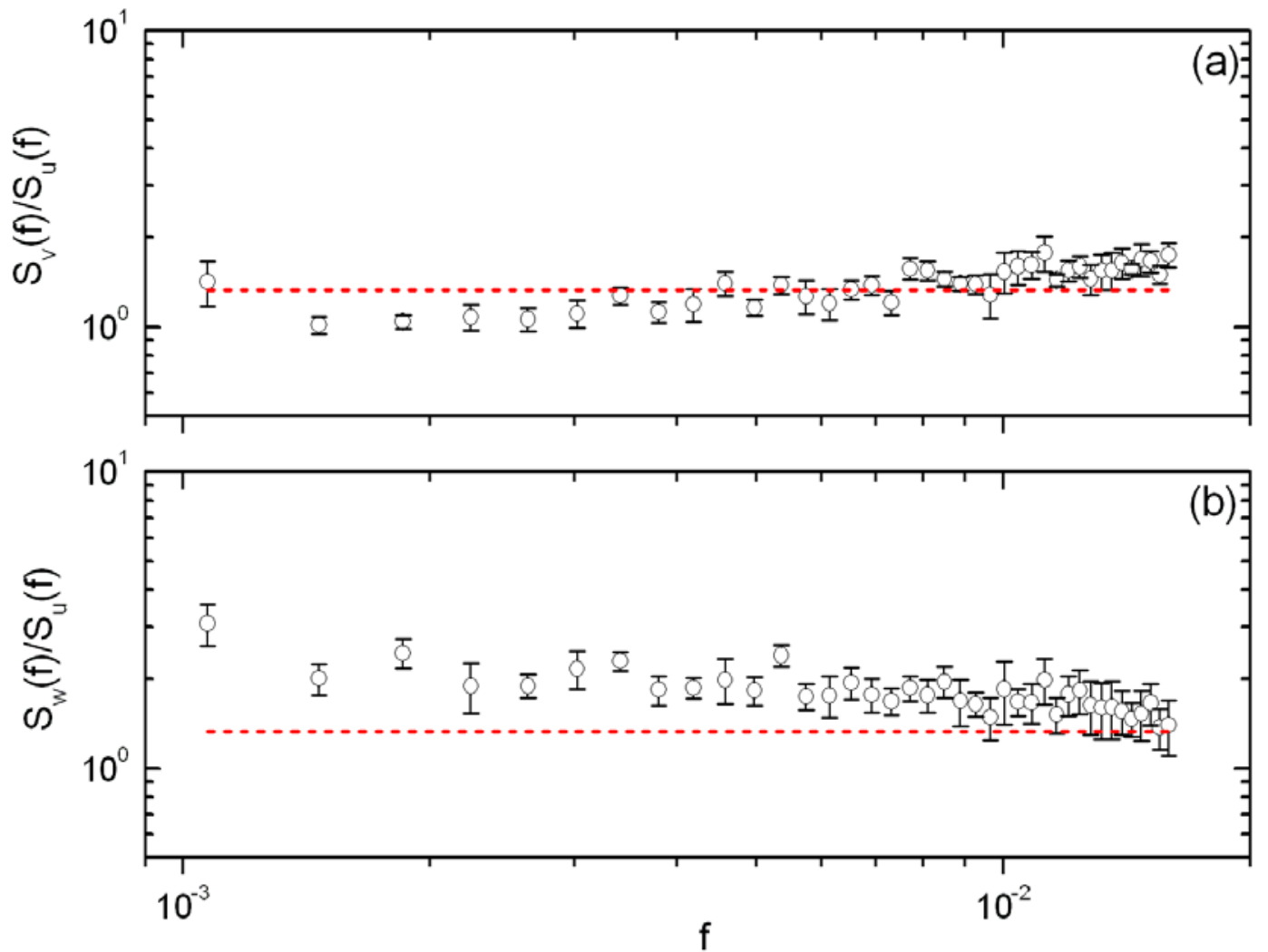

Fig. 4.24 - Relação de isotropia entre as componentes de velocidade: (a) $S_{v}(f) / S_{u}(f)$; (b) $S_{w}(f) / S_{u}(f)$. A linha em vermelho representa o prognóstico teórico 4/3.

\subsection{4 - Escala de comprimento associada aos espectros temporais}

A determinação da escala de comprimento dos turbilhões mais energéticos associada aos espectros temporais segue o mesmo procedimento adotado no caso espacial. A curva de ajuste utilizada para determinar o máximo dos espectros temporais das componentes horizontais de velocidade é descrita por:

$\frac{\mathrm{f} \mathrm{S}_{\mathrm{u}, \mathrm{v}}(\mathrm{f})}{\sigma_{\mathrm{h}}^{2}}=\frac{\mathrm{f}_{\mathrm{i}}}{\left(1+\mathrm{Af}_{\mathrm{i}}^{5 / 3}\right)}$

onde $\mathrm{f}_{\mathrm{i}}=\mathrm{f}_{\mathrm{i}} / \overline{\mathrm{U}}$ é a freqüência adimensional, sendo que a velocidade do vento horizontal refere-se aos valores nos respectivos níveis de coleta das séries temporais. No caso da componente vertical de velocidade, o máximo espectral é determinado visualmente em função de problemas no ajuste. 
Os espectros adimensionais das componentes de velocidade para os dois casos mais convectivos (casos HC2 e DA2) e suas respectivas curvas de ajuste são apresentados nas Figs. (4.25) e (4.26).

(a) Componente Longitudinal
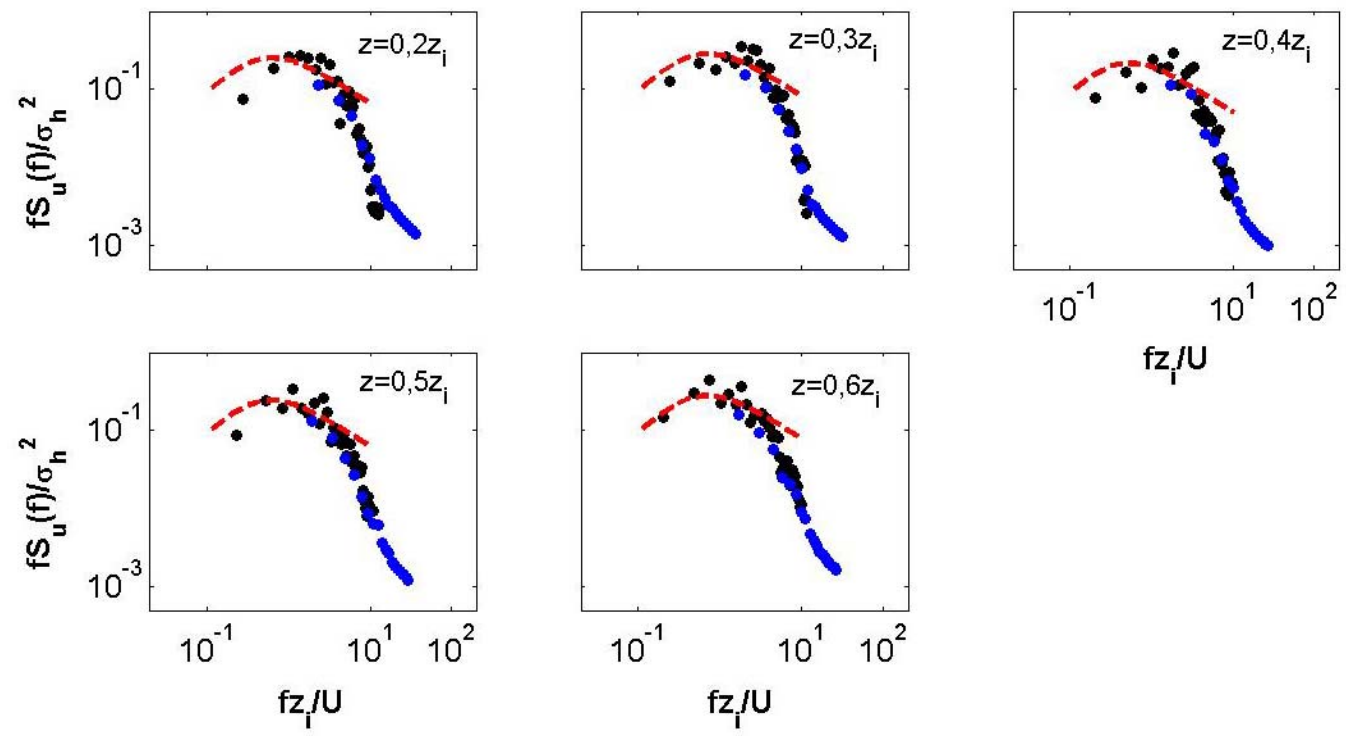

(b) Componente Lateral
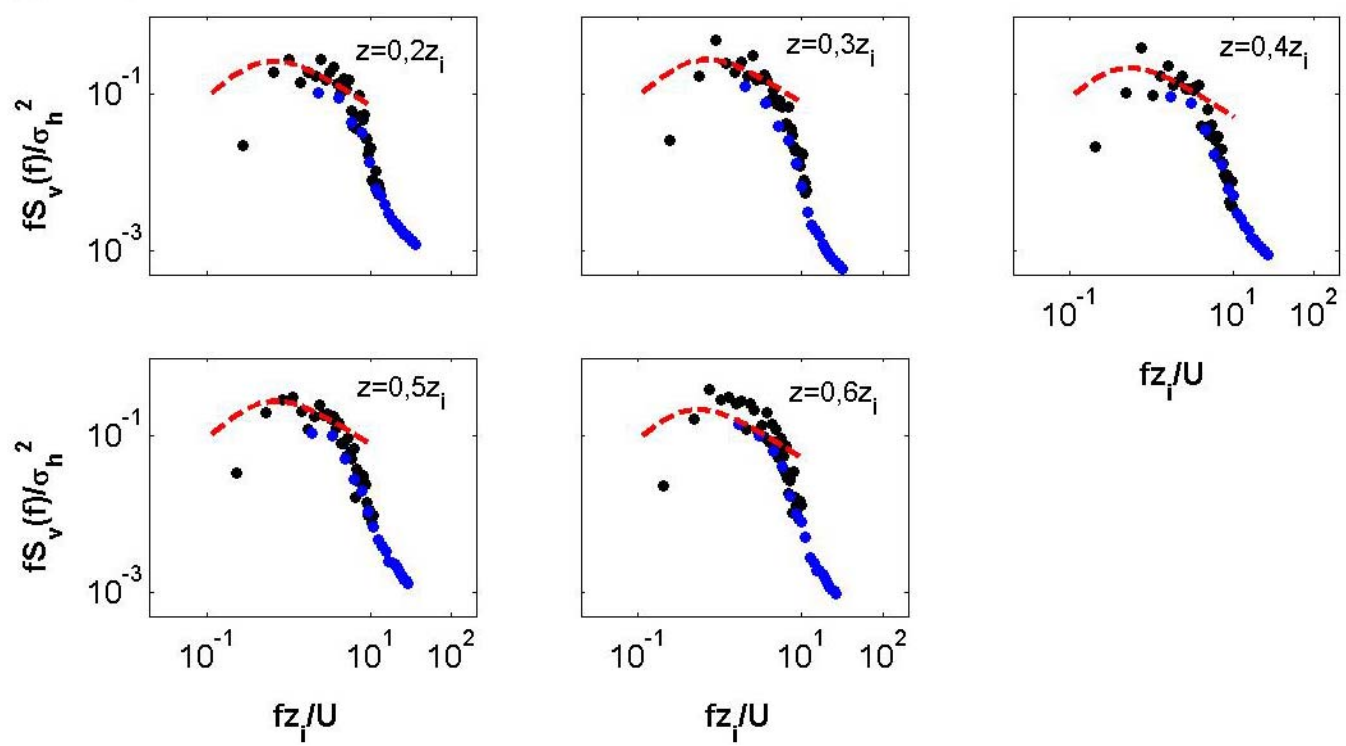

$\mathrm{fz} / \mathrm{I}$

Fig. 4.25 - Espectros temporais adimensionais das componentes de velocidade em diferentes níveis verticais para o caso HC2: (a) longitudinal; (b) lateral; (c) vertical. Os círculos representam: (em preto) baixa freqüência e (em azul) alta freqüência. A linha tracejada em vermelho representa a curva de ajuste similar à proposta por Kaimal (1978) (Eq. 4.8). A velocidade horizontal do vento refere-se ao mesmo valor do nível de cada estimativa espectral. 
(c) Componente Vertical
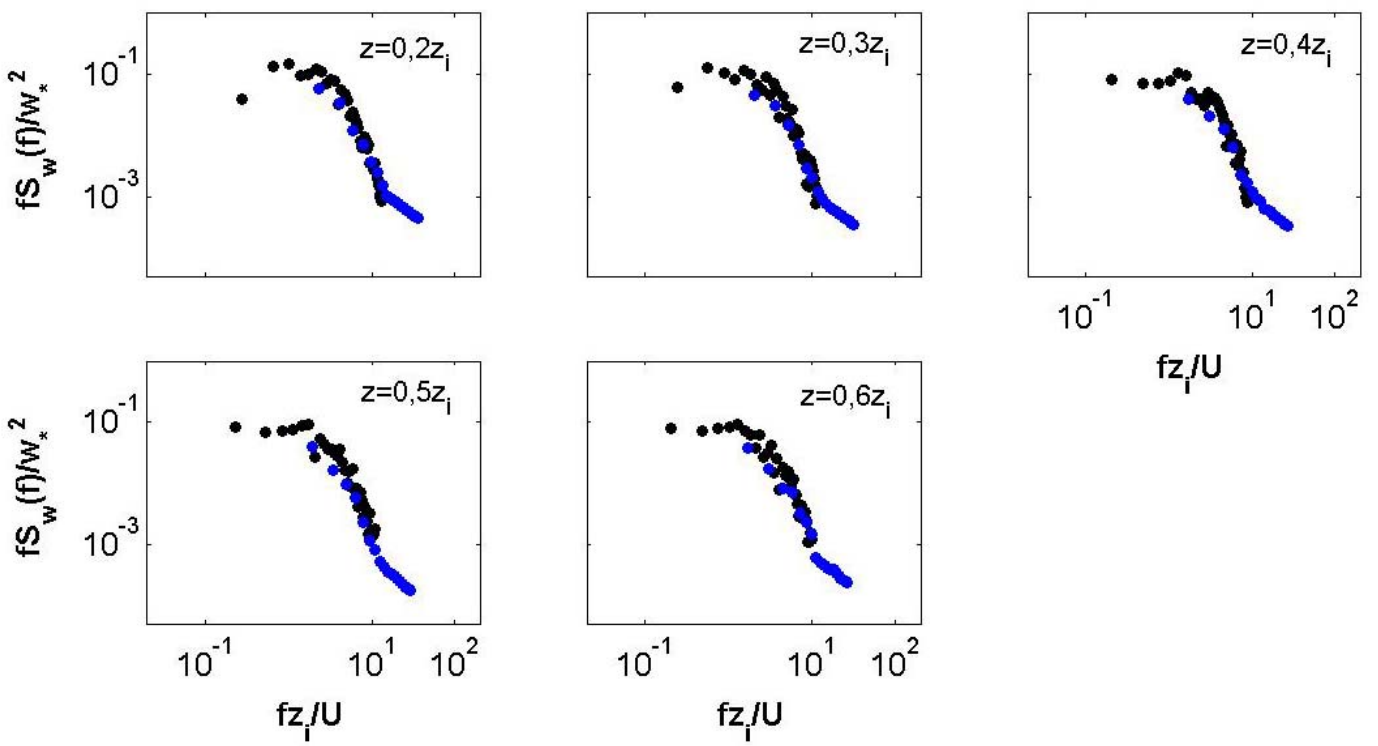

$\mathrm{fz} / \mathrm{U}$

Fig. 4.25 - Continuação.

(a) Componente Longitudinal
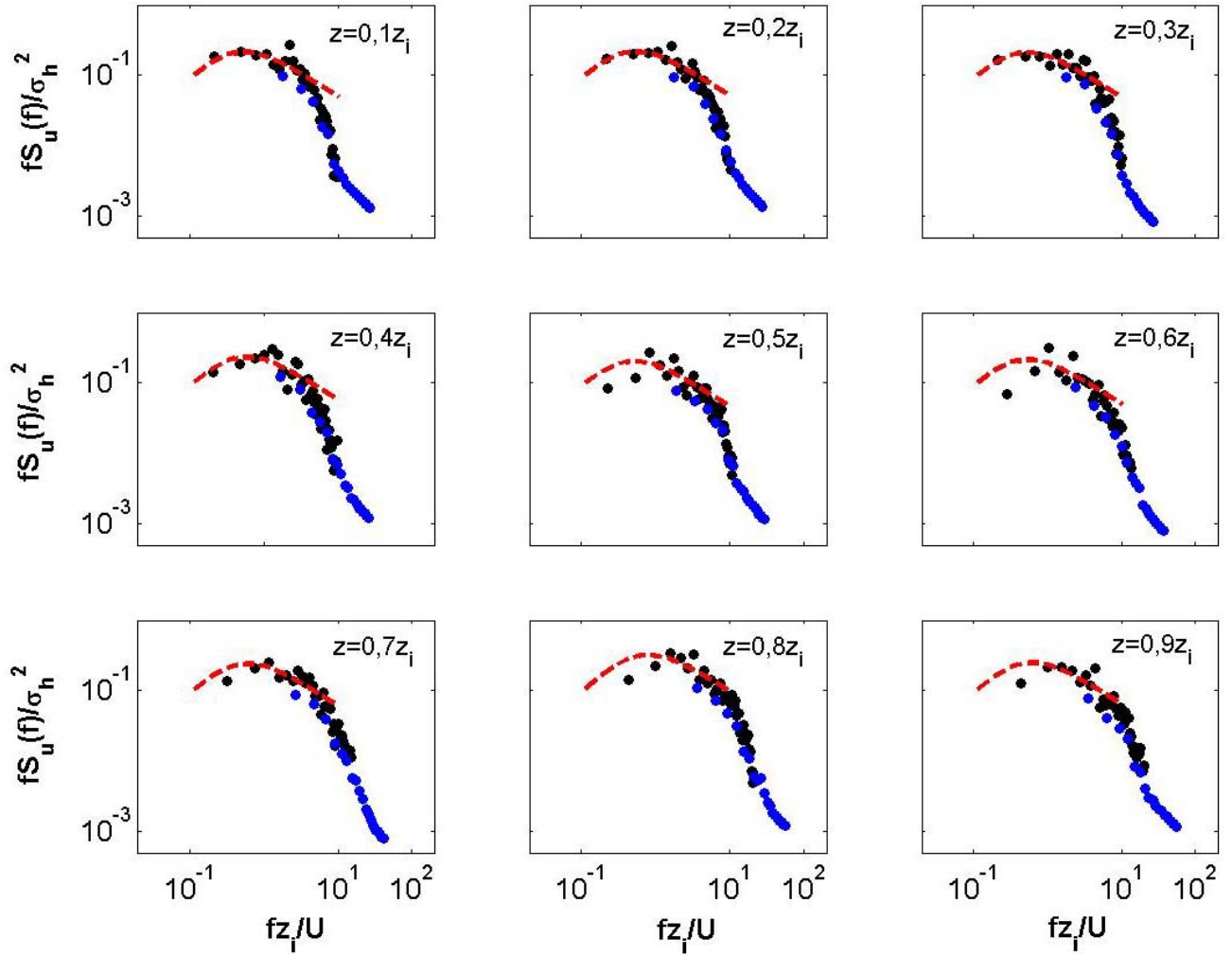

Fig. 4.26 - Similar a Fig. (4.25), mas para o caso DA2. 
(b) Componente Lateral
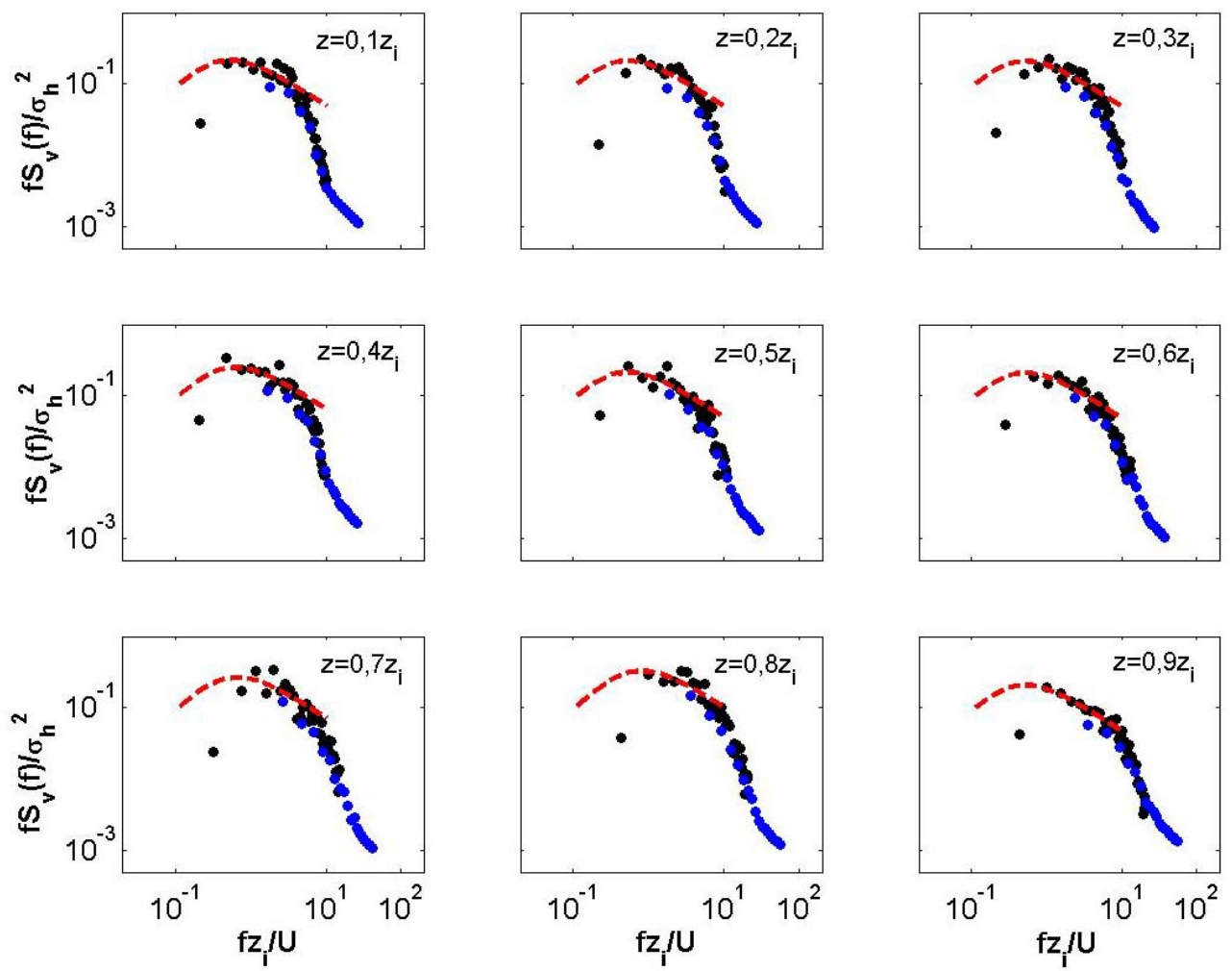

(c) Componente Vertical
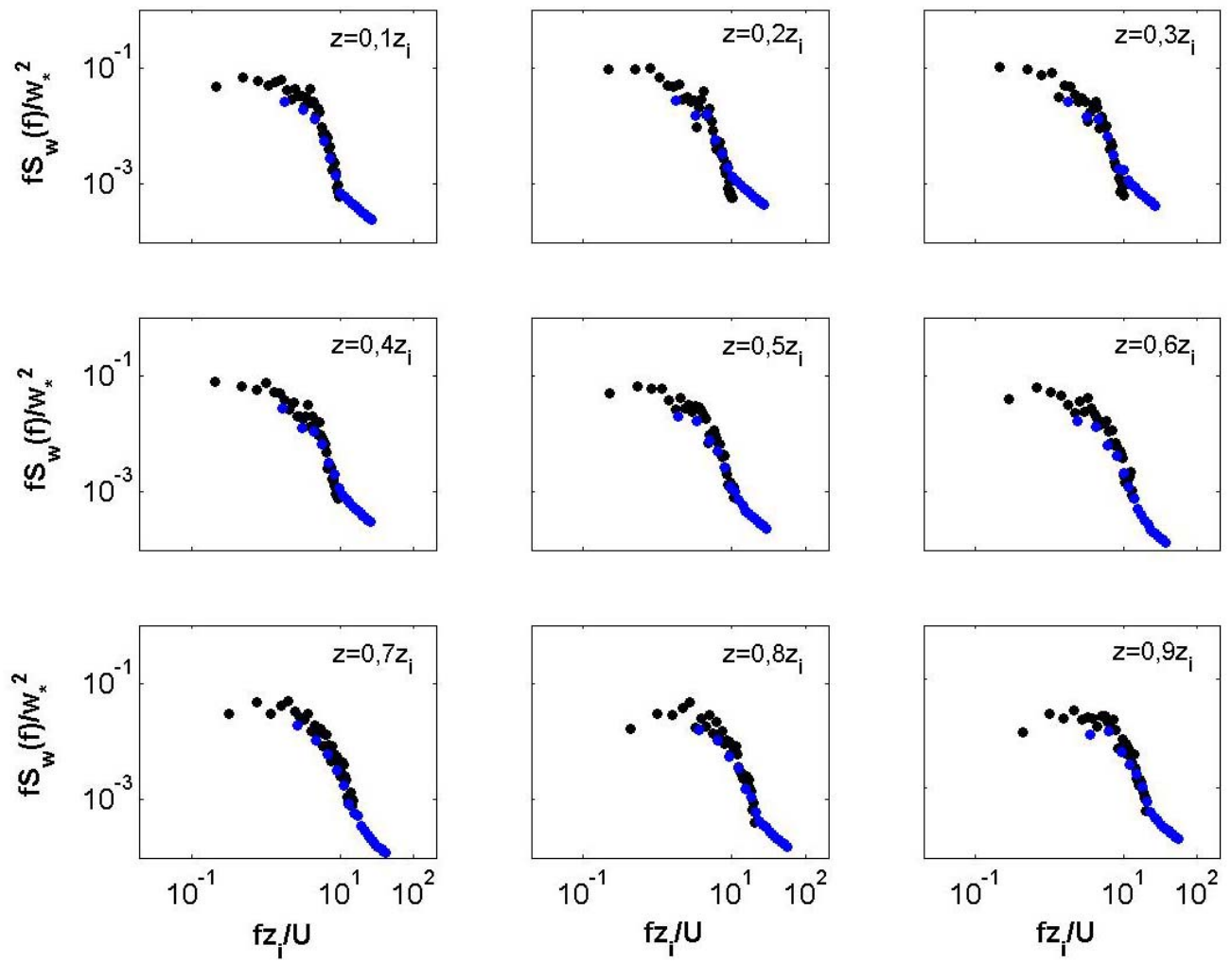

Fig. 4.26 - Continuação. 
Observa-se que os espectros temporais das componentes de velocidade apresentam uma região de produção bem definida. Há uma boa concordância das densidades espectrais entre a baixa e a alta freqüência, enfatizando que a metodologia de cálculo adotada na determinação dos espectros temporais está correta. Nas freqüências adimensionais $\mathrm{fz}_{\mathrm{i}} / \mathrm{U}$ superiores a 10 , os espectros temporais têm inclinação mais acentuada $\left(\propto \mathrm{f}_{\mathrm{i}}^{-2}\right)$ que os prognósticos teóricos para o subintervalo inercial. Isso dificultou a determinação precisa da posição do máximo espectral pela curva de ajuste ocasionando um maior espalhamento das estimativas de $\left(\lambda_{\mathrm{m}}\right)_{\mathrm{u}, \mathrm{v}}$.

Schöroter et al. (2000) simularam o comportamento espectral das componentes de velocidade com um modelo LES e encontraram resultados similares com relação à inclinação dos espectros turbulentos na região do subintervalo inercial. Eles argumentaram que esta inclinação mais acentuada reflete alguma incompatibilidade entre o filtro da escala resolvida e o modelo de subgrade adotado.

Outra explicação para esta discrepância pode estar relacionada à aplicação da hipótese de Taylor.

Alguns trabalhos apresentados na literatura sugerem uma correção na região de alta freqüência dos espectros turbulentos, uma vez que nas escalas menores os turbilhões viajam com velocidade que oscilam em torno da velocidade horizontal do vento (Lumley, 1965; Wyngaard e Clifford, 1977; Gledzer, 1997). Porém, para a região de produção do espectro turbulento ainda não foi encontrada nenhuma maneira de corrigir esse problema (Wyngaard, 1985).

Kaimal (1978) abordou o problema da aplicação da hipótese de Taylor em condições convectivas e sugeriu que as regiões de baixa e alta freqüência dos espectros turbulentos são controladas por diferentes parâmetros de escala. Portanto, é concebível que turbilhões de diferentes escalas sejam transportados com velocidades distintas. Hipoteticamente, Kaimal considerou que nas escalas menores os turbilhões movimentam-se mais lentamente com alguma escala de velocidade associada a $\mathrm{u}_{*}$ ou $\mathrm{w}_{*}$, por exemplo. Nas escalas maiores, os turbilhões têm extensão vertical da ordem da altura da CLP convectiva e a velocidade horizontal do vento seria a escala mais adequada para representar esse transporte, o que estaria de acordo com a hipótese de Taylor. 
Evidências experimentais indicam que na CLS as estruturas coerentes viajam com velocidade diferente da velocidade horizontal do vento médio (Krusche e Oliveira, 2004), o que estaria de acordo com as suposições levantadas por Kaimal. Então, é possível que os efeitos da variação nas escalas de velocidade também afetem a região de produção dos espectros turbulentos.
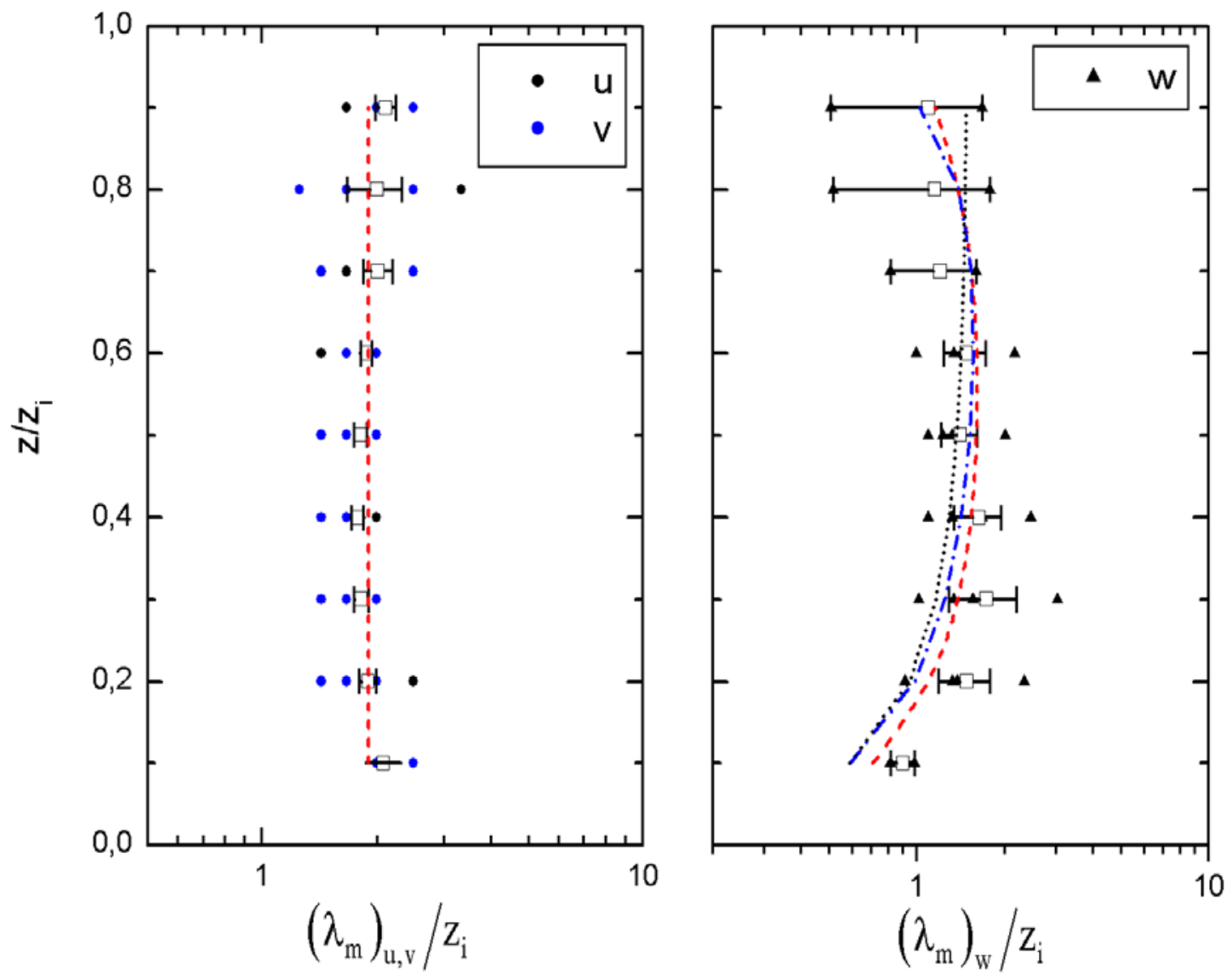

Fig. 4.27 - Comprimento de onda associado ao máximo espectral das componentes de velocidade obtido através dos espectros temporais. As linhas representam as curvas por: (vermelho) ajustadas aos dados estimados pelo LES, $\left(\lambda_{\mathrm{m}}\right)_{\mathrm{u}, \mathrm{v}}=1,9 \mathrm{z}_{\mathrm{i}}$ e $\left(\lambda_{\mathrm{m}}\right)_{\mathrm{w}}=1,9 \mathrm{z}_{\mathrm{i}}\left[1-\exp \left(-4,8 \mathrm{z} / \mathrm{z}_{\mathrm{i}}\right)-0,005 \exp \left(-4,8 \mathrm{z} / \mathrm{z}_{\mathrm{i}}\right)\right]$; (preto) Kaimal et al. (1976); (azul) Caughey e Palmer (1979).

As estimativas dos comprimentos de ondas adimensionais associados ao máximo dos espectros temporais das componentes de velocidade $\left(\lambda_{\mathrm{m}}\right)_{\mathrm{u}, \mathrm{v}} / \mathrm{z}_{\mathrm{i}}$ e $\left(\lambda_{\mathrm{m}}\right)_{\mathrm{w}} / \mathrm{z}_{\mathrm{i}}$ são apresentados na Fig.(4.27). Em comparação aos espectros espaciais, o espalhamento nas estimativas de 
$\left(\lambda_{\mathrm{m}}\right)_{\mathrm{u}, \mathrm{v}} / \mathrm{z}_{\mathrm{i}}$ (Fig. 4.27a) e $\left(\lambda_{\mathrm{m}}\right)_{\mathrm{w}} / \mathrm{z}_{\mathrm{i}}$ (Fig. 4.27b) são maiores em virtude de imprecisões na determinação do máximo espectral e das influências da velocidade horizontal do vento.

Os valores estimados de $\left(\lambda_{\mathrm{m}}\right)_{\mathrm{u}, \mathrm{v}}$ na camada de mistura, $\left\{\left(\lambda_{\mathrm{m}}\right)_{\mathrm{u}, \mathrm{v}}\right\}_{\mathrm{CM}}=(1,93 \pm 0,12) \mathrm{z}_{\mathrm{i}}$, diferem por um fator de $\approx 1,5$ das estimativas obtidas por meio dos espectros espaciais, $\left\{\left(\lambda_{\mathrm{m}}\right)_{\mathrm{u}, \mathrm{v}}\right\}_{\mathrm{CM}}=(1,29 \pm 0,01) \mathrm{z}_{\mathrm{i}}$.

Da mesma forma que $\left(\lambda_{\mathrm{m}}\right)_{\mathrm{u}, \mathrm{v}}$, as estimativas de $\left(\lambda_{\mathrm{m}}\right)_{\mathrm{w}}$ determinado pelos espectros temporais é superior as obtidas pelas espectros espaciais pelo mesmo fator de 1,5.

Com base na curva experimental proposta por Caughey e Palmer (1979), propõe-se que a variação vertical do comprimento de onda $\left(\lambda_{\mathrm{m}}\right)_{\mathrm{w}}$ estimada pelo modelo LES possa ser representada por:

$$
\left(\lambda_{\mathrm{m}}\right)_{\mathrm{w}}=1,9 \mathrm{z}_{\mathrm{i}}\left[1-\exp \left(-4,8 \mathrm{z} / \mathrm{z}_{\mathrm{i}}\right)-0,005 \exp \left(-4,8 \mathrm{z} / \mathrm{z}_{\mathrm{i}}\right)\right]
$$

Kaimal et al. (1982) estudaram as características espectrais na CLP convectiva através de dados experimentais coletados simultaneamente em torre micrometeorológica (equivalente as estimativas temporais) e por avião (equivalente as estimativas espaciais). Apesar de apresentarem formas similares, os espectros da componente vertical de velocidade obtidos à partir das medidas coletadas por avião (espacialmente distribuídos) são deslocados em direção as freqüências maiores quando comparados aos espectros coletados em um ponto fixo do espaço (temporais). Esse deslocamento nos espectros da componente vertical de velocidade ocasionou uma diferença nas estimativas $\left(\lambda_{\mathrm{m}}\right)_{\mathrm{w}}$ por um fator $\approx 2$, superior ao 1,5 obtido com o modelo LES.

Portanto, essa discrepância sistemática entre os máximos espectrais espacial e temporal reproduzida com o modelo LES foi observada experimentalmente (Kaimal et al., 1982). Isso sugere que na CLP convectiva a aplicação da hipótese de Taylor deve ser utilizada com cautela, mesmo na região de produção dos espectros turbulentos.

Esses resultados indicam que o modelo LES pode desempenhar um papel importante na investigação da aplicação da hipótese de Taylor. Parece relevante também, explorar as 
influências do termo de redistribuição de ECT pela flutuação de pressão na região do subintervalo inercial do espectro turbulento.

\subsection{5 - Espectros de escalares}

O comportamento dos espectros turbulentos de escalares na CLP convectiva não pode ser convenientemente generalizado pela teoria de similaridade da camada de mistura (Kaimal et al., 1976). Entretanto, na região do subintervalo inercial esses espectros seguem a lei do equilíbrio universal e podem ser adimensionalizados por suas respectivas escalas características.
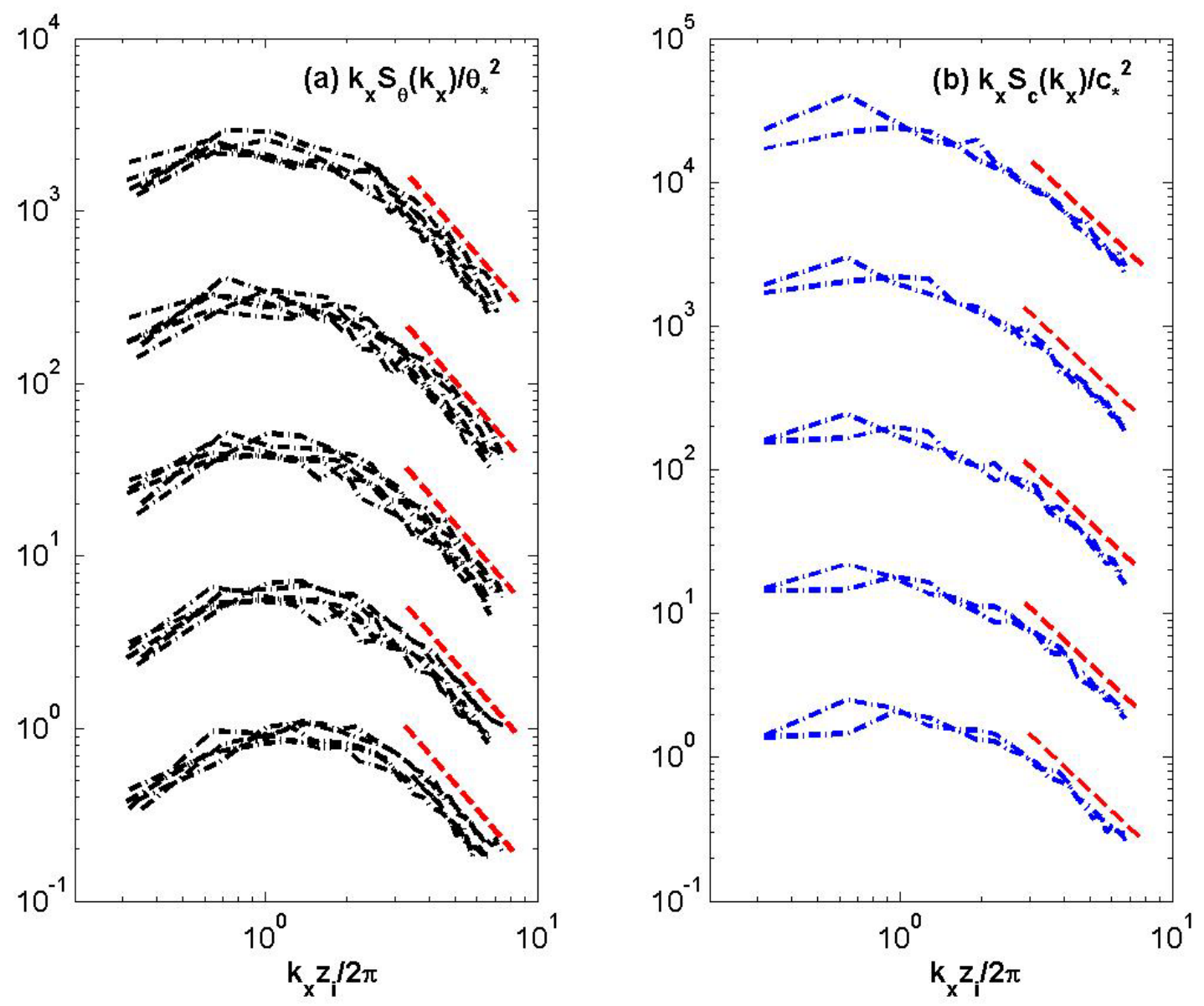

Fig. 4.28 - Variação vertical dos espectros adimensionais espaciais de: (a) temperatura potencial; (b) concentração. A linha tracejada em vermelho representa a inclinação $\mathrm{k}^{-2 / 3}$. 
Os espectros espaciais adimensionais de temperatura potencial e concentração de poluente, estimados de acordo com o procedimento adotado na seção 4.4.1, são apresentados Fig. (4.28).

Nota-se que os espectros apresentam uma região de produção bem definida e um subintervalo inercial com inclinação esperada $\left(\mathrm{k}^{-2 / 3}\right)$. Porém, como não foram exploradas nas seções anteriores, os termos de produção, dissipação e transporte das equações do balanço de variância para a temperatura potencial e concentração de poluente, as propriedades espectrais desses escalares não serão discutidas. Mas é nítida a capacidade do modelo LES em representar também as características espectrais de quaisquer escalares na CLP convectiva.

\subsection{6 - Sumário dos resultados da análise espectral}

Os espectros das componentes de velocidade simulados com o modelo LES apresentaram uma região com inclinação proporcional a $\mathrm{k}^{-5 / 3}$, confirmando que a menor escala resolvida pelo modelo encontra-se na região do subintervalo inercial.

O valor estimado da constante de Kolmogorov foi $\alpha_{k}=0,52$ e está de acordo com os valores sugeridos na literatura.

Nas escalas menores resolvidas pelo modelo, a razão $S_{w}\left(k_{x}\right) / S_{u}\left(k_{x}\right)$ é aproximadamente igual ao valor previsto pela relação de isotropia $\mathrm{S}_{\mathrm{w}}\left(\mathrm{k}_{\mathrm{x}}\right)=\frac{4}{3} \mathrm{~S}_{\mathrm{u}}\left(\mathrm{k}_{\mathrm{x}}\right)$. Para a componente lateral de velocidade, a razão $\mathrm{S}_{\mathrm{v}}\left(\mathrm{k}_{\mathrm{x}}\right) / \mathrm{S}_{\mathrm{u}}\left(\mathrm{k}_{\mathrm{x}}\right)$ não apresentou o mesmo comportamento.

Os espectros espaciais adimensionais das componentes de velocidade apresentam uma região de produção bem definida. No caso dos espectros espaciais horizontais, a variação vertical do comprimento de onda associado ao turbilhão mais energético concorda com o valor sugerido por Kaimal et al. (1976), $\left(\lambda_{\mathrm{m}}\right)_{\mathrm{u}, \mathrm{v}}=1,3 \mathrm{z}_{\mathrm{i}}$.

Baseado em Caughey e Palmer (1979), uma nova formulação foi proposta para representar a variação vertical de $\left(\lambda_{\mathrm{m}}\right)_{\mathrm{w}}$ na CLP altamente convectiva: 
$\left(\lambda_{\mathrm{m}}\right)_{\mathrm{w}}=1,3 \mathrm{z}_{\mathrm{i}}\left[1-\exp \left(-4,8 \mathrm{z} / \mathrm{z}_{\mathrm{i}}\right)-0,005 \exp \left(-4,8 \mathrm{z} / \mathrm{z}_{\mathrm{i}}\right)\right]$

Para os espectros temporais, as escalas $\left(\lambda_{\mathrm{m}}\right)_{\mathrm{u}, \mathrm{v}}$ e $\left(\lambda_{\mathrm{m}}\right)_{\mathrm{w}}$ diferem das escalas obtidas pelos espectros espaciais por um fator de 1,5. Essa diferença é inferior ao fator 2 encontrado por Kaimal et al. (1982) para os espectros da componente vertical de velocidade com dados observados em experimentos de campo com torre micrometeorológica e avião.

Esses resultados confirmam as restrições da aplicação da hipótese de Taylor em uma CLP em condições altamente convectivas e ilustram as discrepâncias existentes entre as observações obtidas em torre micrometeorológica (coletas em um ponto fixo do espaço) e as por avião (espacialmente distribuídas e simultâneas), ressaltando o cuidado que se deve ter no procedimento de descrição das propriedades espectrais da CLP através de observações em torre micrometeorológica em regiões onde predominam essas condições de estabilidade (regiões tropicais e subtropicais do Brasil).

O modelo LES também reproduz as principais características dos espectros espaciais de escalares como temperatura potencial e concentração de poluente.

A grande dificuldade na validação dos resultados gerados com o modelo LES reside na escassez de dados experimentais que caracterizarem de forma detalhada a estrutura da turbulência na CLP altamente convectiva, associada à baixa velocidade do vento. Uma forma alternativa de validação adotada nesse trabalho e que se mostrou satisfatória, foi confrontar os resultados simulados numericamente com os prognósticos teóricos da similaridade da camada de mistura e com a lei do equilíbrio universal de Kolmogorov.

Uma vez estabelecida as principais características da estrutura da turbulência na CLP convectiva, o modelo LES será agora aplicado a estudos de dispersão de poluentes inertes e passivos emitidos por diferentes tipos de fontes (área e pontual), localizadas em diferentes alturas da CLP convectiva. 


\section{5 - DISPERSÃO DE POLUENTES}

Os modelos de dispersão representam uma importante ferramenta na investigação dos transportes de poluentes na CLP contanto que, sejam validados com dados experimentais. Infelizmente, informações sobre a dispersão na CLP com resolução e precisão apropriadas são muito difíceis de serem obtidas. Uma alternativa para preencher está lacuna observacional é a utilização dos modelos do tipo LES, que desde os anos 70 têm sido utilizados na investigação da dispersão de poluentes (Deardorff, 1972).

Com o desenvolvimento computacional das últimas décadas, já é possível a realização de simulações numéricas mais realísticas por meio da adoção de superfícies heterogêneas sobre regiões de topografia complexa (Gopalakrishnan e Avissar, 2000). A validação mais comum dos padrões de dispersão simulados com o modelo LES é a utilização dos resultados apresentados por Willis e Deardorff (1974, 1976a e b, 1978) em seus clássicos experimentos realizados em tanque de convecção (Nieuwstadt e Valk, 1987; Henn e Sykes, 1992; Gopalakrishnan e Avissar, 2000; Rizza et al., 2003).

Do ponto de vista numérico o transporte de poluentes na CLP pode ser determinado através de duas abordagens distintas, euleriana e lagrangiana. Na abordagem euleriana a principal dificuldade reside na determinação da difusividade turbulenta para as diferentes condições de estabilidade encontradas na CLP (por exemplo, no caso convectivo as evidências indicam que não é possível utilizar um fechamento local, tipo teoria $\mathrm{K}$, nas regiões da CLP mais afastadas da superfície). A abordagem lagrangiana tem a vantagem de não apresentar difusão numérica artificial (Lamb, 1984; Wilson \& Sawford, 1996; Stohl, 1998), mas existem dificuldades quanto à obtenção das propriedades estatísticas relevantes da turbulência atmosférica, uma vez que a maior parte dos dados experimentais utilizados para descrever os escoamentos turbulentos na CLP são coletados em um sistema de referência euleriano, e na determinação do termo estocástico que representa o campo de velocidade na escala de subgrade.

Neste trabalho, a dispersão de um poluente atmosférico inerte e passivo será investigada considerando dois tipos básicos de fontes: área e pontual contínua. Esses tipos de fontes representam uma grande variedade de processos de contaminação ambiental, entre os quais, citam-se: as emissões veiculares em regiões densamente povoados como a cidade de São 
Paulo, que podem ser reproduzidas através de fonte área contínua; e as contribuições industriais, que podem ser estudas através de fontes pontuais contínuas.

\section{1 - Dispersão euleriana para fonte área contínua (próxima à superfície)}

Nos últimos tempos, o aumento vertiginoso da frota veicular tem contribuído para a deterioração da qualidade do ar na região metropolitana de São Paulo (RMSP), especialmente no período de inverno quando as condições para a dispersão de poluentes são insatisfatórias.

Segundo dados publicados no relatório da Operação Inverno 2003 (CETESB, 2004), o monóxido de carbono (CO), que tem como principal fonte à queima incompleta de combustíveis fósseis, está entre os poluentes que contribuem para a piora dos padrões de qualidade do ar nesse período. Embora não seja possível determinar com precisão o tempo de vida médio global para o CO devido a sua variabilidade local, estima-se que nos trópicos seja da ordem de 1 mês (Seinfeld e Pandis, 1998). Portanto, na escala de algumas horas o CO pode ser tratado como um poluente inerte.

Em 2001 a RMSP tinha uma frota de aproximadamente 7 milhões de veículos automotores (Abrantes et al., 2004) e estima-se que esses veículos (caminhões, ônibus, carros e motos) sejam responsáveis por 98\% das emissões superficiais de CO (CETESB, 2004). Dessa maneira, a evolução diária da concentração de CO em regiões urbanas está diretamente relacionada à evolução temporal do tráfego de veículos e as condições meteorológicas locais como, altura da inversão térmica e intensidade da turbulência atmosférica (Oliveira, 1986; Bogo et al., 2001).

A evolução temporal da concentração média horária de CO durante o mês de julho entre os anos de 1996 e 2000 é apresentada na Fig. (5.1). Os dados foram coletados em duas estações de medições automáticas da CETESB (Lapa e Cerqueira César) que apresentam intenso tráfego de veículos automotores. Observa-se que ao longo do dia a concentração de CO tem dois picos distintos. Nas primeiras horas da manhã, o tráfego de veículos automotores é intenso e o aquecimento da superfície pela radiação solar ainda não é suficiente para romper a camada de inversão térmica da noite anterior, fazendo com que os poluentes permaneçam concentrados em regiões próximas à superfície. Após ás 10 horas da manhã, a intensidade do tráfego diminui e o crescimento da CLP faz com que os poluentes sejam transportados para as 
camadas superiores em função da forte atividade convectiva, o que favorece a dispersão por toda camada. Com isso, os níveis de concentração na superfície decaem e voltam a se elevar no período da tarde, quando a atividade convectiva diminui e o tráfego de veículos automotores se intensifica.

Apesar da concentração média horária de CO durante o mês de julho ficar abaixo de 4 ppm, é comum a ocorrência de picos de concentração superiores a 10 ppm durante o período de inverno, como pode ser observado na Tabela 5.1.

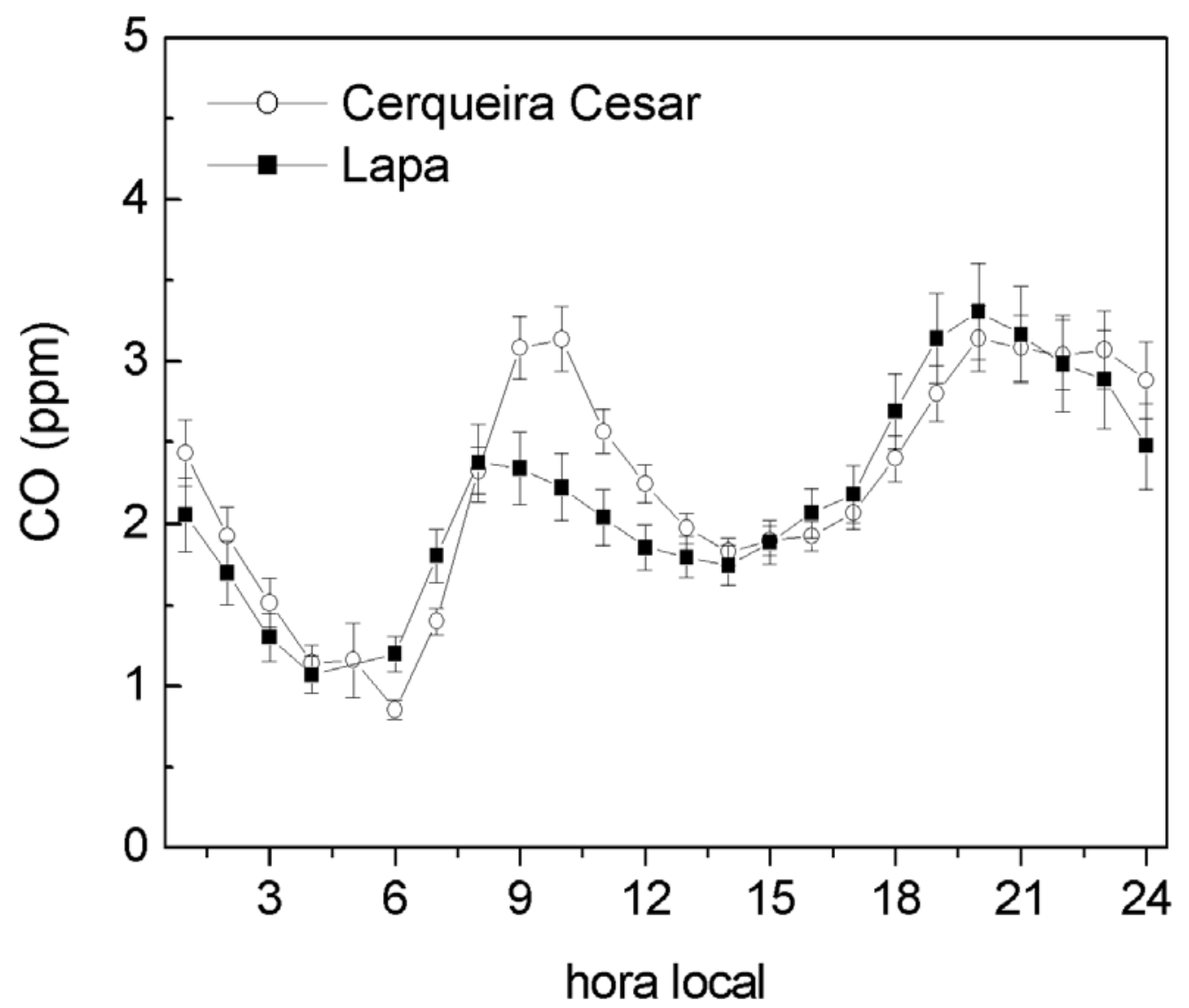

Fig. 5.1 - Concentração horária média mensal de Monóxido de Carbono (CO) para o mês de julho entre os anos de 1996 a 2000.

Fonte: Codato (2004).

A estrutura da turbulência na CLP convectiva sobre superfícies urbanas heterogêneas ainda não é bem compreendida. De acordo com Cai (1999) os três principais fatores que a influenciam CLP sobre superfícies urbanas são: a transferência de momento pela interação 
entre o vento horizontal e a rugosidade superficial; a transferência de calor devido ao padrão desigual de cobertura da superfície; e a transferência de umidade.

Tabela 5.1 - Concentração média horária do Monóxido de Carbono (CO) no período de 01/05/2003 a 30/09/2003.

\begin{tabular}{|c|c|c|c|c|}
\hline ESTAÇAO & $\begin{array}{c}\mathrm{N}^{2} \text { DE ULTRAPASSAGENS } \\
\text { DO PQAR HORARIO } \\
35 \mathrm{ppm}\end{array}$ & $\begin{array}{c}\text { MEDIA } \\
\text { ARITMETICA } \\
\text { DAS MAX. } \\
\text { DE } 1 \text { hora } \\
\text { ppm }\end{array}$ & $\begin{array}{c}1^{2} \\
\text { MAXIMA } \\
\text { ppm }\end{array}$ & $\begin{array}{l}2^{2} \\
\text { MAXIMA } \\
\text { ppm }\end{array}$ \\
\hline P. D. PEDRO II & 0 & 3,1 & 11,2 & 10,2 \\
\hline IBIRAPUERA & 0 & 2,4 & 10,3 & 9,3 \\
\hline SAO CAETANO DO SUL & 0 & 4,6 & 16,8 & 16,6 \\
\hline CONGONHAS & 0 & 4,7 & 16,2 & 12,7 \\
\hline LAPA & 0 & - & $\cdot$ & - \\
\hline CERQUEIRA CESAR & 0 & 3,0 & 8,1 & 7,5 \\
\hline CENTRO & 0 & 3,6 & 13,3 & 9,2 \\
\hline S. ANDRE - CENTRO & 0 & 3,0 & 14,7 & 13,9 \\
\hline SANTO AMARO & 0 & 2,2 & 7,1 & 6,8 \\
\hline OSASCO & 0 & 4,4 & 9,9 & 8,8 \\
\hline PINHEIROS & 0 & - & - & - \\
\hline
\end{tabular}

Fonte: Relatório da Operação Inverno 2003 - CETESB (2004)

Os aspectos climáticos da cidade de São Paulo são típicos de regiões subtropicais do Brasil, caracterizados por invernos secos entre os meses de junho e agosto e verões úmidos durante dezembro e março. No período de inverno, a velocidade média do vento dificilmente excede os $2 \mathrm{~ms}^{-1}$ (Oliveira et al., 2003), enquanto a radiação solar global atinge valor máximo médio mensal da ordem de $500 \mathrm{Wm}^{-2}$ (Oliveira et al., 2002) como pode ser observado na Fig. (5.2). Considerando que a radiação líquida durante o dia é determinada pela radiação global e que o albedo sobre regiões urbanas varia entre 0,15 e 0,30 (Sailor e Fan, 2002), resultanto em uma radiação líquida disponível entre $350 \mathrm{Wm}^{-2}$ e $425 \mathrm{Wm}^{-2}$. Sobre regiões urbanas o fluxo de calor sensível é bem superior ao fluxo de calor latente e representa aproximadamente $70 \%$ da radiação líquida disponível no período entre 10h e 13hr (Oke, 1987), resultando em um fluxo de calor sensível entre $245 \mathrm{Wm}^{-2}$ e $297,5 \mathrm{Wm}^{-2}$. Isso possibilita, mesmo durante o período de inverno, a ocorrência de dias com condições de estabilidade atmosférica altamente convectivas em São Paulo. 
Vale ressaltar, que na RMSP a brisa marítima desempenha um papel fundamental no transporte de poluentes e auxilia no processo de limpeza da CLP (Karam, 2002). Porém, as simulações realizadas são representativas de um período que se estende entre as $10 \mathrm{~h}$ e $13 \mathrm{~h}$ (considerado altamente convectivo), sobre uma superfície horizontalmente homogênea, em condições de céu claro e sobre uma região suficientemente afastada do litoral para que os efeitos da brisa não sejam considerados.

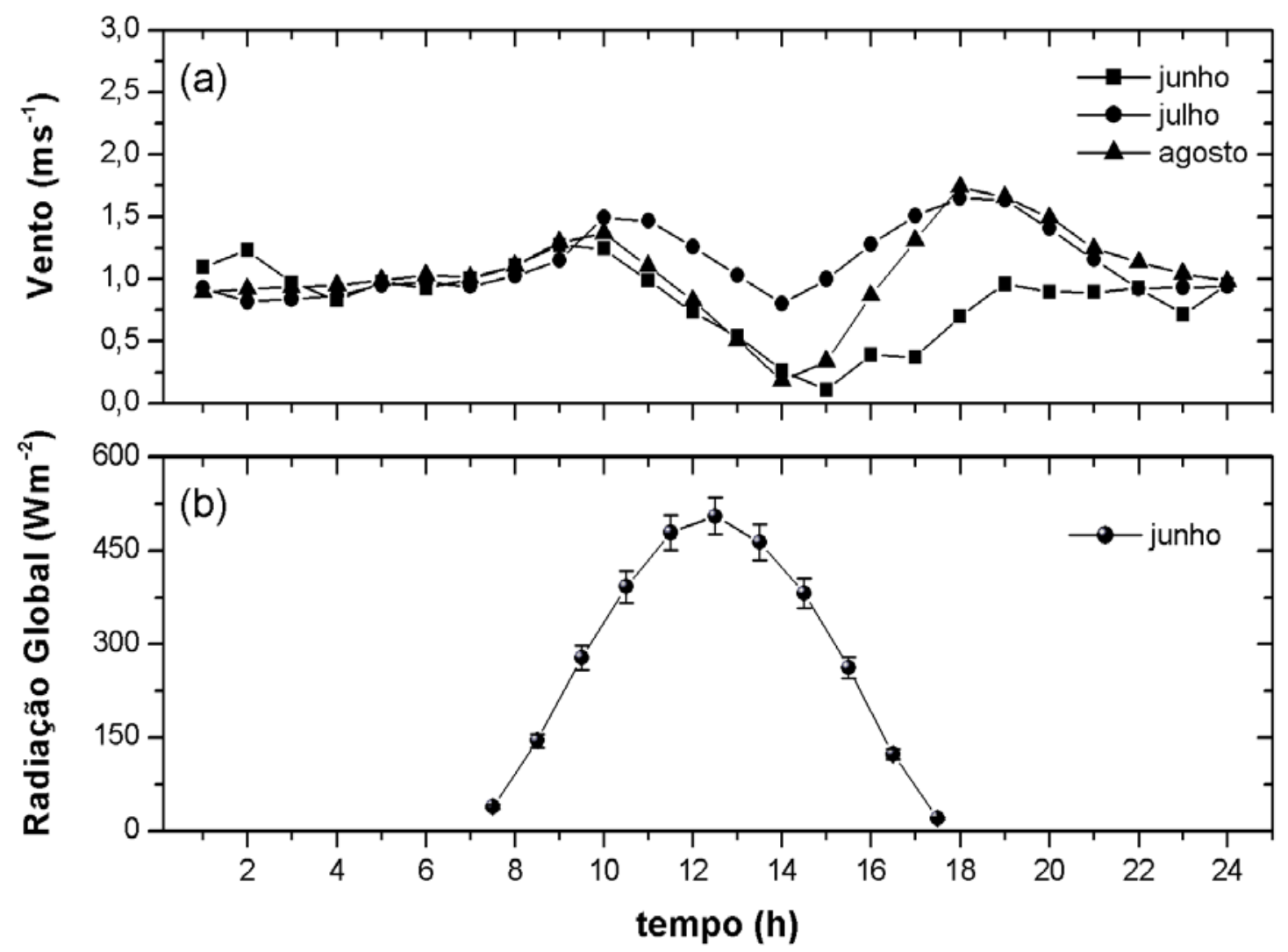

Fig. 5.2 - Média horária mensal: (a) velocidade do vento; (b) radiação solar global. Fonte: Adaptado de Oliveira et al. (2003) (a) e de Oliveira et al. (2002) (b).

Para a solução dos problemas de dispersão de poluentes em regiões urbanas é prática comum utilizar modelos de dispersão tipo pluma gaussiana fornecidos pela agência reguladora norteamericana Enviroment Protection Agency (EPA). Esses modelos adotam uma solução muito simplista para representar a dispersão e apresentam várias deficiências, principalmente em condições de baixa velocidade do vento, sobre terrenos complexos e em condições nãoestacionárias (Weil, 1988; Goyal et al., 2002, Pereira, 2004). 
Existem diversas dificuldades envolvidas na realização de experimentos de campo que forneçam informações detalhadas sobre a estrutura da turbulência na CLP urbana e dos padrões associados à dispersão de poluentes. O elevado custo financeiro envolvido e as dificuldades experimentais de medir as variáveis meteorológicas relevantes fazem com que a utilização de modelos numéricos seja recomendada.

Os modelos operacionais de mesoescala têm resolução horizontal máxima da ordem de $1 \mathrm{~km}$, e são indicados para representar os transportes turbulentos de médio alcance na CLP (Zannetti, 1990), uma vez que parametrizam importantes fenômenos associados aos processos turbulentos nas escalas inferiores a $1 \mathrm{~km}$. Como visto nas seções anteriores, o modelo LES é capaz de reproduzir as principais características da turbulência na CLP convectiva e conseqüentemente, do transporte turbulento de curto alcance. Em virtude disso, será investigado nessa parte da Tese o potencial do modelo LES na validação de modelos operacionais aplicados a estudos de dispersão de poluentes.

O comportamento da dispersão de um poluente inerte e passivo emitido por uma fonte área contínua de $5 \mathrm{~km}$ x $5 \mathrm{~km}$, localizada próxima à superfície é simulado com a utilização do modelo LES. Esse procedimento proporciona uma descrição detalhada da estrutura vertical da CLP como perfis médios, fluxo turbulento, variância e skewness da concentração. Por outro lado, os resultados obtidos com o modelo LES podem servir de base para formulações de novas parametrizações que representem os processos turbulentos em uma CLP altamente convectiva de forma mais precisa.

Apesar da atmosfera modelada ser seca e das condições de fronteira inferior não serem representativas de uma CLP urbana, já que se considerou uma superfície horizontalmente homogênea, os padrões de dispersão simulados podem ser considerados representativos de uma área relativamente plana da RMSP, caracterizada por intenso tráfego de veículos automotores, durante períodos de forte convecção térmica associada à baixa velocidade do vento. Alguns resultados apresentados na literatura corroboram com essa consideração, uma vez que as escalas espaciais das simulações numéricas são da ordem de $5 \mathrm{~km} \mathrm{x} 5 \mathrm{~km}$ nas direções horizontais.

Segundo Cai (1999), em condições altamente convectivas, a rugosidade aerodinâmica não é um parâmetro relevante, pois a geração da turbulência é predominantemente térmica (como pode ser observado nos balanços de ECT apresentados Fig. 4.10). Hetchtel et al. (1990) 
utilizaram o modelo LES para estudar os efeitos da adoção de fluxos turbulentos diferenciais na superfície sobre as propriedades estatísticas da CLP convectiva e não encontraram nenhuma diferença significativa quando comparado às simulações sobre superfícies homogêneas. Resultados similares foram encontrados por Gopalakrishnan e Avissar (2000), onde a inclusão de fluxo diferencial de calor e de topografia não causaram impacto significativo sobre as estatísticas da dispersão para escalas de comprimento da ordem de 5 $\mathrm{km}$.

Para obter estimativas da dispersão de poluentes emitidos por uma fonte do tipo área localizada na superfície foram realizadas duas simulações numéricas (casos DA1 e DA2), cujas condições iniciais correspondem a perfis verticais de concentração igual a 10 ppm nos primeiros 40 níveis da grade (inferior a metade do domínio vertical) e fluxo de poluente na superfície constante e igual a $0,18 \mathrm{ppm} \mathrm{m}^{-2} \mathrm{~s}^{-1}$ (Oliveira, 1986).

A evolução temporal do perfil vertical de concentração de poluente (Fig. 5.3a) indica uma diminuição nos valores de concentração na camada mistura durante a simulação. Essa diminuição é da ordem de $\partial\langle\mathrm{c}\rangle / \partial \mathrm{t} \approx 0,15 \mathrm{ppm} \mathrm{h}^{-1}$, ligeiramente inferior ao valor médio de $0,20 \mathrm{ppm} \mathrm{h}^{-1}$ observado entre às $10 \mathrm{hs}$ e $13 \mathrm{hrs}$ (Fig. 5.1). Essa diminuição está associada ao entranhamento de ar limpo da camada estável acima para dentro da CLP (Wyngaard e Brost, 1984; Moeng e Wyngaard, 1984; Sorbjan, 1999), como será observado nos campos instantâneos das flutuações de velocidade vertical e de concentração de poluente, nas discussões seguintes. A intensa convecção térmica contribui para manter a estrutura vertical da camada bem misturada até a região próxima ao topo da CLP, onde ocorre uma grande variação vertical de concentração $\left\{\langle\Delta \overline{\mathrm{c}}\rangle_{\mathrm{i}}\right\} \approx-8,0 \mathrm{ppm}$.

O fluxo vertical turbulento adimensional de poluente $\left(\left\langle\mathrm{w}^{\prime} \mathrm{c}^{\prime}\right\rangle+\left\langle\tau_{\mathrm{cw}}\right\rangle\right) / \mathrm{w}_{*} \mathrm{C}_{*} \quad$ (Fig. 5.3b) é máximo próximo à superfície e decresce linearmente por toda camada de mistura até atingir $50 \%$ de seu valor inicial em $\mathrm{z} \approx \mathrm{Z}_{\mathrm{i}}$. Ao alcançar a camada de entranhamento, esse decréscimo é mais pronunciado. O fluxo de poluente resultante dos processos de entranhamento está relacionado a variação vertical de concentração $(\Delta \bar{c})_{i}$ e a razão de entranhamento $\left(\mathrm{w}_{\mathrm{e}}=\partial \mathrm{z}_{\mathrm{i}} / \partial \mathrm{t}\right)$, por meio da equação $\left(\left\langle\mathrm{w}^{\prime} \mathrm{c}^{\prime}\right\rangle+\left\langle\tau_{\mathrm{cw}}\right\rangle\right)_{\mathrm{i}}=-\langle\Delta \overline{\mathrm{c}}\rangle \mathrm{w}_{\mathrm{e}}$ obtida por Tennekes (1973). 

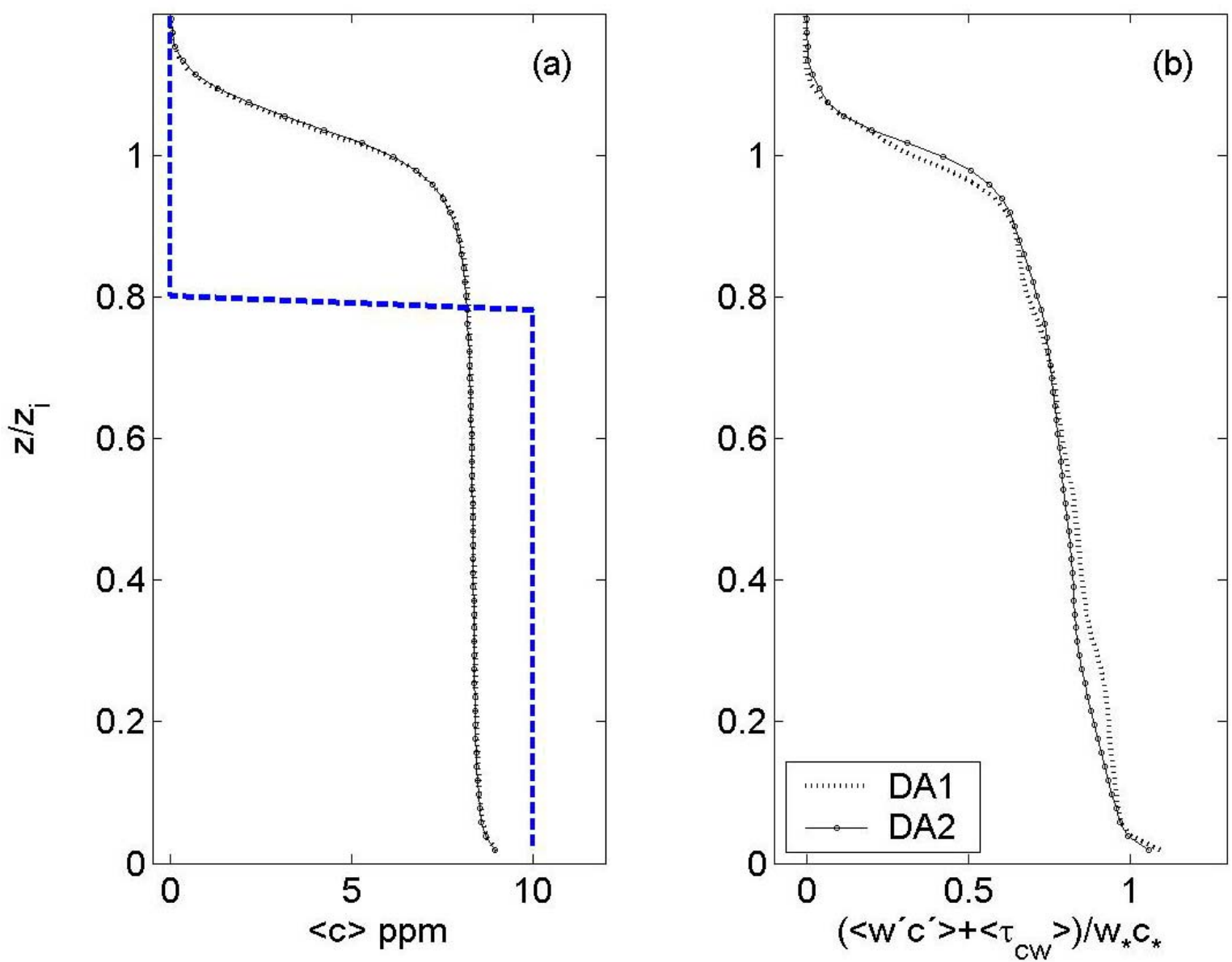

Fig. 5.3 - Perfis verticais: (a) concentração de poluente; (b) fluxo turbulento adimensional de poluente. A linha tracejada em azul representa as condições iniciais.

Após estabelecida a condição de quase-equilíbrio, a média de conjunto da velocidade de entranhamento é $\left\{\mathrm{w}_{\mathrm{e}}\right\} \approx(0,011) \mathrm{ms}^{-1}$, resultando em um fluxo médio de poluente da ordem de $\left(\left\langle\mathrm{w}^{\prime} \mathrm{c}^{\prime}\right\rangle+\left\langle\tau_{\mathrm{cw}}\right\rangle\right)_{\mathrm{i}} \approx 0,09 \mathrm{ppm} \mathrm{ms}^{-1}$, o qual está em acordo com o valor obtido através dos perfis verticais do fluxo turbulento de poluente em $\mathrm{z} \approx \mathrm{Z}_{\mathrm{i}}$.

A variância adimensional da concentração de poluente $\left\langle\mathrm{c}^{\prime 2}\right\rangle / \mathrm{c}_{*}^{2}$ (Fig. 5.4a) tem um pequeno decréscimo na região próxima a CLS e se mantém aproximadamente constante até a metade inferior da CLP. Aumenta acima desta camada até alcançar um máximo em $\mathrm{z} \approx \mathrm{z}_{\mathrm{i}}$, a partir do 
qual volta a decrescer. Os valores elevados de $\left\langle\mathrm{c}^{2}\right\rangle / \mathrm{c}_{*}^{2}$ acima de $\mathrm{z} \approx 0,8 \mathrm{z}_{\mathrm{i}}$ estão relacionados a variação negativa de concentração na camada de entranhamento (Deardorff, 1974b).
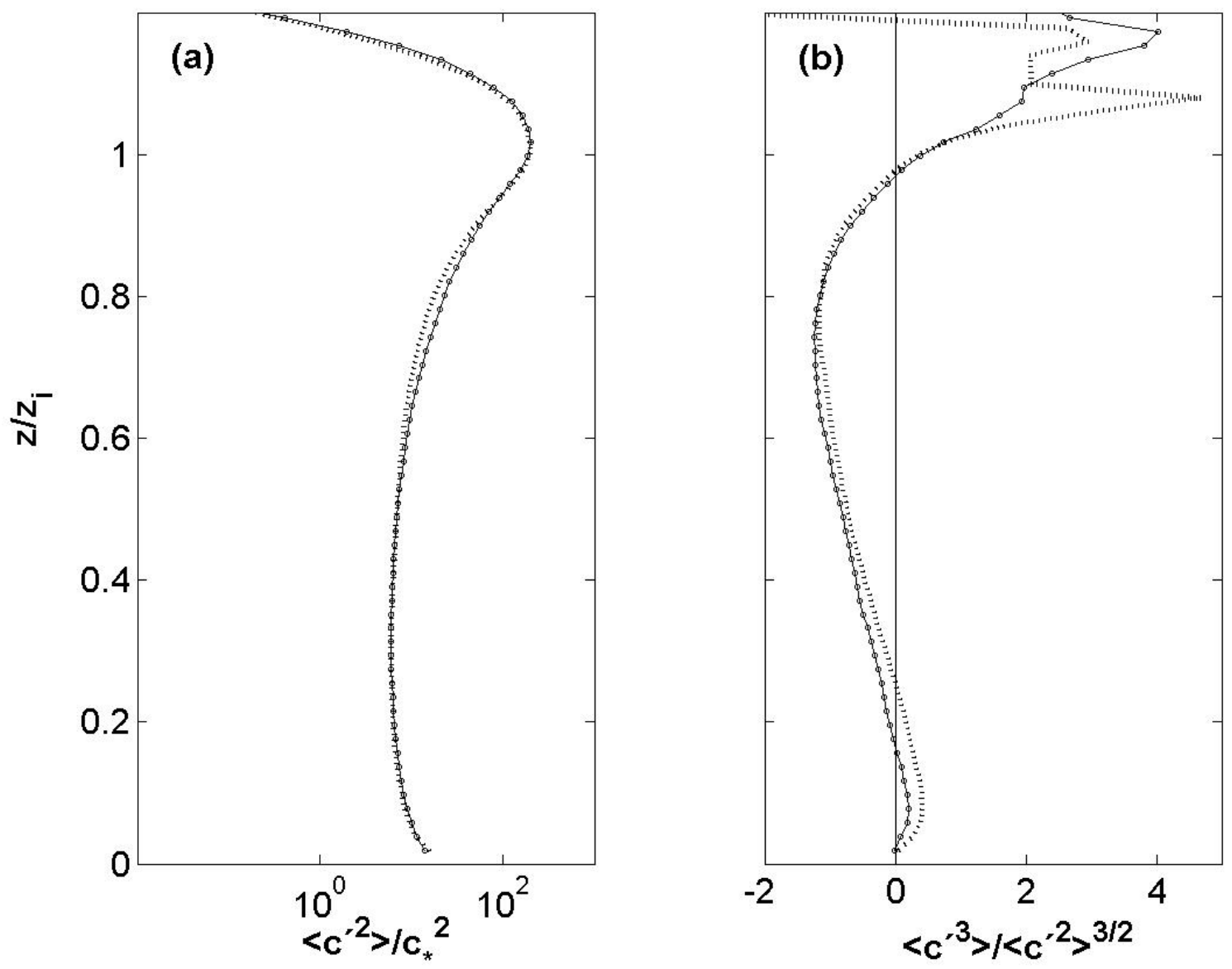

Fig. 5.4 - Perfis verticais adimensionais: (a) fluxo turbulento adimensional de poluente; (b) skewness de concentração de poluente.

Na Fig. (5.4b) observa-se que o perfil vertical do skewness de concentração de poluente $\left\langle c^{\prime 3}\right\rangle /\left\langle c^{\prime 2}\right\rangle^{3 / 2}$ é negativo por quase toda a extensão da camada de mistura, com exceção das regiões próximas a superfície $\left(\mathrm{z}<0,2 \mathrm{z}_{\mathrm{i}}\right)$ e junto ao topo da CLP $\left(\mathrm{z}>0,9 \mathrm{z}_{\mathrm{i}}\right)$. Essas flutuações negativas estão relacionadas à penetração de parcelas de ar limpo no topo da CLP, que descem em direção à superfície em zonas horizontalmente estreitas e verticalmente extensas, provocando uma diminuição da concentração de poluente. Resultados similares foram encontrados por Deardorff (1974b) e por Bernard-Trottolo et al. (2004) para umidade. 
O espalhamento dos perfis próximo ao topo da CLP convectiva pode estar relacionado as diferentes condições iniciais dos casos simulados.

O tempo no qual o poluente atmosférico alcança o topo da CLP é determinado por $\mathrm{t}_{*}$ (turnover time), que nos casos DA1 e DA2 é da ordem de $t_{*} \approx 530 \mathrm{~s}(\approx 9 \mathrm{~min})$ (apresentados na Tabela 4.2).

O processo de limpeza da CLP convectiva pelo entranhamento de parcelas de ar limpo da camada estável acima pode ser visualizado nas Figs. (5.5a e b), onde são apresentados, respectivamente, os cortes verticais dos campos instantâneos de velocidade vertical e concentração de poluente para o caso DA2 em um dado intervalo de tempo $\left(t \approx 12 t_{*}\right)$.

Na Fig. (5.5a) é possível identificar uma região de forte movimento ascendente entre $2000 \mathrm{~m} \leq \mathrm{y} \leq 2500 \mathrm{~m}$ (updrafts), que penetra a camada de inversão e induz movimentos descendentes (downdrafts), que por sua vez trazem ar limpo da camada estável acima para dentro da CLP. Esse processo de limpeza aparece nitidamente junto ao topo da CLP (Fig. 5.5b) e nas regiões onde os níveis de concentração são menores (regiões mais claras), principalmente em $\mathrm{y} \leq 500 \mathrm{~m}$ e entre $3500 \mathrm{~m} \leq \mathrm{y} \leq 4800 \mathrm{~m}$. As regiões com níveis de concentração elevada estão bem correlacionadas com as regiões de updrafts, o que enfatiza o papel dessas estruturas no transporte de poluentes desde a superfície até as camadas superiores da CLP.

Apesar do modelo LES apresentar deficiências na representação dos processos que ocorrem próximo a superfície, os resultados simulados para a fonte do tipo área contínua localizada na superfície são satisfatórios. Possivelmente, isto acontece porque o poluente foi emitido de forma homogênea em todo domínio horizontal inferior da grade desde o instante inicial da simulação (antes mesmo do campo turbulento atingir o estado de quase-equilíbrio). Esses dois aspectos favorecem a interação entre o poluente e o campo velocidade na escala resolvida (da ordem de $z_{i}$ ) minimizando os efeitos de subgrade.

Dessa forma, o grau de limpeza da CLP altamente convectiva está diretamente relacionado à intensidade do processo de entranhamento que influencia, mesmo em regiões próximas à superfície, a distribuição do poluente. A inexistência de dados experimentais de dispersão de poluentes emitidos por uma fonte área contínua dificulta uma abordagem mais detalhada desse tipo de problema. 

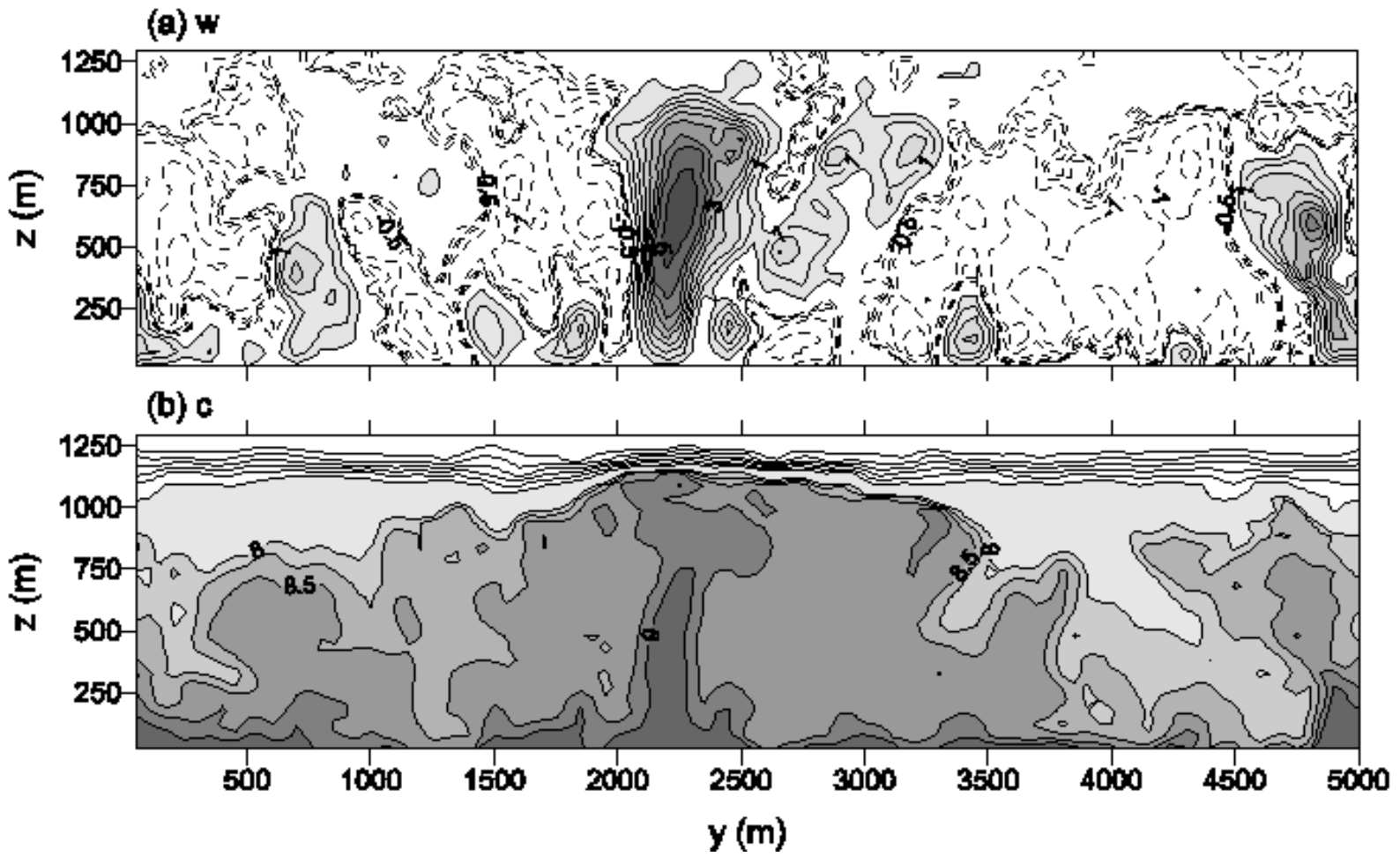

Fig. 5.5 - Campos verticais instantâneos de: (a) velocidade vertical; (b) concentração de poluente (CO); ambas para o caso DA2 em $\mathrm{t} \approx 12 \mathrm{t}_{*}$.

Um dos procedimentos considerado padrão para validação das simulações de dispersão e que será utilizado neste trabalho, consiste na reprodução do comportamento da pluma de um poluente inerte e passivo, emitido por uma fonte pontual contínua localizada em diferentes alturas da CLP (Willis e Deardorff,1974; 1976a; 1978).

Além dessa validação canônica, será investigado o potencial do modelo LES na validação de modelos de dispersão operacionais. A idéia por traz deste procedimento é comparar os campos de concentração gerados por fontes pontuais contínuas, onde o processo de dispersão é representado tanto na forma euleriana quanto lagrangiana. Tendo em vista que o modelo LES é capaz representar o transporte turbulento de forma precisa em ambos os casos, os campos de concentração simulados deverão apresentar um grau elevado de similaridade desde que a dispersão euleriana e lagrangiana esteja representada de forma adequada. 


\section{2 - Dispersão euleriana para fontes pontuais contínuas (alturas elevadas)}

Na CLP convectiva as características da dispersão de poluentes dependem da localização da fonte e não podem ser descritas em termos da teoria de difusão padrão (Lamb, 1984; Weil, 1988; Nieuwstadt e Meeder, 1997). Dessa forma, o modelo LES tornou-se uma importante ferramenta no auxílio ao desenvolvimento de novas teorias, por exemplo, bottom-up/top-down (Moeng e Wyngaard, 1984).

A versão do modelo LES utilizada neste trabalho possui equações prognósticas para determinação da distribuição temporal e espacial de escalares inertes e passivo na CLP. Porém, a condição de fronteira lateral do modelo LES é cíclica o que permite a reentrada do poluente emitido por uma fonte pontual contínua após o mesmo ultrapassar o domínio horizontal da grade, ou seja, para tempos superiores ao travel time. Para contornar essa dificuldade foi adotada a metodologia euleriana proposta por Nieuwstadt e Valk (1987), onde a emissão de poluente por uma fonte pontual contínua é representada pela emissão por uma fonte linha instantânea.

As duas simulações numéricas realizadas têm dimensões e resoluções espaciais da grade iguais as utilizadas nos casos HC1 e HC2 (Tabela 3.1), mas com passo de tempo variável $(2 \mathrm{~s} \leq \Delta \mathrm{t} \leq 3 \mathrm{~s})$. O tempo total da simulação é de aproximadamente $1 \mathrm{~h}$. As condições iniciais foram pré-estabelecidas de forma a gerar CLPs com diferentes graus de instabilidade $\left(-\mathrm{z}_{\mathrm{i}} / \mathrm{L}=580\right.$ e $\left.-\mathrm{z}_{\mathrm{i}} / \mathrm{L}=800\right)$.

No instante de tempo em que os campos turbulentos alcançam o estado de quase-equilíbrio, chamado de instante inicial $\left(\mathrm{t}_{0} \approx 1000 \Delta \mathrm{t}\right)$, uma fonte linha instantânea de um poluente inerte e passivo é introduzida no domínio numérico do modelo e posicionada paralelamente ao eixo longitudinal (x) em uma dada altura z, conforme ilustrado na Fig. (5.6).

De acordo com Nieuwstadt e Valk (1987), a fonte linha instantânea deve ser realocada em diferentes posições longitudinais (x) e laterais (y) de modo a obter um conjunto de simulações independentes da dispersão de poluentes. Nos casos apresentados nesse trabalho optou-se pela utilização de um conjunto de 14 realizações (campos tridimensionais) obtidas a partir de cada uma das simulações realizadas de forma independente. 
A distribuição inicial da concentração de poluente na grade é assumida gaussiana, como forma de reduzir valores espúrios e negativos das flutuações de concentração causadas pelo esquema numérico (Cai, 2000).
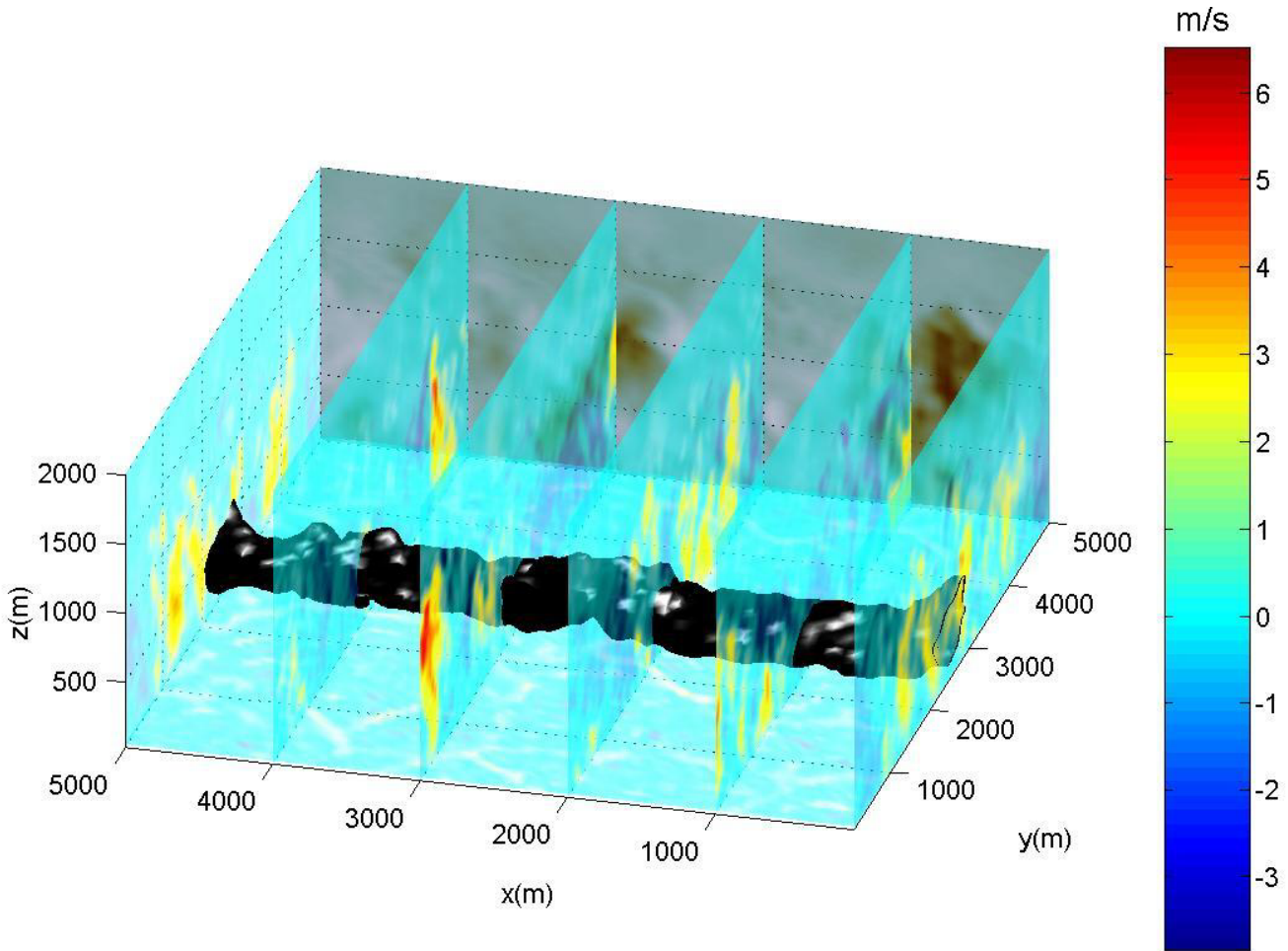

Fig. 5.6 - Configuração tridimensional inicial da linha fonte instantânea de um poluente inerte e passivo na grade (superfície em preto) no instante $\mathrm{t} \approx \mathrm{t}_{0}$. Os cortes instantâneos distribuídos pelo volume representam a velocidade vertical na escala resolvida indicada na barra de cores.

A evolução da linha fonte é calculada simultaneamente aos campos de velocidade gerados pelo modelo LES resolvendo-se a equação de conservação do poluente (Eq. 2.16).

Os resultados obtidos para fonte linha instantânea podem ser interpretados em termos da dispersão de um poluente emitido por uma fonte pontual contínua se a difusão da pluma ao longo da direção longitudinal (downstream) for desprezível com respeito ao transporte horizontal, ou seja, $1,2 \mathrm{w}_{*} \leq \overline{\mathrm{U}} \leq 6,0 \mathrm{w}_{*}$. Tal interpretação é baseada na aplicação da hipótese de Taylor $\left(\mathrm{t}_{\mathrm{T}}=\mathrm{x} / \overline{\mathrm{U}}\right)$. Com isso, o tempo de liberação do poluente pode ser associado à distância adimensional longitudinal da fonte (Willis e Deardorff, 1976b; Nieuwstadt e Valk, 
1987). Porém, a velocidade do vento horizontal adotada nas simulações é inferior a $1 \mathrm{~m} \mathrm{~s}^{-1}$ (isto é, $\overline{\mathrm{U}} \leq 0,5 \mathrm{w}_{*}$ ), valor este que está fora o limite de validade sugerido por Willis e Deardorff para aplicação da hipótese de Taylor $\left(1,2 \mathrm{w}_{*} \leq \overline{\mathrm{U}} \leq 6,0 \mathrm{w}_{*}\right)$. Portanto, fez-se necessário a utilização do tempo de liberação (t) em substituição a escala de tempo de Willis e Deardorff $\left(t_{T}=x / \bar{U}\right)$. Dessa forma, considerou-se a distância adimensional longitudinal da fonte dada por: $\mathrm{X}_{*} \approx \frac{\mathrm{W}_{*}}{\mathrm{z}_{\mathrm{i}}} \mathrm{t}$ ao invés de $\mathrm{X}_{*} \approx \frac{\mathrm{W}_{*}}{\mathrm{z}_{\mathrm{i}}} \frac{\mathrm{X}}{\overline{\mathrm{U}}}$.

A concentração integrada lateralmente é definida por:

$$
\overline{\mathrm{C}}_{\mathrm{y}}(\mathrm{z}, \mathrm{t})=\int_{\mathrm{Ly}} \int_{\mathrm{Lx}} \overline{\mathrm{c}}(\mathrm{x}, \mathrm{y}, \mathrm{z}, \mathrm{t}) \mathrm{dx} \mathrm{dy}
$$

onde $\bar{c}$ é a concentração instantânea e Lx e Ly são as extensões do domínio horizontal na direção longitudinal e lateral, respectivamente. A concentração $\overline{\mathrm{c}}_{\mathrm{y}}(\mathrm{z}, \mathrm{t})$ é adimensionalizada dividindo-a por $\mathrm{M} / \mathrm{z}_{\mathrm{i}}$, onde $\mathrm{M}$ é a massa total de poluente inserida na fonte linha.

Para que a condição de conservação de massa seja satisfeita o valor da concentração $\overline{\mathrm{C}}_{\mathrm{y}}(\mathrm{z}, \mathrm{t}) / \mathrm{M}$ integrada por toda a CLP deve ser igual a 1,0. Durante o período de simulação $\overline{\mathrm{c}}_{\mathrm{y}}(\mathrm{z}, \mathrm{t}) / \mathrm{M}$ variou entre 1,0 e 0,98, resultando numa margem de erro menor ou igual a $2 \%$.

Na Fig. (5.7) são apresentadas as concentrações adimensionais integradas lateralmente $\overline{\mathrm{c}}_{\mathrm{y}}(\mathrm{z}, \mathrm{t}) \mathrm{z}_{\mathrm{i}} / \mathrm{M}$ para um poluente emitido nas respectivas alturas adimensionais, $\mathrm{z}_{\mathrm{s}} \approx 0,20 \mathrm{z}_{\mathrm{i}} \mathrm{e}$ $\mathrm{z}_{\mathrm{s}} \approx 0,45 \mathrm{z}_{\mathrm{i}}$, onde $\mathrm{z}_{\mathrm{s}}$ é a altura da fonte.

Apesar da curta distância adimensional da fonte simulada $\left(\mathrm{X}_{*} \leq 1.6\right)$ os campos de $\overline{\mathrm{c}}_{\mathrm{y}}(\mathrm{z}, \mathrm{t}) \mathrm{z}_{\mathrm{i}} / \mathrm{M}$ concordam qualitativamente com os resultados apresentados na literatura (Willis e Deardorff, 1978; Henn e Sykes, 1992; Rizza et al., 2003) e reproduzem o comportamento esperado da pluma de um poluente inerte e passivo emitido na CLP convectiva. 

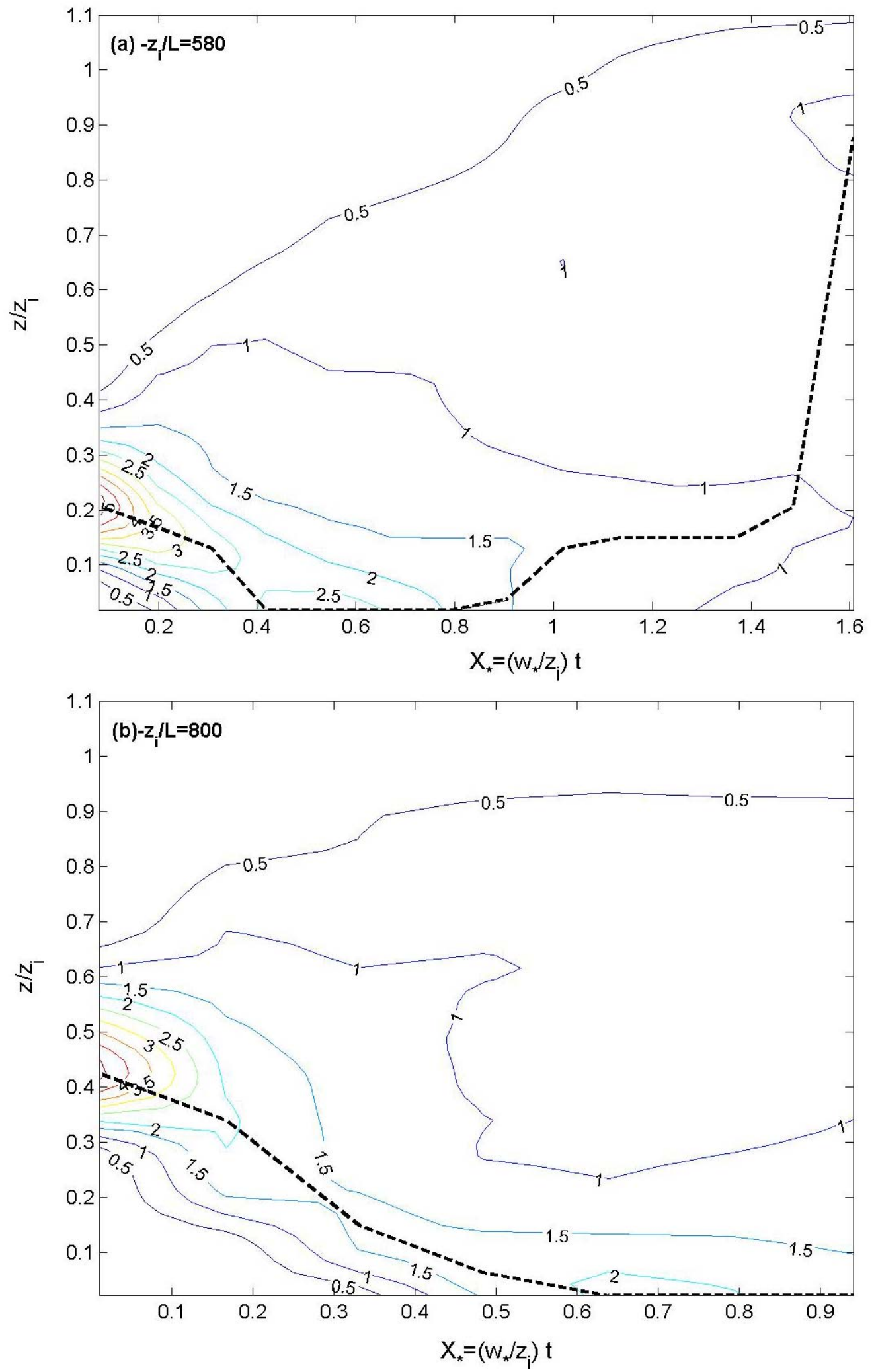

Fig. 5.7 - Concentração média adimensional integrada lateralmente em função da distância longitudinal adimensional da fonte. Fontes pontuais contínuas localizadas em: (a) $\mathrm{z}_{\mathrm{s}} \approx 0,20 \mathrm{z}_{\mathrm{i}}$ e (b) $\mathrm{z}_{\mathrm{s}} \approx 0,45 \mathrm{z}_{\mathrm{i}}$. A linha tracejada representa a concentração máxima. 
No caso do poluente liberado em $\mathrm{z}_{\mathrm{s}} \approx 0,20 \mathrm{z}_{\mathrm{i}}$ (Fig. 5.7a), a concentração máxima $\overline{\mathrm{c}}_{\max }$ se propaga para baixo e atinge a superfície em $\mathrm{X}_{*} \approx 0,4$. Entre $0,4 \leq \mathrm{X}_{*} \leq 0,8$ a concentração é máxima na superfície e a partir de $\mathrm{X}_{*}>0,8$ a pluma afasta-se da mesma, alcançando as camadas superiores. A concentração se mantêm máxima na superfície por uma distância $\Delta \mathrm{X}_{*} \approx 0,4 \quad\left(0,4 \leq \mathrm{X}_{*} \leq 0,8\right)$, equivalente a obtida por Willis e Deardorff (1978).

Para a fonte de emissão localizada em $\mathrm{z}_{\mathrm{s}} \approx 0,45 \mathrm{z}_{\mathrm{i}}$ (Fig. 5.7b) a concentração é máxima na superfície em $\mathrm{X}_{*} \approx 0,6$, que está de acordo com os resultados apresentados por Henn e Sykes (1992). Porém, não é possível estimar a distância na qual $\overline{\mathrm{c}}_{\max }$ permanece próximo a superfície devido ao tempo curto da simulação.

Essas características de dispersão podem ser compreendidas em termos da liberação do poluente dentro dos updrafts e downdrafts. De acordo com Lamb (1984), o fenômeno que causa o movimento descendente da pluma próximo à origem para fontes de emissão localizadas em alturas elevadas $\left(\mathrm{z}_{\mathrm{s}}>0,1 \mathrm{z}_{\mathrm{i}}\right)$ é a assimetria da função densidade de probabilidade da velocidade vertical da escala resolvida $(\overline{\mathrm{w}})$ no plano horizontal.

Nas Figs. (5.8) são apresentadas as distribuições de freqüências da velocidade vertical adimensional nos respectivos níveis de emissão. Os resultados estão de acordo com o padrão não-gaussiano da dispersão vertical de poluente inertes e passivos na CLP convectiva. Quanto mais próximo à superfície é a localização da fonte, mais a moda desta distribuição se distância de $\mathrm{w} / \mathrm{w}_{*}=0$ (Lamb, 1984; Weil, 1988). Apesar de grande parte do plano horizontal ser dominado pelos movimentos descendentes ( $\approx 60 \%$ de downdrafts), o skewness da velocidade vertical é positivo, uma vez que os updrafts são bem mais intensos (como pode ser observado na Fig. 4.9b).

O padrão assimétrico da distribuição vertical do poluente na CLP também pode ser observado nos perfis verticais de concentração integrada lateralmente (Eq. 5.1) adimensionalizada pela concentração máxima em diferentes distâncias adimensionais $\overline{\mathrm{C}}_{\mathrm{y}}\left(\mathrm{X}_{*}, \mathrm{z}\right) / \overline{\mathrm{c}}_{\max }\left(\mathrm{X}_{*}, \mathrm{z}\right)$ (Fig. 5.9).

Observa-se que a distribuição vertical do poluente deixa de ser gaussiana em uma curta distância após a emissão $\left(\mathrm{X}_{*}=0,1\right)$. A concentração é máxima na superfície entre 
$0,3 \leq X_{*} \leq 0,5$. Para distâncias adimensionais $\left(X_{*} \geq 1,0\right)$, a variação vertical do poluente é relativamente pequena e tende a se tornar uniformemente distribuída por toda camada (Henn e Sykes, 1992; Cai, 2000).

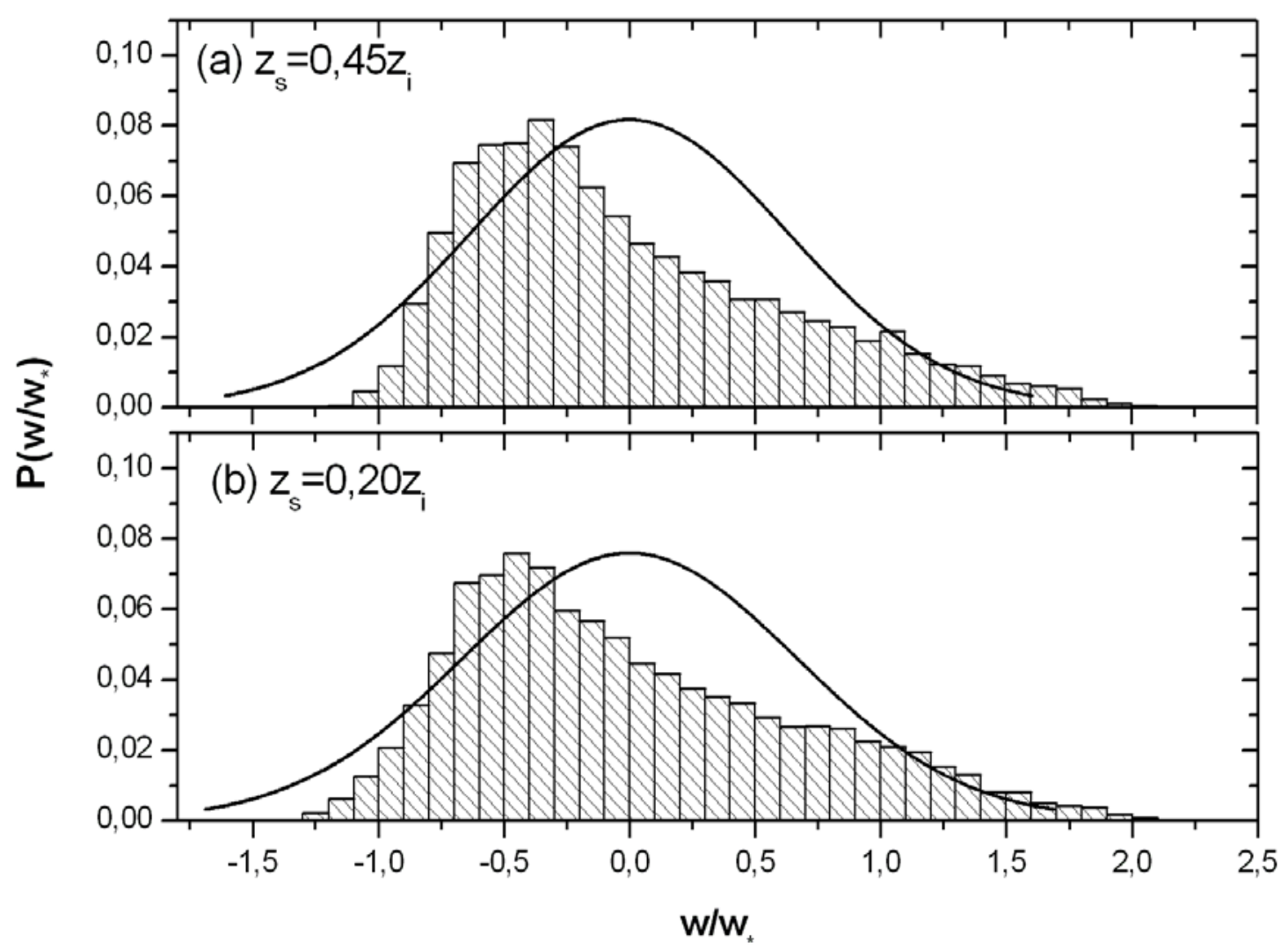

Fig. 5.8 - Distribuição de freqüências da velocidade vertical adimensional no plano horizontal para os níveis de emissão: (a) $\mathrm{z}_{\mathrm{s}} \approx 0,45 \mathrm{z}_{\mathrm{i}}$ e (b) $\mathrm{z}_{\mathrm{s}} \approx 0,20 \mathrm{z}_{\mathrm{i}}$. A linha contínua em preto representa a distribuição gaussiana.

Na Fig. (5.10) são apresentadas as concentrações adimensionais ao nível da superfície $\left(\overline{\mathrm{c}}_{\mathrm{y}} \mathrm{z}_{\mathrm{i}} / \mathrm{M}\right)_{0}$ para as duas alturas de emissão. Para fonte de emissão localizada em $\mathrm{z}_{\mathrm{s}} \approx 0,20 \mathrm{z}_{\mathrm{i}}$ (Fig. 5.10a) a distribuição de $\left(\overline{\mathrm{C}}_{\mathrm{y}} \mathrm{z}_{\mathrm{i}} / \mathrm{M}\right)_{0}$ ajusta-se perfeitamente aos dados experimentais de Willis e Deardorff, inclusive com relação a posição do máximo.

No caso da fonte localizada em $\mathrm{z}_{\mathrm{s}} \approx 0,45 \mathrm{z}_{\mathrm{i}}$ (Fig. 5.10b) $\left(\overline{\mathrm{c}}_{\mathrm{y}} \mathrm{z}_{\mathrm{i}} / \mathrm{M}\right)$ é máximo em $\mathrm{X}_{*} \approx 0,7$, inferior a distância adimensional $\mathrm{X}_{*} \approx 0,8$ obtida por Willis e Deardorff (1981) e Venkatran 
(1983). Essa diferença pode estar relacionada à baixa velocidade horizontal do vento considerada nas simulações, o que faz com que o transporte vertical de poluente seja mais efetivo (Sharan et al., 1996; Goyal et al., 2000). De acordo com Weil et al. (1997 e 2000) as condições de estabilidade também influênciam o padrão de dispersão, ou seja, quanto menor $-\mathrm{z}_{\mathrm{i}} / \mathrm{L}$ mais lenta é a dispersão de poluentes.

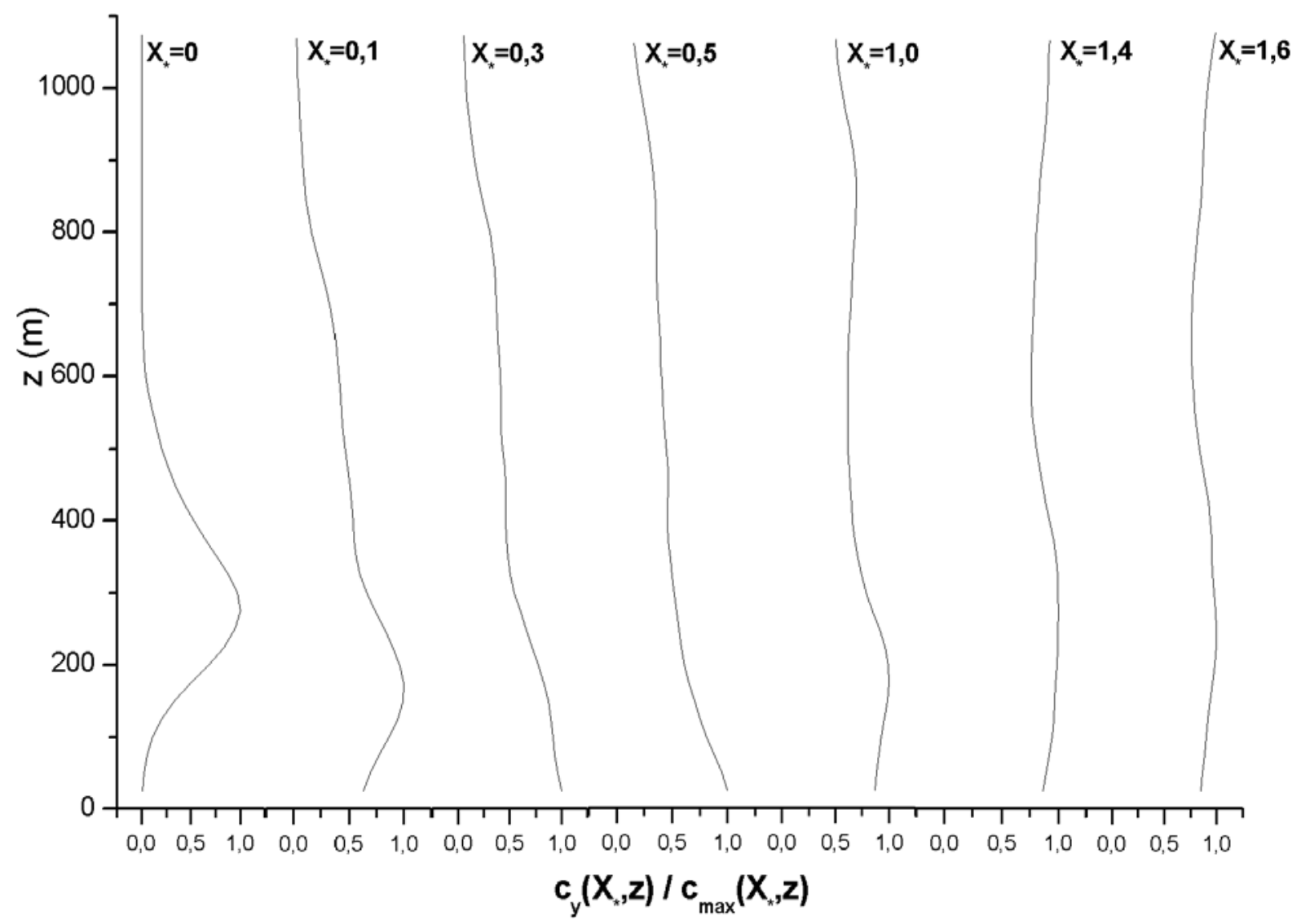

Fig. 5.9 - Perfis verticais adimensionais de concentração média integrada em diferentes instantes de tempos, onde $c_{\max }$ é o valor máximo da concentração em cada instante de tempo.

Para fontes localizadas próximo à superfície $\left(\mathrm{z}<0,1 \mathrm{z}_{\mathrm{i}}\right)$, as simulações numéricas realizadas com o modelo LES não foram capazes de reproduzir o comportamento esperado da pluma, e portanto, os estudos de dispersão euleriana ficaram restritos a fontes elevadas.

Segundo Henn e Sykes (1992), esse problema refere-se à incapacidade do modelo LES em resolver os movimentos de pequena escala (subgrade) que são os principais responsáveis pela 
dispersão de poluentes nessa região. Porém, vale ressaltar, que o limitado número de simulações realizadas (duas) pode ter sido insuficiente para obtenção de médias de conjunto que representem significativamente as propriedades estatísticas da dispersão de poluentes (sujeitas a variabilidades). O ideal seria a realização um conjunto maior de simulações para que o comportamento médio da pluma do poluente seja estatisticamente representativo do campo turbulento, interagindo com um número significativo de turbilhões.

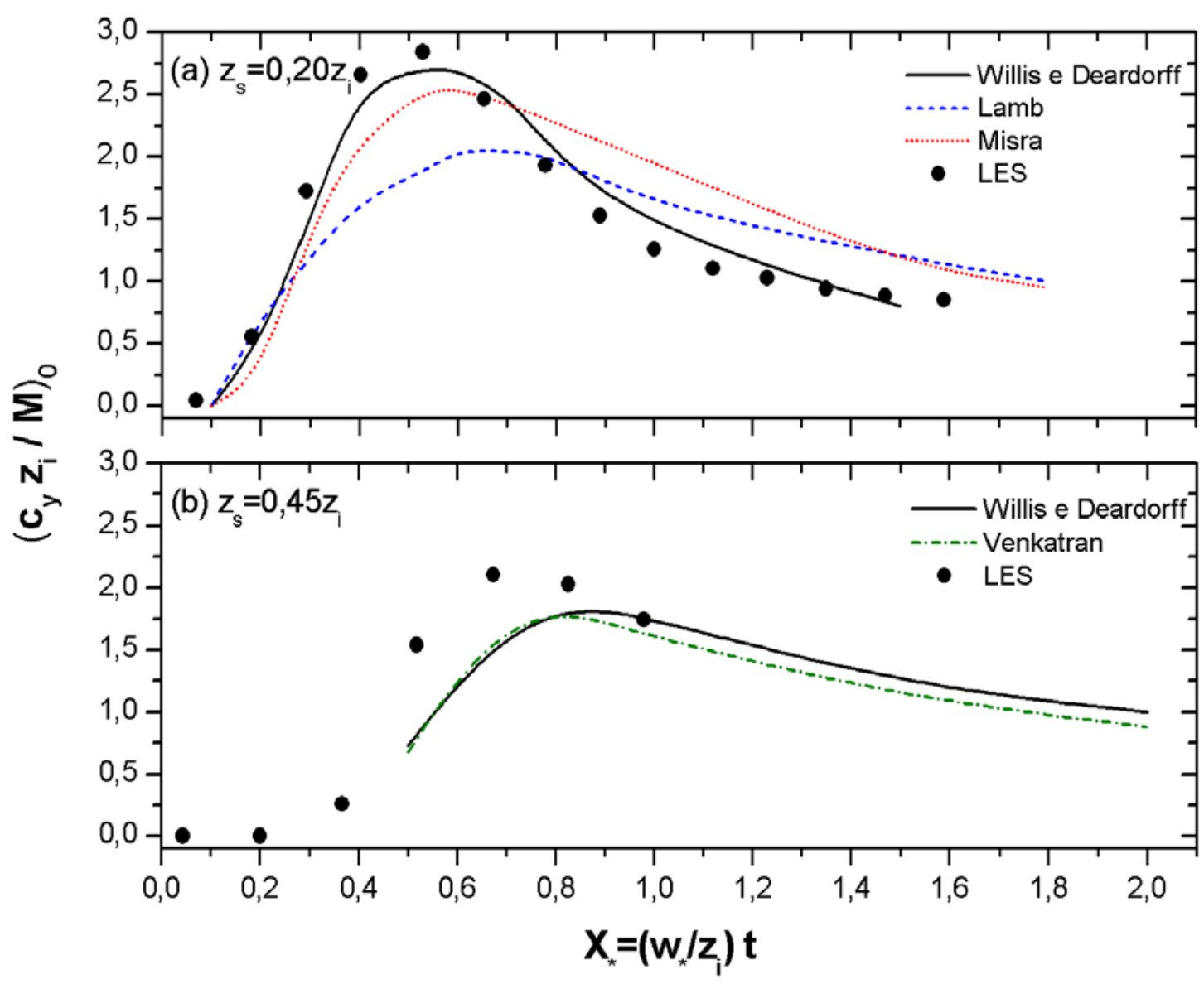

Fig. 5.10 - Concentração média adimensional ao nível da superfície para fontes pontuais contínuas localizadas em: (a) $\mathrm{z}_{\mathrm{s}}=0,20 \mathrm{z}_{\mathrm{i}}$; (b) $\mathrm{z}_{\mathrm{s}}=0,45 \mathrm{z}_{\mathrm{i}}$. Os círculos em preto representam as simulações eulerianas realizadas e as curvas os dados experimentais (Willis e Deardorff, 1978 e 1981) e modelos numéricos baseados em fdps (Misra,1982; Venkatran; 1983; Lamb, 1984).

Quantitativamente, os resultados obtidos pela metodologia euleriana para estudos de dispersão de poluentes na CLP altamente convectiva reproduziram o comportamento esperado da pluma 
para fontes de emissão localizadas em alturas elevadas $\left(\mathrm{z}_{\mathrm{s}}>0,1 \mathrm{z}_{\mathrm{i}}\right)$. Portanto, espera-se que os padrões de dispersão de um poluente emitido por fonte área contínua localizada na superfície sejam representativos do comportamento da dispersão de CO na RMSP (seção 5.1). As simulações eulerianas da dispersão de poluentes foram realizadas com a versão antiga do código serial do modelo LES implementado no supercomputador CRAY-J90. A capacidade de processamento e o espaço disponível para o armazenamento dos dados não permitiam a realização de simulações simultâneas por longos períodos de tempo $(5.000 \leq \Delta \mathrm{t} \leq 10.000)$. Desse modo, seriam necessários meses para que fosse possível obter um conjunto de simulações representativo. Essa é uma das desvantagens de utilizar a metodologia proposta por Nieuwstadt e Valk (1987).

Para contornar este problema seria necessário implementar uma rotina de dispersão euleriana que estimasse a concentração de poluentes após a determinação dos campos de velocidade simulados numericamente pelo modelo LES, de acordo com procedimento adotado por Rizza et al. (2003). A vantagem desta metodologia é a possibilidade de realizar simulações de dispersão sobre fontes pontuais contínuas sem a adoção de aproximações como a utilizada neste trabalho. Além disso, o poluente que ultrapassar o domínio horizontal da grade pode ser abandonado, o que evitaria os problemas com condição de fronteira cíclica. A principal desvantagem deste método é a necessidade de técnicas numéricas que satisfaçam: (a) conservação de massa; (b) concentração sempre positiva; (c) baixa difusão e baixa dispersão numérica.

Sendo assim, as comparações das estimativas de dispersão euleriana e lagrangiana ficarão restritas a concentração ao nível da superfície para fontes elevadas.

\section{3 - Dispersão lagrangiana para fontes pontuais contínuas}

A abordagem lagrangiana é uma forma alternativa de estudar a dispersão de um poluente inerte e passivo na CLP, uma vez que não necessita da aplicação da teoria de difusão padrão. Nesta aproximação, a concentração de um poluente é determinada por meio da distribuição espacial de um conjunto de partículas liberadas continuamente, ou instantaneamente, em diferentes locais da CLP convectiva (Lamb, 1984; Nieuwstadt e Meeder, 1997; Gopalakrishnan e Avissar, 2000; Weil et al., 2000; Gioia et al, 2004). 
Para investigar a dispersão de poluentes do ponto de vista lagrangiano realizou-se um conjunto de quatro simulações, com a fonte de emissão localizada em diferentes alturas da CLP convectiva. A grade numérica é de $96^{3}$ pontos cobrindo um domínio espacial de $10 \mathrm{~km} \mathrm{x}$ 10 km x 2 km nas direções x, y e z, respectivamente.

As condições iniciais são similares as adotadas nas simulações anteriores, com velocidade do vento médio $(\bar{U})$ igual a $2,5 \mathrm{~ms}^{-1}$ ou $4,0 \mathrm{~ms}^{-1}$. Essas condições geraram CLPs altamente convectivas duas intensidades de convecção, $-\mathrm{Z}_{\mathrm{i}} / \mathrm{L} \approx 150\left(\overline{\mathrm{U}} \approx 1,2 \mathrm{w}_{*}\right)$ e $-\mathrm{z}_{\mathrm{i}} / \mathrm{L} \approx 70\left(\overline{\mathrm{U}} \approx 1,9 \mathrm{w}_{*}\right)$, que concordam com os limites de validade estabelecidos por Willis e Deardorff (1976b) para aplicação da hipótese de Taylor $\left(1,2 \mathrm{w}_{*} \leq \overline{\mathrm{U}} \leq 6,0 \mathrm{w}_{*}\right)$. Desse modo, é possível converter o tempo de liberação em distância longitudinal adimensional da fonte $\mathrm{X}_{*}=\left(\mathrm{w}_{*} / \mathrm{z}_{\mathrm{i}}\right)(\mathrm{x} / \overline{\mathrm{U}})$, onde $\mathrm{t}_{\mathrm{T}}=\mathrm{x} / \overline{\mathrm{U}}$ representa o tempo gasto para as partículas percorrerem o domínio longitudinal (travel time) e $\mathrm{z}_{\mathrm{i}} / \mathrm{w}_{*}$ é a escala de tempo lagrangina (turnover time) (Weil et al, 2000).

Para garantir a aplicação da hipótese de Taylor as simulações de dispersão lagrangiana foram realizadas com condições de estabilidade altamente convectivas diferentes das adotodas nas simulações eulerianas (seção 5.2).

Após os campos turbulentos atingirem a condição de quase-equilíbrio, as partículas são inseridas por fontes pontuais contínuas distribuídas ao longo da direção lateral no início do domínio longitudinal da grade. A inclusão de mais de uma fonte pontual torna o processo de dispersão mais eficiente, uma vez que as partículas inseridas no domínio irão sofrer influência de um número representativo de turbilhões.

Nos estudos de dispersão são consideradas duas alturas de emissões distintas, próximo à superfície $\left(\mathrm{z}_{\mathrm{s}}=0,07 \mathrm{z}_{\mathrm{i}}\right)$ e no meio da $\operatorname{CLP}\left(\mathrm{z}_{\mathrm{s}}=0,50 \mathrm{z}_{\mathrm{i}}\right)$. Essas alturas são similares às adotadas por Willis e Deardorff em seus experimentos de laboratório. Nas fronteiras superior (camada de inversão) e inferior (superfície) são assumidas a reflexão de partículas, e nas fronteiras laterais (cíclicas) as partículas que cruzam o domínio horizontal são abandonadas. A taxa de emissão de poluente (Q) variou de 10 a 40 partículas a cada $\Delta \mathrm{t}$, gerando um número total de partículas presentes no domínio da grade entre 18.000 e 46.000 . 
As trajetórias das partículas são integradas de acordo com a Eq. (2.18) por um período aproximado de $50 \mathrm{~min}$, já descontado o tempo que as partículas levam para percorrer o domínio longitudinal (x/Ū) (Rizza et al., 2003). O campo velocidade necessário para integrar a Eq. (2.18) é obtido por meio de uma interpolação bilinear com os oito pontos de grade mais próximos da partícula, nos quais estão definidos os campos tridimensionais de velocidade gerados pelo modelo LES (Press et al., 1986).

Vale ressaltar que nas simulações realizadas neste estudo nenhum modelo de subgrade é utilizado para descrever as trajetórias de partículas na escala não resolvida. Primeiramente, por se tratar de simulações de dispersão em condições convectivas, onde os grandes turbilhões apresentam escalas da ordem da altura da CLP, e posteriormente, em função da alta resolução espacial da grade $(\Delta x \approx 104 \mathrm{~m})$ (Nieuwstadt e Meeder, 1997; Gopalakrishnan e Avissar, 2000).

No caso da dispersão lagrangiana, a concentração média integrada lateralmente é definida por:

$$
\overline{\mathrm{c}}_{\mathrm{y}}(\mathrm{x}, \mathrm{z})=\frac{1}{\Delta \mathrm{T}} \int_{\Delta \mathrm{T}} \int_{\mathrm{Ly}} \overline{\mathrm{c}}(\mathrm{x}, \mathrm{y} \cdot \mathrm{z}) \mathrm{dydt}
$$

onde $\Delta \mathrm{T}$ é o intervalo de tempo total considerado na determinação da concentração média $(\approx 50 \mathrm{~min})$ e Ly é igual a $10.000 \mathrm{~m}$. A adimensionalização de $\overline{\mathrm{c}}_{\mathrm{y}}(\mathrm{x}, \mathrm{z})$ é feita dividindo-a por $\mathrm{Q} / \overline{\mathrm{U}} \mathrm{z}_{\mathrm{i}}$ e a distância adimensional da fonte é definida por $\mathrm{X}_{*}$.

Baseados na concentração média, diversos parâmetros estatísticos da dispersão de poluentes podem ser computados. Entre eles, a altura média da pluma, dada por:

$$
\overline{\mathrm{Z}}=\frac{\int_{0}^{\mathrm{z}_{\mathrm{i}}} \mathrm{z} \overline{\mathrm{C}}_{\mathrm{y}}(\mathrm{x}, \mathrm{z}) \mathrm{dz}}{\int_{0}^{\mathrm{z}_{i}} \overline{\mathrm{C}}_{\mathrm{y}}(\mathrm{x}, \mathrm{z}) \mathrm{dz}}
$$

e o parâmetro de dispersão vertical da pluma, definido como:

$$
\overline{z^{2}}=\frac{\int_{0}^{z_{i}}\left(z-z_{s}\right)^{2} \bar{c}_{y}(x, z) d z}{\int_{0}^{z_{i}} \bar{c}_{y}(x, z) d z}
$$


As plumas do poluente, representadas por $\overline{\mathrm{c}}_{\mathrm{y}} \mathrm{Uz}$ i $/ \mathrm{Q}$, geradas pelas diferentes simulações são apresentadas nas Figs. (5.11). No caso de fontes de emissão localizadas próximas à superfície $\mathrm{z}_{\mathrm{s}}=0,07 \mathrm{z}_{\mathrm{i}}$ (Figs. 5.11a e 5.11b) o comportamento da pluma para as diferentes condições de estabilidade são bastante similares, com o máximo de concentração ascendendo após percorrer uma curta distância longitudinal. Esse comportamento é causado pela convergência das partículas localizadas próximo à superfície para dentro dos updrafts, que as transportam verticalmente causando um máximo de concentração na parte superior da CLP, como evidenciado pelo contorno fechado de $\overline{\mathrm{C}}_{\mathrm{y}} \mathrm{Uz} / \mathrm{Q}=1$,25. A reprodução dessa região de máximo está de acordo com os dados de laboratório de Willis e Deardorff (1976a) e com as simulações numéricas realizadas por Gopalakrishnan e Avissar (2000) e Weil et al. (2000).

Nota-se também, que no caso onde $-\mathrm{z}_{\mathrm{i}} / \mathrm{L}=150$ (Fig. 5.11b) a região de máxima de concentração na parte superior da CLP é mais extensa que encontrada no caso onde $-\mathrm{z}_{\mathrm{i}} / \mathrm{L}=70$ (Fig. 5.11a). Segundo Weil et al. (1997 e 2000) a variação da escala de tempo lagrangiana com a estabilidade determina este padrão de dispersão.

Para fontes de emissão localizadas em alturas elevadas $z_{s}=0,50 z_{i}$ (Figs. 5.11c e 5.11d) os resultados concordam qualitativamente com os simulados anteriormente pela metodologia euleriana (Fig. 5.7b). Como será discutido posteriormente, tais diferenças refletem as distintas condições de estabilidade das simulações (Weil et al., 1997 e 2000).

A altura adimensional da pluma $\overline{\mathrm{z}} / \mathrm{z}_{\mathrm{i}}$ e seu parâmetro de dispersão vertical $\overline{\mathrm{z}^{2}} / \mathrm{z}_{\mathrm{i}}$ dão uma clara idéia sobre as influências da estrutura assimétrica da turbulência sobre a dispersão de poluentes. No caso de fontes de emissão localizadas próximo à superfície (Figs. 5.11a e 5.11b), mais da metade das partículas são transportadas para a região superior da CLP em uma distância adimensional $\mathrm{X}_{*} \approx 1$ (equivalente ao tempo de emissão $\mathrm{t} \approx 1 \mathrm{t}_{*}$ ). Para distâncias maiores a tendência é que a intensa mistura vertical da camada torne o campo de concentração homogêneo (bem misturado), o que faz com a altura média da pluma permaneça próxima ao nível $\mathrm{z} \approx 0,5 \mathrm{z}_{\mathrm{i}}$. 

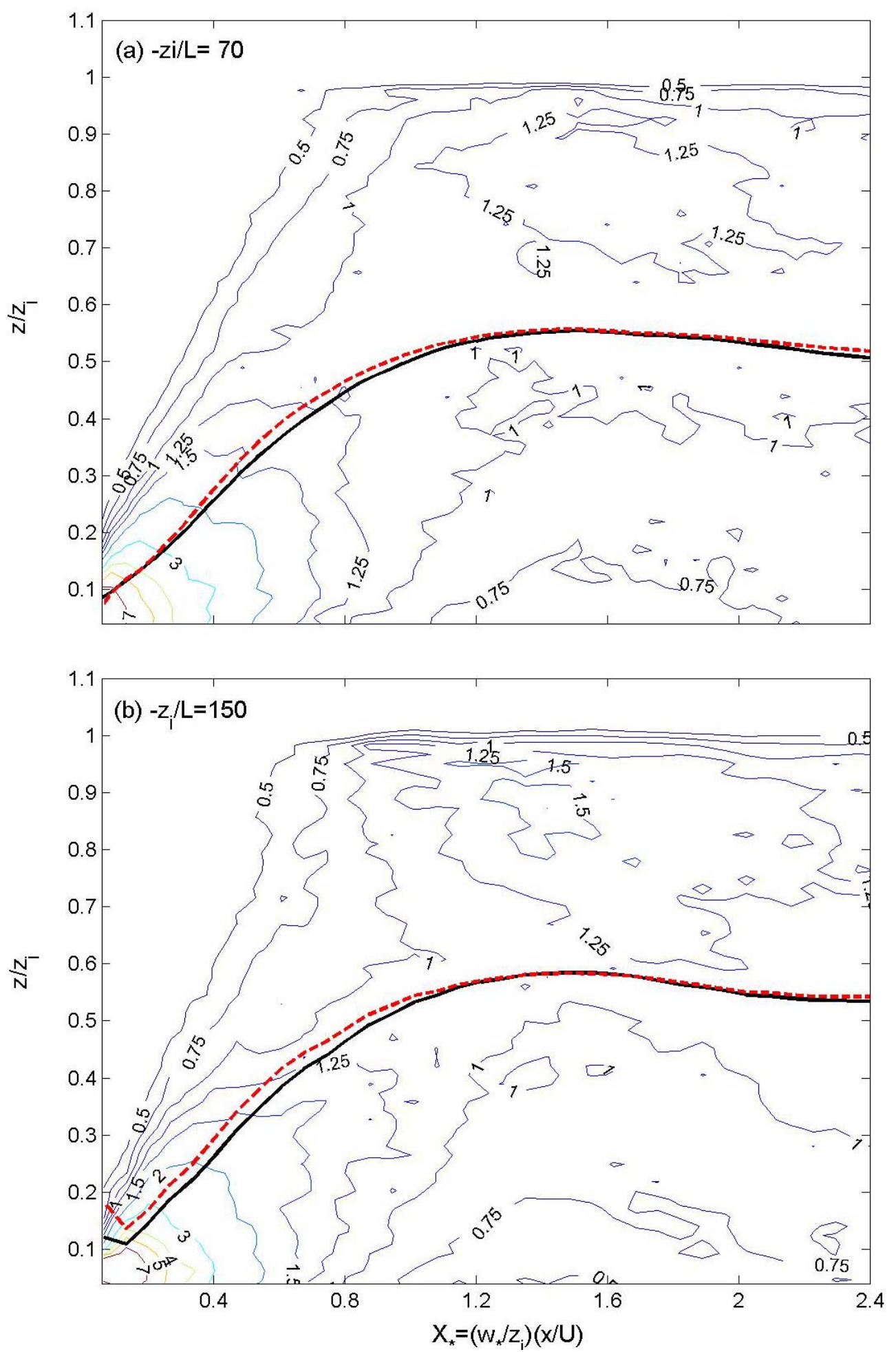

Fig. 5.11 - Concentração média adimensional integrada lateralmente em função da distância adimensional longitudinal da fonte para diferentes condições de estabilidade. Fontes pontuais contínuas localizadas nas seguintes alturas adimensionais: (a e b) $\mathrm{z}_{\mathrm{s}}=0,07 \mathrm{z}_{\mathrm{i}}$; (c e d) $\mathrm{z}_{\mathrm{s}}=0,50 \mathrm{z}_{\mathrm{i}}$. As linhas representam: (contínua em preto) a altura adimensional da pluma (Eq. 5.3); (tracejada em vermelho) dispersão vertical adimensional da pluma (Eq. 5.4). 

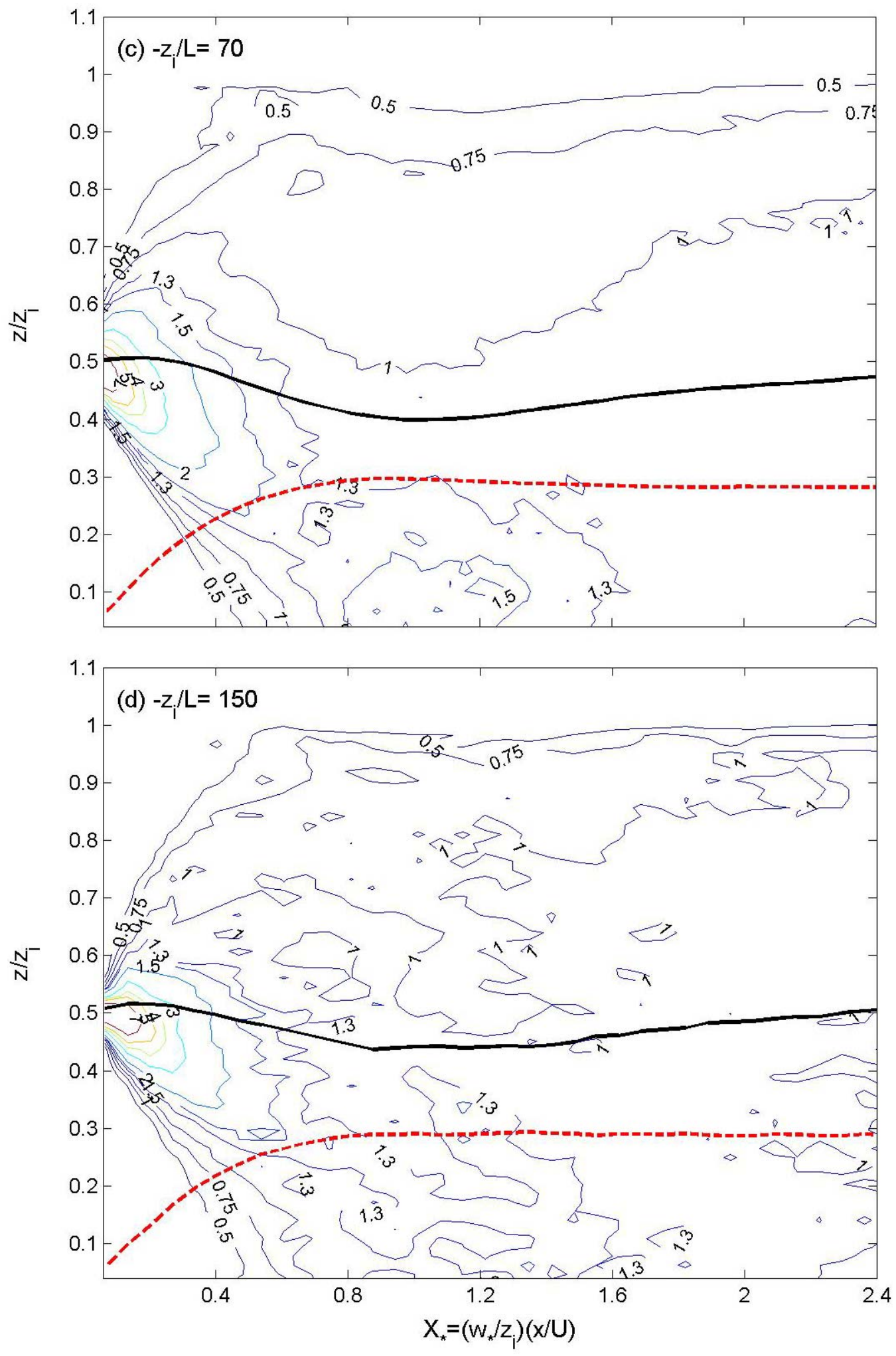

Fig. 5.11 - Continuação. 
No caso de fontes elevadas (Figs. 5.11c e 5.11d), a altura média e a dispersão vertical da pluma apresentam comportamentos distintos, com $\bar{z} / z_{i}$ oscilando entre $0,4 z_{i} \leq z \leq 0,5 z_{i}$, enquanto $\overline{\mathrm{z}^{2}} / \mathrm{z}_{\mathrm{i}}$ após um crescimento inicial em $\mathrm{X}_{*}<0,8$, se mantêm constante em $\mathrm{z} \approx 0,3 \mathrm{z}_{\mathrm{i}}$.

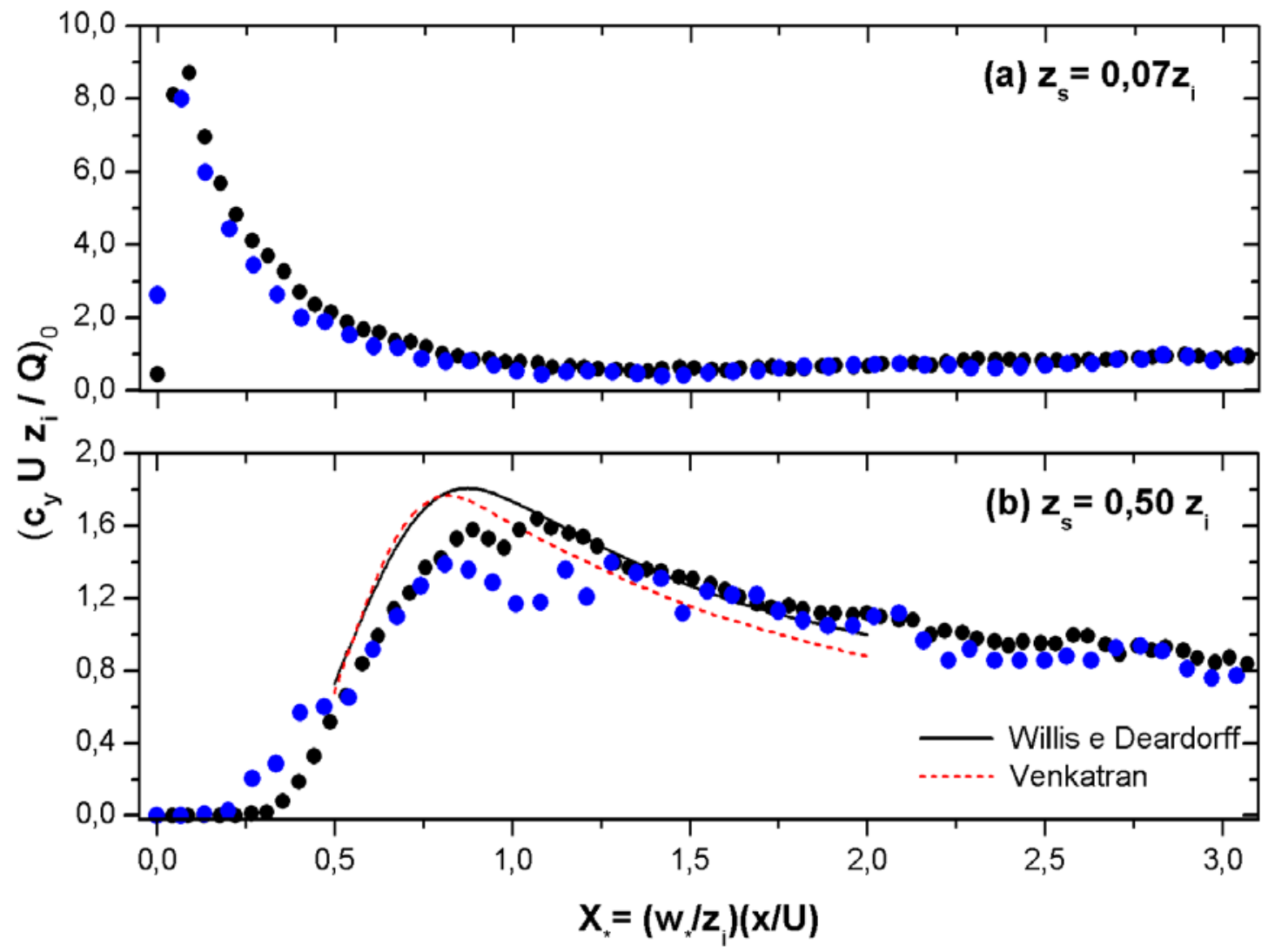

Fig. 5.12 - Concentração média adimensional ao nível da superfície para fontes pontuais contínuas localizadas em: (a) $\mathrm{z}_{\mathrm{s}}=0,07 \mathrm{z}_{\mathrm{i}}$; (b) $\mathrm{z}_{\mathrm{s}}=0,50 \mathrm{z}_{\mathrm{i}}$. Os círculos representam as simulações lagrangianas realizadas: (em preto) $-z_{i} / L=70$ e (em azul) $-\mathrm{z}_{\mathrm{i}} / \mathrm{L}=150$. As curvas representam: dados experimentais (Willis e Deardorff, 1978 e 1981); modelo numérico baseado em fdp (Venkatran; 1983).

As estimativas da concentração ao nível da superfície $\overline{\mathrm{c}_{\mathrm{y}}}(\mathrm{x}) \mathrm{Uz}_{\mathrm{i}} / \mathrm{Q}$ para fontes localizadas próximo a superfície (Fig. 5.12a) apresentam um máximo logo após a emissão seguido de um acentuado decréscimo. $\mathrm{O}$ valor deste máximo é $\approx 8,3$, na média, em $\mathrm{X}_{*} \approx 0,07$ e o valor mínimo é $\approx 0,5$ em $\mathrm{X}_{*} \approx 1,0$. Estes resultados estão de acordo com os valores apresentados 
por Luhar et al. (1996). As condições de estabilidade da CLP também influenciam a posição do máximo de $\overline{\mathrm{c}_{\mathrm{y}}}(\mathrm{x}) \mathrm{U} \mathrm{z}_{\mathrm{i}} / \mathrm{Q}$ ao nível da superfície (Weil et al., 1997 e 2000).

Para fontes localizadas em alturas elevadas (Fig. 5.12b) a concentração simulada tem um comportamento similar aos dados de laboratório de Willis e Deardorff e ao modelo numérico proposto por Venkatran, apesar de estarem ligeiramente subestimadas em $\mathrm{X}_{*}<1,0$.

\section{4 - Sumário dos resultados da dispersão de poluentes}

De uma maneira geral, as propriedades da dispersão de um poluente inerte e passivo emitido em diferentes alturas da CLP convectiva foram reproduzidas adequadamente pelo modelo LES. Na dispersão euleriana de um poluente emitido por uma fonte área contínua localizada na superfície, o grau de limpeza da CLP está diretamente relacionado à intensidade dos processos de entranhamento no topo. Isso fica evidente nas análises dos perfis verticais de skewness de concentração de poluente e na visualização dos campos instantâneos de velocidade vertical e concentração. A taxa de variação temporal da concentração simulada pelo modelo LES é $\partial\langle\mathrm{c}\rangle / \partial \mathrm{t} \approx 0,15 \mathrm{ppm} \mathrm{h}^{-1}$, enquanto que a observada em São Paulo no período compreendido entre as $10 \mathrm{~h}$ e $13 \mathrm{~h} \approx 0,20 \mathrm{ppm} \mathrm{h}^{-1}$. Esses resultados podem ser considerados como representativos da dispersão de CO na RMSP, sobre uma superfície horizontalmente homogênea e com intenso tráfego de veículos automotores.

Para dispersão de poluentes emitidos por fontes pontuais contínuas localizadas em alturas elevadas da CLP, as plumas simuladas reproduziram o comportamento esperado, tanto do ponto de vista euleriano quanto lagrangiano. A concentração máxima ocorre na superfície antes de se propagar pelas camadas superiores. Esse padrão reflete a assimetria na distribuição de freqüências do campo de velocidade vertical, que indica a maior probabilidade de ocorrência de downdrafts $(\approx 60 \%)$.

Quanto maior a convecção térmica mais intensa é a mistura vertical do poluente na CLP. Isso faz com que a distribuição vertical do poluente torne-se homogênea em distâncias adimensionais pequenas. Além disso, a condição de estabilidade influencia, diretamente, a distância adimensional na qual a concentração é máxima na superfície (Fig. 5.13). 
Comparativamente as duas metodologias de dispersão adotadas geraram resultados muito similares.

Essa concordância confirma a hipótese levantada neste trabalho de que o modelo LES pode ser utilizado como uma ferramenta de validação de modelos operacionais de dispersão.

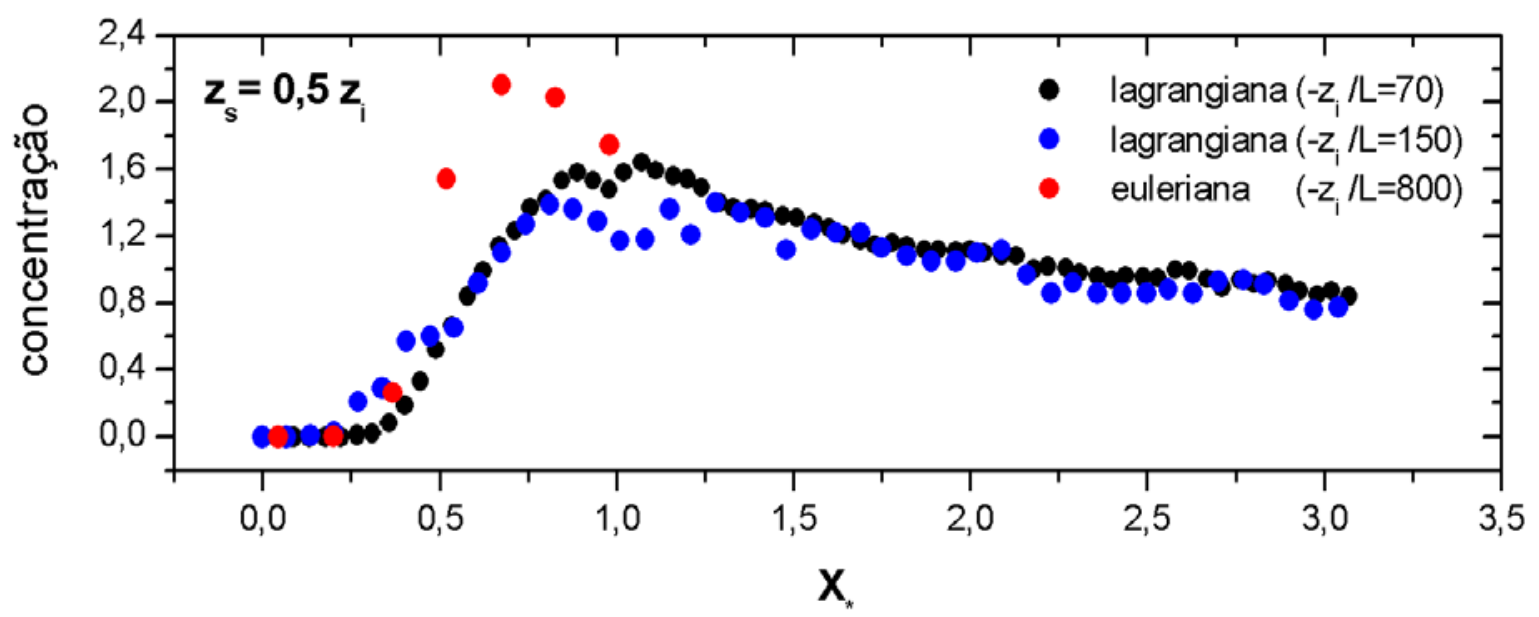

Fig. 5.13 - Comparação da concentração média adimensional ao nível da superfície em função da distância adimensional para fontes pontuais contínuas localizadas em $\mathrm{z}_{\mathrm{s}} \approx 0,5 \mathrm{z}_{\mathrm{i}}$. Os círculos representam as simulações: (em vermelho) euleriana $\left(-\mathrm{z}_{\mathrm{i}} / \mathrm{L}=800\right)$; (em preto) lagrangiana $\left(-\mathrm{z}_{\mathrm{i}} / \mathrm{L}=70\right)$ e (em azul) lagrangiana $\left(-\mathrm{z}_{\mathrm{i}} / \mathrm{L}=150\right)$.

Para fontes pontuais contínuas localizadas próximo a superfície a metodologia euleriana não foi capaz de representar o comportamento esperado da pluma. Provavelmente este problema foi agravado pelo baixo número de simulações realizadas, o que dificultou a obtenção de resultados estatisticamente representativos.

Por outro lado, a dispersão lagrangiana de poluentes é capaz de reproduzir o comportamento da pluma em qualquer altura de emissão e os resultados apresentados aqui concordam a literatura.

Apesar dos resultados, extensivamente explorados nesse trabalho, serem válidos para uma CLP altamente convectiva sobre uma superfície horizontalmente homogênea, espera-se que esta metodologia de validação de modelos de dispersão possa também ser apropriadas para outras condições de estabilidade, ocupação do solo e topografia. 


\section{6 - CONCLUSÕES}

Nesse trabalho, o modelo LES foi utilizado para descrever as propriedades estatísticas da turbulência em uma CLP altamente convectiva, associada à baixa velocidade do vento, sobre uma superfície horizontalmente homogênea. Com a estrutura da turbulência determinada, foi realizado um estudo sobre a dispersão de um poluente inerte e passivo por meio de duas abordagens distintas, a euleriana e a lagrangiana.

Realizou-se um conjunto de simulações numéricas com $80^{3}$ e $96^{3}$ de pontos de grade e dimensões de $5 \mathrm{~km}$ x $5 \mathrm{~km}$ x $2 \mathrm{~km}$ e $10 \mathrm{~km}$ x $10 \mathrm{~km}$ x $2 \mathrm{~km}$. As condições iniciais foram estabelecidas de forma a gerar CLPs convectivas com diferentes graus de instabilidade $\left(62 \leq-\mathrm{z}_{\mathrm{i}} / \mathrm{L} \leq 800\right)$. Cinco dessas simulações (Tabela 3.1) serviram de base para a caracterização da estrutura da turbulência e as demais foram utilizadas nos estudos de dispersão de um poluente inerte e passivo. Devido à inexistência de dados experimentais obtidos em campo, os resultados simulados foram confrontados com os prognósticos teóricos da similaridade da camada de mistura e com a lei do equilíbrio universal concebida por Kolmogorov.

A condição de quase-equilíbrio dos escoamentos turbulentos simulados foi alcançada após os $3.000 \Delta \mathrm{t}$ iniciais. O critério de verificação da evolução temporal da ECT total integrada na CLP mostrou-se adequado nos casos em que a intensidade da inversão térmica no topo $\langle\Delta \bar{\theta}\rangle_{\mathrm{i}}$ foi maior (HC3, DA1 e DA2), o que inibe a formação de ondas de gravidade. Porém, avaliando os perfis verticais do fluxo de calor sensível e do balanço de ECT, todas simulações apresentaram características que satisfazem a condição de quase-equilíbrio.

As estruturas dinâmicas e termodinâmicas das CLPs simuladas pelo modelo LES foram similares às esperadas para uma camada em condições altamente convectivas. O aumento médio de $\langle\bar{\theta}\rangle$ na camada de mistura mostrou-se consistente com a taxa de aquecimento obtida pelo modelo proposto por Tennekes (1973). O fluxo de calor sensível apresentou um decréscimo linear com a altura, indicando que o regime turbulento estava em condição de quase-equilíbrio.

Os perfis verticais de velocidade horizontal do vento apresentaram uma forma logarítmica na região próxima à superfície e um gradiente praticamente nulo no restante da CLP. Nessas 
condições de estabilidade, os fluxos de momento não seguiram a teoria da similaridade da camada de mistura.

A variância das componentes horizontais de velocidade é aproximadamente constante com a altura em quase toda a camada de mistura. Por outro lado, a variância da componente vertical de velocidade $\left\{\left\langle\mathrm{w}^{\prime 2}\right\rangle+\left\langle\tau_{\mathrm{ww}}\right\rangle\right\}$ apresentou um máximo de $(0,48 \pm 0,01) \mathrm{w}_{*}^{2}$ em torno de $\mathrm{z} \approx 0,38 \mathrm{z}_{\mathrm{i}}$, o que está aproximadamente de acordo com os valores sugeridos por Deardorff (1974).

Comparando-se os perfis verticais de $\left\{\left\langle\mathrm{w}^{\prime 2}\right\rangle+\left\langle\tau_{\mathrm{ww}}\right\rangle\right\} / \mathrm{w}_{*}^{2}$ com a curva experimental proposta por Lenschow et al. (1980) $\left(\overline{\left[\mathrm{w}^{\prime 2}\right]} / \mathrm{w}_{*}^{2}=1,8\left(\mathrm{z} / \mathrm{z}_{\mathrm{i}}\right)^{2 / 3}\left(1-0,8 \mathrm{z} / \mathrm{z}_{\mathrm{i}}\right)^{2}\right)$ observa-se que eles apresentam formas similares, porém, o máximo simulado encontra-se acima do proposto por Lenschow.

Os perfis verticais da variância de temperatura potencial $\left(\left\langle\theta^{\prime 2}\right\rangle+\left\langle\tau_{\theta \theta}\right\rangle\right) / \mathrm{T}_{*}^{2}$ mostram dois máximos distintos, um próximo à superfície e outro junto ao topo da CLP, e concordam qualitativamente com as curvas experimentais propostas por Moeng e Wyngaard (1984) e Bernard-Trottolo et al. (2004).

Os campos instantâneos das flutuações de velocidade vertical, temperatura potencial e dos fluxos turbulentos locais permitiram identificar o padrão assimétrico das estruturas coerentes na CLP altamente convectiva. As análises dos campos instantâneos do fluxo local de calor sensível mostram que as distribuições espaciais dos updrafts e downdrafts estão de acordo com os resultados apresentados na literatura (Schmidt e Schumann, 1989; Moeng e Sullivan, 1994; Khanna e Brasseur, 1998). Isto ficou evidenciado no campo tridimensional instantâneo da componente vertical de velocidade $\overline{\mathrm{w}}$.

O parâmetro de assimetria do escoamento turbulento ou skewness, é positivo por quase toda a CLP com exceção da região próxima à superfície, em virtude de limitações do modelo de subgrade.

Em relação ao balanço de ECT, a variação local de ECT foi aproximadamente nula por camada, confirmando a condição de quase-equilíbrio dos escoamentos turbulentos simulados. 
A produção térmica de ECT é o termo predominante na geração da turbulência por quase toda a CLP, como esperado em condições de estabilidade altamente convectivas. Nos casos onde a velocidade horizontal do vento é maior (HC1 e DA1), o termo de produção mecânica de ECT tem uma contribuição significativa apenas na região próxima à superfície, sendo aproximadamente nulo no restante da camada.

Os termos de transporte distribuem a ECT espacialmente e apresentam perfis verticais com sinais opostos, sendo que o transporte devido à flutuação de pressão é um termo fonte de ECT próximo à superfície.

As parametrizações dos termos da equação do balanço de ECT na CLP convectiva, propostas por Lenschow (1974), Lenschow et al. (1980) e Moeng e Sullivan (1994), reproduziram com grande fidelidade as estimativas dos termos de produção de ECT na CLP convectiva. Já os termos de transporte de ECT foram superestimados junto ao topo. Os perfis verticais do termo de dissipação simulados com o modelo LES não concordam com os perfis propostos pelos pesquisadores acima.

Os espectros das componentes de velocidade simulados com o modelo LES apresentaram uma região com inclinação proporcional a $\mathrm{k}^{-5 / 3}$, confirmando que a menor escala resolvida pelo modelo encontra-se na região do subintervalo inercial.

O valor estimado da constante de Kolmogorov foi $\alpha_{k}=0,52$ e está de acordo com os valores sugeridos na literatura.

Nas escalas menores resolvidas pelo modelo, a razão $S_{w}\left(k_{x}\right) / S_{u}\left(k_{x}\right)$ é aproximadamente igual ao valor previsto pela relação de isotropia $\mathrm{S}_{\mathrm{w}}\left(\mathrm{k}_{\mathrm{x}}\right)=\frac{4}{3} \mathrm{~S}_{\mathrm{u}}\left(\mathrm{k}_{\mathrm{x}}\right)$. Para a componente lateral de velocidade, a razão $\mathrm{S}_{\mathrm{v}}\left(\mathrm{k}_{\mathrm{x}}\right) / \mathrm{S}_{\mathrm{u}}\left(\mathrm{k}_{\mathrm{x}}\right)$ não apresentou o mesmo comportamento.

Os espectros espaciais adimensionais das componentes de velocidade apresentam uma região de produção bem definida. No caso dos espectros espaciais horizontais, a variação vertical do comprimento de onda associado ao turbilhão mais energético concorda com o valor sugerido por Kaimal et al. (1976), $\left(\lambda_{\mathrm{m}}\right)_{\mathrm{u}, \mathrm{v}}=1,3 \mathrm{z}_{\mathrm{i}}$.

Baseado em Caughey e Palmer (1979), uma nova formulação foi proposta para representar a variação vertical de $\left(\lambda_{\mathrm{m}}\right)_{\mathrm{w}}$ na CLP altamente convectiva: 
$\left(\lambda_{\mathrm{m}}\right)_{\mathrm{w}}=1,3 \mathrm{z}_{\mathrm{i}}\left[1-\exp \left(-4,8 \mathrm{z} / \mathrm{z}_{\mathrm{i}}\right)-0,005 \exp \left(-4,8 \mathrm{z} / \mathrm{z}_{\mathrm{i}}\right)\right]$

Para os espectros temporais, as escalas $\left(\lambda_{\mathrm{m}}\right)_{\mathrm{u}, \mathrm{v}}$ e $\left(\lambda_{\mathrm{m}}\right)_{\mathrm{w}}$ diferem das escalas obtidas pelos espectros espaciais por um fator de 1,5. Essa diferença é inferior ao fator 2 encontrado por Kaimal et al. (1982) para os espectros da componente vertical de velocidade com dados observados em experimentos de campo com torre micrometeorológica e avião.

Esses resultados confirmam as restrições da aplicação da hipótese de Taylor em uma CLP em condições altamente convectivas e ilustram as discrepâncias existentes entre as observações obtidas em torre micrometeorológica (coletas em um ponto fixo do espaço) e as por avião (espacialmente distribuídas e simultâneas), ressaltando o cuidado que se deve ter no procedimento de descrição das propriedades espectrais da CLP através de observações em torre micrometeorológica em regiões onde predominam essas condições de estabilidade (regiões tropicais).

O modelo LES também reproduz as principais características dos espectros espaciais de escalares como temperatura potencial e concentração de poluente.

Uma vez estabelecidas as principais características da estrutura da turbulência na CLP convectiva, o modelo LES foi aplicado a estudos de dispersão de poluentes inertes e passivos emitidos continuamente por diferentes tipos de fontes (área e pontual), localizadas em diferentes alturas da CLP convectiva. De uma maneira geral, as propriedades da dispersão de um poluente inerte e passivo emitido em diferentes alturas da CLP convectiva foram reproduzidas adequadamente pelo modelo LES.

Na dispersão euleriana de um poluente emitido por uma fonte área contínua localizada na superfície, o grau de limpeza da CLP está diretamente relacionado à intensidade dos processos de entranhamento no topo. Isso fica evidente nas análises dos perfis verticais de skewness de concentração de poluente e na visualização dos campos instantâneos de velocidade vertical e concentração. A taxa de variação temporal da concentração simulada pelo modelo LES é $\partial\langle\mathrm{c}\rangle / \partial \mathrm{t} \approx 0,15 \mathrm{ppm} \mathrm{h}^{-1}$, enquanto que a observada em São Paulo no mês de junho, entre as $10 \mathrm{~h}$ e $13 \mathrm{~h}$ é $\approx 0,20 \mathrm{ppm} \mathrm{h}^{-1}$. Esses resultados podem ser considerados como representativos da dispersão de CO na RMSP, sobre uma superfície horizontalmente homogênea e com intenso tráfego de veículos automotores. 
Para dispersão de poluentes emitidos por fontes pontuais contínuas localizadas em alturas elevadas da CLP, as plumas simuladas reproduziram o comportamento esperado tanto do ponto de vista euleriano, quanto lagrangiano. A concentração máxima ocorre na superfície, antes de se propagar pelas camadas superiores. Esse padrão reflete a assimetria na distribuição de freqüência do campo de velocidade vertical, que indica a maior probabilidade de ocorrência de downdrafts $(\approx 60 \%)$.

Quanto maior a convecção térmica, mais intensa é a mistura vertical do poluente na CLP. Isso faz com que a distribuição vertical do poluente torne-se homogênea em distâncias adimensionais pequenas. Além disso, a condição de estabilidade influencia diretamente a distância adimensional na qual a concentração é máxima na superfície. Comparativamente as duas metodologias de dispersão adotadas geraram resultados similares.

Essa concordância confirma a hipótese levantada neste trabalho, de que o modelo LES pode ser utilizado como uma ferramenta de validação de modelos operacionais de dispersão.

A metodologia utilizada na dispersão euleriana não foi capaz de representar o comportamento da pluma para poluentes emitidos próximo à superfície. Provavelmente este problema foi ocasionado pelo baixo número de simulações realizadas, o que dificultou a obtenção de resultados estatisticamente representativos.

Por outro lado, a dispersão lagrangiana de poluentes é capaz de reproduzir o comportamento da pluma em qualquer altura de emissão e os resultados apresentados aqui concordam com a literatura.

Apesar dos resultados extensivamente explorados nesse trabalho serem válidos para uma CLP altamente convectiva sobre uma superfície horizontalmente homogênea, espera-se que esta metodologia de validação de modelos de dispersão possa também ser apropriada para outras condições de estabilidade, ocupação do solo e topografia.

O nível de detalhe e de realismo fornecido pelo modelo LES irá auxiliar o desenvolvimento de novas parametrizações que representem de forma adequada os transporte turbulentos na CLP pelos modelos operacionais. 
Como sugestões para trabalhos futuros:

1) Explorar as propriedades coespectrais e os termos de retorno à isotropia;

2) Implementar algumas modificações no código do modelo LES de forma a simular CLPs úmidas;

3) Avaliar a capacidade do modelo LES em simular escoamentos turbulentos da CLP sob condições de estabilidade estável.

4) Modificar o modelo de subgrade para que os processos próximos à superfície sejam representados de forma adequada;

5) Implementar heterogeneidades superficiais no modelo, como, por exemplo, o acoplamento do modelo LES com algum balanço de energia na superfície. Isso possibilitaria simular os escoamentos turbulentos da CLP sobre regiões complexas. 


\section{7 - REFERÊNCIAS BIBLIOGRÁFICAS}

Abrantes, R.; Assunção, J. V. e Pesquero, C. R. 2004: Emission of polycyclic aromatic hydrocarbons from ligtht-duty diesel vehicles exhaust. Atmospheric Environment, 38, 1631-1640.

Acevedo, O. C. e Fitzjarrald, D. R. 2001: The early evening surface-layer transition: temporal and spatial variability. Journal of the Atmospheric Sciences, 58, 2650-2667.

Bernard-Trottolo, S.; Campistron, B.; Druilhet, A.; Lohou, F. e Saïd, F. 2004: Trac98: detection of coherent structures in a convective boundary layer using airborne measurements. Boundary-Layer Meteorology, 111, 181-224.

Boffetta, G.; Celani, A.; Cencini, M.; Lacorata, G. e Vulpiani, A. 2002: Non asymptotic properties of transport and mixing, Chaos, 10, 1-9.

Bogo, H.; Gómez, D. R.; Reich, S. L.; Negri, R. M. e San Román, E. 2001: Traffic pollution in a downtown site of Buenos Aires City. Atmospheric Environment, 35, 1717-1727.

Cai, X.-M. 1999: Large-eddy simulation of the convective boundary layer over an idealized patchy urban surface. Quart. Journal R. Meteorological Society, 125, 1427-1444.

Cai, X.-M. 2000: Dispersion of a passive plume in an idealized urban convective boundary layer: a large-eddy simulation. Atmospheric Environment, 34, 61-72.

Caughey, S. J. e Wyngaard, J. C. 1979: The turbulence kinetic energy budget in convective conditions. Quart. Journal R. Meteorological Society, 105, 231-239.

Caughey, S. J. e Palmer, S. G. 1979: Some aspects of turbulence through the depth of the convective boundary layer. Quart. Journal R. Meteorological Society, 105, 811-827.

CETESB, 2004: Operação Inverno 2003 - Qualidade do Ar. Relatório Técnico, (http://www.cetesb.sp.gov.br/Ar/relatorios/relatorios.asp), 101 p.

Codato, G. 2004: Estudo observacional da radiação solar na cidade de São Paulo. Relatório Parcial CNPq-PIBIC.

Cuijpers, J. W. M. e Holtslag, A. A. M. 1998: Impact of skewness and nonlocal effects on scalar and buoyancy fluxes in convective boundary layers. Journal of the Atmospheric Sciences, 55, 151-162.

Deardorff, J. W. 1972: Numerical investigation of neutral and unstable planetary boundary layers. Journal of the Atmospheric Sciences, 29, 91-115.

Deardorff, J. W. 1973: Three-dimensional numerical modeling of the planetary boundary layer. In: Workshop on Micrometeorology. Edited by Haugen, D. A.; American Meteorological Society, 271-311. 
Deardorff, J. W. 1974a: Three-dimensional numerical study of the height and mean structure of a heated planetary boundary layer. Boundary-Layer Meteorology, 7, 81-106.

Deardorff, J. W. 1974b: Three-dimensional numerical study of turbulence in an entraining mixed layer. Boundary-Layer Meteorology, 7, 199-226.

Deardorff, J. W. 1980: Stratocumulus-capped mixed layers derived from a three-dimensional model. Boundary-Layer Meteorology, 18, 495-527.

Deardorff, J. W. e Willis, G. E. 1985: Further results from a laboratory model of the convective planetary boundary layer. Boundary-Layer Meteorology, 32, 205-236.

Dutton, J. A. e Fitchl, G. H. 1969: Approximate Equations of Motion for Gases and Liquids. Journal of the Atmospheric Sciences, 26, 241-254.

Fedorovich, E.; Conzemius, R. e Mironov, D. 2004: Convective entrainment into shear-free, linearly stratified atmosphere: bulk models reevaluated through large eddy simulations. Journal of the Atmospheric Sciences, 61, 281-295.

Frisch, U. 1995: Turbulence: the legacy of A. N. Kolmogorov. Cambridge Academic Press, 296 p.

Garratt, J. R.; Hess, G. D.; Physick, W. L. e Bougeault, P. 1996: The atmospheric boundary layer - advances in knowledge and application. Boundary-Layer Meteorology, 78, 9-37.

Gioia, G.; Lacorata, G.; Marques Filho, E. P.; Mazzino, A. e Rizza, U. 2004: The Richardson's law in large-eddy simulations of boundary layer flows. Aceito para publicação Boundary-Layer Meteorology, 2004.

Gledzer, E. 1997: On the Taylor hypothesis corrections for measured energy spectra of turbulence. Physica D, 104, 163-183.

Gopalakrishnan, S.G. e Avissar, R. 2000: An LES study of the impacts of land surface heterogeneity on dispersion in the convective boundary layer. Journal of the Atmospheric Sciences, 57, 352-371.

Gopalakrishnan, S. G.; Roy, S. B. e Avissar, R. 2000: An evaluation of the scale at which topographical features affect the convective boundary layer using large eddy simulations. Journal of the Atmospheric Sciences, 57, 334-351.

Goulart, A.; Degrazia, G.; Rizza, U. e Anfossi, D. 2003: A theoretical model for the study of convective turbulence decay and comparison with large-eddy simulation data. Boundary-Layer Meteorology, 107, 143-155.

Goyal, P. e Rama Krishna, T. V. B. P. S. 2002: Dispersion of pollutants in convective low Wind: a case study of Delhi. Atmospheric Environment, 36, 2071-2079.

Hanna, S. R. 1984: Applications in air pollution modeling. In: Atmospheric Turbulence and Air Pollution Modelling. Edited Nieuwstadt, F. T. M. e van Dop, H. Reidel: Dordrecht,275-310. 
Hechtel, L. M.; Moeng, C-H. e Stull, R. B. 1990: The effects of nonhomogeneous surface fluxes on the convective boundary layer: a case study using large-eddy simulation. Journal of the Atmospheric Sciences, 47, 1721-1741.

Henn, D. S. e Sykes, R. I. 1992: Large-eddy simulation of dispersion in the convective boundary layer. Atmospheric Enviroment, 26A, 3145-3159.

Hogström, U. 1996: Review of some basic characteristics of the atmospheric surface layer. Boundary-Layer Meteorology, 78, 215-246.

Kaimal, J. C.; Wyngaard, J. C.; Izumi, Y e Coté, O. R. 1972: Spectral characteristics of surface-layer turbulence. Quart. Journal R. Meteorological Society, 98, 563-589.

Kaimal, J. C. 1973: Turbulence spectra, length scales and structure parameters in the stable surface layer. Boundary-Layer Meteorology, 4, 289-309.

Kaimal, J. C.; Wyngaard, J. C.; Haugen, D. A.; Coté, O. R.; Izumi, Y.; Caughey, S. J. e Readings, C. J. 1976: Turbulence structure in the convective boundary layer. Journal of the Atmospheric Sciences, 33, 2152-2169.

Kaimal, J. C. 1978: Horizontal velocity spectra in an unstable surface layer. Journal of the Atmospheric Sciences, 35, 18-24.

Kaimal, J. C.; Eversole, R. A.; Lenschow, D. H.; Stankov, B. B.; Kahn, P. H. e Businger, J. A. 1982: Spectral characteristics of the convective boundary layer over uneven terrain. Journal of the Atmospheric Sciences, 39, 1098-1114.

Kaimal, J. C. e Finnigan, J. J. 1994: Atmospheric Boundary Layer Flows: Their structure and measurement. New York: Oxford-University-Press, 289 p.

Kaiser, R. e Fedorovich, E. 1998: Turbulence spectra and dissipation rates in a wind tunnel model of the atmospheric convective boundary layer. Journal of the Atmospheric Sciences, 55, 580-594.

Karam, H. A. 2002: Estudo do Jato de Baixos Níveis de Iperó e das Implicações no Transporte de Poluentes no Estado de São Paulo. Tese de Doutorado, IAG-USP, São Paulo, 196 p.

Karam, H. A. e Marques Filho, E. P. 2004: Simplex optimization applied to fit modeled curves to the spectral data obtained of a large eddy simulation model. Submetido ao Iberian Latin American Congress on Computational Methods.

Khanna, S. e Brasseur, J. G. 1998: Three-dimensional buoyancy- and shear-induced local structure of the atmospheric boundary layer. Journal of the Atmospheric Sciences, 55, 710-743.

Krusche, N. e Oliveira, A. P. 2004: Characterization of coherent structures in the atmospheric surface layer. Boundary-Layer Meteorology, 110, 191-211. 
Lamb, R. G. 1984: Diffusion in the convective boundary layer. In: Atmospheric Turbulence and Air Pollution Modelling. Edited Nieuwstadt, F. T. M. e van Dop, H. Reidel: Dordrecht,159-229.

Lamesa, J. E. 2001: Estudo Espectral da Camada Limite Superficial de Iperó - SP. Dissertação de Mestrado, IAG-USP, São Paulo, 93 p.

Lemone, M. A. 1976: Modulation of Turbulence Energy by Longitudinal Rolls in an Unstable Planetary Boundary Layer. Journal of the Atmospheric Science, 33, 1308-1320.

Lenschow, D. H. 1970: Airplane measurements of planetary boundary layer structure. Journal Appl. Meteorology, 9, 874-884.

Lenschow, D. H. 1974: Model of the height variation of the turbulent kinetic energy budget in the unstable planetary boundary layer. Journal of the Atmospheric Sciences, 31, 465474.

Lenschow, D. H.; Wyngaard, J. C. e Pennel, W. T. 1980: Mean-field and second-moment budgets in a baroclinic, convective boundary layer. Journal of the Atmospheric Sciences, 37, 1313-1326.

Lenschow, D. H. e Stephens, P. L. 1980: The role of thermals in the convective boundary layer. Boundary-Layer Meteorology, 19, 509-532.

Leonard, A. 1974: Energy cascade in large-eddy simulations of turbulent fluid flows. Advances in Geophysics, 18, 237-248.

Lesieur, M. e Métais, O. 1996: New trends in large-eddy simulation of turbulence. Annual Rev. Fluids Mech., 28, 45-82.

Lin, C-L. 2000: Local pressure-transport structure in a convective atmospheric boundary layer. Physics of Fluids, 12, 1112-1128.

Luhar, A. K.; Hibberd, M. F. e Hurley, P. J. 1996: Comparison of closure schemes used to specify the velocity pdf in lagrangian stochastic dipersion models for convective conditions. Atmospheric Environment, 30, 1407-1418.

Lumley, J. L. E Panofsky, H. A. 1964: The Structure of Atmospheric Turbulence. Interscience, $239 \mathrm{p}$.

Lumley, J. L. 1965: Interpretation of time spectra measured in high-intensity shear flows. Physics of Fluids, 8, 1056-1062.

Mahrt, L. 1998: Flux sampling errors for aircraft and towers. Journal of Atmospheric and Oceanic Technology, 15, 416-429.

Marques Filho, E. P. 1999: Alguns Aspectos Teóricos e Experimentais da CLS acima da Região do Pantanal Matogrossense. Dissertação de Mestrado, INPE, São José dos Campos, 155 p. 
Mason, P. J. 1994: Large-eddy simulation: a critical review of the technique. Quart. Journal R. Meteorological Society, 120, 1-26.

Mason, P. J. e Brown, A. R. 1999: On subgrid models and filter operations in large-eddy simulations. Journal of the Atmospheric Sciences, 56, 2101-2114.

McBean, G. A. e Elliottt, J. A. 1975: The vertical transports of kinetic energy by turbulence and pressure in the boundary layer. Journal of the Atmospheric Sciences, 32, 753-766.

Mesinger, F. e Arakawa, A. 1982: Numerical methods used in atmospheric models. Garp Publications Series, 63 p.

Mestayer, P. 1982: Local isotropy and anisotropy in high-Reynolds number turbulent boundary layer. J. Fluid Mechanics, 125, 475-503.

Misra, P. K. 1982: Dispersión of non-buoyant particles incide a convective boundary layer. Atmospheric Environment, 16, 239-243.

Moeng, C-H. 1984: A large-eddy simulation model for the study of planetary boundary-layer turbulence. Journal of the Atmospheric Sciences, 41, 2052-2062.

Moeng, C-H. e Wyngaard, J. C. 1984: Statistics of conservative scalars in the convective boundary layer. Journal of the Atmospheric Sciences, 41, 3161-3169.

Moeng, C-H. e Wyngaard, J. C. 1986: An analysis of closures for pressure-scalar covariances in the convective boundary layer. Journal of the Atmospheric Sciences, 43, 2499-2513.

Moeng, C-H. e Wyngaard, J. C. 1988: Spectral analysis of large-eddy simulations of the convective boundary layer. Journal of the Atmospheric Sciences, 45, 3573-3587.

Moeng, C-H. e Rotunno, R. 1990: Vertical-velocity skewness in the buoyancy-driven boundary layer. Journal of the Atmospheric Sciences, 47, 1149-1162.

Moeng, C-H. e Sullivan, P. P. 1994: A comparison of shear- and buoyancy-driven planetary boundary layer flows. Journal of the Atmospheric Sciences, 51, 999-1022.

Moeng, C-H. e Sullivan, P. P. 2002: Large Eddy Simulation. In: Encyclopedia of Atmospheric Sciences. Edited by Holton, J. R.; Pyle, J. e Curry, J. A.; Academic Press, 1140-1150.

Monin, A. S. e Yaglom, A. M. 1971: Statistical Fluid Mechanics: Mechanics of Turbulence. Massachussets: MIT, 769 p.

Nieuwstadt, F. T. M. e Brost, R. A. 1986: The decay of convective turbulence. Journal of the Atmospheric Sciences, 43, 532-546.

Nieuwstadt, F. T. M. e Valk, J. P. J. M. M. 1987: A large eddy simulation of buoyant and non-buoyant plume dispersion in the atmospheric boundary layer. Atmospheric Enviroment, 21, 2573-2587. 
Nieuwstadt, F. T. M.; Mason, P. J.; Moeng, C-H. e Schumann, U. 1992: Large-eddy simulation of the convective boundary layer: A comparison of four computer codes. In: Turbulent Shear Flows 8. Edited by Durst, F. et al.; Berlin: Springer, 343-367.

Nieuwstadt, F. T. M. e Meeder, J. P. 1997: Large-eddy simulation of air pollution dispersion dispersion: a review. In: New tools in turbulence modelling. Edited by Métais, O. e Ferziger, J.; Berlin: Springer, 265-280.

Oke, T. R. 1987: Boundary Layer Climates. Methuen: London, 435 p.

Oliveira, A. P. 1986: Evolução da Camada Limite Planetária e Implicações na Qualidade do Ar. Dissertação de Mestrado, IAG-USP, São Paulo, 126 p.

Oliveira, A.P.; Soares, J.; Tirabassi, T. e Rizza, U. 1998: A surface energy-budget model coupled with a Skewed Puff Model for Investigating the Dispersion of radionuclides in a Subtropical area of Brazil, Il Nuovo Cimento, 21C, 631-637.

Oliveira, A. P.; Escobedo, J. F.; Machado, A. J. e Soares, J. 2002: Diurnal evolution of solar radiation at the surface in the city of São Paulo: seasonal variation and modeling. Theoretical and Applied Climatology, 71, 231-249.

Oliveira, A. P.; Bornstein, R. e Soares, J. 2003: Annual and diurnal wind patterns in the city of São Paulo. Water, Air and Soil Pollution - FOCUS, 3, 3-15.

Panofsky, J. A. 1969: Spectra of atmospheric variables in the boundary layer. Radio Science, 4, 1101-1109.

Panofsky, J. A. e Dutton, J. A. 1984: Atmospheric Turbulence - Models and Methods for Engineering Applications. Edited by Wiley-Interscience, New York, 397 pp.

Peltier, L. J.; Wyngaard, J. C.; Khanna, S. e Brasseur, J. G. 1996: Spectra in the unstable surface layer. Journal of the Atmospheric Sciences, 53, 49-61.

Pereira, M. M. R. 2004: Estudo do Transporte Local de Poluentes em Iperó por Meio de um Modelo Lagrangiano de Partículas. Tese de Doutorado, IAG-USP, São Paulo, 103 p.

Phillips, O. M. 1991: The Kolmogorov spectrum and its oceanic cousins: a review. Proc. R. Society London, 434, 125-138.

Pino, D.; Arellano, J. V.-G. e Duynkerke, P. G. 2003: The contribution of shear to the evolution of a convective boundary layer. Journal of the Atmospheric Sciences, $\mathbf{6 0}$, 1913-1925.

Piper, M.; Wyngaard, J. C.; Snyder, W. H. e Lawson Jr, R. E. 1995: Top-down, bottom-up diffusion experiments in a water convection tank. Journal of the Atmospheric Sciences, 52, 3607-3619.

Porté-Agel, F.; Meneveau, C. e Parlange, M. B. 2000: A scale-dependent dynamic model for large-eddy simulation: application to a neutral atmospheric boundary layer. Journal Fluid Mech., 415, 261-284 
Press, W. H; Flannery, B. P.; Taukolsky, S. A. e Vetterling, W. T. 1986: Numerical recipies, the art of scientific computing. Cambrigde-University-Press, 256 p.

Rizza, U.; Gioia, G.; Mangia, C. e Marra, G. P. 2003: Development of a grid-dispersion model in large-eddy simulation generated planetary boundary layer. Il Nuovo Cimento, 26C, 297-309.

Sailor, D. J. e Fan, H. 2002: Modeling the diurnal variability of effective albedo for cities. Atmospheric Environment, 36, 713-725.

Sawford, B. 2001: Turbulent relative dispersion. Annual Rev. Fluids Mech., 33, 289-317.

Schmidt, H. e Schumann, U. 1989: Coherent structure of the convective boundary layer derived from large-eddy simulations. Journal Fluid Mechanics, 200, 511-562.

Schröter, M.; Bange, J. e Raasch, S. 2000: Simulated airborne flux measurements in a les generated convective boundary layer. Boundary-Layer Meteorology, 95, 437-456.

Seinfeld, J. H. e Pandis, S. N. 1998: Atmospheric Chemistry and Physics: from Air Pollution to Climate Change. New York: Wiley-Interscience publication, 1326 p.

Sharan, M.; Singh, M. P. e Yadav, A. K. 1996: Mathematical model for atmospheric dispersion in low winds with eddy diffusivities as linear function of downwind distance. Atmospheric Environment, 30, 1137-1145.

Smagorinsky, J. 1963: General circulation experiments with primitive equations: I - The basic experiment. Mon. Weather Review, 91: 99-164.

Smagorinsky, J. 1984: Some Historical Remarks on the Use of Nonlinear Viscosities. In: Large Eddy Simulation of Complex Engineering and Geophysical Flows. Edited by Galperin, B. e Orszag, S. A.; Cambridge, 69-106.

Sorbjan, Z., 1986: On similarity in the atmospheric boundary layer. Boundary-Layer Meteorology, 35, 377-397.

Sorbjan, Z., 1996: Numerical study of penetrative and "solid lid" nonpenetrative convective boundary layers. Journal of the Atmospheric Sciences, 53, 101-112.

Sorbjan, Z., 1999: Similarity of scalar fields in the convective boundary layer. Journal of the Atmospheric Sciences, 56, 2212-2221.

Stohl, A. 1998: Computation, accuracy and applications of trajectories - a review and bibliography. Atmospheric Environment, 32, 947-966.

Stull, R. B. 1988: An introduction to boundary layer meteorology. Dordrecht: Kluwer, 666 p.

Sullivan, P.; McWilliams, J. C. e Moeng, C-H. 1994: A subgrid-scale model for large-eddy simulation of planetary boundary-layer flows. Boundary-Layer Meteorology, 71, 247276. 
Taylor, G. I. 1938: The spectrum of turbulence. Proc. Roy. Society London, A132, 476-490.

Tennekes, H. 1973: A model for the dynamics of the inversion above a convective boundary layer. Journal of the Atmospheric Sciences, 30, 558-567.

van Haren, L. e Nieuwstadt, F. T. M. 1989: The behavior of passive and buoyant plumes in convective boundary layer, as simulated with a large-eddy model. Journal Applied Meteorology, 28, 818-832.

Venkatran, A. 1983: On dispersion in the convective boundary layer. Atmospheric Environment, 17, 529-533.

Zanetti, P. 1990: Air Pollution Modeling. Teories, Computational Methods and Available Software. Ed. Van Nostrand Reinhold, 444p.

Weil, J. C. 1988: Dispersion in the convective boundary layer. In: Lectures on Air Pollution Modeling. Edited by Venkatram, A. e Wyngaard, J. C.; Boston: American Meteorological Society, 167-227.

Weil, J. C.; Sullivan, P. P. e Moeng, C-H. 1997: Lagrangian modeling of dispersion in the convective boundary layer using les velocity fields. 12th Symp. on Boundary Layers and Turbulence, Vancouver, Canada, Amer. Meteor. Soc., 108-109.

Weil, J. C.; Sullivan, P. P. e Moeng, C-H. 2000: Lagrangian modeling of dispersion in the convective boundary layer over a range of stability. 11th Joint Conference on the Applications of Air Pollution Meteorology with the Air and Waste Management Association, Boston, MA, 30-34.

Willis, G. E. e Deardorff, J. W. 1974: A laboratory model of the unstable planetary boundary layer. Journal of the Atmospheric Sciences, 31, 1297-1307.

Willis, G. E. e Deardorff, J. W. 1976a: A laboratory model of diffusion into the convective planetary boundary layer. Quart. Journal R. Meteorological Society, 102, 427-445.

Willis, G. E. e Deardorff, J. W. 1976b: On the use of Taylor's translation hypothesis for diffusion in the mixed layer. Quart. Journal R. Meteorological Society, 102, 817-822.

Willis, G. E. e Deardorff, J. W. 1978: A laboratory study of dispersion from an elevated source in a convective mixed layer. Atmospheric Environment, 12, 1305-1313.

Willis, G. E. e Deardorff, J. W. 1981: A laboratory study of dispersion from a source in the middle of the convectively mixed layer. Atmospheric Environment, 15, 109-117.

Wilson, J. D. e Sawford, B. L. 1996: Review of lagrangian stochastic models for trajectories in the turbulent atmosphere. Boundary-Layer Meteorology, 78, 191-210.

Wyngaard, J. C. e Coté, O. R. 1971: The budgets of turbulent kinetic energy and temperature variance in the atmospheric surface layer. Journal of the Atmospheric Sciences, 28, 190201. 
Wyngaard, J. C. e Clifford, S. F. 1977: Taylor's hypothesis and high-frequency turbulence spectra. Journal of the Atmospheric Sciences, 34, 922-929.

Wyngaard, J. C. e Brost, R. A. 1984: Top-down and bottom-up diffusion of a scalar in the convective boundary layer. Journal of the Atmospheric Sciences, 41, 102-112.

Wyngaard, J. C. 1984: Boundary layer modeling. In: Atmospheric Turbulence and Air Pollution Modelling. Edited Nieuwstadt, F. T. M. e van Dop, H. Reidel: Dordrecht, 69106.

Wyngaard, J. C. 1985: Measurements Physics. In: Probing the Atmospheric Boundary Layer. Edited by Lenschow, D.; American Meteorological Society, 5-18.

Wyngaard, J. C. 1992: Atmospheric turbulence. Annu. Rev. Fluid Mech., 24, 205-233. 